\title{
ANTIBODY-CATALYZED FORMATION OF A 14-MEMBERED RING LACTONE
}

\author{
by
}

Michael D. Pungente

B.Sc.(Hons.), University of Victoria, 1989

\author{
A THESIS SUBMITTED IN PARTIAL FULFILLMENT OF \\ THE REQUIREMENTS FOR THE DEGREE OF \\ DOCTOR OF PHILOSOPHY \\ in \\ THE FACULTY OF GRADUATE STUDIES \\ (Department of Chemistry)
}

We accept this thesis as conforming

to the required standard

THE UNIVERSITY OF BRITISH COLUMBIA

October 1997

(C) Michael D. Pungente, 1997 
In presenting this thesis in partial fulfilment of the requirements for an advanced degree at the University of British Columbia, I agree that the Library shall make it freely available for reference and study. I further agree that permission for extensive copying of this thesis for scholarly purposes may be granted by the head of my department or by his or her representatives. It is understood that copying or publication of this thesis for financial gain shall not be allowed without my written permission.

Department of CHemistry

The University of British Columbia Vancouver, Canada

Date 0 व. 18,1997

DE -6 (2/88) 


\section{ABSTRACT}

A number of macrolide antibiotics have a 14-membered ring lactone skeleton. Besides the stereochemical challenges associated with the syntheses of these macrocyclic compounds, the difficulty in controlling the ring forming step has provided the basis for many synthetic organic methodology studies. Attempts to use enzymes in aqueous and organic solvents to catalyze medium to large ring lactonizations has met with limited success, particularly with secondary alcohols. We report monoclonal antibody F123, raised against transition state analogue $\mathbf{5 0}$, which catalyzed the intramolecular transesterification of hydroxyester $\mathbf{5 7}$ to give the 14-membered ring lactone 19. The reaction of antibody F123 with substrate $\mathbf{5 7}$ displayed enzyme-like<smiles>CC1CCCCCCCCCCCP(=O)(OCCCCCN)O1</smiles>

50<smiles>CC(O)CCCCCCCCCCCC(=O)Oc1ccc([N+](=O)[O-])cc1</smiles>

57<smiles>C[C@H]1CCCCCCCCCCCC(=O)O1</smiles>

19 
Michaelis-Menten kinetics. The kinetic parameters of this antibody reaction were determined by two methods, namely a multiwell method and the spectrophotometric cuvette method. Analysis of the reaction of F123 with 57 via the multiwell method yielded a $K_{m}$ of $250 \pm 10 \mu \mathrm{M}, V_{\max }$ of $0.62 \pm 0.01$ $\mu \mathrm{mol} / \mathrm{min} \mathrm{mg}$ and $a k_{\text {cat }}$ of $1.1 \mathrm{~min}^{-1}$. The spectrophotometric cuvette method yielded a $K_{m}$ of $330 \pm 50 \mu \mathrm{M}, V_{\max }$ of $1.4 \pm 0.1 \mu \mathrm{mol} / \mathrm{min} \mathrm{mg}$ and a $k_{\text {cat }}$ of 2.2 $\mathrm{min}^{-1}$. The results obtained from these two methods were found to be in good agreement once the delay times in determining initial rates, characteristic of the multiwell method, were accounted for. In both methods, the observed rates were

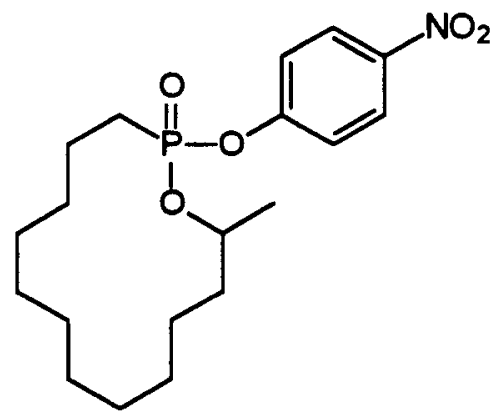

60

corrected for the background hydrolysis in buffer. Substrate specificity and competitive inhibition by the hapten derivative $60\left(\mathrm{~K}_{\mathrm{i}}=2.9 \pm 0.4 \mu \mathrm{M}\right)$ demonstrated that the catalytic activity was associated with binding in the antibody-combining site. Finally, the lactone product was isolated from pooled antibody-catalyzed reactions by ether extraction and identified using gas chromatography-mass spectroscopy by comparison with an authentic lactone sample. 


\section{TABLE OF CONTENTS}

ABSTRACT ii

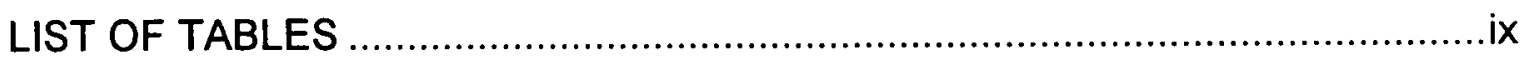

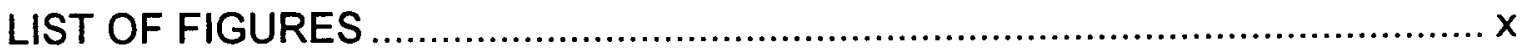

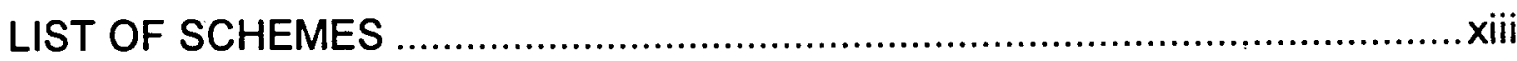

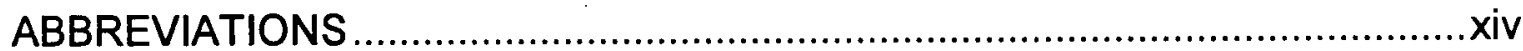

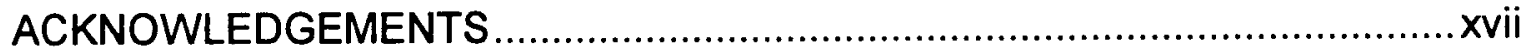

CHAPTER I INTRODUCTION TO MACROLIDES ...................................... 1

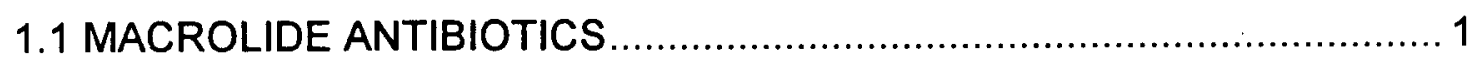

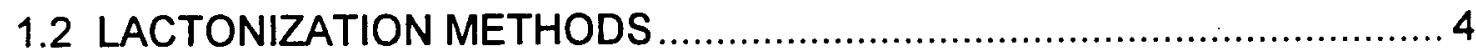

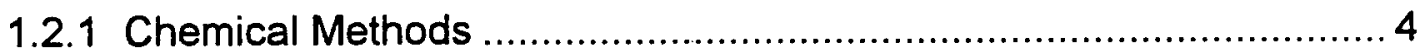

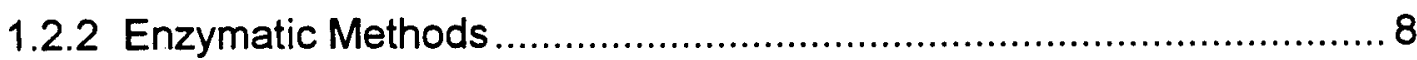

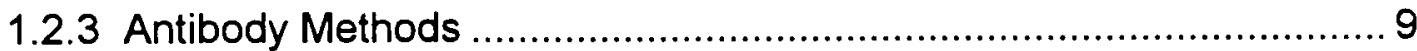

CHAPTER ॥ INTRODUCTION TO CATALYTIC ANTIBODIES ..................... 10

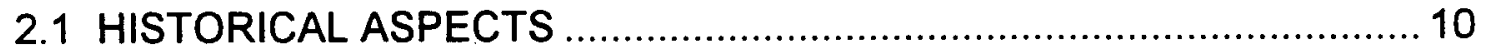

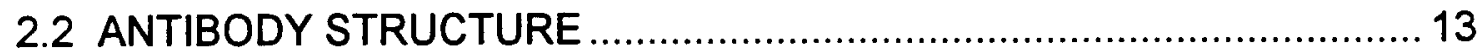

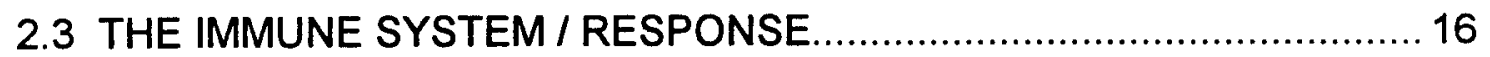

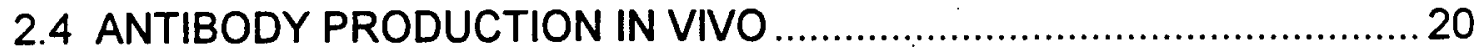

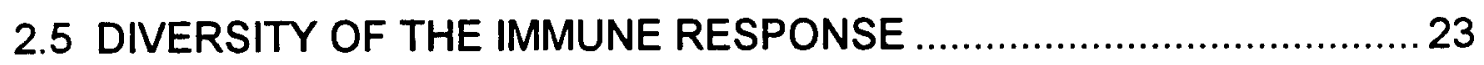

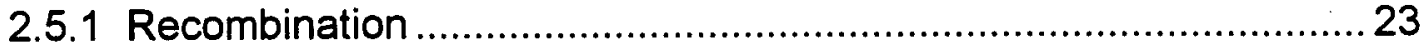

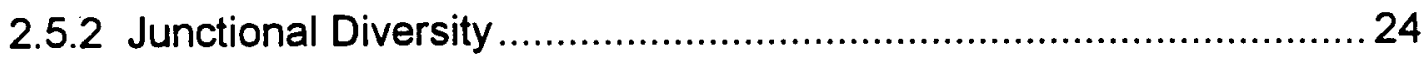

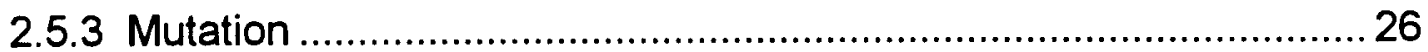

2.5.4 Association Of Heavy And Light Chains ..................................... 26

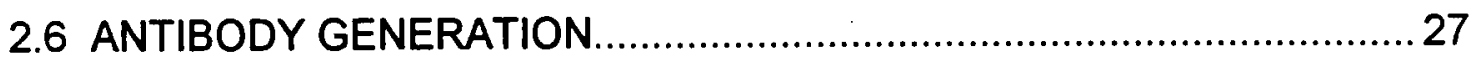

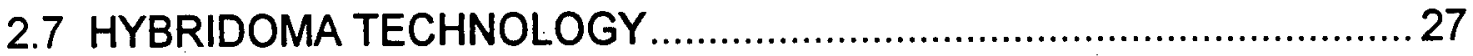

2.8 SCREENING OF HYBRIDOMAS FOR HAPTEN BINDING ..................29 


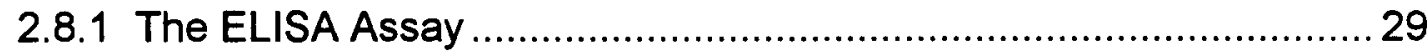

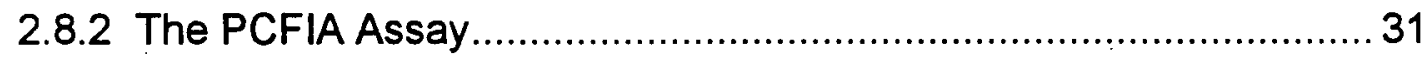

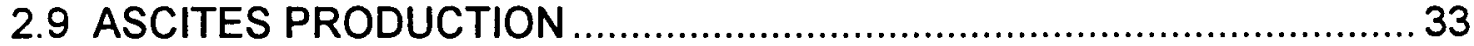

2.10 ENZYME KINETICS AND RELEVANCE TO SYNTHESIS ....................34

2.11 ENZYMES AND CATALYTIC ANTIBODIES IN ORGANIC SOLVENTS42

2.12 DESIGN OF TRANSITION STATE ANALOGUES …........................ 44

2.13 REACTION TYPES CATALYZED BY ANTIBODIES ..........................45

2.13.1 Lactonization of $\gamma, \delta$-unsaturated acids .........................................48

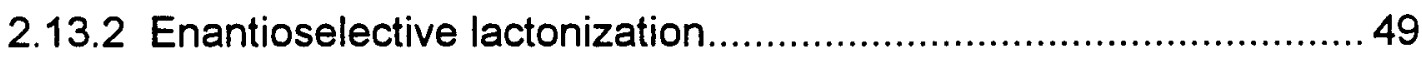

2.13.3 Intramolecular acyl migration .................................................. 50

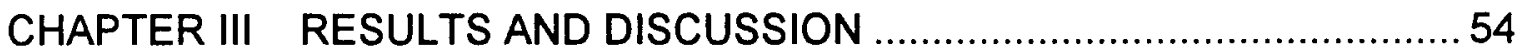

3.1 SYNTHESIS OF MACROCYCLIC PHOSPHONATE 20_......................54

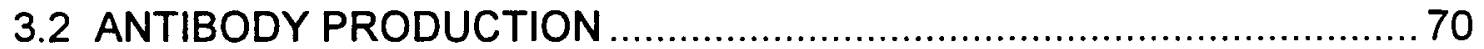

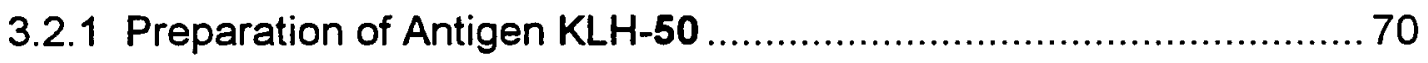

3.2.2 Antibody Raised Against Antigen KLH-50 ................................ 74

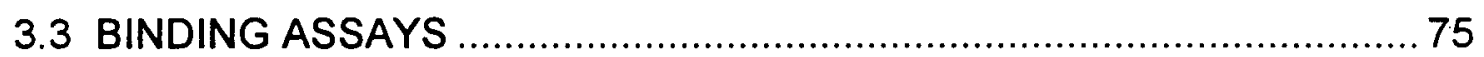

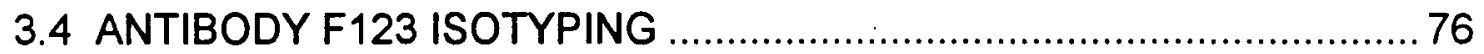

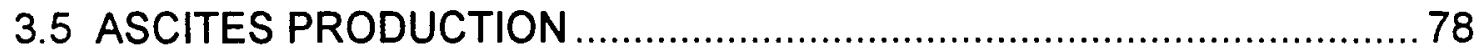

3.6 SYNTHESIS OF SUBSTRATES AND HAPTEN DERIVATIVES ............79

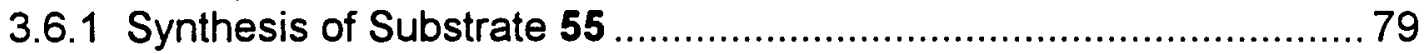

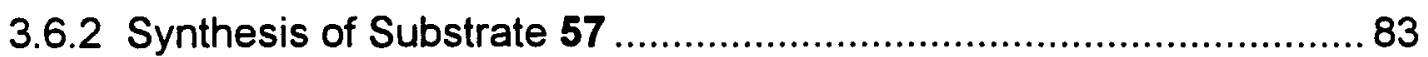

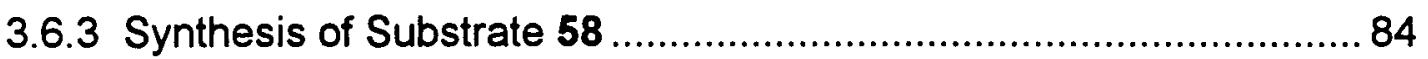

3.6.4 Synthesis of Hapten Derivatives 60a and 60b ............................. 84

3.6.5 Synthesis of Six-membered Ring PhenylPhosphonates 61a

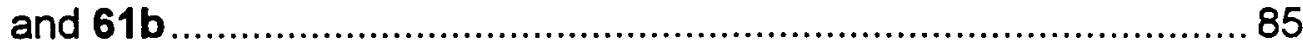

3.7 INVESTIGATION INTO THE RELATIVE STEREOCHEMISTRY OF CYCLIC PHOSPHONATES 38a AND 38b......................................... 87

3.8 INITIAL INVESTIGATION FOR REACTIVITY OF MAB'S WITH SUBSTRATE 57. 
3.9 ISOLATION OF F123-CYCLIZED MACROLACTONE 19 ................... 96

3.10 SPECIFICITY OF MONOCLONAL F123....................................... 98

3.11 REACTION OF P-NITROPHENYL TETRADECANOATE WITH F123... 98

3.12 INHIBITION ASSAYS ............................................................. 100

3.13 DETERMINATION OF $K_{m}, V_{\max }$ AND $k_{\text {cat }}$ FOR ANTIBODY $F 123$ WITH SUBSTRATE 57.

3.13.1 Determination of the Solubility Limit of Substrate $\mathbf{5 7}$ and the $\mathrm{pH}$ of the Reaction Solution.

3.13.2 Determination of $K_{m}, V_{\max }$ and $k_{\text {cat }}$ for Monoclonal F123 with

Substrate 57

3.13.2.1 Determination $K_{m}, V_{\max }$ and $K_{\text {cat }}$ for Monoclonal $F 123$ with $\mathbf{5 7}$ via the Multiwell Method 109

3.13.2.2 Determination of $K_{m}, V_{\max }$ and $K_{\text {cat }}$ for Monoclonal $F 123$ with 57 via the Spectrophotometer Cuvette Method

3.14 SUMMARY AND CONCLUSIONS 114

3.15 SUGGESTIONS FOR FUTURE WORK ....................................... 117

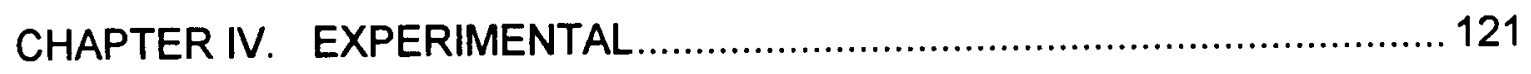

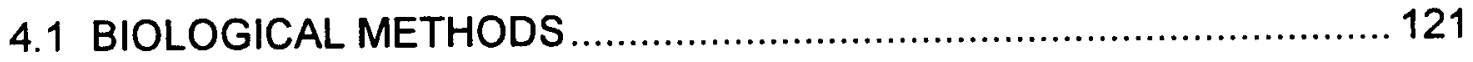

4.1.1 Monoclonal Antibody Purification................................................ 121

4.1.2 Preparation of Immuno- and Binding-conjugates of 50 ................ 122

4.1.2.1 KLH-50 Hapten Conjugate ................................................. 122

4.1.2.2 BSA-49 Hapten Conjugate-Coated Carboxyl Polystyrene Particles 122

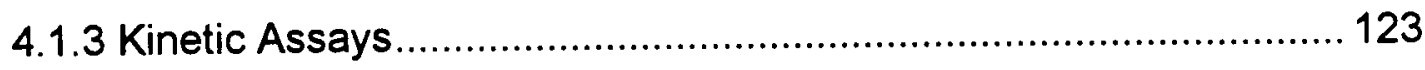

4.1.3.1 Multiwell Method ............................................................... 123

4.1.3.2 Spectrophotometer Cuvette Method ................................... 124

4.1.4 General Immunological Techniques........................................... 125

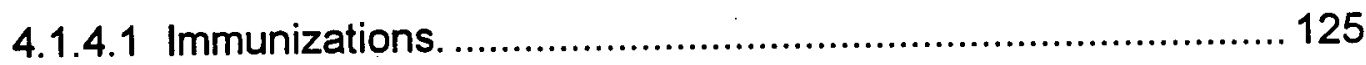

4.1.4.2 Test Bleeds................................................................... 125

4.1.5 Polyethylene Glycol (PEG) Fusion.......................................... 126 


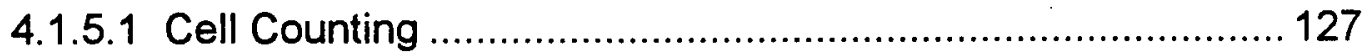

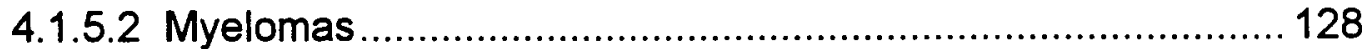

4.1.5.3 PEG Solution for Cell Fusion............................................. 128

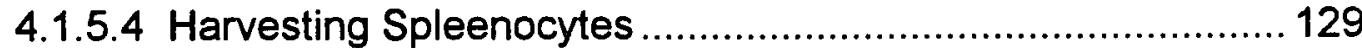

4.1.5.5 Harvesting Myelomas..................................................... 130

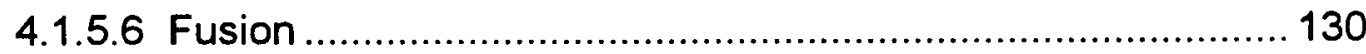

4.1.5.7 Transferring Fused Cells to the Growth Plates ..................... 131

4.1.5.8 Selection and Expansion of Hybridomas ............................ 131

4.1.5.9 Cloning Cell Lines............................................................ 132

4.1.5.10 Ascites Production ............................................................ 133

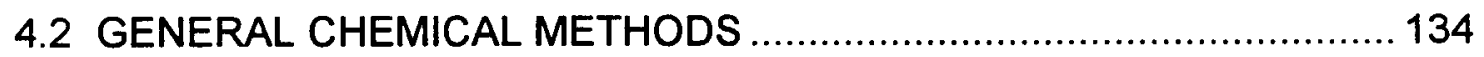

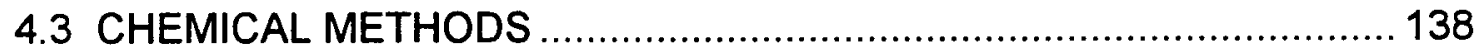

11-(Tetrahydropyranyloxy)-1-dodecanal (33).................................... 138

1-Diphenylphosphinyl-12-(tetrahydropyranyloxy)-1-tridecene

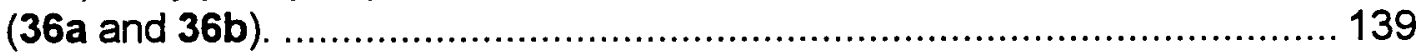

12-Hydroxy-1-diphenylphosphinyl-tridecane (37) ................................. 141

1-Phenyl-10xo-1-phospho-13-tetradecanolide (38a and 38b)

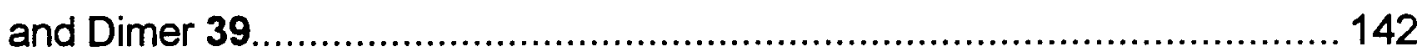

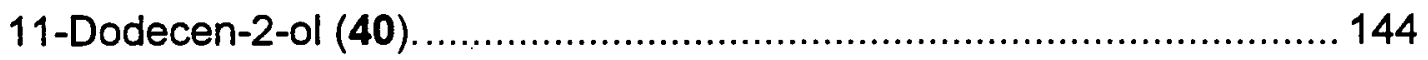

11-(Tetrahydropyranyloxy)-1-dodecene (41) ..................................... 145

11-(Tetrahydropyranyloxy)-1-dodecanol (42) .................................... 147

1-Diphenylphosphinyl-12-(tetrahydropyranyloxy)-tridecane (43). ............... 148

Phenyl 12-Hydroxytridecane Phosphonic Acid (44) ................................ 149

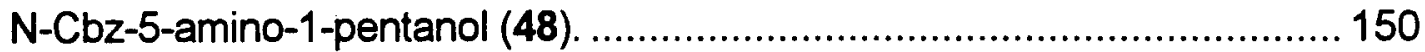

1-O-Cbz-linker-1-oxo-1-phospho-13-tetradecanolide (49a)...................... 152

1-O-Cbz-linker-1-oxo-1-phospho-13-tetradecanolide (49b). ..................... 153

1-O-linker-1-oxo-1-phospho-13-tetradecanolide (50)................................ 154

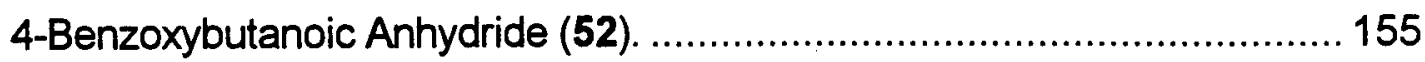

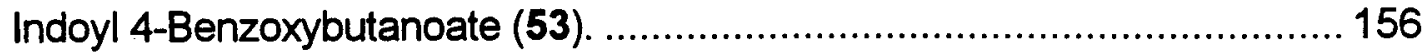


(Indoyl butanoate) 13-Hydroxytetradecanoate (55)................................. 157

p-Nitrophenyl 13-Hydroxytetradecanoate (57) ...................................... 158

p-Nitrophenyl Tetradecanoate (58)..................................................... 160

1-Oxo-1-phosphonic acid-13-tetradecanolide (59) ................................... 161

1-(p-Nitrophenyl)-1-oxo-1-phospho-13-tetradecanolide

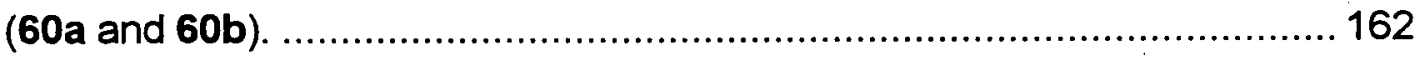

6-Methyl-2-oxo-2-phenoxy-1,2-oxaphosphorinane (61a and 61b)............. 164

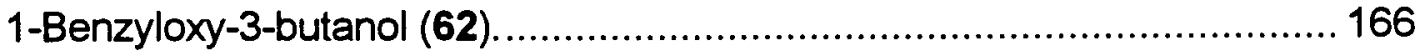

1-Benzyloxy-3-(Tetrahydropyranyloxy) butane (63) .............................. 167

3-(Tetrahydropyranyloxy) butan-1-ol (64) ............................................... 168

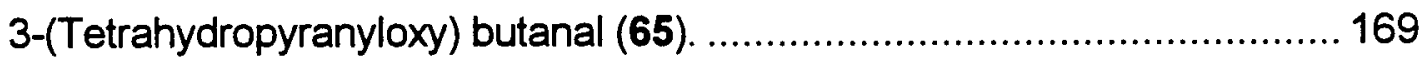

1-Diphenylphosphinyl-4-(tetrahydropyranyloxy)-1-pentene (66)................. 170

4-Hydroxy-1-diphenylphosphinyl-1-pentene (67) ................................... 171

1-Diphenylphosphinyl pentan-4-ol (68).................................................. 172

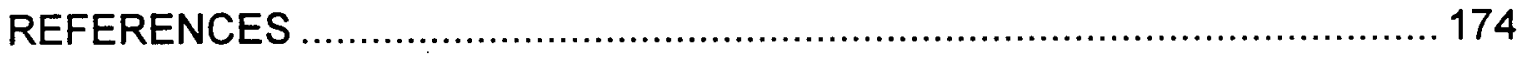

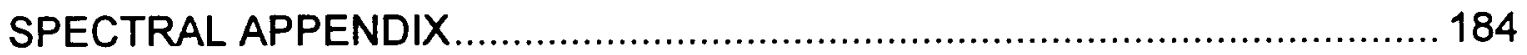




\section{LIST OF TABLES}

ix

Table 1. Relative rate constants at $0^{\circ} \mathrm{C}$ for the cyclization of various $\omega$-bromoalkyl-carboxylate ions

Table 2. Characteristics of antibody classes............................................ 15

Table 3. Reactions catalyzed by antibodies............................................ 47

Table 4. Comparison of the ${ }^{1} H$ NMR chemical shift data for the methine and methyl signals of the open chain hydroxy acid 44 with those of themacrocyclic phosphonates $38 \mathrm{a}$ and $38 \mathrm{~b}$.

Table 5. Key ${ }^{1} \mathrm{H}$ and ${ }^{31} \mathrm{P}$ NMR chemical shifts ( $\delta$ values) and TLC $R_{r}$-values for the cyclic phosphonates.

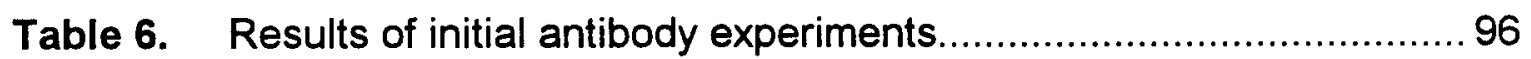

Table 7. Solubility study of substrate 57 with Triton $X-100 \ldots \ldots \ldots \ldots \ldots \ldots \ldots . . . . . . . . . .104$

Table 8. A comparison of the catalytic efficiency $\left(K_{\text {cat }} / K_{m}\right)$ of antibody F123 with that of the antibody reported by Napper, et al. ${ }^{59}$

Table 9. Media and components used in hybridoma production 126 


\section{LIST OF FIGURES}

Figure 1. Examples of macrolides..................................................... 2

Figure 2. Free energy diagram of an antibody-catalyzed reaction compare to the corresponding uncatalyzed reaction.

Figure 3. The schematic structure of immunoglobins (antibodies), (taken from ref 64, p 288).

Figure 4. Overview of the immune system. 19

Figure 5. Kappa ( $\mathrm{k}$ ) rearrangements in germ line and B-lymphocytes (taken from ref $65, p$ 13).

Figure 6. Heavy chain VDJ joining (taken from ref $65, \mathrm{p} 15$ ). 25

Figure 7. Hybridoma technology for the production of monoclonal antibodies.

Figure 8. ELISA assay for screening mouse antibodies. 30

Figure 9. PCFIA assay for screening mouse antibodies. 33

Figure 10. The effect of substrate concentration on the rate of the enzyme-catalyzed reaction.

Figure 11. A double-reciprocal plot, or a Lineweaver-Burk plot, of enzyme kinetics: $1 / v$ is plotted as a function of $1 /[\mathrm{S}]$ 40

Figure 12. The putative transition state and the corresponding phosphonate transition state analogue for the displacement reaction of an ester.

Figure 13. Stereoview of an ORTEP representation of dimeric cyclic phosphonate, 39 , showing $33 \%$ probability ellipsoids. 66

Figure 14. Relative stereochemistry about the phosphorus atom and the $\mathrm{C}-1$ carbon atom of dimer 39 as interpreted from Figure 13 
Figure 15. Monoclonal antibodies F123 (O), F125 ( $\square$ ) and F150 (•), each at a concentration of $2 \mu \mathrm{M}$, were assayed for activity with substrate $57(200 \mu \mathrm{M})$ in PBS buffer ( $\mathrm{pH} 7.4)$ containing $10 \%$ DMSO and $0.5 \%$ Triton $\mathrm{X}-100$ at $37^{\circ} \mathrm{C}$

Figure 16. Initial experiments with antibody $F 123$, substrate 57 , and hapten derivative 60 using PBS buffer ( $\mathrm{pH} \mathrm{7.4)}$ containing $10 \%$ DMSO and $0.5 \%$ Triton $\mathrm{X}-100$ at $37^{\circ} \mathrm{C}$. Reactions were run; (i) (•) $88 \mu \mathrm{M}$ in 57 and $0.88 \mu \mathrm{M}$ in F123, (ii) (O) $88 \mu \mathrm{M}$ in 57 and $0.44 \mu \mathrm{M}$ in $\mathrm{F} 123$, (iii) () $88 \mu \mathrm{M}$ in $57,0.88 \mu \mathrm{M}$ in $\mathrm{F} 123$ and $0.22 \mu \mathrm{M}$ of 60 (1:1 ratio of diastereomers). 95

Figure 17. GC chromatograms of: (a) an independently synthesized sample of lactone 19; (b) ether extracts from a large-scale F123 catalyzed cyclization reaction of substrate 57 ; (c) a spiked GC run of the ether extracts from the antibody experiment with an authentic sample of 19.

Figure 18. The activity of monoclonal $F 123(0)$ is compared to that of a control monoclonal antibody, HIL-2O (•), using substrate 57 in both of the experiments. Each experiment was run $200 \mu \mathrm{M}$ in $\mathbf{5 7}$ and $2 \mu \mathrm{M}$ in antibody, carried out in PBS buffer ( $\mathrm{pH} 7.4$ ) containing 10\% DMSO and $0.5 \%$ Triton $X-100$ 99

Figure 19. Comparison of antibody F123 activity with hydroxy ester substrate $57(0)$; with ester $58(\bullet)$. In each case, antibody was $0.46 \mu \mathrm{M}$; substrates were $100 \mu \mathrm{M}$; carried out in PBS buffer ( $\mathrm{pH} 7.4$ ) containing 10\% DMSO and $0.5 \%$ Triton $\mathrm{X}-100$; total reaction volume was $225 \mu \mathrm{L}$. 100

Figure 20. Antibody F123 activity with hydroxy ester substrate $57(0)$; with hydroxy ester substrate 57 in the presence of an equimolar amount of lactone $19(\bullet)$. Experiments were carried out in PBS buffer (pH 7.4) with 10\% DMSO; $0.46 \mu \mathrm{M}$ in antibody $\mathrm{F} 123 ; 200 \mu \mathrm{M}$ in substrate; total reaction volume was $250 \mu \mathrm{L}$ 
Figure 21. Competitive inhibition of the F123-catalyzed macrolactonization of substrate 57 by a one-to-one mixture of 4-nitrophenyl phosphonate diastereomers $60 \mathrm{a}$ and $60 \mathrm{~b}$. The reactions were performed in PBS buffer, $\mathrm{pH} 7.4$, containing $10 \%$ DMSO and $0.5 \%$ Triton $X-100$. The concentrations of the one-to-one mixture of $60 \mathrm{a}$ and $60 \mathrm{~b}$

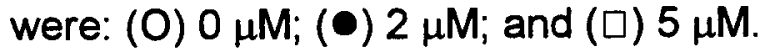

Figure 22. Antibody F123 reaction with substrate $\mathbf{5 7}$ compared to the background hydrolysis of $\mathbf{5 7}$ in the reaction buffer alone.

Figure 23. Comparison of the $\mathrm{F} 123$ reaction with substrate $\mathbf{5 7}$ and background hydrolysis of $\mathbf{5 7}$ using 10\% DMSO and $1.0 \%$ Triton X-100 in $8 \mu \mathrm{M}$ PBS buffer (pH 6.95); and F123 and 57 in a $10 \%$ DMSO with $1.0 \%$ Triton X-100 in $500 \mu \mathrm{M}$ PBS buffer (pH 7.45).

Figure 24. A Lineweaver-Burk analysis of the F123-catalyzed macrolactonization of hydroxy ester substrate $\mathbf{5 7}$ using the multiwell method.

Figure 25. A Lineweaver-Burk analysis of the F123-catalyzed macrolactonization of hydroxy ester substrate $\mathbf{5 7}$ using the spectrophotometer cuvette method. 


\section{LIST OF SCHEMES}

Scheme 1. Lactonization strategies which proceed through activated activated carboxyl intermediates; (a) Corey method (from ref 45); (b) Mukaiyama method (from ref 46);

(c) Yamaguchi method (from ref 47). 6

Scheme 2. Synthesis of macrocyclic phosphonate 22 ..............................55

Scheme 3. Proposed synthetic sequence for compound 35......................58

Scheme 4. A proposed mechanism for the Mitsunobu reaction (from ref 138).

62

Scheme 5. Possible pathways in the Mitsunobu reaction (from ref 138).....62

Scheme 6. Synthesis of macrocyclic phosphonates 38a and 38b..............65

Scheme 7. Coupling of the BSA-50 conjugate with the carboxy polystyrene particles (PSP).

76

Scheme 8. Exocyclic (path a) versus endocyclic (path b) hydrolysis of immuno-conjugate $\mathrm{KLH}-50$ in mouse serum. 78

Scheme 9. Chromogenic assay reported by Gong, et al. (taken from ref 88 ). 80

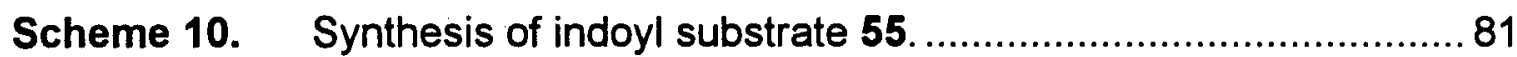

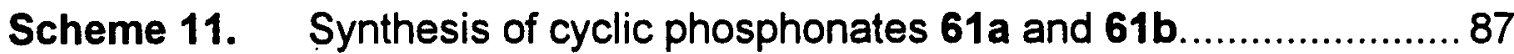




\section{ABBREVIATIONS}

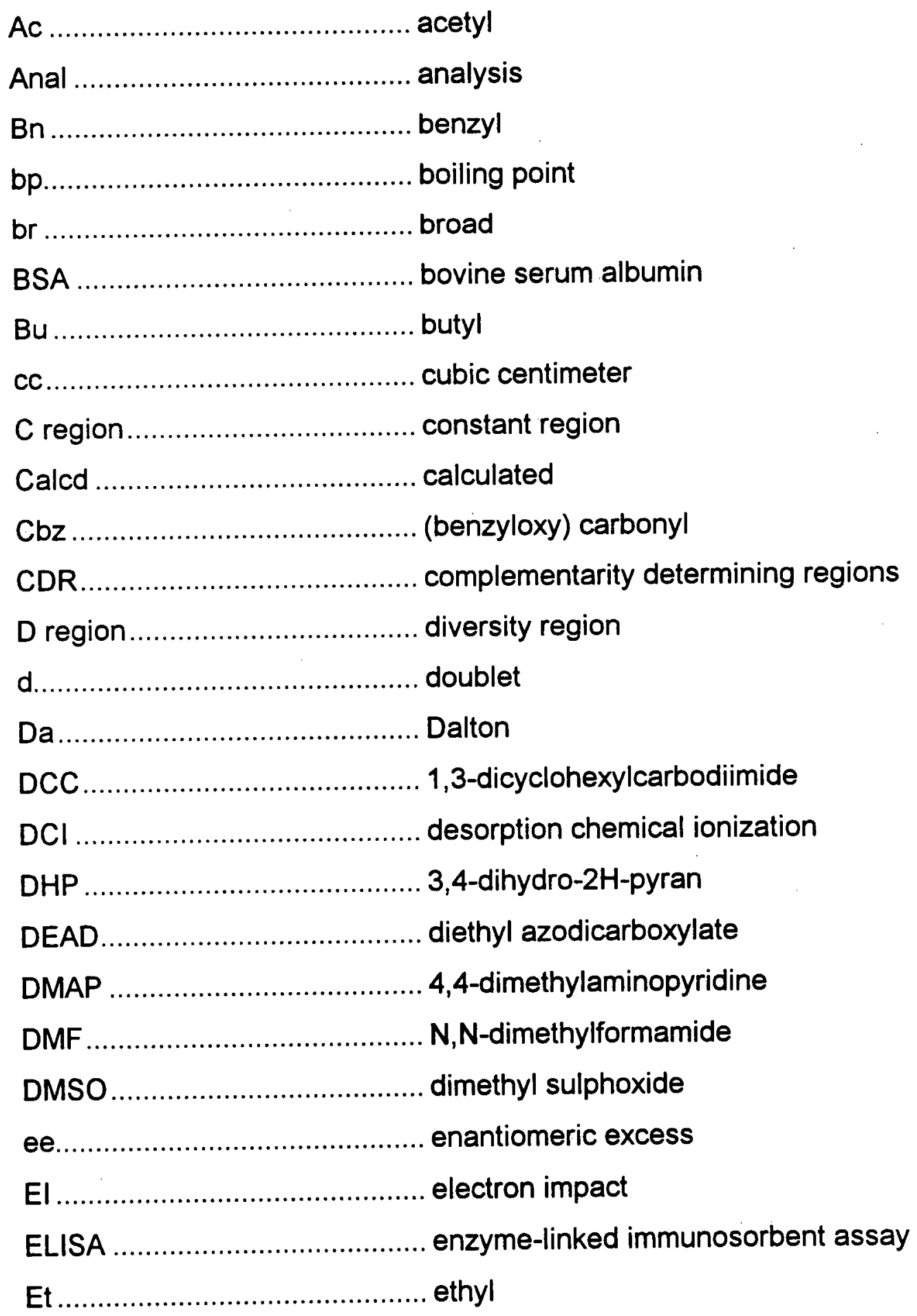




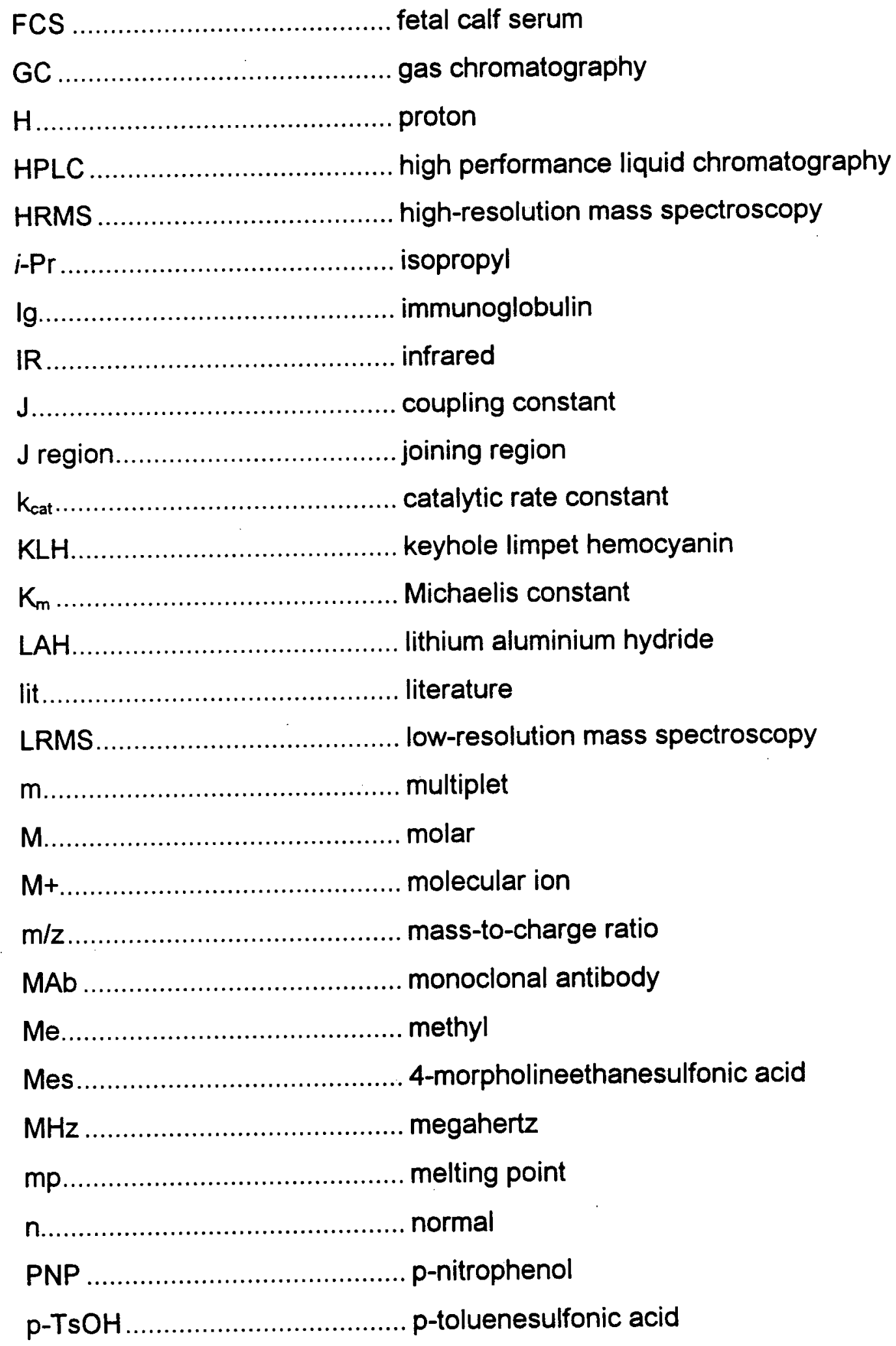




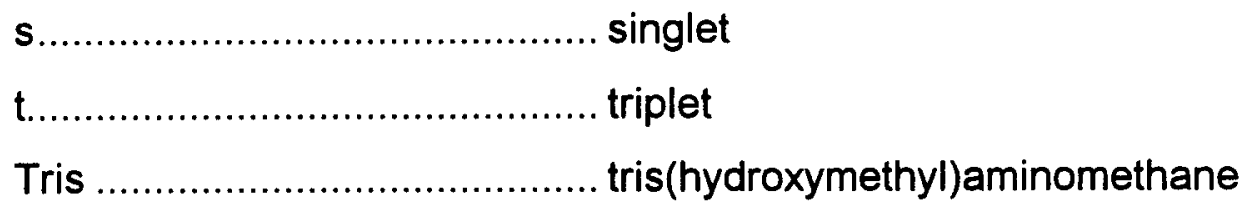




\section{ACKNOWLEDGEMENTS}

I would like to thank Professor Larry Weiler for his guidance and encouragement throughout the course of this project, and in the preparation of this thesis.

For providing me with an introduction to immunology, and without whos help and expertise this project would not have been possible, I would like to thank Professor Hermann Ziltener and his technicians Helen Merkens and Michael Williams at the Biomedical Research Center.

I would also like to thank Professor Steve Withers and his research group for their generous guidance and support with the kinetic studies performed in this thesis.

I am indebted to the service personnel of the Chemistry Department including the Mass Spec. and the Microanalytical laboratories. I am especially grateful to the NMR staff for the numerous routine and non-routine experiments they performed on my behalf.

To my lab-mates, both past and present, I extend my thanks for their contributions and freindship throughout my stay in the Weiler lab.

Finally, I would like to thank my family and friends for their unending support and encouragement during the preparation of this thesis. 
xviii

This thesis is dedicated to my parents. 


\section{CHAPTER I. INTRODUCTION TO MACROLIDES}

\subsection{MACROLIDE ANTIBIOTICS}

Macrolide antibiotics, a class of natural products largely isolated from microorganisms, have been characterized extensively with regard to their structure and function. Ever since the isolation and structure elucidation of this general class of naturally-occurring macrocyclic antibiotics starting in the 1950's, syntheses of these large ring compounds have posed a challenge to chemists. The first of these macrocyclic antibiotics to be isolated was pikromycin, in $1950 .^{1}$

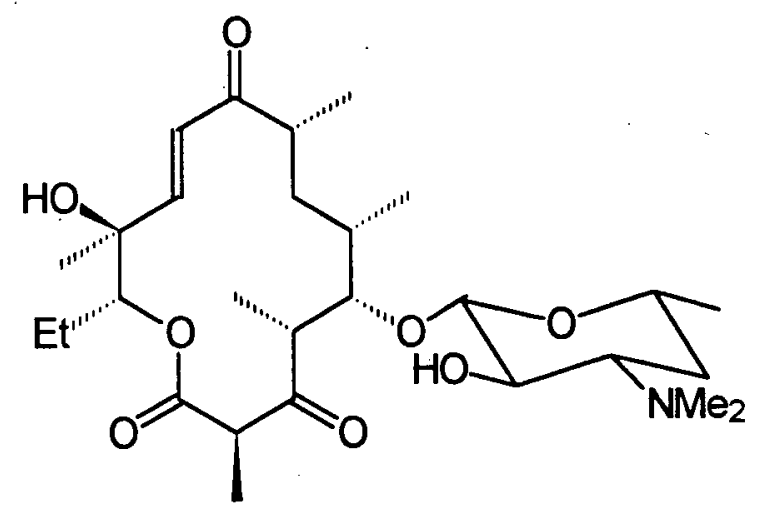

\section{Pikromycin}

Woodward ${ }^{2}$ originally suggested that the name "macrolide" apply only to those compounds containing a macrocyclic lactone ring such as pikromycin or erythromycin A. Today, however, that definition has been expanded to include a wider range of macrocyclic compounds, for instance, polyene macrolides such 


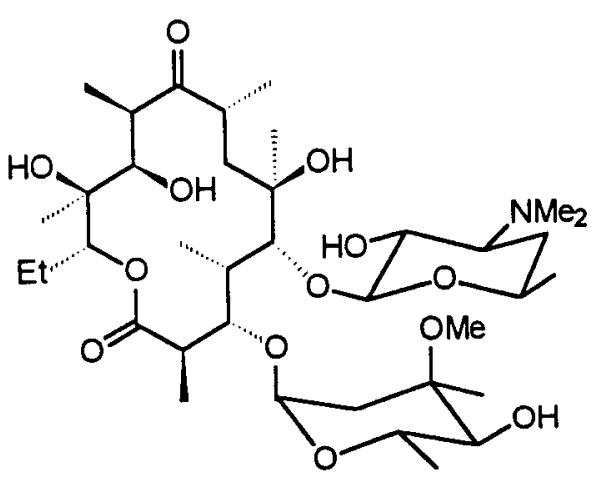

Erythromycin A

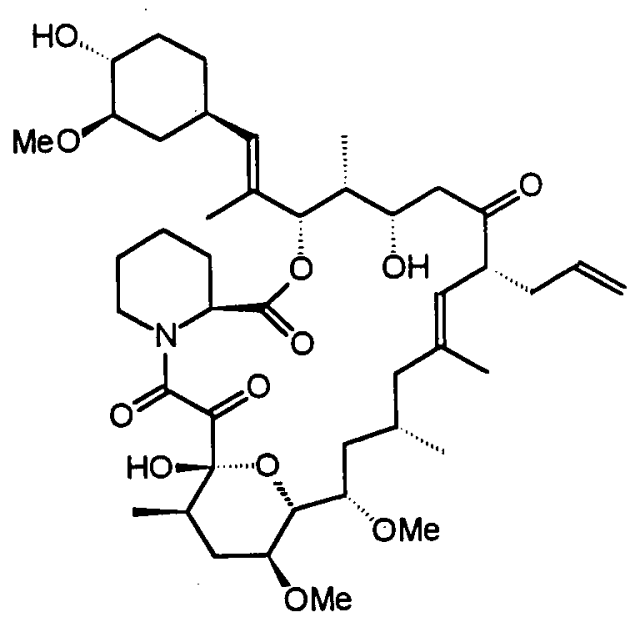

FK-506

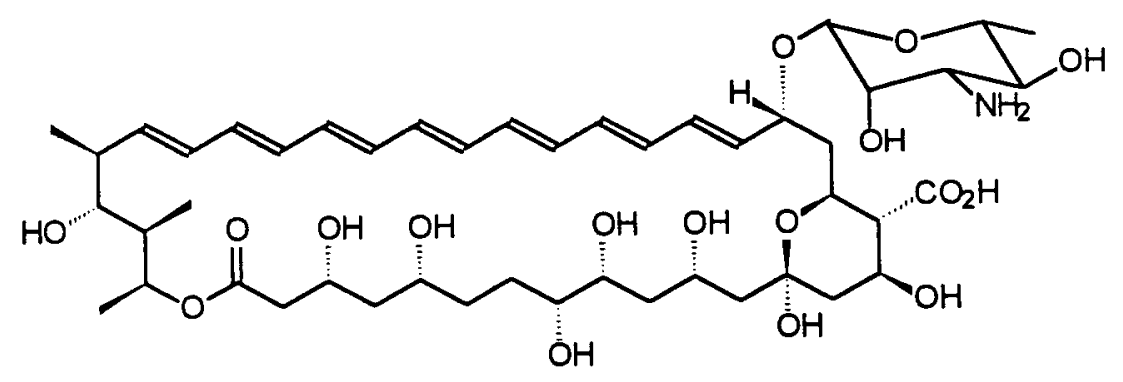

Amphotericin B

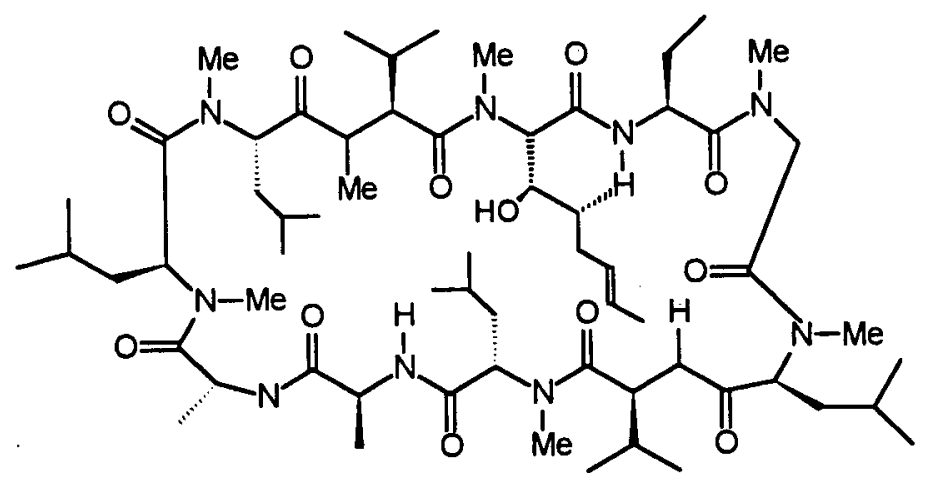

\section{Cyclosporin A}

Figure 1. Examples of some macrolides. 
as amphotericin B, lactams such as FK-506, and cyclic peptides such as cyclosporin A (Figure 1). The production, isolation, and biological activity of the macrolide class of compounds has been reviewed elsewhere. ${ }^{3-12}$

Although the macrolides have been studied for several years, they still remain of interest to researchers for a number of reasons. Some macrolides have been shown to function as insect pheromones, while many others are clinically important. Erythromycin, for example, used in the treatment of Legionnaires' disease, ${ }^{13,14}$ is a commonly prescribed antibiotic. ${ }^{15-17}$ The macrolides FK-506 and cyclosporin A are immunosuppressants, while others have shown anticancer activity. ${ }^{18-21}$ And lastly, the complex structure and stereochemistry associated with these compounds presents a significant challenge to synthetic chemists. Since the introduction of penicillin as a medicine half a century ago, more than 80 antibiotics have been developed as human medicines, agrochemicals and veterinary medicines. ${ }^{22}$ The development of ampicillin in 1961 by chemical modification of penicillin lead to the evolution of semisynthetic antibiotics through the considerable efforts of organic chemists. Clearly, the stereochemical complexity of the macrocylic compounds attracts the interest of synthetic chemists, however, their clinical importance necessitates a search for general, efficient methods for their preparation. Some reviews have been published which focus on the efforts towards the synthesis of these compounds. ${ }^{23-27}$ 
The majority of synthetic approaches used to build these macrocyclic compounds rely on first constructing a complex acyclic precursor and then cyclizing this precursor late in the synthesis. An alternative approach that has been the focus of our research group for some time is the macrocyclic conformational approach. In this route, the macrocyclic ring is formed early in the synthesis and the conformation of the ring is used to introduce the various substituents with regiochemical and stereochemical control. Efforts using this conformational approach have been published by our research group ${ }^{28-34}$ and others. $^{35-38}$

\subsection{LACTONIZATION METHODS}

\subsubsection{Chemical Methods}

Lactone formation becomes significantly slower in going from 5- and 6 -membered rings to large ring sizes (Table 1). ${ }^{39}$ The difficulty in carrying out the ring-forming step has lead to the development of a number of methodologies to effect large ring lactonization. ${ }^{40}$

The direct cyclization of $\omega$-hydroxy acids in the presence of mineral or Lewis acids at high temperature and in dilute solution is not recommended because other functional groups present in the molecule often are destroyed under such conditions. Research in this area began to focus on methods to activate the 
reacting groups of the open-chain $\omega$-hydroxy acids. Activation of the carboxylic acid, involving such derivatives as active esters, mixed anhydrides or thiol esters, is a common cyclization strategy. Alternatively, one could enlist an approach which activates the hydroxyl end of the $\omega$-hydroxy acid, for example using the Mitsunobu method..$^{41-43}$ The remainder of this section will detail examples of both approaches.

Table 1. Relative rate constants at $0^{\circ} \mathrm{C}$ for the following reaction (taken from ref 44);

\begin{tabular}{cc}
$\mathrm{Br}\left(\mathrm{CH}_{2}\right)_{\mathrm{n}-2} \mathrm{CO}_{2}^{-} \longrightarrow\left(\mathrm{CH}_{2}\right)_{\mathrm{n-2}}^{\mathrm{C}} \mathrm{C}=\mathrm{O}+\mathrm{Br}^{-}$ \\
\hline Ring size & Relative rate \\
\hline 3 & 21.7 \\
4 & $5.4 \times 10^{3}$ \\
5 & $1.5 \times 10^{6}$ \\
6 & $1.7 \times 10^{4}$ \\
7 & 97.3 \\
8 & 1.00 \\
9 & 1.12 \\
10 & 3.35 \\
11 & 8.51 \\
12 & 10.6 \\
13 & 32.2 \\
14 & 41.9 \\
15 & 45.1 \\
16 & 52.0 \\
18 & 51.2 \\
23 & 60.4 \\
\hline
\end{tabular}

In 1974 Corey and Nicoloau ${ }^{45}$ reported a lactonization method which involved activation of the carboxyl moiety of $\omega$-hydroxy acids using triphenylphosphine and 2,2'-dipyridyl disulfide in xylene at room temperature to form 2-pyridinethiol 
esters (Scheme 1a). Without isolation, the slow addition of these activated intermediates to refluxing xylene to achieve high-dilution resulted in lactone formation. Mukaiyama et al. ${ }^{46}$ followed with an activation methodology which involved slow addition of the $\omega$-hydroxy acid to an excess of 2-chloro-1-methylpyridinium iodide and triethylamine in refluxing acetonitrile or dichloromethane to afford lactones. A third approach, reported by Yamaguchi

(a)<smiles>O=C(O)CCCCCCO</smiles>

(b)<smiles>O=C(O)CCCCCCO</smiles><smiles>c1ccc(SSc2ccccn2)nc1</smiles><smiles>OCCCCCCOSc1ccccn1</smiles><smiles>C=CC</smiles><smiles>O=C1CCCCCCCCO1</smiles><smiles>CCN(CC)C(Cl)=[N+](C)c1ccccc1Cl</smiles><smiles>C[n+]1ccccc1OC(=O)CCCCCCCCO</smiles>

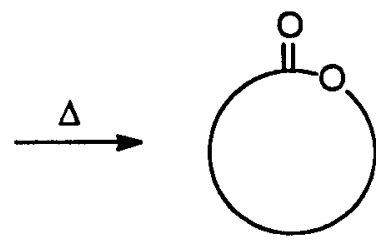<smiles>CCN(F)C(=O)c1c(Cl)cc(Cl)cc1Cl</smiles><smiles>O=C(OC1CCCCCCCCO1)c1c(Cl)cc(Cl)cc1Cl</smiles><smiles>CC(C)(C)[C@H]1CCC(=O)CCCCCCCOC1=O</smiles>

Scheme 1. Lactonization strategies which proceed through activated carboxyl intermediates; (a) Corey method (ref 45); (b) Mukaiyama method (ref 46); (c) Yamaguchi method (ref 47). 
and co-workers in $1979,{ }^{47}$ involved the reaction of the $\omega$-hydroxy acid in THF with one equivalent of 2,4,6-trichlorobenzoyl chloride. After removal of the triethylammonium chloride, the filtrate was diluted with a large volume of toluene and slowly added to a solution of refluxing toluene containing 3-6 equivalents of 4-dimethylaminopyridine to effect lactonization.

Lactonization methods of $\omega$-hydroxy acids via activation at the hydroxyl end are less common. The Mitsunobu method is a simple one-pot approach which uses a mixture of triphenylphosphine $\left(\mathrm{Ph}_{3} \mathrm{P}\right)$ and diethyl azodicarboxylate (DEAD) as dehydrating agent in the synthesis of lactones under mild, neutral conditions (Equation 1). ${ }^{41-43}$ It has been suggested that the key intermediate of this method is the alkoxyphosphonium salt that undergoes nucleophilic displacement by the carboxylate anion with inversion of stereochemistry, releasing the very stable by-product triphenylphosphine oxide $\left(\mathrm{Ph}_{3} \mathrm{P}=0\right)$. Smith et al. ${ }^{48}$ demonstrated the use of the Mitsunobu protocol, in the total synthesis of the latrunculins (Equation 2 ), to effect a macrocyclization of compound 1 with inversion of configuration at the secondary hydroxyl position giving compound 2 .

These chemical approaches require that at least an equimolar ratio of reagent to hydroxy acid be used. A catalytic reagent would be of value. An added bonus would occur if the cyclizing reagent (or catalyst) was enantioselective. 


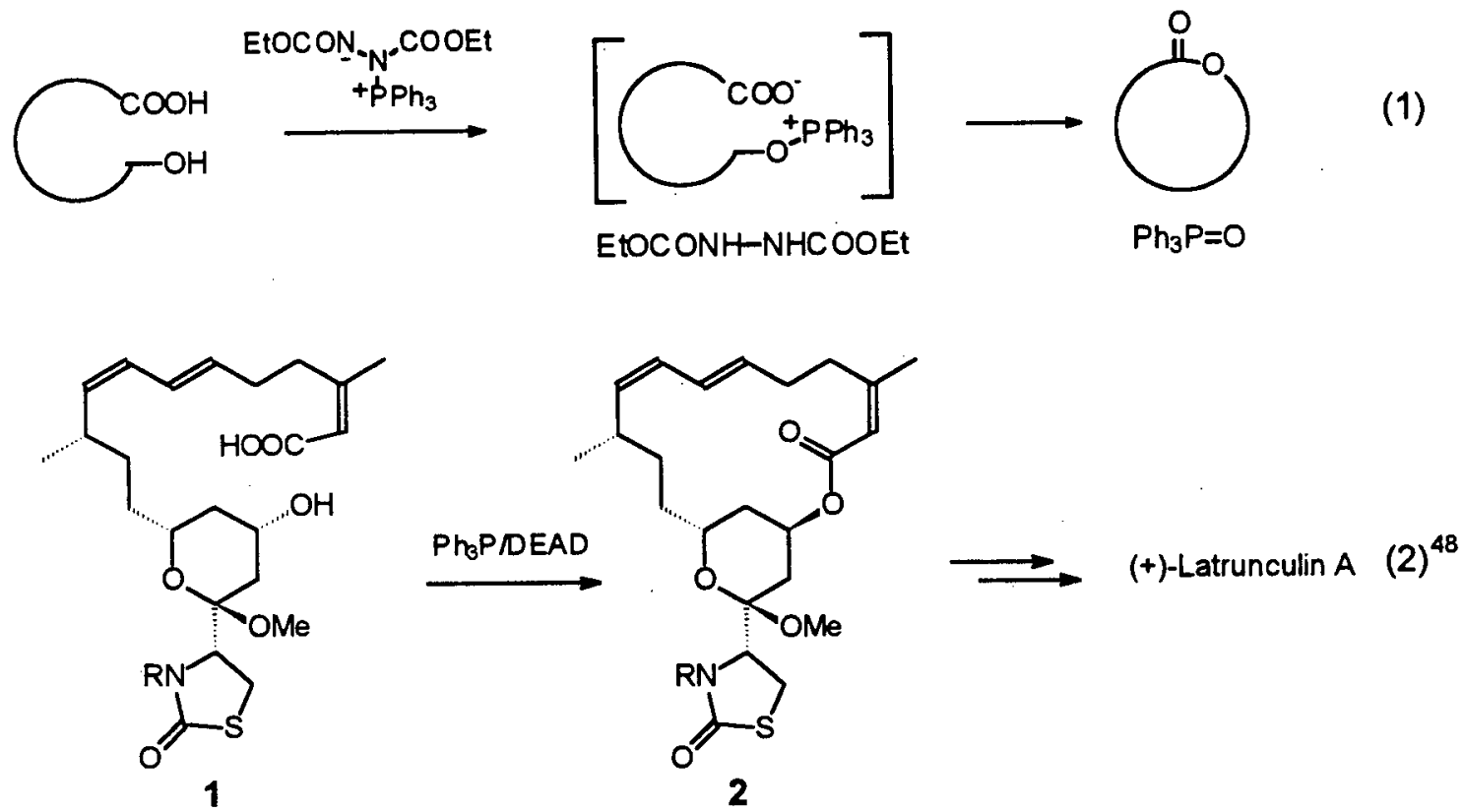

\subsubsection{Enzymatic Methods}

Macrolactonization strategies involving the use of enzymes to effect stereoselective catalytic cyclizations have also been investigated. In 1984, Gatfield $^{49}$ was the first to report the intramolecular esterification of 15-hydroxypentadecanoic acid catalyzed by Mucor miehei lipase to obtain pentadecanolide. Yamada and co-workers ${ }^{50}$ reported that Pseudomonas sp. and porcine pancreas lipases mediate macrolactonization of methyl esters of $\omega$-hydroxy acids $C_{12}-C_{16}$, producing mono- and dilactones. Subsequently others have also reported the use of lipases in macrolactonizations. ${ }^{51-53}$ For example, Guo et al. found the direction of the reaction and the yield of mono-, di-, and trilactones from 16-hydroxyhexadecanoic acid depended on the lipase used. ${ }^{53}$ 
Attempts to use enzymes in aqueous and organic solvents to catalyze medium to large ring lactonization of secondary alcohols have met with only limited success. $^{54,55}$

\subsubsection{Antibody Methods}

Since the first successful reports by Lerner ${ }^{56}$ and Schultz ${ }^{57}$ on the use of antibodies to catalyze chemical transformations, a large number of antibody-catalyzed reactions have been reported (Table 3, Chapter 2). Two reports to date describe the use of catalytic antibodies to effect 5- and 6 -membered ring lactone cyclizations. ${ }^{58,59}$ These two examples illustrate the successful use of antibodies to act as chiral catalysts in enantioselective lactonizations. The difficulties associated with the macrolactonization reaction mentioned earlier (section 1.2) pose a challenge in the syntheses of macrolide antibiotics. We believe the use of catalytic antibodies may provide a key for the formation of 12-16 membered ring lactones (macrolides), and in addition, may function enantioselectively and catalytically as in the small ring examples. Chapter 2 of this thesis will examine the general use of antibodies as catalysts in a range of organic transformations. 


\section{CHAPTER II. INTRODUCTION TO CATALYTIC ANTIBODIES}

\subsection{HISTORICAL ASPECTS}

The vast repertoire of antibodies expressed by the immune system enables it to generate a response to virtually any foreign molecule. Scientists have been able to exploit this diversity, and use the immune response to study various chemical processes. The first reports on the use of antibodies to catalyze chemical transformations appeared in $1986,{ }^{56,57}$ when two research groups independently published their results on acyl transfer reactions. However, the idea of harnessing the adaptive ability of the immune system to produce chemically useful catalysts was first eluded to by Linus Pauling in $1946 .{ }^{60}$ It was, in fact, Pauling's recognition of the similarity of antibodies and enzymes with respect to complementarity and the nature of catalysis that is acknowledged as one of the most important contributions to the field of catalytic antibodies. Despite a lack of details about protein structure, Pauling concluded that enzymes were similar to antibodies in that they both are complementary to the species they bind. The fundamental difference between these two types of proteins is that an antibody binds a stable species (hapten), while an enzyme binds the activated complex of the substrate in an enzymatic reaction. Pauling also pointed out that non-covalent factors, such as strain and ground state destabilization, are important for enzymatic catalysis. 
It was approximately 20 years later that Jencks wrote "if complementarity between the active site and the transition state contributes significantly to enzymatic catalysis, it should be possible to synthesize an enzyme by constructing such an active site. One way to do this is to prepare an antibody to a haptenic group which resembles the transition state of a given reaction. The combining site of such antibodies should be complementary to the transition state and should cause an acceleration by forcing bound substrates to resemble the transition state. ${ }^{n 1}$ The stabilization gained in the binding associated with the antibody combining site is illustrated in the free energy diagram below (Figure 2).

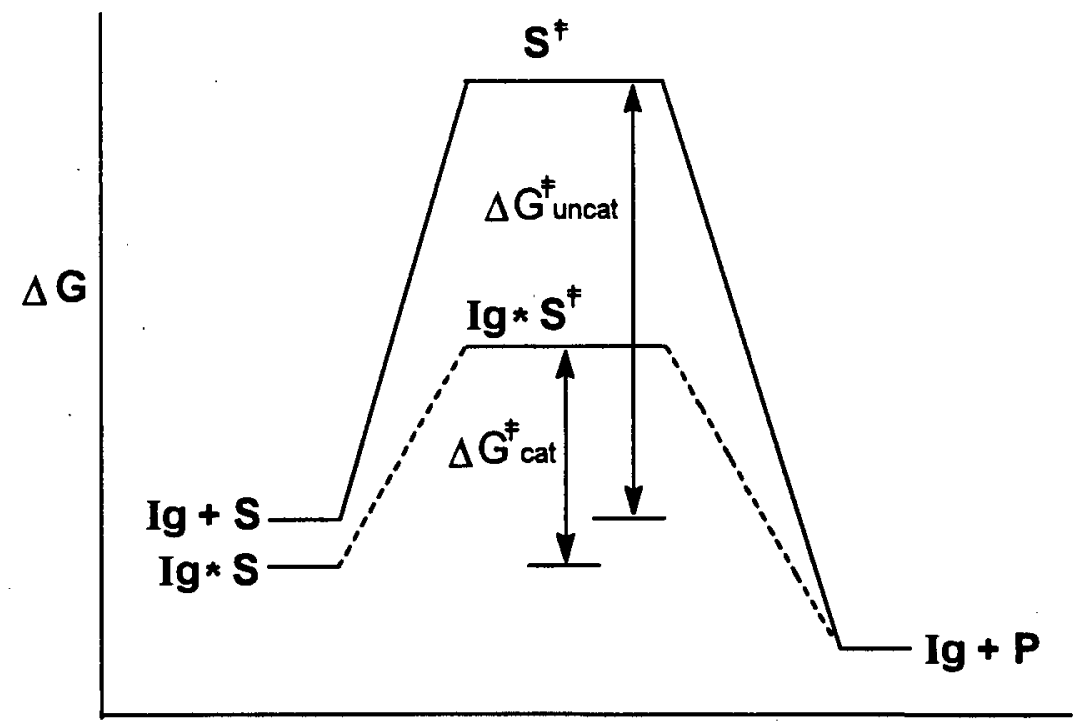

Reaction Coordinate

Figure 2. Free energy diagram of an antibody-catalyzed reaction compared to the corresponding uncatalyzed reaction. 
The basis of this approach to the generation of catalytic antibodies requires a stable transition state analogue (a hapten) that is similar in size, shape, and charge distribution to the putative transition state of the reaction of interest. Furthermore, small molecules are generally not recognized by the immune system, and require coupling to a high molecular weight carrier protein before immunization, typically in mice or rabbits. Booster injections of the hapten-protein conjugate (antigen) are required at regular intervals, following the primary immune response to the initial immunization, until the antigen-antibody binding interaction has reached a plateau. That is to say, the primary immune response to the antigen is mounted by the animal's existing "naive" antibody repertoire, which upon repeated exposure to antigen, evolves through mutations to a more complimentary binding association between antigen and antibody. At this point, a blood sample is taken from the host animal and the antibodies are partially purified, and screened for binding and catalytic activity. Early attempts to test the transition state hypothesis were disappointing because the researchers used this polyclonal sera, i.e., a mixture of many antibodies. Later work using monoclonal antibodies, ${ }^{62}$ the development for which Köhler and Milstein $^{63}$ were awarded the Nobel prize in Physiology and Medicine in 1984 , lead to the initial successful demonstrations of catalytic antibodies by the research groups of Lerner ${ }^{56}$ and Schultz. ${ }^{57}$ 


\subsection{ANTIBODY STRUCTURE}

Antibodies are large Y-shaped molecules (molecular weight $\cong 150 \mathrm{kDa}$ ) that belong to a group of proteins called immunoglobins. The antibody molecule consists of four polypeptide chains - two identical heavy chains (50 kDa each) and two identical light chains ( $25 \mathrm{kDa}$ each) held together by covalent disulfide linkages between the two heavy chains and between the heavy and light chains (Figure 3). The light chains are composed of two distinct structural domains known as the variable $\left(V_{L}\right)$ and constant $\left(C_{L}\right)$ regions. The heavy chains contain

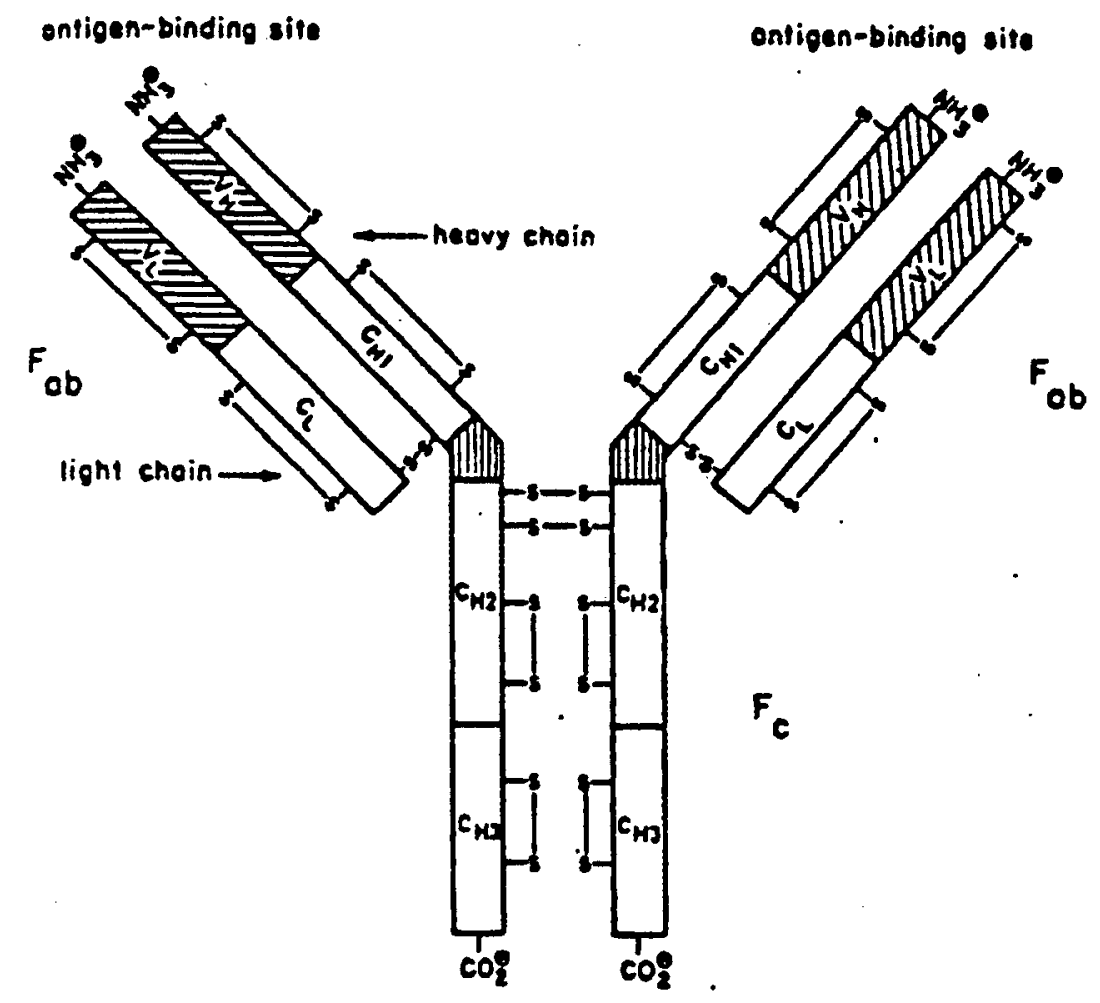

Figure 3. The schematic structure of immunoglobins (antibodies), (taken from ref 64). 
four domains: $V_{H}, C_{H 1}, C_{H 2}$, and $C_{H 3}$, each of which is composed of approximately 110 amino acids.

Enzymatic digestion of the antibody molecule with pepsin gives rise to three fragments; two of which are identical (Fab fragments) and contain the variable region where antigen binding occurs, the third fragment is readily crystallizable $(F c)$ and is responsible for immune regulation (i.e. effector functions). In the uncleaved antibody, the Fab and Fc fragments meet at a region called the hinge, which allows lateral and rotational movement of the molecule.

Antibodies are divided into five classes, $\lg G, \lg M, \lg A, \lg E$, and $\lg D$. Each antibody class, or isotype, is distinguished by the type of heavy chain found in the molecule. The heavy chains of IgG molecules are known as $\gamma$-chains, IgMs have $\mu$-chains, IgAs have $\alpha$-chains, IgEs have $\varepsilon$-chains, and IgDs have $\delta$-chains. The differences in their heavy chains allows each isotype to function in different immune responses, and at different stages of the developing immune response. As for the light chains, there are only two different types, $\kappa$ and $\lambda$. Recall that in the Y-shape antibody molecule, the two light polypeptide chains each associate with one heavy chain (Figure 3). Although there exist five classes of heavy chains and two of light, each antibody molecule will have only one type of light chain and one type of heavy chain. Furthermore, different classes of antibodies may vary in the number of $Y$-like units that join to form the complete 
immunoglobin (Table 2). The $\lg G$ class along with the $\lg E$ and $\lg D$ antibodies are monomeric (only one $Y$ unit), while the IgA class can form either monomeric, dimeric, or trimeric complexes, and finally, the IgM antibodies are pentameric (containing five $Y$ units each). These $Y$ units are joined at the base of the Fc regions via short polypeptide chains in the oligomers. IgM antibodies then, being pentamers, have 10 identical antigen binding sites, while monomeric IgG antibodies have two identical binding sites. In addition, the differences in the heavy chains between the antibody classes accounts for the different molecular weights of the various monomers. IgG monomers, for example, have a molecular weight of approximately $150 \mathrm{kDa}$, while IgM monomers are approximately $175 \mathrm{kDa}$.

Table 2. Characteristics of the various Antibody classes (taken from ref 65).

\begin{tabular}{|c|c|c|c|c|c|}
\hline Characteristics & IgG & IgM & IgA & IgE & IgD \\
\hline Heavy Chain & $y$ & $\mu$ & $\alpha$ & $\varepsilon$ & $\delta$ \\
\hline Light Chain & $x \operatorname{or} \lambda$ & $x$ or $\lambda$ & $x$ or $A$ & xor 1 & $x \operatorname{or} \lambda$ \\
\hline $\begin{array}{l}\text { Molecular } \\
\text { Formula } \\
\text { Y Structure }\end{array}$ & $\gamma_{2} \alpha_{2}$ or $\gamma_{2} \lambda_{2}$ & $\left(\mu_{2} \kappa_{2}\right)_{5}$ or $\left(\mu_{2} \lambda_{2}\right)_{s}$ & $\left(a_{2} \alpha_{2}\right)_{n}{ }^{*}$ or $\left(a_{2} \lambda_{2}\right)_{n}$ & $\varepsilon_{2} \kappa_{2}$ or $\varepsilon_{2} \lambda_{2}$ & $\delta_{2} x_{2}$ or $\delta_{2} \lambda_{2}$ \\
\hline Valency & 2 & 10 & 2,4, or 6 & 2 & 2 \\
\hline $\begin{array}{l}\text { Concentration } \\
\text { in Serum }\end{array}$ & $8-16 \mathrm{mg} / \mathrm{ml}$ & $0.5-2 \mathrm{mg} / \mathrm{ml}$ & $1-4 \mathrm{mg} / \mathrm{ml}$ & $10-400 \mathrm{ng} / \mathrm{ml}$ & $0-0.4 \mathrm{mg} / \mathrm{ml}$ \\
\hline Punction & $\begin{array}{c}\text { Secondary } \\
\text { response }\end{array}$ & $\begin{array}{l}\text { Primary } \\
\text { response }\end{array}$ & $\begin{array}{l}\text { Protects } \\
\text { mucous } \\
\text { membranes }\end{array}$ & $\begin{array}{l}\text { Protects } \\
\text { against } \\
\text { parasites (?) }\end{array}$ & $?$ \\
\hline
\end{tabular}

in $=1,2$, or 3 . 
The variable or Fab region of an antibody consists of one $V_{H}$ and one $V_{L}$ chain, to form one antigen binding site. The diversity of the variable region provides the basis for the large repertoire of binding sites that constitutes an effective immune response. However, the diversity within the variable region is limited to only those regions where contact with the antigen occurs, known as hypervariable regions. The light and heavy chains have three hypervariable regions each, and these form the majority of contact residues for the binding of the antigen to the antibody. Because they are the actual contact points with the antigen, they are referred to as the complementarity determining regions or CDRs. The nature of these structural details, including the secondary and tertiary structure of antibodies and the features of the binding site, have come from X-ray crystallographic studies of variable fragments, some of which contain the complexed antigen. ${ }^{66,67}$ In the case of small organic molecules, the binding occurs in clefts with volumes on the order of $600 A^{368}$. The clefts exclude water and antigen binding occurs via van der Waals forces, hydrophobic and electrostatic interactions, and hydrogen bonding, in the same manner as observed for substrate and inhibitor binding to enzymes.

\subsection{THE IMMUNE SYSTEM / RESPONSE}

The principal function of the immune system is to protect animals from foreign molecules and organisms. This highly efficient defense mechanism utilizes 
proteins and cells which circulate throughout the body to perform this function. There are many different mechanisms which act in this system, all of which can be divided into two broad categories - nonadaptive and adaptive immunity.

Nonadaptive immunity is mediated by cells that respond nonspecifically to foreign molecules. This response does not improve with repeated exposure. Examples of nonadaptive immunity are phagocytosis by macrophages, secretion of lysozyme by lacrimal cells, and cell lysis by natural killer cells. Conversely, adaptive immunity is directed at specific molecules and is enhanced by repeated exposure. Adaptive immunity is mediated by cells called lymphocytes, which have two main functions, namely the synthesis of cell-surface receptors or secretion of proteins that bind specifically to foreign molecules. These secreted proteins are known as antibodies. The terms "antigen" and "immunogen" are used to describe different properties of molecules in the context of the immune system. An antigen is any molecule that will bind to an antibody, while an immunogen is defined as a molecule that induces an immune response. Furthermore, a "hapten" is a small molecule which by itself cannot act as an immunogen, but when coupled to a high molecular weight carrier protein, the complex is capable of eliciting an immune response.

The immune system contains more than $10^{\circ}$ lymphocyte cells which travel throughout the blood and lymphatic system, enabling them to respond promptly 
to foreign molecules. The lymphocytes are found in higher concentrations in the lymphoid organs, namely the lymph nodes and spleen. It is in these organs that the immunogens tend to accumulate, thus, becoming the focus of the immune response.

A number of different lymphocytes have been identified within the immune system. Three basic types of lymphocytes have been found to be associated with the cellular functions of the immune system, namely B cells, killer or cytotoxic $T$ cells, and helper $T$ cells (Figure 4). B lymphocytes, which originate in the bone marrow, secrete antibodies and carry a bound form of the same antibody on their cell surface, where it acts as a receptor for antigens. T lymphocytes, originate in the thymus, and carry out either a regulatory role (helper $\mathrm{T}$ cells) or an antigen attacking role (cytotoxic $\mathrm{T}$ cells) through their surface antigen receptors, known as T-cell receptors. While they share similar structural features, the surface antibodies on B cells and the T-cell receptors are encoded by separate gene families; and their expression is cell-type specific. In addition, the surface antibodies on B cells can bind to soluble antigens, while the T-cell receptors recognize antigens only when displayed on the surface of other cells. Once an antigen is bound to the surface antibody on a B cell, for instance, the helper $T$ cells play an essential regulatory role in governing the subsequent response of $B$ cells and cytotoxic $T$ cells during an immune response. The molecular basis for the specificity of the immune response is controlled by a 
simple mechanism - all the surface antigen receptors on a single lymphocyte cell, whether a B-or T-lymphocyte, are identical and recognize one and only one antigen.

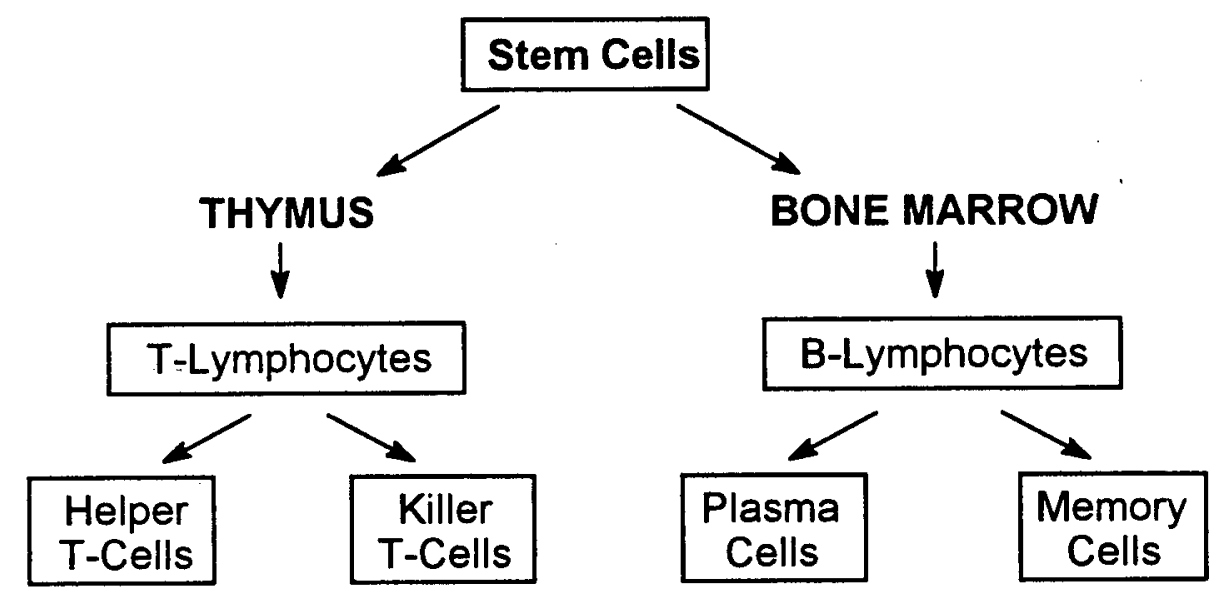

Figure 4. Overview of the immune system.

While the immune system is challenged constantly by a large number of foreign molecules, it has the ability to distinguish these invaders from natural components of the body. By constantly eliminating lymphocytes that bind to and attack self molecules, an organism is said to have tolerance. Should this self-preserving mechanism, called clonal deletion, break down and the organism mounts a response against itself, a range of disorders known collectively as autoimmune diseases may result (e.g. rheumatoid arthritis, diabetes, Graves' disease). Clonal deletion occurs in the thymus during the development of the immune system by a poorly understood process. Another important feature of 
the immune system is immunological memory. Upon first exposure to a foreign antigen, an animal's immune response is slow. This slow response may be insufficient to prevent disease if the antigen is pathogenic. On subsequent exposures to the same antigen, the response is stronger and more rapid due to this immunological memory. The memory is specific for each antigen and can last as long as the animal lives.

\subsection{ANTIBODY PRODUCTION IN VIVO}

Antibody molecules are produced by white blood cells called B cells (bone marrow derived cells committed to producing antibodies). With no prediction of the shapes of foreign molecules to be encountered during the lifetime of an organism, nature has evolved a "catch-all" defense mechanism which is strengthened by a positive feedback system. The production of naive antigen receptors occurs in the absence of antigen. A diverse repertoire of $B$ cells each with a unique antigen receptor, more than $10^{7}$ in number, is produced continuously and ready for interaction with antigen. Each individual B cell or colony of identical B cells ("clones") makes numerous antibody molecules. The naive repertoire is expressed on the surface of the B cells, with each individual cell expressing many molecules of a unique antibody. Initially, when an antigen or foreign material is encountered, it binds to a limited number of B cells which express an antibody with some affinity for that invader. These cells are 
stimulated and divide. This involves a complicated series of events, and ultimately is responsible for the differentiation of B cells into plasma cells and memory cells. Plasma cells are short-lived cells found primarily in the lymphoid organs that specialize in secreting large amounts of antibodies. Memory cells, however, are long-lived cells that remain in circulation and do not secrete antibodies. Rather, memory cells retain cell-surface antibodies and are primed to respond to any subsequent exposure to the antigen.

The differentiation of B cells has two important processes associated with it; affinity maturation, a process that involves point mutations in the immunoglobin (Ig) $\mathrm{V}$ genes followed by the selective proliferation of B cells expressing antibodies with increased affinity for antigen; and class switching, a process that involves rearrangement of the chromosomal DNA encoding for the heavy chain polypeptide.

Early in an immune response, division of B cells results in hypermutation of the antibody genes, leading to the production of many variants of the initial clones selected. The antigen in turn binds to and stimulates most effectively those clones having the highest affinity for the antigen. Affinity maturation is effectively a Darwinian process, involving variation resulting from mutations, followed by selection of cells driven by the requirement for high antigen-affinity 
for cell survival. Rounds of mutation and selection thus act to single-out the highest affinity clones; this is the basis of affinity maturation.

After the affinity maturation process, class switching follows which leads to the production of antibodies with different specific functions. This process involves rearrangement of the chromosomal DNA encoding for the heavy chain polypeptide. The result of this heavy chain shuffling allows the same variable region to be expressed with different constant regions. It is the heavy chain that dictates which class (isotype) the antibody belongs to, and these different classes have different functions. During a typical immune response, class switching is responsible for the replacement of IgM antibodies, characteristic of the early immune response, by $\lg G$ antibodies. As well, because the affinity maturation has taken place, IgG molecules typically have higher affinities for the antigen than the short-lived lgMs.

The level of antibodies in the system peaks about 7-10 days after first contact with the antigen and the secreted antibodies enhance the rate of clearance of the foreign molecule. If no further antigen is present after this time, the number of plasma cells will decrease but the helper T-cells and memory cells remain in circulation. Upon re-exposure to the antigen, the secondary response will occur. This secondary response involves a similar sequence of events as in the primary response; however, there are some differences. Due to the high number of 
helper T-cells and memory cells already in the system, the response is faster. Also, since the antibodies have already undergone affinity maturation, they have a higher affinity for the antigen making the response stronger. This immunological memory can remain with the animal for its entire lifetime, leaving the immune system primed for any further contact with the antigen.

\subsection{DIVERSITY OF THE IMMUNE RESPONSE}

The naive immune repertoire consists of some $10^{7}-10^{9}$ different antibody molecules before any exposure to a foreign material or antigen. This large repertoire is expected to be able to recognize, albeit with moderate affinity, virtually any foreign material. The interpretation of the diversity of this extraordinary system has been the subject of several reviews. ${ }^{69-72}$ This next section will look at the four main sources of this diversity, namely recombination, junctional diversity, mutation, and association of heavy and light chains.

\subsubsection{Recombination}

Recombination essentially involves the rearrangement of the germ-line DNA (the nonfunctional gene) of both the heavy and light chains to produce mature B-cell DNA (the functional gene). The coding sequences for the variable and constant regions of the germ-line DNA are separated by several hundred kilobase pairs, and as a result the gene is silent in these cells. During B cell differentiation, 
these intervening regions are excised and the variable and constant regions are joined, producing a functional B cell gene. The diversity in the recombination step arises from the number of different associations possible between the variable and constant regions of the germ-line DNA. An example which illustrates this diversity involves cells synthesizing functional $k$ chains. In this case, there are approximately 200 different $\mathrm{k}$ variable regions and only one constant region. During the recombination process, one of the variable regions is selected basically at random, and is joined to the constant region to produce a functional gene (Figure 5).

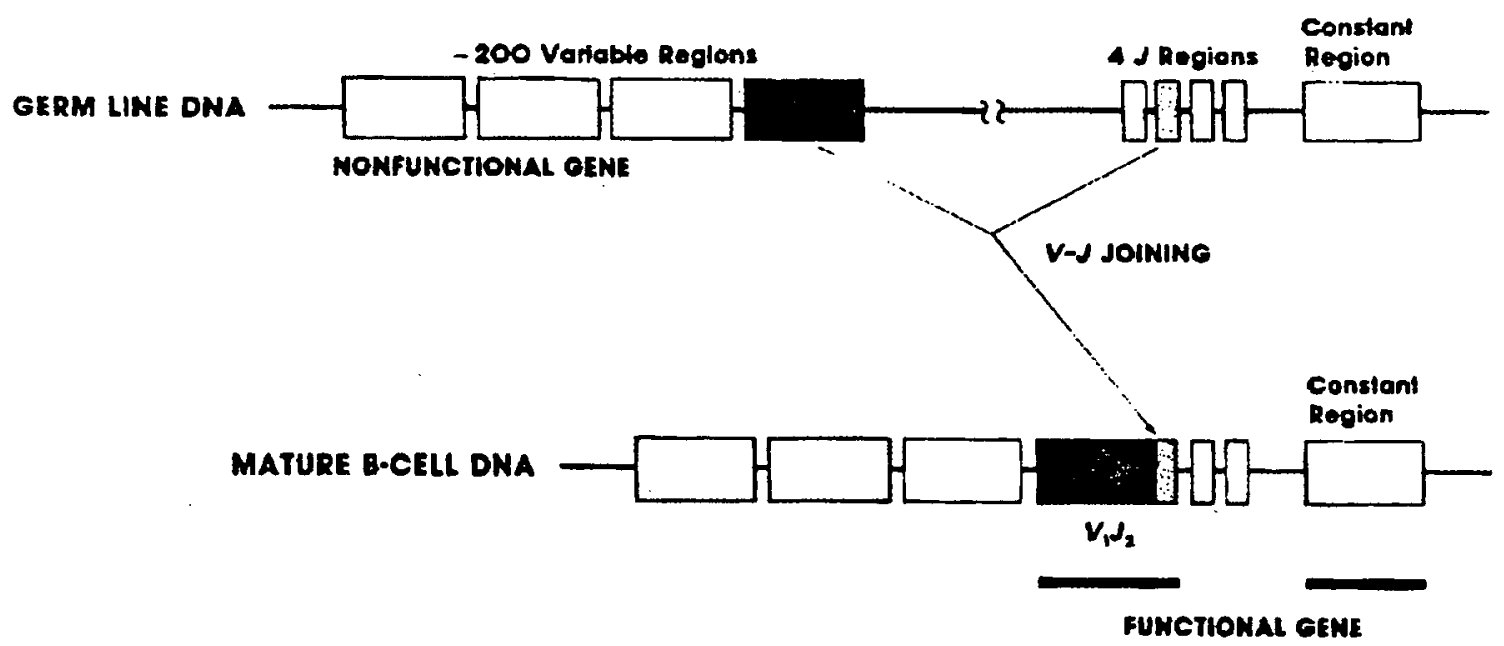

Figure 5. Kappa ( $\mathrm{\kappa}$ ) rearrangements in germ line and B-lymphocytes (taken from ref 65).

\subsubsection{Junctional Diversity}

It became clear however, after further studies of the fine structure of the recombination process between the variable and constant regions, that 
recombination alone does not account for all the variation detected in the immune repertoire. A third segment, known as the $\mathrm{J}$ region for joining, was discovered to exist between the variable and constant regions. Recombination, then, brings the randomly selected variable region together with one of the four functional $\mathrm{J}$ regions making a $\mathrm{V}-\mathrm{J}$ fragment, which on association with the constant region produces a functional $\mathrm{k}$ gene. In addition, the recombination events between the variable and $\mathrm{J}$ regions do not always occur at exactly the same nucleotides, and this allows for further diversity in the $\mathrm{V}-\mathrm{J}$ junction.

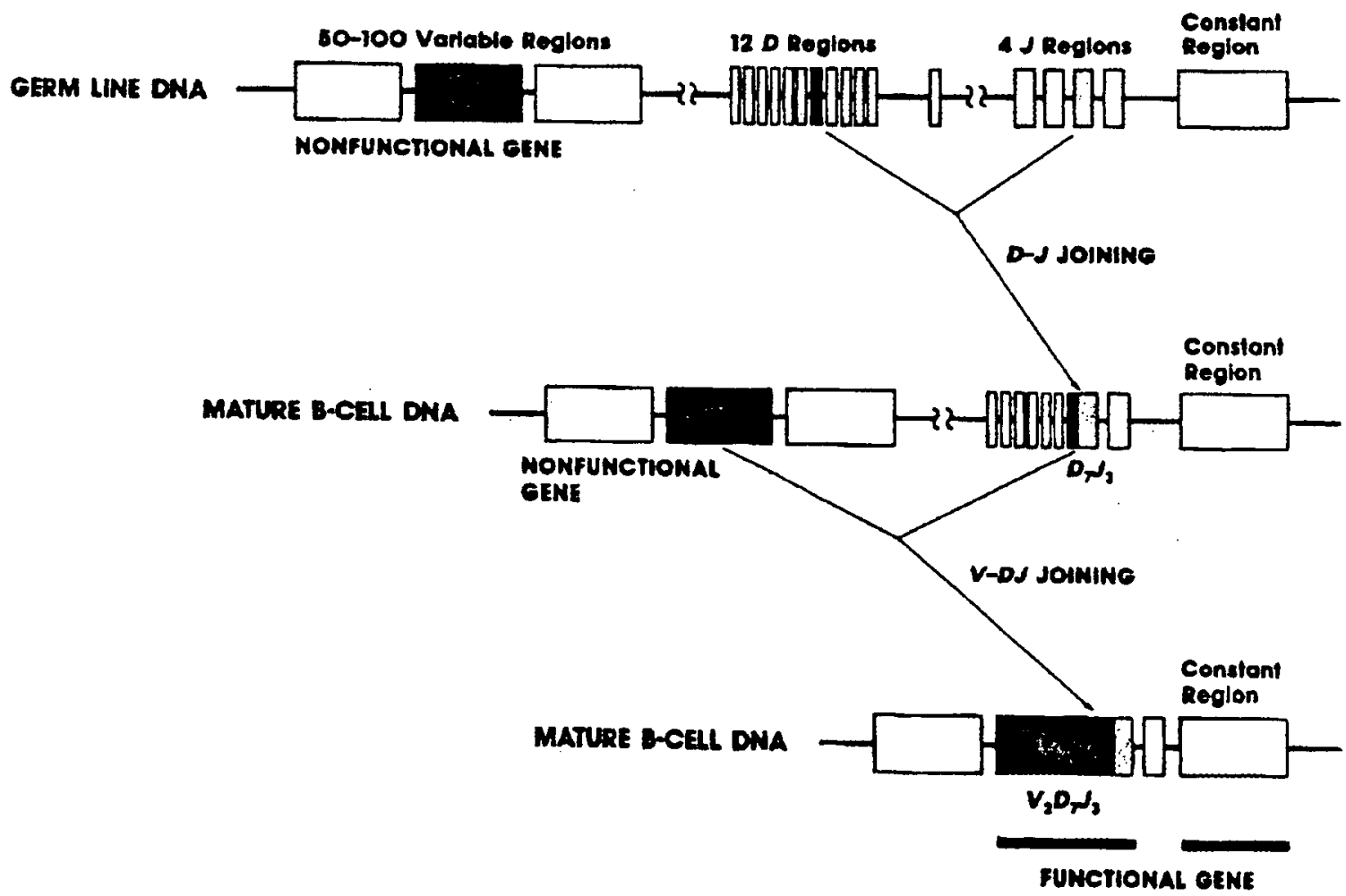

Figure 6. Heavy chain VDJ joining (taken from ref 65).

Heavy chains have, in addition to the variable, $\mathrm{J}$, and constant regions, a fourth coding region referred to as the $D$, or diversity, region. Thus, two recombination 
events are required for the production of a functional heavy chain gene, the first joins the $\mathrm{D}$ region to a J-constant region, and a second joins a variable region to the $D$ region (Figure 6).

\subsubsection{Mutation}

Mutations arising from a complex process referred to as affinity maturation lead to fine-tuning of the binding site, thus creating a better fit for antigen-antibody interaction. These mutations occur during an immune response to a foreign molecule or antigen, and the mechanisms that produce these mutations are not known.

\subsubsection{Association Of Heavy And Light Chains}

The genetic events described above provide heterogeneity in both heavy and light chains. The complete antibody molecule then requires joining of a heavy and a light chain. Once recombination has lead to the generation of functional heavy and light chain genes, a poorly understood process, called allelic exclusion, prevents further recombination, fixing the antigen binding site for the life of the cell. This explains why B lymphocytes secrete antibodies with only one type of antigen binding site, and why antibodies have only one type of light chain. The type, or class, of heavy chain produced by a particular B lymphocyte is determined by the process of class switching described earlier. Because the 
different classes and subclasses determine the functional roles of antibodies, class switching is an important mechanism for controlling where and how the antigen binding site will be used in the immune response.

\subsection{ANTIBODY GENERATION}

The method used to produce catalytic monoclonal antibodies is the same as that used to produce monoclonal antibodies used for other purposes. ${ }^{63}$ The synthesis of the hapten is often the most difficult and time demanding part to the production of catalytic monoclonal antibodies. Once the appropriate hapten has been made, it is then coupled to a carrier protein such as keyhole limpet hemocyanin $(\mathrm{KLH})$ for immunization. The coupling strategies used must be compatible with the hapten design, and produce a conjugate that is stable under physiological conditions. The hapten is coupled to the carrier protein via a spacer arm, which typically is on the order of $6 \AA^{73-76}$ so as to avoid any steric interference from the carrier. The spacer arm usually has a carboxy or an amine terminus to allow amide bond formation between the hapten and corresponding amino or carboxy groups on the surface of the carrier protein.

\subsection{HYBRIDOMA TECHNOLOGY}

The basis of the hybridoma technique involves combining the nuclei of normal antibody-producing cells with those of their malignant counterparts with retention 
of both types of function (Figure 7). In this way, an immortal hybridoma cell line that secretes an antigen-specific monoclonal antibody is obtained. This monumental advancement in immunology made possible the isolation and

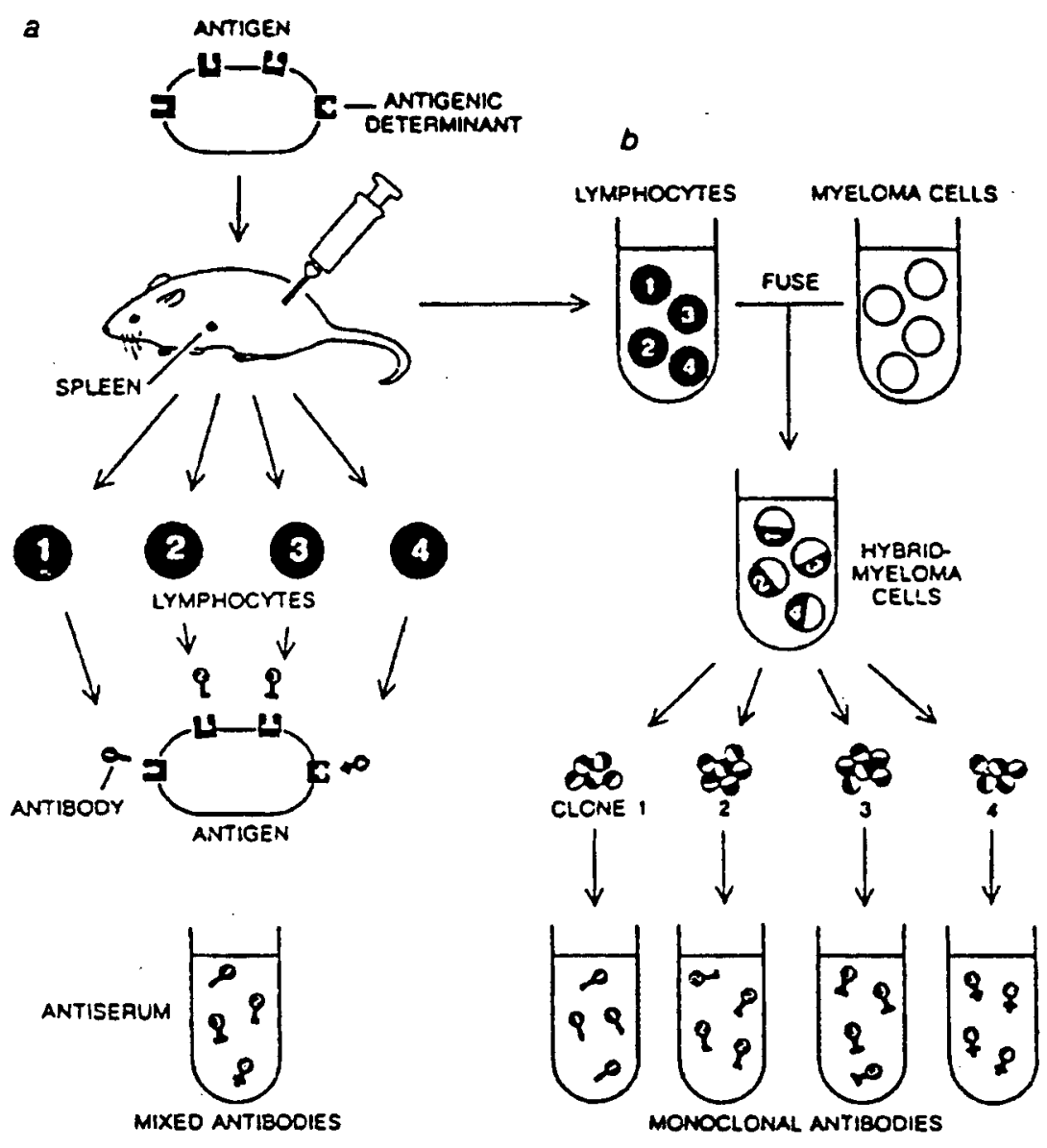

Figure 7. IMMUNE RESPONSE is initiated (a) when an antigen molecule carrying several antigeninc determinants enters the body of an animal. The immune system responds: lines of B-lymphocytes proliferate, each secreting an immunoglobulin molecule that fits a single antigenic determinant (or part of it). Conventional antiserum contains a mixture of these antibodies. Monoclonal antibodies are derived by fusing lymphocytes from the mouse spleen with malignant myeloma cells (b). Individual hybrid cells are cloned, and each of the clones secretes a monoclonal antibody that specifically binds a single antigenic determinant on the antibody molecule (from ref 77 ). 
production of large quantities of monoclonal antibodies that would specifically bind virtually any molecule. ${ }^{63}$

\subsection{SCREENING OF HYBRIDOMAS FOR HAPTEN BINDING}

Following the hybridization of the mouse spleen cells using the hybridoma technology, the stable clones are screened for binding activity against the same hapten to which they were raised. Currently, because there is no general assay available for directly screening the library of hybridomas for catalytic activity, clones must be selected for further studies based on their ability to bind to hapten. The assumption is made that strong hapten binding translates to catalytic activity.

The two binding assays that will be discussed in this section are, first, the enzyme-linked immunosorbent assay (ELISA), and second, the particle concentration fluorescence immuno-assay (PCFIA).

\subsubsection{The ELISA Assay}

The ELISA assay is widely used to study hapten binding of catalytic antibodies. With this assay, the hapten molecule is coupled to a carrier protein different from the protein used for the immunization protocol. $\mathrm{KLH}$ is often chosen as the immunization carrier protein, while bovine serum albumin (BSA) is frequently 
chosen as the conjugating protein for binding assays. This ensures that antibodies are selected for binding specifically to the hapten, rather than the

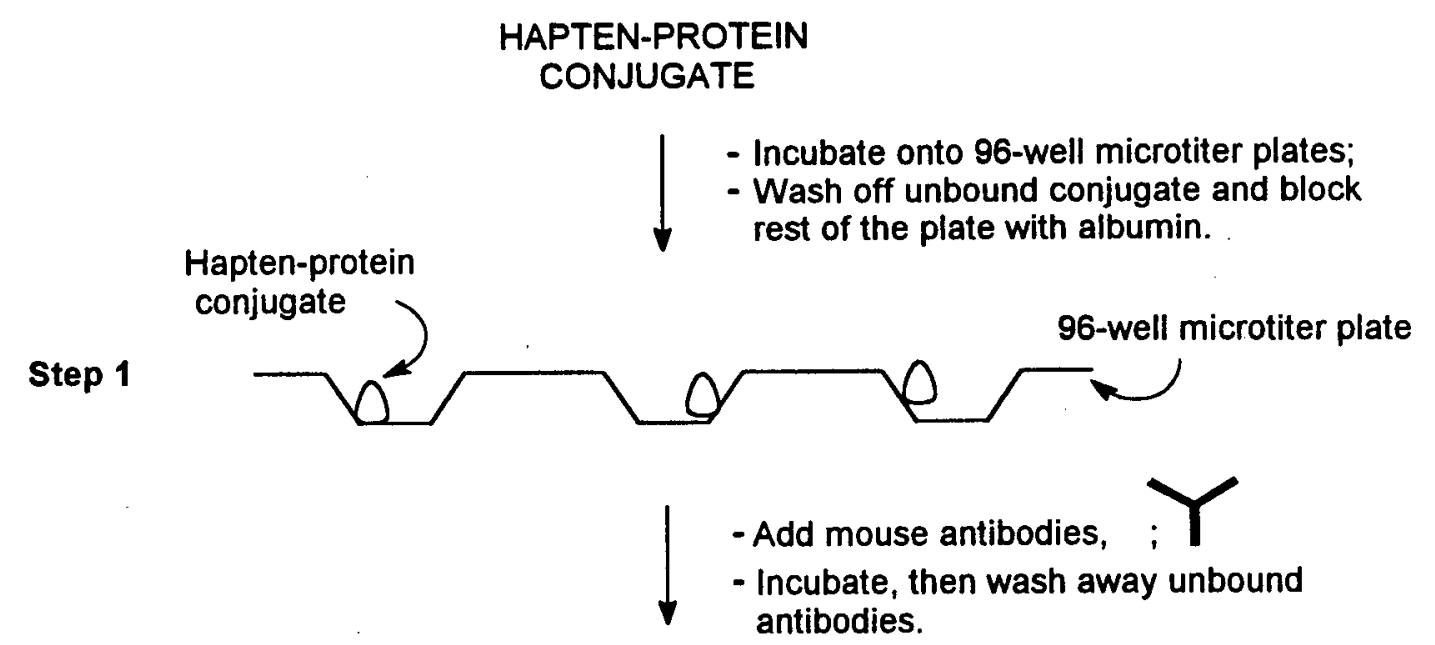

Step 2

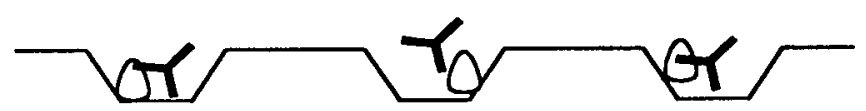

- Add enzyme-linked anti-mouse antibody, $f_{E}$

- Incubate, then wash away unbound antibody.

Step 3

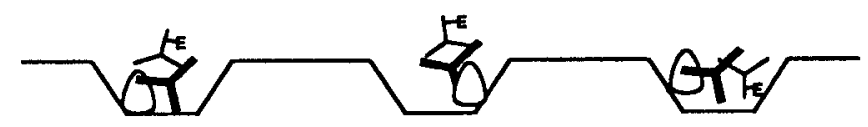

- Add substrate;

- Incubate, then detect absorbance

of released chromophore ( *).

Step 4

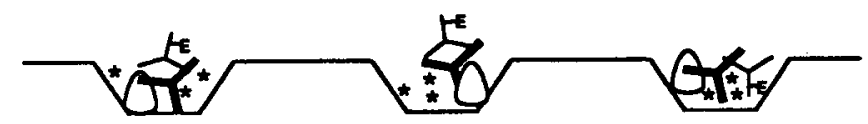

Figure 8. ELISA assay for screening mouse antibodies (figure provided by Gay Yuyitung). 
carrier protein. In the ELISA assay (Figure 8 ), the BSA-hapten conjugate is affinity bound to the wells of a polystyrene microtiter plate via nonspecific interactions, and the excess conjugate is washed away (Step 1). Any free binding sites in the polystyrene wells are blocked with the protein albumin. In the next step, the antibody-containing serum or hybridoma supernatant of interest is incubated with the bound hapten-protein conjugate, and unbound portions are washed away (Step 2). An enzyme-linked antibody (or secondary antibody) that binds to immunoglobulin bound to the plate (i.e. binding to antibody having specific affinity for the hapten) is added, and after an appropriate incubation time unbound secondary antibody is then washed away (Step 3). A substrate is added to each well and it is subsequently processed by the enzyme coupled to the secondary antibody, producing a chromogenic product $(*)$ that is detected and quantified spectroscopically (Step 4).

\subsubsection{The PCFIA Assay}

The PCFIA assay, commonly referred to as the Pandex binding assay, can be used in place of the traditional ELISA assay for the initial screening of hybridomas. Because this technique uses fluorescence detection, it is more sensitive than ELISA. The PCFIA assay (see Figure 9) uses hapten-protein conjugate-coated carboxyl polystyrene particles in 96-well filter assay plates, and a goat anti-mouse fluorescein isothiocyanate (FITC) secondary antibody for detection. The filter assay plates allow loading and incubating of buffered 
solutions in the wells, followed by suction filtration and washing of excess reagents through the bottoms of the wells. Once the hapten-protein conjugate-coated carboxyl polystyrene particles (hapten-beads) are made, these are added to the 96-well filter assay plates (Step 1). The antibody-containing serum or hybridoma supernatant of interest is incubated with the hapten-beads, and unbound immunoglobulins are washed away (Step 2). Next, the fluorescent labelled secondary antibody is added and binds to antibodies recognizing the hapten. The excess FITC labelled secondary antibody is washed away prior to reading the wells for a fluorescent signal, indicating specific hapten binding (Step 3).

Once hapten-specific hybridomas are selected based on the binding assay results, large quantities of monoclonal antibodies can be obtained by expanding the cells in tissue culture and harvesting the antibody secreted into the supernatant, or more commonly, the cells can be propagated in vivo in other mice to produce tumors which secrete a high concentration of antibody (ascites fluid). The characterization of binding and reaction kinetics of the monoclonal antibody with various substrates requires large quantities of antibody. 
HAPTEN-PROTEIN

CONJUGATE

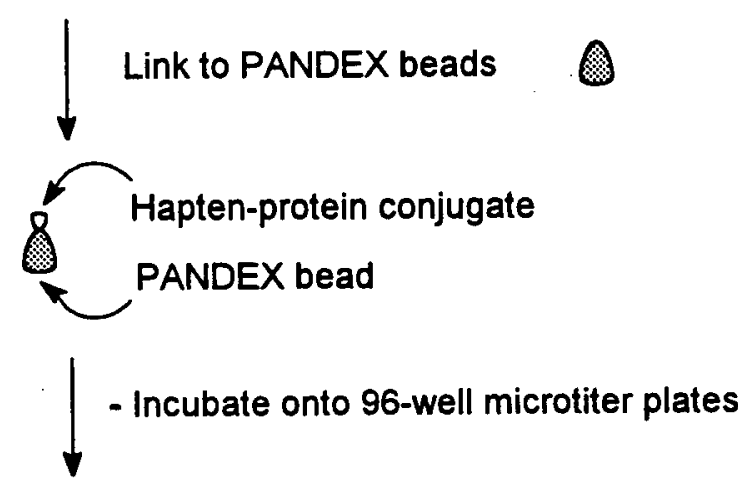

Step 1

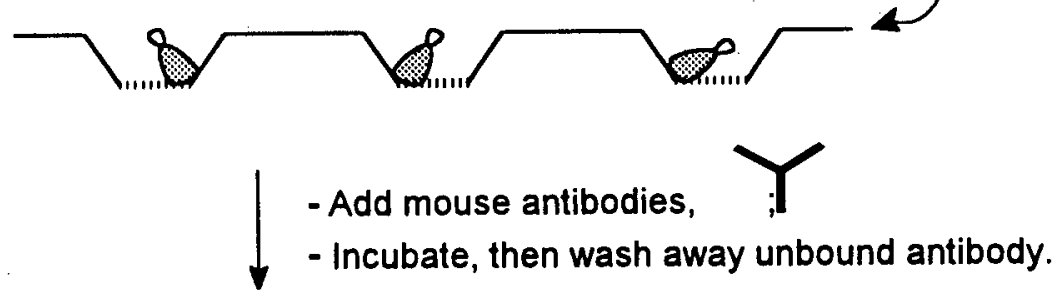

Step $2 \longrightarrow$

- Add anti-mouse antibody labelled with FITC, ; F*

- Incubate, then wash away unbound antibody;

- Read fluoresence of FITC.

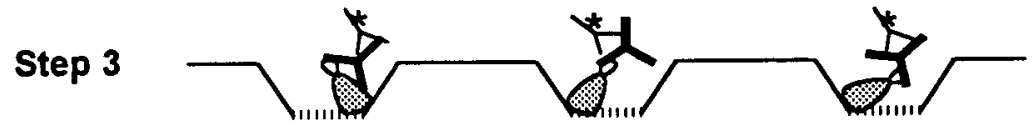

Figure 9. PCFIA assay for screening mouse antibodies (figure provided by Gay Yuyitung).

\subsection{ASCITES PRODUCTION}

Ascites fluid is an intraperitoneal fluid that forms as a result of an intraperitoneal tumor produced by injection of a hybridoma cell line into the mouse. Hybridoma cells are injected intraperitoneally into a mouse. The cells grow to a high density 
and thus produce a high titer solution of the monoclonal antibody, typically between 0.5 and $10.0 \mathrm{mg} / \mathrm{mL}^{65}$

\subsection{ENZYMATIC KINETICS AND RELEVANCE TO SYNTHESIS}

Enzymatic reactions can be broken down into two components: substrate binding and catalysis. Most enzymes are highly selective in binding their substrates, and particularly selective in binding the transition state of the reaction they catalyze, which explains the catalytic specificity of enzymes. In 1902, Brown ${ }^{78}$ proposed that the substrate dependence of enzyme-catalyzed reaction rates could best be described qualitatively by Equation 3 below. In the absence of inhibition, the free enzyme (E) first complexes with the substrate (S) to form one distinct enzyme-substrate complex (ES), with a rate constant $k_{1}$. Once formed, the ES complex, according to Equation 3, has two possible fates. It can dissociate to $E$ and $S$, with a rate constant $k_{1}$, or it can be converted to the free enzyme and product $(P)$, with a rate constant $k_{2}$.

$$
\mathrm{E}+\mathrm{S} \underset{k_{-1}}{\stackrel{k_{1}}{\rightleftharpoons}} \mathrm{ES} \stackrel{k_{2}}{\longrightarrow} \mathrm{E}+\mathrm{P}
$$

This qualitative picture of enzyme reactions was subsequently put into a mathematical framework first by $\mathrm{Henri}^{79}$ in 1903 and later by Michaelis and Menten ${ }^{80}$ in 1913 . The basic rate equation derived below is commonly referred to as the Michaelis-Menten equation, although, some writers have recently taken 
to referring to the equation as the Henri-Michaelis-Menten equation. For the situation where the initial step in formation of the ES complex is not rate-limiting, a general expression that relates the rate of reaction $(v)$ to the concentrations of substrate and enzyme and the rates of the individual steps can be derived, starting with the general rate expression,

$$
v=\frac{\mathrm{d}[\mathrm{P}]}{\mathrm{d} t}=k_{2}[\mathrm{ES}]
$$

From Equation 3, the net change in concentration of the ES complex with time (d[ES]/dt) can be expressed as follows:

$$
\frac{\mathrm{d}[\mathrm{ES}]}{\mathrm{d} t}=k_{1}[\mathrm{E}][\mathrm{S}]-k_{-1}[\mathrm{ES}]-k_{2}[\mathrm{ES}]
$$

Equation 3 can represent steady-state conditions. In a steady state, the concentrations of intermediates remain constant while the concentrations of starting materials and products are changing. Hence, the rate of formation of ES must equal its rate of consumption over most of the course of the reaction; that is,

$$
\frac{\mathrm{d}[\mathrm{ES}]}{\mathrm{d} t}=0
$$

According to Equation 5, therefore,

$$
k_{1}[E][S]=\left(k_{-1}+k_{2}\right)[E S]
$$

By rearranging Equation 7, 


$$
[E S]=\frac{[E][S]}{\left(k_{-1}+k_{2}\right) / k_{1}}
$$

Equation 8 can be simplified by combining the rate constants into a new constant, $K_{m}$ referred to as the Michaelis constant:

$$
\mathrm{K}_{\mathrm{m}}=\frac{\left(k_{-1}+k_{2}\right)}{k_{1}}
$$

and substituting it into Equation 8, which then becomes

$$
[E S]=\frac{[E][S]}{K_{m}}
$$

Therefore, $K_{m}$ is a ratio of the rate constants for the breakdown of the ES complex, $k_{1}+k_{2}$, over the rate constant for the formation of $E S, k_{1}$. The magnitude of $K_{m}$ is routinely used as a measure of the inverse relative affinity an enzyme has for a particular substrate. The significance of $K_{m}$ will later be discussed in more detail.

Experimentally, substrate concentrations are typically very large compared to the enzyme concentration (e.g. $\mathrm{mM}$ in substrate and $\mathrm{nM}$ in enzyme). Under these conditions, the concentration of uncombined substrate, [S], is essentially equal to the total substrate concentration. The concentration of uncombined enzyme, $[E]$, is equal to the total enzyme concentration, $\left[E_{T}\right]$, minus the concentration of the ES complex. 


$$
[E]=\left[E_{T}\right]-[E S]
$$

By substituting this expression for $[E]$ in Equation 10, we get

$$
[E S]=\frac{\left(\left[E_{T}\right]-[E S]\right)[S]}{K_{m}}
$$

Solving Equation 12 for [ES] now gives

$$
[E S]=\left[E_{T}\right] \frac{[S] / K_{m}}{1+[S] / K_{m}}
$$

or

$$
[E S]=\frac{\left[E_{T}\right][S]}{[S]+K_{m}}
$$

On substituting this expression for [ES] into Equation 4, the initial rate of the reaction can then be expressed in terms of the experimentally measurable quantities $\left[E_{T}\right]$ and $[S]$, as shown below in the Michaelis-Menten equation:

$$
v=\frac{k_{\text {cat }}\left[E_{T}\right][S]}{[S]+K_{m}}
$$

where a rate constant $k_{\text {cat }}$ is commonly written as $k_{2}$ and often referred to as the catalytic constant of the enzyme. $k_{\text {cat }}$ is also known as the turnover number of the enzyme because it is the number of reaction processes (turnovers) that each enzyme molecule catalyzes per unit time. 
The effect of substrate concentration on the rate of the enzyme-catalyzed reaction is shown in Figure 10. At low substrate concentrations or high $\mathrm{K}_{\mathrm{m}}$ 's, where $[S] \ll K_{m}$, the initial rate of the reaction is proportional to the substrate concentration, and Equation 15 simplifies to:

$$
v=\frac{k_{\text {cat }}\left[\mathrm{E}_{\mathrm{T}}\right][S]}{\mathrm{K}_{\mathrm{m}}}
$$

Conversely, at saturating substrate concentrations, where [S] $\gg K_{m}$ (so that $[S] /(S]+K m)$ approaches 1$)$, the initial rate of the reaction becomes independent of the substrate concentration, and approaches a constant maximum rate, $V_{\max }$ :

$$
v=k_{\text {cat }}\left[\mathrm{E}_{\mathrm{T}}\right]=\mathrm{V}_{\max }
$$

Therefore, the parameter $K_{m}$ represents the concentration of substrate at which the initial rate of the reaction is equal to one-half of the maximal rate, i.e. $v=V_{\max } / 2$, as shown in Figure 10. In addition, from Equation 3, when $k_{1}>k_{2}$, Equation 9 simplifies to give $K_{m} \approx k_{1} / k_{1}$, and the value of $K_{m}$ gives an inverse measure of the stability of the enzyme-substrate complex (ES). An enzyme with a low $K_{m}$ has a high affinity for a substrate.

The Michaelis constant, $K_{m}$, and the maximal rate, $V_{\max }$ can be readily determined from rates of reaction measured at different substrate concentrations for enzyme systems that operate under steady state conditions as in Equation 3. 


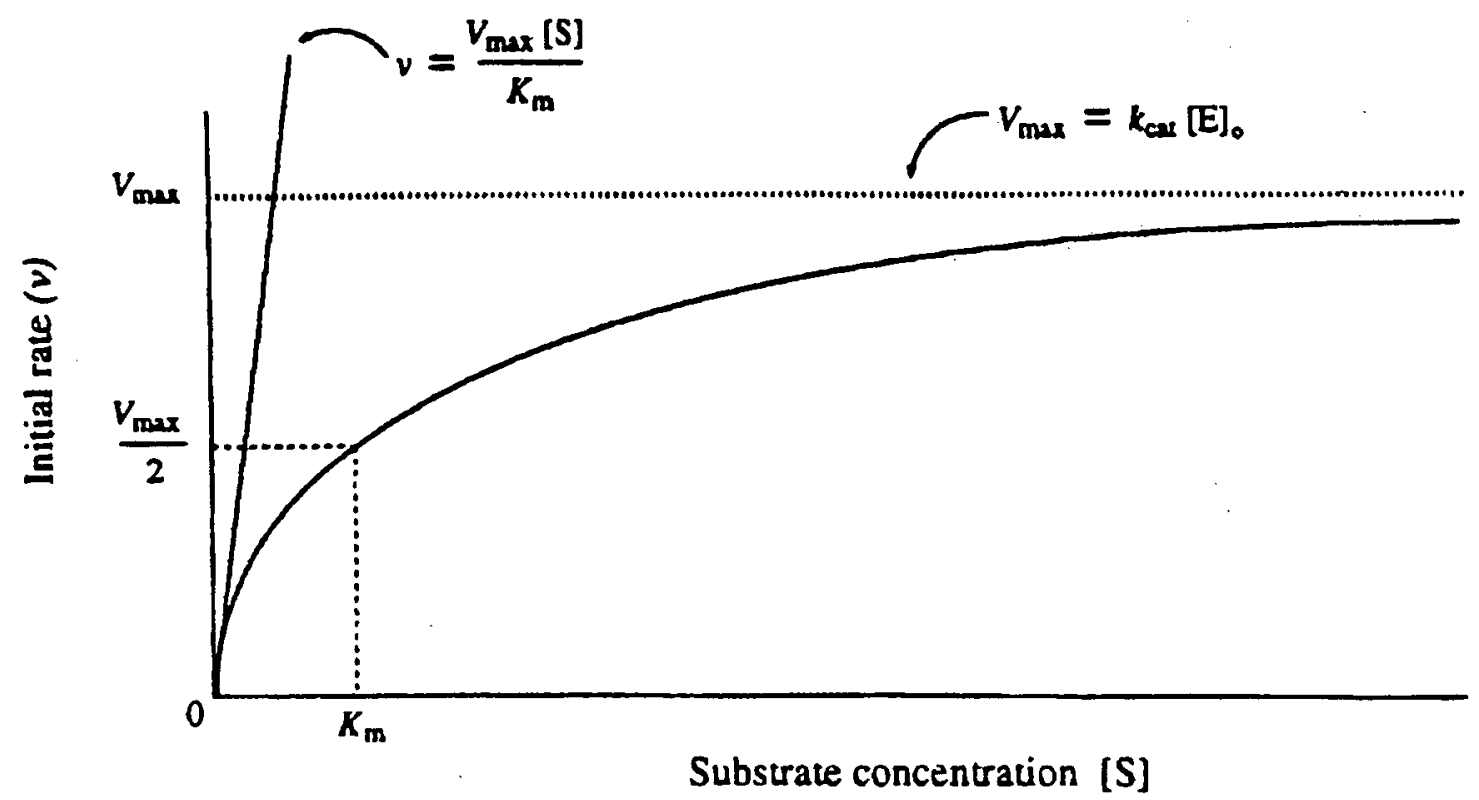

Figure 10. The effect of substrate concentration on the rate of the enzyme-catalyzed reaction.

Traditionally, the values of $K_{m}$ and $V_{\max }$ were obtained by transforming the Michaelis-Menten equation, Equation 15, into a straight line plot by substituting in the expression $\mathrm{k}_{\text {cat }}\left[\mathrm{E}_{T}\right]=\mathrm{V}_{\text {max }}$, then taking the reciprocal of both sides to give:

$$
\frac{1}{v}=\frac{1}{V_{\max }}+\frac{K_{m}}{V_{\max }} \cdot \frac{1}{[S]}
$$

A plot of $1 / v$ versus $1 /[S]$, called a Lineweaver-Burk plot, yields a straight line with an intercept of $1 N_{\max }$ and a slope of $\mathrm{K}_{\mathrm{m}} N_{\max }$ as shown in Figure 11. More commonly today, these values are determined by fitting the rate data to a weighted nonlinear regression of the Michaelis-Menten equation using a computer program, such as Grafit ${ }^{\mathrm{TM}}$. 


$$
\frac{1}{v}=\frac{1}{V_{\max }}+\frac{K_{\mathrm{m}}}{V_{\max }}\left(\frac{1}{[S]}\right)
$$

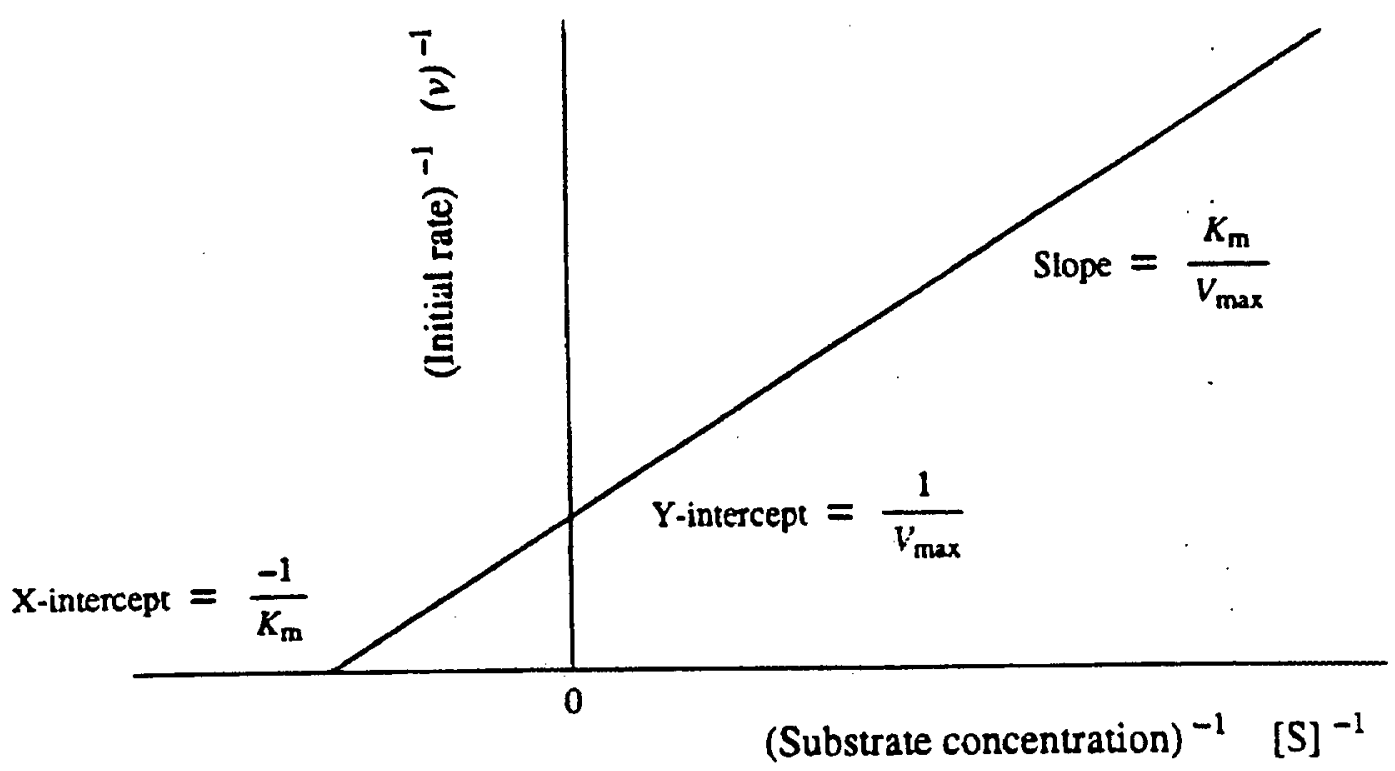

Figure 11. A double-reciprocal plot, called a Lineweaver-Burk plot, of enzyme kinetics: $1 / \mathrm{v}$ is plotted as a function of $1 /[\mathrm{S}]$.

The quantity $k_{\text {cat }} / K_{m}$, often referred to as the enzyme's catalytic efficiency, is also referred to as the enzyme's specificity constant. When the substrate concentration is much greater than $K_{m}$, the rate of catalysis is equal to $k_{2}$ (or $k_{\text {cat }}$ ) which equals the turnover number, as described above in Equation 16. Thus, when [S] $\ll K_{m}$, the enzymatic rate depends on the value of $k_{2} / K_{m}$, or $K_{c a t} / K_{m}$, and on [S]. It should be noted that this ratio depends on $k_{1}, k_{1}$, and $k_{2}$, as can be shown by substituting for $\mathrm{K}_{\mathbf{m}}$ : 


$$
\frac{k_{\text {cat }}}{\mathrm{K}_{\mathrm{m}}}=\frac{k_{2} k_{1}}{\left(k_{-1}+k_{2}\right)}<k_{1}
$$

Therefore, the ultimate limit on the value of $k_{\text {cat }} / K_{m}$ is set by $k_{1}$, the rate of formation of the ES complex. This rate of formation of the ES complex cannot be faster than the diffusion-controlled encounter of an enzyme and its substrate. Hence, the upper limit on $k_{\text {cat }} / K_{m}$ is between $10^{8}$ and $10^{9} \mathrm{M}^{-1} \mathrm{~s}^{-1}$, the diffusion-controlled limit for small molecules with macromolecules such as enzymes. ${ }^{81}$

While knowledge of the kinetic constants for the enzymatic reaction used in a synthetic organic chemistry application is not required, obtaining and understanding the kinetic constants enables maximum efficiency of the use of the enzyme. For instance, if the substrate concentration is too low, a certain fraction of enzyme active sites are vacant at equilibrium, whereas, in some cases, if substrate concentrations are too high, the enzyme may be deactivated (as the character of the solvent becomes markedly different from that of water). The Michaelis constant $K_{m}$ is therefore valuable in determining the minimum concentration of substrate which must be maintained in solution to achieve efficient use of the enzyme. 
Without kinetic analyses of the enzyme system employed, often the catalytic activity of the enzyme observed under synthetic conditions is lower than the value obtainable under ideal (assay or $\mathrm{V}_{\max }$ ) conditions. This discrepancy in rates may have several origins, a few being nonspecific deactivation of the enzyme by high or inappropriate concentrations of substrates, products, buffers, ions $(\mathrm{pH})$, or co-solvents.

\subsection{ENZYMES AND CATALYTIC ANTIBODIES IN ORGANIC SOLVENTS}

Water is a poor solvent for the majority of reactions in organic chemistry because most organic compounds are insoluble in this medium. In addition, side-reactions such as hydrolysis, polymerization, racemization and decomposition are common in the presence of water. These limitations were avoided long ago by the use of organic solvents for nearly all organic chemical reactions. Conversely, biocatalysts have mainly been used in aqueous solutions since they generally display their highest catalytic power in water, and may be destroyed in organic solvents. However, this commonly held perception is far too general, and has likely impeded investigations into the utility of enzymes in nonaqueous media in the past. Review articles are becoming available dealing with the developing field of enzyme-catalyzed reactions in organic solvents. ${ }^{82}$ While the optimal amount of exogenous water to be added to the organic solvent 
is enzyme dependent, there is a general consensus that some water is required for the catalytic function of the enzyme. ${ }^{83}$

Although activities are generally lower in an organic environment, many other advantages can be accrued by using biocatalysts in organic solvents. Some advantages of biocatalysts over chemical catalysts include: enzymes are very efficient catalysts, typically employed in a mole fraction of $10^{-3}-10^{-4} \%$ whereas most chemical catalysts are generally used in a mole fraction of $0.1-1 \%$; enzymes are environmentally acceptable unlike heavy metals often employed in chemical catalysts; enzymes act under mild conditions; enzymes can catalyze a broad range of chemical transformations; and, enzymes often exhibit a high substrate tolerance by accepting a variety of unnatural substances and often they are not limited to a purely aqueous environment.

Both enzymes and catalytic antibodies have been successfully used in organic solvents under a variety of conditions, including: (i) the enzyme $e^{84,85}$ or antibody $^{86-91}$ dissolved in a monophasic aqueous-organic solution consisting largely of water and a water-miscible organic co-solvent (such as dimethyl sulfoxide, dimethyl formamide, acetonitrile) or surfactant (such as Triton X-100) to facilitate substrate solubility; (ii) the enzyme ${ }^{92,93}$ or antibody ${ }^{94}$ dissolved in a biphasic aqueous-organic solution consisting of two macroscopic phases; (iii) the enzyme $e^{95,96}$ or antibody ${ }^{97}$ suspended in a monophasic organic solution (with $<2 \%$ 
water content); (iv) the enzyme $e^{98-103}$ or antibody ${ }^{104-106}$ immobilized onto solid supports or in reverse micelles; and, $(v)$ at least one example of a lipid-coated antibody in water-miscible organic solvents. ${ }^{107}$

Such successful demonstrations of biocatalsyts in organic solvents continue to increase, providing organic chemists with alternate and often unique solutions to challenging synthetic transformations.

\subsection{DESIGN OF TRANSITION STATE ANALOGUES}

The approaches used to generate catalytic antibodies have been based largely on principles of enzymatic catalysis such as transition state stabilization, ${ }^{108}$ general acid-base catalysis, nucleophilic and electrophilic catalysis, as well as strain and proximity effects. ${ }^{61,109}$ Clearly, the success of catalytic antibodies has and will continue to depend on the clever design of haptens or transition state analogues. This is the fundamental requirement when one sets out to study catalytic antibodies. A number of functional groups, some examples being sulphones, phosphonates and phosphonamidates, quaternary ammonium ions, 1,3-diketones and secondary alcohols, have proved successful in mimicking the reactive centers in a transition state. Phosphonates have been most widely used, undoubtedly due to their proven utility as transition state inhibitors ${ }^{108}$ for a variety of enzymes including a number of proteases and esterases. The dipole 
of the $P=O$ bond of phosphonate analogues reflects the developing negative charge on the carbonyl oxygen in the transition state of transesterification reactions (figure 12). In addition, antibodies complementary to the tetrahedral phosphonate haptens should have considerably lower affinity for the trigonal products, thereby reducing product inhibition. The efficiency of enzymes is the result of employing several of the above mentioned catalytic mechanisms simultaneously, to achieve large rate enhancements. In order to realize similar rate accelerations with antibodies, it may require the simultaneous application of more than one of these strategies for introducing catalytic activity into antibodies as well. There have been a few reports of hydrolytic antibodies that appear to utilize active site acid-base chemistry in addition to the expected transition state stabilization. ${ }^{86,87,110,111}$

The great diversity offered by the immune system, coupled with well designed transition state analogues, has allowed chemists to exploit the immune system to study the antibody catalysis of a number of diverse reactions.

\subsection{REACTION TYPES CATALYZED BY ANTIBODIES}

The ability of enzymes to use binding energies to orient a substrate into a reactive conformation or to bring two molecules together in the proper orientation 
<smiles>[R20]C([R])=O</smiles><smiles>[R9]OC([R])([O])C([R])([O-])[O-]</smiles>

Putative Transition State<smiles>[R]OC([R])=O</smiles>

$\mathrm{R}_{2} \mathrm{OH}$<smiles>[R6]OP([R20])([R])=O</smiles>

\section{Transition State Analogue}

Figure 12. The putative transition state and the corresponding phosphonate transition state analogue for the displacement reaction of an ester.

for a reaction to occur represents an effective way to compensate for the entropy losses that may accompany such a chemical transformation. Mechanistic investigations of antibody-catalyzed reactions involving structural modifications to substrates and $X$-ray crystal structure studies have shown that antibodies utilize binding energies analogously to enzymes to effect chemical catalysis.

While all antibodies share a common structural motif, the shape of the binding site can vary extensively, from deep pockets, clefts and grooves to flatter surfaces, complimenting the antigen against which it was raised. This versatility, essential for the ability of these antibodies to maintain surveillance against foreign molecules in vivo, also accounts for the ability of these antibodies to distinguish subtle changes in substrate molecules, and is responsible for their 
ability to catalyze different types of reactions. The field of catalytic antibodies has been extensively reviewed elsewhere, and since the first successful reports, has flourished to encompass an impressive array of antibody-catalyzed reactions. Table 3 below outlines many of these antibody-catalyzed reactions.

Table 3. Reactions Catalyzed by Antibodies.

\begin{tabular}{lc}
\hline \multicolumn{1}{c}{ Reaction Type } & Reference \\
\hline Ester, carbonate hydrolysis & 56,57 \\
Lactonization of $\gamma, \delta$-unsaturated acids & 58 \\
Enantioselective lactonization & 59 \\
Amide bond formation/hydrolysis & $112-114$ \\
Redox & 115,116 \\
$\beta$-Elimination & 117 \\
Porphyrin-mediated metal chelation & 118 \\
Protecting group removal & 119,120 \\
Transesterification & 86 \\
Enantiofacial protonation & 121 \\
Cis-trans isomerization of alkenes & 122 \\
Glycosidic bond hydrolysis & 123 \\
Stereoelectronically disfavoured cyclization & 88 \\
Diels-Alder reactions & $124-126$ \\
Regio- and enantioselective reduction & 127 \\
Michael addition & 128 \\
Aldol condensation & $129-131$ \\
\hline
\end{tabular}


Two successful antibody-catalyzed reactions listed above, and a third attempt, not in the above list, are of particular relevance to this project and will be discussed in detail. They are:

(1) Lactonization of $\gamma, \delta$-unsaturated acids;

(2) Enantioselective lactonization;

(3) Intramolecular acyl migration.

\subsubsection{Lactonization of $\gamma, \delta$-unsaturated acids}

In 1995 Kitazume and Takeda described the use of antibodies to catalyze the cyclization of unsaturated carboxylic acids to 5 - and 6-membered ring lactones. ${ }^{58}$ The authors employed hapten-conjugates 3 and 4 , cyclic ethers bearing a sulfoxide group, to elicit antibodies to catalyze the lactonization of the $\gamma, \delta$-unsaturated acid 5. Two diastereomers of the KLH-hapten conjugate 3 (the cis and trans isomers; referring to the relative stereochemistry of the trifluoromethyl and sulfoxide containing side chains) were used to immunize $B A L B / c$ mice.

The antibodies induced from hapten 3 , derived from the trans- $\gamma$-lactone, acted to promote exclusively exocyclic ring closure of the $\gamma, \delta$-unsaturated acid 5 to the trans- $\gamma$-lactone 6 with a $\mathrm{K}_{\text {cat }}$ of $0.86 \mathrm{~min}^{-1}$, a $\mathrm{K}_{\mathrm{m}}$ of $190 \mu \mathrm{M}$, and a selectivity of $>97 \%$ de $(58 \%$ yield). The antibodies raised against the cis isomer of hapten 3 
<smiles></smiles><smiles>CC1CC(C(F)(F)F)C(=O)O1</smiles><smiles>C=CCC(C(=O)O)C(C)(F)F</smiles><smiles>O=C1OCCCC1C(F)(F)F</smiles>

catalyzed the formation of the cis- $\gamma$-lactone isomer of 6 , from reaction with the same substrate 5 , with a $\mathrm{K}_{\text {cat }}$ of $0.64 \mathrm{~min}^{-1}$, a $\mathrm{K}_{\mathrm{m}}$ of $170 \mu \mathrm{M}$, and a selectivity of $>96 \%$ de $(61 \%$ yield). In addition, antibodies were elicited to the trans $\mathrm{KLH}$-hapten conjugate 4 , and were found to promote cyclization of 5 to form the $\delta$-lactone 7 with a $k_{\text {cat }}$ of $0.81 \mathrm{~min}^{-1}$, a $K_{m}$ of $180 \mu \mathrm{M}$, and a selectivity of $>94 \%$ ee $(\delta$-lactone $7: \gamma$-lactone $6=93: 7)$, and the antibody induced from the cis isomer of 4 acted to form the $\delta$-lactone 7 ( $\delta$-lactone : $\gamma$-lactone $=94: 6)$ with $a$ comparable enantioselectivity.

\subsubsection{Enantioselective lactonization}

In 1987, Napper, et al. reported the enantioselective lactonization of the corresponding racemic 5-hydroxy ester 8 to lactone 9 by a catalytic monoclonal antibody. ${ }^{59}$ Antibodies were raised against the cyclic phosphonate hapten 10. 
This hapten is a transition state mimic for the six-membered ring cyclization. Lactonization of 8 was catalyzed until $50 \%$ of the initially added substrate was consumed. Upon addition of a second aliquot of substrate, the antibody again converted $50 \%$ of the freshly added substrate. Although the hapten and the substrate were racemic, the monoclonal antibody, being chiral, showed selectivity for the (R)-(-)-enantiomer of 8 . The monoclonal antibody (MAB) displayed enzyme-like Michaelis-Menten kinetics with a $k_{\text {cat }}$ of $0.5 \mathrm{~min}^{-1}$, a $\mathrm{K}_{\mathrm{m}}$ of $76 \mu \mathrm{M}$ and a $k_{\text {eat }} / k_{\text {uncat }}$ of 167 , which afforded the 6-membered ring lactone 9 in an enantiomeric excess of 94 percent.<smiles>CCCCCNC[C@H]1CCCC(=O)O1</smiles><smiles>O=C(CCC(=O)ON1C(=O)CCC1=O)NCC1CCCP(=O)(Oc2ccccc2)O1</smiles>

\subsubsection{Intramolecular acyl migration}

Antibodies were raised against the cyclic phosphonate 13 in an attempt to obtain antibodies capable of catalyzing an intramolecular acyl migration reaction. ${ }^{132}$ 
Antibodies specific for phosphonate 13 were expected to bind substrate 11 with the hydroxyl group in close proximity to the carbonate, resulting in a rapid acyl migration to give 12. Monoclonal antibodies raised against hapten 13 did not catalyze the desired acyl migration of 11 to 12 , but simply hydrolyzed the substrate, giving 14, $\mathrm{CO}_{2}$, and $\mathrm{ROH}$. The author speculated that the hapten-protein conjugate 15 may have hydrolyzed during the course of the<smiles>[R]OC(=O)Oc1ccc([N+](=O)[O-])cc1CCO</smiles><smiles></smiles><smiles>[R]OC(=O)OCCc1cc([N+](=O)[O-])ccc1[O-]</smiles>
11<smiles>O=C(O)CCCOP1(=O)Cc2ccc([N+](=O)[O-])cc2CCO1</smiles>

13

immunization, yielding 16, a hapten now resembling the phosphonic acid transition state analogues employed to obtain antibodies which catalyze hydrolytic reactions. 
11

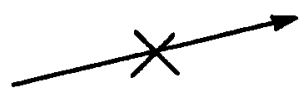

12
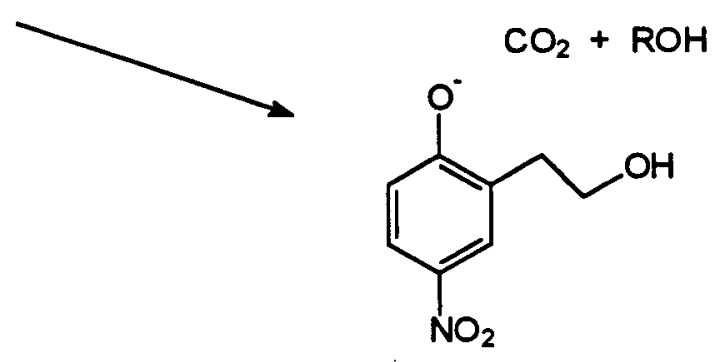

14

If hydrolysis of the hapten did occur during the course of immunization, endocyclic cleavage would have had to occur (as illustrated in path a above) for the hapten to remain intact with the carrier protein, and lead to the production of
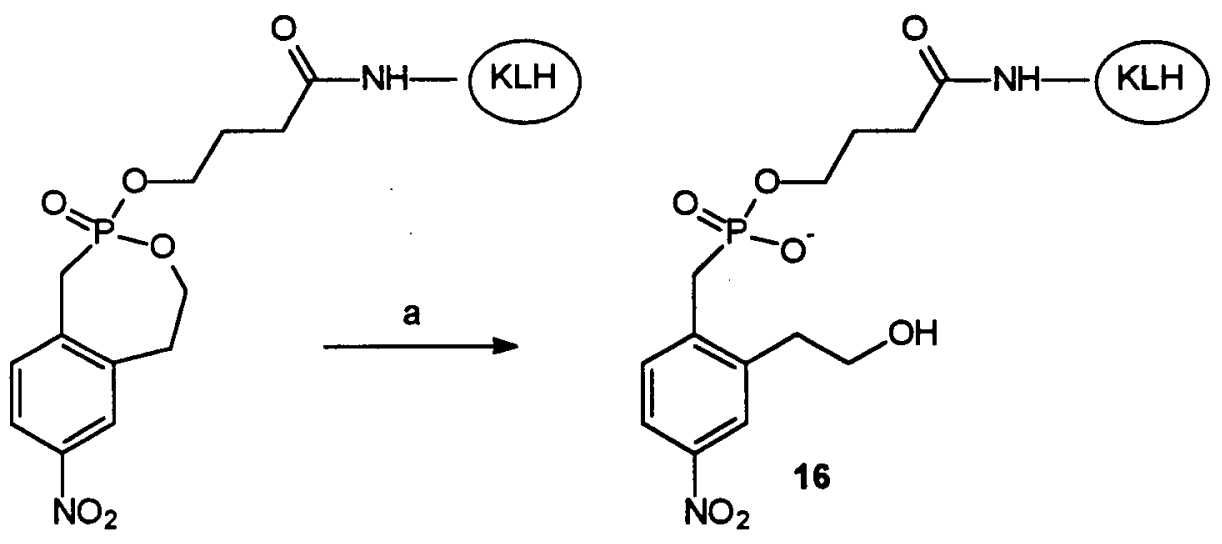

15

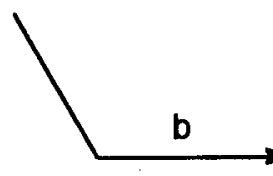<smiles>Cc1cc([N+](=O)[O-])ccc1CP(=O)(O)O</smiles> 
hydrolytic antibodies. Exocyclic cleavage would have resulted in the hapten molecule being cleaved from the carrier protein, and such small molecules alone usually do not induce an immune response.

The antibody-catalyzed lactonization by Napper, et al., mentioned above, provided the impetus for our investigation of catalytic antibodies in the synthesis of macrocyclic lactones. As outlined in Chapter 1, investigators have searched for a general high-yielding method to prepare these macrocyclic compounds. An antibody capable of catalyzing such a macrolactonization step, with high enantioselectivity, would be a welcome and interesting achievement in the field of macrolide chemistry. 


\section{CHAPTER III. RESULTS AND DISCUSSION}

\subsection{SYNTHESIS OF MACROCYCLIC PHOSPHONATE 20}

Based on the success by Napper et al., ${ }^{59}$ our initial goal towards the generation of a catalytic antibody for macrocyclic lactonization was the synthesis of the macrocyclic phosphonate hapten 20. Phosphonate $\mathbf{2 0}$ is a stable analogue of the putative transition state for the lactonization of hydroxy ester 18 to macrolactone 19.

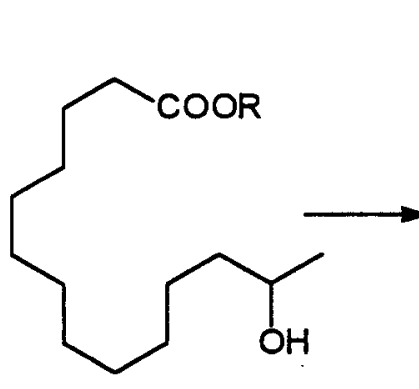

18

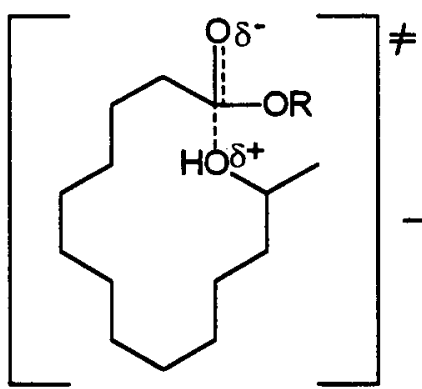<smiles>[R]OP1(=O)CCCCCCCCCCCC(C)O1</smiles>

20

The synthesis of compound $\mathbf{2 0}$ was intended as an introductory study for the investigation of the stability and spectral characteristics of macrocyclic phosphonates. Earlier attempts in our laboratory toward the synthesis of the 
macrocyclic methyl phosphonate 22 from $\mathbf{2 1}$ via a direct displacement reaction (Scheme 2) carried out under high dilution conditions resulted in low and irreproducible yields of the desired product. ${ }^{133}$ To our knowledge, this was the first synthesis of such a macrocyclic phosphonate. However, this is not a practical method to prepare large quantities of these compounds, therefore we turned our attention to an alternate approach.<smiles>CCP(=O)(CCCCCCCCCCCC(C)O)OC</smiles>

21

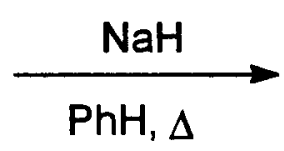

Scheme 2. Synthesis of macrocylic phosphonate 22.

In this alternate approach, the final steps in the synthesis of phosphonate $\mathbf{2 0}$ were envisioned to proceed via an intramolecular Wittig reaction using the acyclic precursor $\mathbf{2 3}$, followed by hydrogenation of the vinyl phosphonate. 
<smiles>[R]OP(=O)([PH2+])OC(C)CCCCCCCCCC=O</smiles>

23
1) $\Delta$

2) $\mathrm{H}_{2}, \mathrm{Pd}-\mathrm{C}$<smiles>[R]OP(=O)(CCCCCCCCCCCCC)OC</smiles>

20

Carbon-carbon bond formation can be carried out under near-neutral conditions using a stabilized Wittig reagent. This methodology was successfully used by $W_{i l s o n}{ }^{134}$ to yield the 12 -membered ring $\alpha, \beta$-unsaturated ketone 25 from 24 .<smiles>O=C(C=Pc1ccccc1)CCCCCCCCCCO</smiles>

24

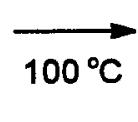

$0-30 \%)$

Other reports ${ }^{135,136}$ demonstrate intramolecular cyclization reactions of aldehyde phosphonates for the construction of macrocyclic $\alpha, \beta$-unsaturated lactones of 13 and more carbon atoms with varying degrees of substitution. The 14-membered $\alpha, \beta$-unsaturated lactone $\mathbf{2 7}$ was obtained by the intramolecular condensation of the phosphonate 26 in a $40-50 \%$ yield. Such examples from the literature suggested that our strategy for the synthesis of compound 20 was reasonable. 
<smiles>CCO[PH](=O)CC(=O)OC(C)(C)CCCCCCCCCC=O</smiles>

26

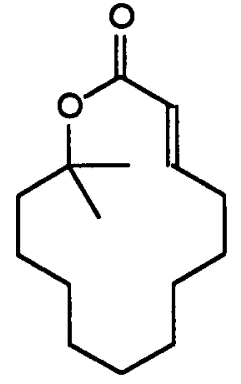

27

Before embarking on a synthesis of the cyclic phosphonate 20 , however, we decided to carry out a model study using phosphonate 30. Direct displacement of the iodide of compound $\mathbf{2 8}$ with triphenylphosphine in an attempt to produce intermediate 29 was not successful. A report by Moffatt and coworkers ${ }^{137}$

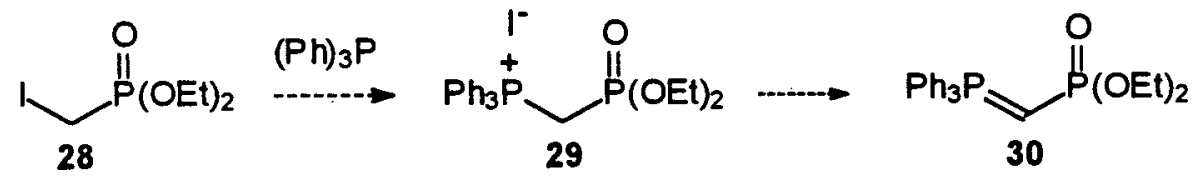
detailed the synthesis of a diphenylphosphonate analogue of the Wittig reagent 30, and in the same report, discussed the difficulties associated with the displacement route from 28 to 29 . Using the Moffatt method, the stabilized Wittig reagent 32 was synthesized in good yield. Commercially available chloromethylphosphonic dichloride was reacted with 2 equivalents of phenol to produce 31 in $90 \%$ yield. Subsequently, quaternization of triphenylphosphine with 31 at $175^{\circ} \mathrm{C}$ and deprotonation lead to 32 in $77 \%$ yield. 


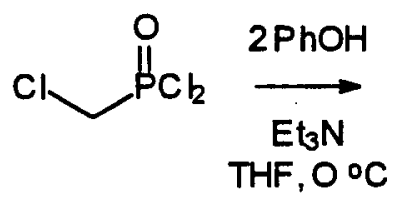

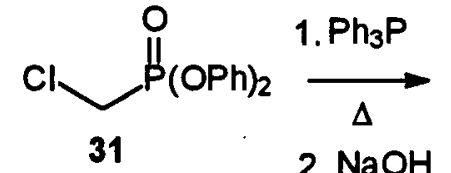<smiles>O=[Pb](C=P)OP</smiles>

2. $\mathrm{NaOH}$

32

$\mathrm{THF}-\mathrm{H}_{2} \mathrm{O}$

Aldehyde 33 was also prepared (Scheme 6) for subsequent conversion to compound 34, which would be followed by coupling with 32 to produce the stabilized Wittig $\mathbf{3 5}$ as in Scheme 3 below. However, with $\mathbf{3 3}$ and $\mathbf{3 2}$ in hand, a Wittig coupling of these two compounds was carried out, and the vinyl phosphonates $36 \mathrm{a}$ and $36 \mathrm{~b}$ were produced in a moderate yield of $52 \%$ with a<smiles></smiles>

33

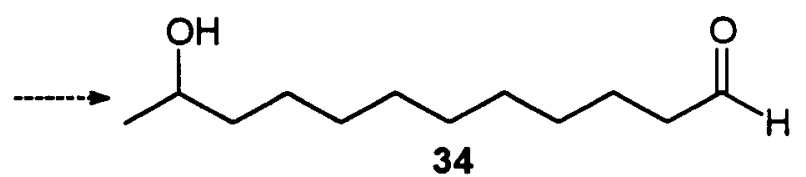<smiles>CCCCCCCCCC(C)OP(=O)(CCCCC)OP(=O)(c1ccccc1)c1ccccc1</smiles>

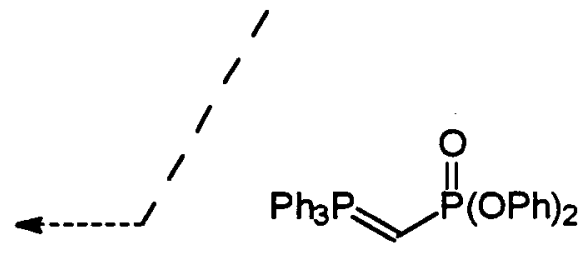

32

$$
35
$$

Scheme 3. Proposed synthetic sequence for compound 35.

4:1 ratio of trans to cis isomers, respectively, based on the integration of the 400 $M H z{ }^{1} H$ NMR of the crude mixture. 
<smiles></smiles>

33
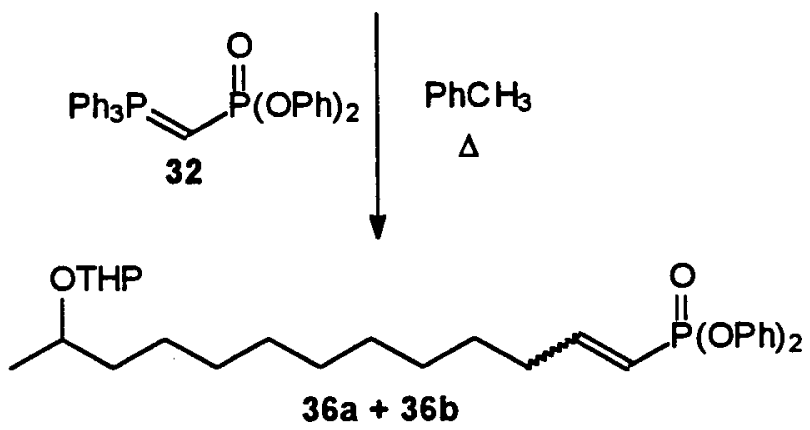

This synthesis of 36 inspired an alternate route towards the synthesis of macrocyclic phosphonate 20. With compound $\mathbf{3 6}$ in hand, all that remained was hydrogenation of the double bond followed by cleavage of the THP ether giving rise to 37 , and finally, a viable means of condensing the phosphonate moiety with the secondary hydroxyl of 37 to give 38 .

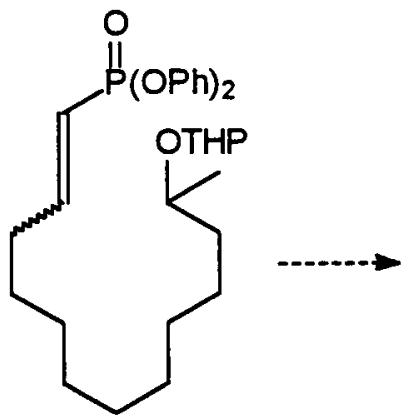

36<smiles>CC(O)CCCCCCCCCC[Pb](=O)O</smiles>

37

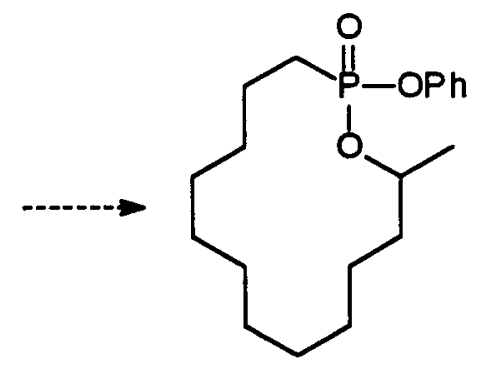

38 
Furthermore, we anticipated that the intended model compound 38 could be further modified at the phosphonate center with a linker molecule to enable

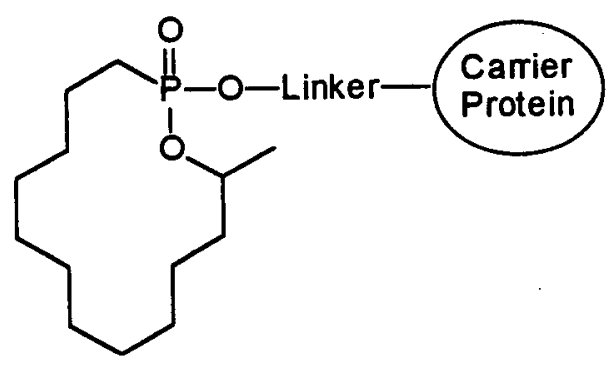

39

coupling to a carrier protein, and the resulting conjugate 39 might be used as an antigen for the production of a lactonizing catalytic antibody. One concern we had regarding the use of such a conjugate was the hydrolysis problem encounter by Jacobs with a similar 7-membered ring phosphonate mentioned in Chapter 1. ${ }^{132}$ However, we felt our 14-membered ring hapten would not undergo hydrolysis as readily as the 7-membered ring phosphonate employed by Jacobs, since 14-membered ring macrocycles in general possess less ring strain than their 7-membered ring counterparts.

To achieve cyclization of the hydroxy phosphonate ester 37 to give 38 , we turned our attention to the Mitsunobu reaction. Over the past two decades, the Mitsunobu reaction has found extensive use in organic synthesis, particularly for the inversion of alcohols via an esterification/hydrolysis procedure. ${ }^{42}$ The 
Mitsunobu reaction has also been proven a mild coupling reaction for the preparation of mixed phosphonates from phosphonic acid monoesters and primary or secondary alcohols (Equation 3). ${ }^{138}$ It has been used with carboxylic

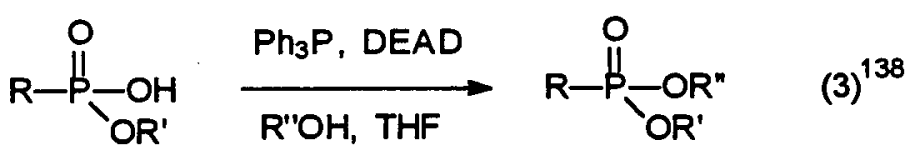

acids, phenols, phosphates, and phosphonic acids as the nucleophilic component. Thus we hoped the Mitsunobu reaction would prove successful in the transformation of the monophosphonic acid of $\mathbf{3 7}$ into the cyclic phosphonate 38. The precedent by Smith et al. in employing the Mitsunobu protocol in the key lactone forming step in the total synthesis of the latrunculins (14-membered ring lactone compounds; Equation 2$)^{48}$ suggested that our strategy was reasonable. A proposed mechanism for the Mitsunobu reaction of benzoic acid and a secondary alcohol ${ }^{139}$ is shown in Scheme 4 below.

While a variety of acids have been employed in the Mitsunobu reaction, benzoic acid has been the most widely used. Subsequently, it has been found that the strength of the acid used has an effect on the relative reactivity of the phosphonium adduct. Thus, for a successful Mitsunobu esterification to occur, the alcohol must react faster (path A) than the carboxylate (path B) with the phosphonium adduct as shown in Scheme 5. If the conjugate acid of the 


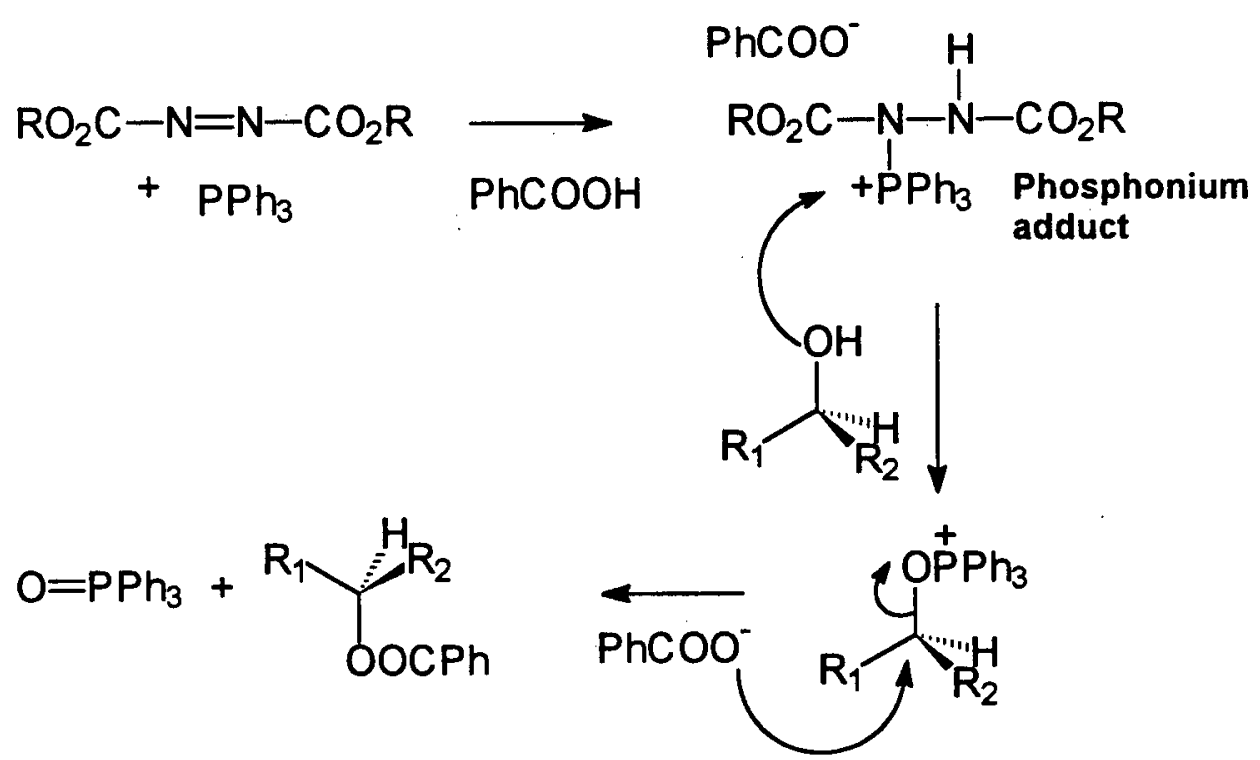

Scheme 4. A proposed mechanism for the Mitsunobu reaction (from ref 139).

carboxylate is a relatively strong acid, then the carboxylate will be stable and a poor nucleophile, and path A is favoured. If, however, the conjugate acid is a weak acid, its conjugate base may be sufficiently nucleophilic to compete with the alcohol, resulting in path B being favoured and thus lowering the yield of the desired product.
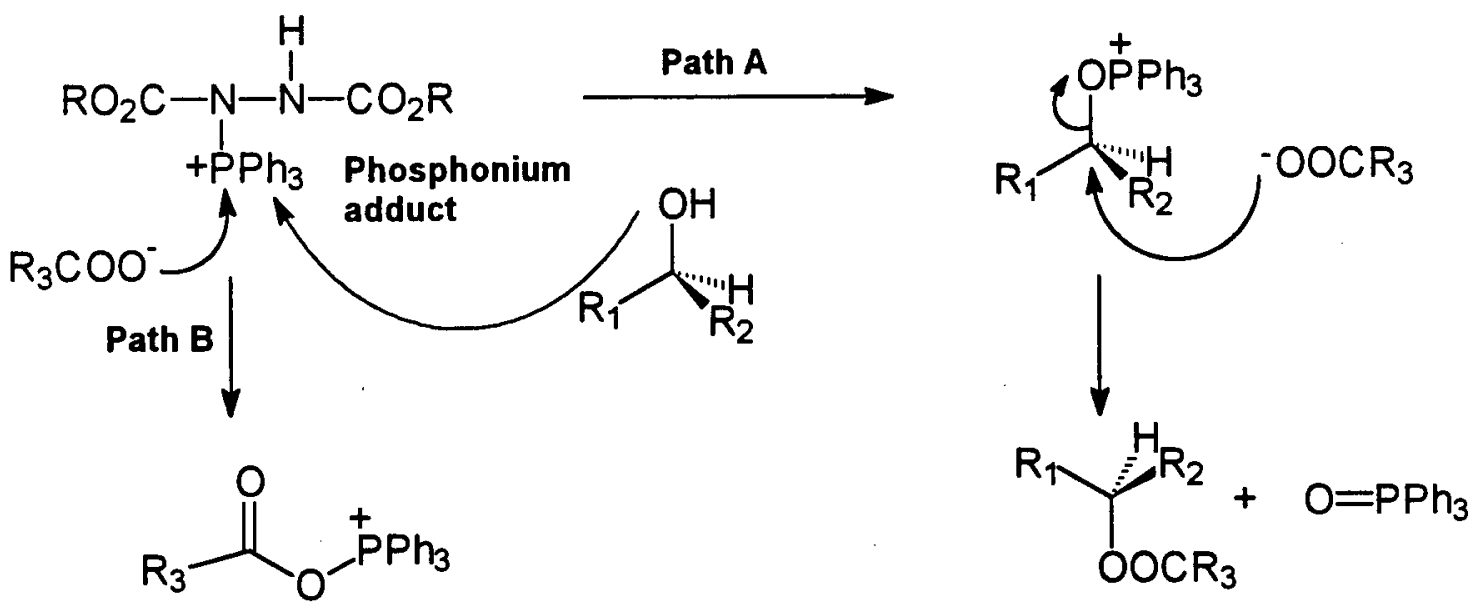

Scheme 5. Possible pathways in the Mitsunobu reaction (from ref 139). 
With the new synthetic strategy involving an intramolecular Mitsunobu reaction decided, the synthesis of phosphonate 38 (Scheme 6) was attempted, beginning with the Grignard reaction of commercially available undecylenic aldehyde and methylmagnesium bromide to give the hydroxy alkene $\mathbf{4 0}$ in $90 \%$ yield. The hydroxyl group of $\mathbf{4 0}$ was protected as the THP ether 41 in $84 \%$ yield. This addition of the THP group created a second chiral centre in 41 , and therefore, two diastereomers of $\mathbf{4 1}$ were isolated. The two diastereomers were obtained in a $1: 1$ ratio as seen in the ${ }^{1} H$ NMR spectrum of 41 , which reveals two methyl doublets of equal intensity and two methine multiplets, corresponding to the methine proton of the THP group, also of equal intensity. The two diastereomers of 41 were not separated, but treated together in the following sequences. Hydroboration of $\mathbf{4 1}$ followed by oxidation gave $\mathbf{4 2}$ in $96 \%$ yield. The alcohol 42 was subsequently oxidized under the Swern conditions to give the aldehyde $\mathbf{3 3}$ in $87 \%$ yield. Aldehyde $\mathbf{3 3}$ was then reacted with the stabilized Wittig reagent 32 in refluxing toluene to give the vinyl phosphonate $\mathbf{3 6}$ in a moderate yield of $52 \%$ with a $4: 1$ ratio of trans to cis isomers based on the integration of the 400 $\mathrm{MHz}{ }^{1} \mathrm{H}$ NMR of the crude mixture. The alkene 36 was then reduced using $\mathrm{H}_{2}$ and $10 \% \mathrm{Pd} / \mathrm{C}$ in EtOAc to give the saturated diphenyl phosphonate $\mathbf{4 3}$ in $99 \%$ yield. Phosphonate $\mathbf{4 3}$ was subsequently reacted with p-toluenesulphonic acid to liberate the secondary hydroxyl of compound 37 in $86 \%$ yield. Removal of the THP group from 43 eliminated one of the two chiral centres in the molecule, reflected in the ${ }^{1} \mathrm{H}$ NMR spectrum of 37 which contains only one methyl doublet. 
The hydrolysis of a single "OR" group of a symmetric phosphonate such as $\mathbf{3 7}$ is readily achieved under refluxing aqueous sodium or potassium hydroxide, while the hydrolysis of both "OR" groups can be achieved in refluxing hydrochloric acid. ${ }^{140}$ Therefore, phosphonic acid monoester 44 was produced in $76 \%$ yield by the base hydrolysis of 37 .

The key step in the synthesis of the macrocyclic hapten phosphonate $\mathbf{3 8}$ was the cyclization of $\mathbf{4 4}$ to give the 14-membered ring phosphonate 38 . The hydroxy phosphonic acid monoester 44 was reacted with DEAD and triphenylphosphine in benzene under high dilution conditions to produce the cyclic phosphonates $38 \mathrm{a}$ and $38 \mathrm{~b}$ in an $82 \%$ yield and a $5: 1$ ratio of diastereomers based on the ${ }^{1} \mathrm{H}$ NMR of the crude. For each pair of 14-membered ring phosphonate diastereomers referred to in this thesis, the distinction between isomer ' $a$ ' and isomer 'b' of a pair of diastereomers was made based on their relative $R_{r}-$ values from thin-layer chromatography (TLC) performed on Merck silica gel $F_{254}$ pre-coated aluminium sheets. With each pair of 14-membered ring phosphonate diastereomers studied, the ' $a$ ' isomer has a higher $R_{f}$ value (i.e. travelled faster on the TLC plate) than its corresponding ' $b$ ' diastereomer. 

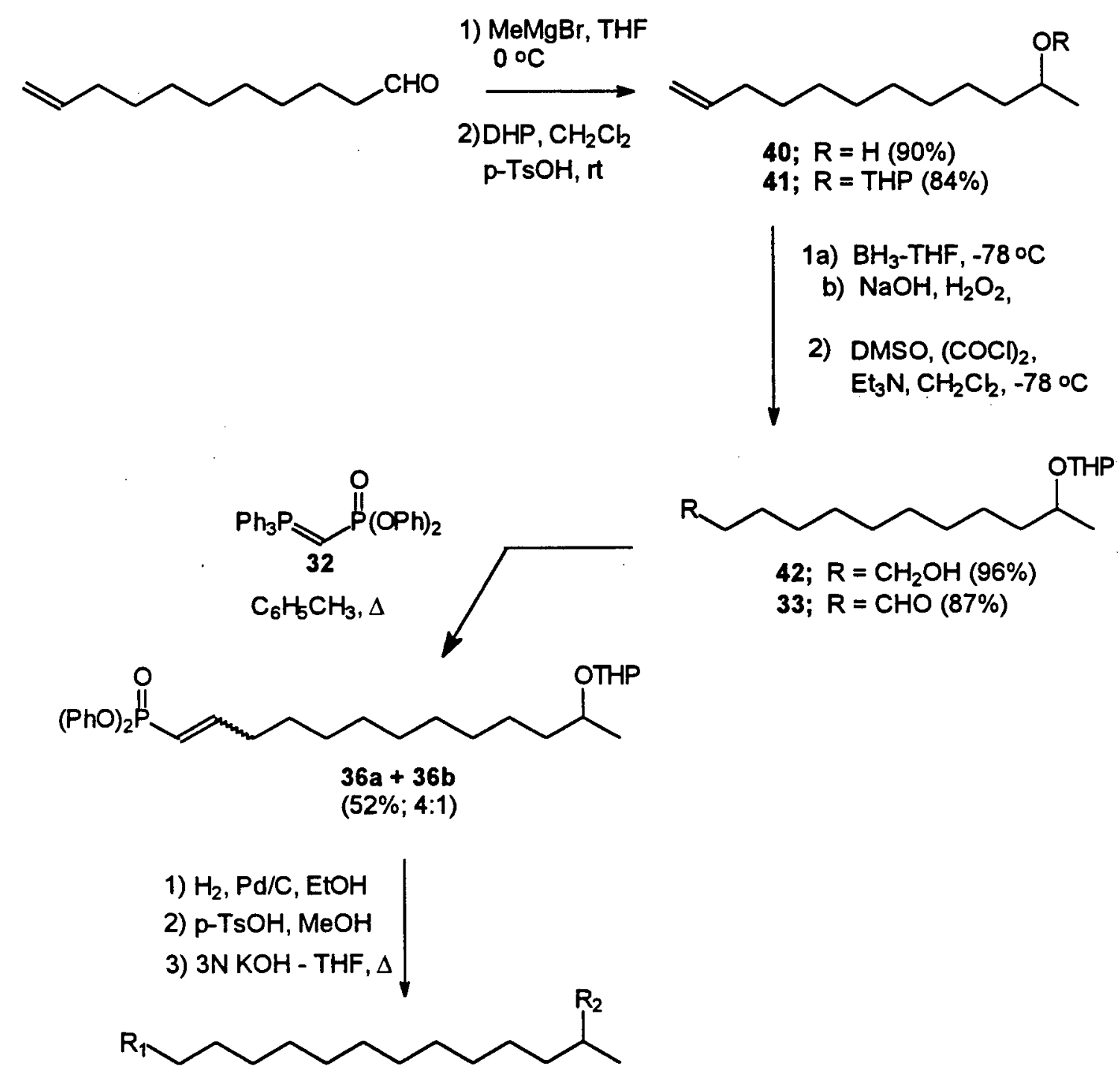

43; $\mathrm{R}_{1}=(\mathrm{PhO})_{2}(\mathrm{O}) \mathrm{P} \mathrm{R}_{2}=\mathrm{OTHP}(99 \%)$

37; $\mathrm{R}_{1}=(\mathrm{PhO})_{2}(\mathrm{O}) \mathrm{P} \mathrm{R}_{2}=\mathrm{OH}(86 \%)$

44; $R_{1}=(P h O)(H O)(O) P R_{2}=O H(76 \%)$
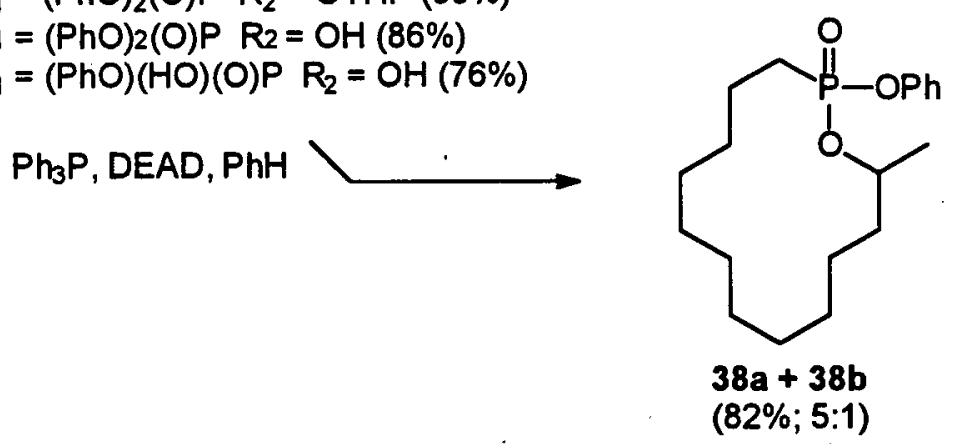

Scheme 6. Synthesis of macrocyclic phosphonates $38 \mathrm{a}$ and $38 \mathrm{~b}$. 
In addition to the two 14-membered ring diastereomers $38 \mathrm{a}$ and $38 \mathrm{~b}$, a cyclic dimer side product 39 was isolated as rod-shaped crystals on purification of $38 \mathrm{a}$

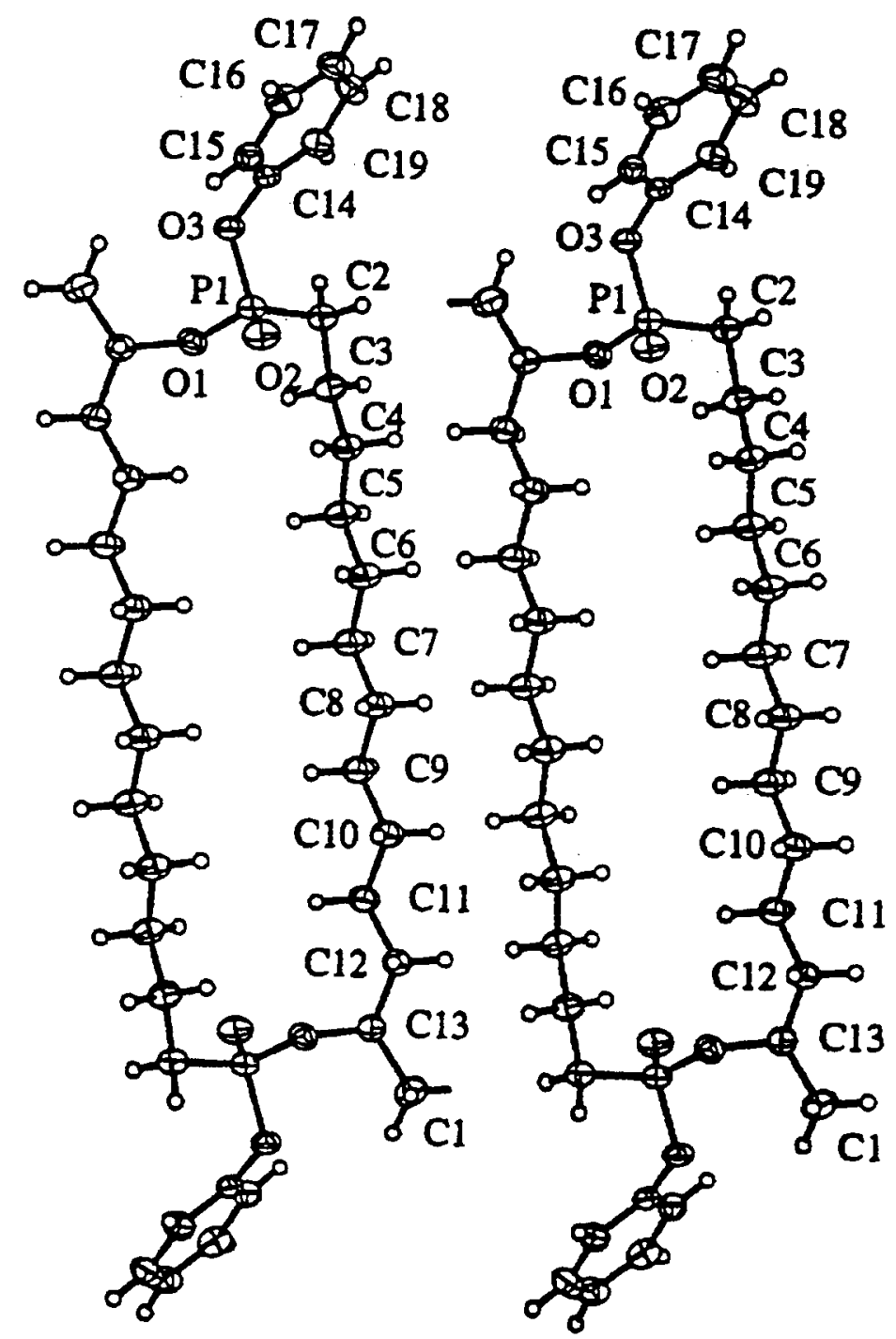

Figure 13. Stereoview of an ORTEP representation of dimeric cyclic phosphonate, 39 , showing $33 \%$ probability ellipsoids. Hydrogen atoms have been given arbitrary thermal parameters for clarity.

and $\mathbf{3 8 b}$. The structure of dimer $\mathbf{3 9}$ was determined by single-crystal $\mathrm{X}$-ray diffraction (Figure 13). Dimer 39, a centrosymmetric 28-membered ring 
compound with two parallel chains bridged at both ends by the phosphonate group, contains four stereogenic centres with $R^{\star} R^{\star}$ stereochemistry on one bridge, and the mirror image $S^{*} S^{*}$ stereochemistry at the opposite bridge. Dale has reported that cycloalkanes above twenty carbons have the collapsed shape of two parallel straight chains bridged at both ends ${ }^{141}$ as in dimer 39 . This collapsed shape is likely a result of a sufficiently large interior "hole" which allows for stabilizing hydrophobic interactions across the ring. Groth reported the X-ray structure of cyclohexaeicosane, which was also found to have a centre of symmetry. ${ }^{142}$ Dimer 39 has a centre of symmetry as a result of the $R^{\star} R^{*}$ and $S^{*} S^{\star}$ stereochemistry at the bridge ends.

In an attempt to explain why dimer 39 has the $R^{\star} R^{\star}$ relative stereochemistry, rather than $S^{*} R^{*}$, molecular models of the transition states leading to the $R^{*} R^{*}$ and $S^{*} R^{*}$ products were examined. The transition state leading to the $R^{*} R^{*}$ stereochemistry, illustrated by $\mathbf{A}$ below, proceeds with lower steric interactions than transition state $B$ which would result in the $S^{\star} R^{\star}$ stereochemistry. In B there is a steric interaction between the methyl group on the secondary alcohol and the phosphonate oxygen that is not found in model $\mathbf{A}$. If the $\mathbf{A}$ transition state leading to the $R^{*} R^{*}$ stereochemistry is extended to the monomers $38 a$ and $38 \mathrm{~b}$, it is reasonable to suggest that the major monomer $38 \mathrm{a}$ might also exhibit the $R^{*} R^{*}$ relative stereochemistry. 


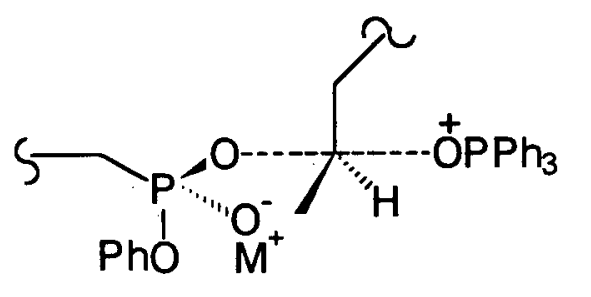

A

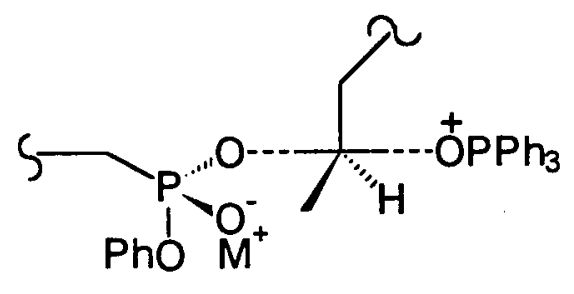

B

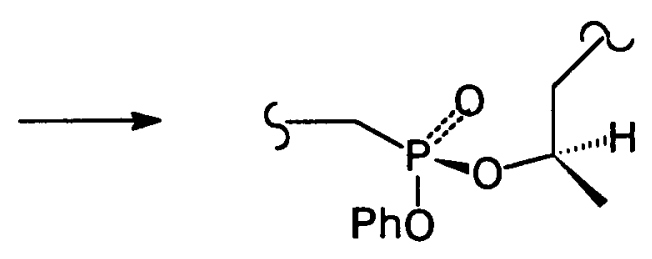

$\mathbf{R}^{\star} \mathbf{R}^{\star}$

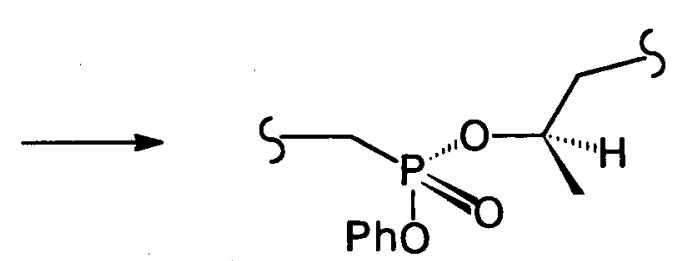

$\mathbf{S}^{*} \mathbf{R}^{*}$

$$
\mathrm{M}^{+}=\text {cation or solvent molecule }
$$

The bimolecular condensation of two molecules of $\mathbf{4 4}$ via the Mitsunobu methodology resulted in the $R^{*} R^{*}$ stereochemistry, and it follows that closure of the opposite end of the acyclic dimer would be governed by the same steric control, resulting in either the SS or RR stereochemistry for the second phosphonate bridge. Then the question to answer is why the only dimer molecule isolated on cyclization of 44 was the $R^{*} R^{*} S^{*} S^{*}$ dimer 39 ? Molecular models of the $R^{\star} R^{\star} S^{\star} S^{\star}$ and $R^{\star} R^{\star} R^{\star} R^{\star}$ diastereomers of dimer 39 were constructed. The $R^{*} R^{*} S^{*} S^{*}$ model was constructed according to the X-ray structure obtained for dimer 39 . The $R^{\star} R^{\star} R^{\star} R^{\star}$. model was constructed from the same conformation as 39 , where the second $R^{*} R^{*}$ bridge was created by 
inverting the stereochemistry at the $S^{\star} S^{\star}$ bridge. This $R^{\star} R^{\star} R^{\star} R^{\star}$ model retained one $R^{\star} R^{*}$ bridge common to 39 , where the aryloxy moiety attached to the phosphorus atom occupies an equatorial position, projecting away from the ring while the doubly-bonded oxygen atom projects into the ring (as in Figure 13). However, the $R^{\star} R^{*}$ stereochemistry at the opposite bridge of the $R^{\star} R^{*} R^{*} R^{*}$ model forces the methyl and aryloxy moieties to project in toward the ring, as illustrated below. MACROMODEL calculations ${ }^{143}$ on the $R^{*} R^{*} S^{*} S^{*}$ and $R^{\star} R^{\star} R^{\star} R^{\star}$ dimers using the MM2 force field ${ }^{144}$ gave a lower energy conformation for the $R^{*} R^{*} S^{*} S^{*}$ dimer, $92.40 \mathrm{~kJ} / \mathrm{mol}$, compared to $109.23 \mathrm{~kJ} / \mathrm{mol}$ for the $R^{\star} R^{\star} R^{\star} R^{\star}$ dimer. These calculations suggest that the $R^{\star} R^{\star} S^{\star} S^{\star}$ dimer is of lower energy, and may provide a rationale for why only this dimer was isolated on cyclization of compound 44 .

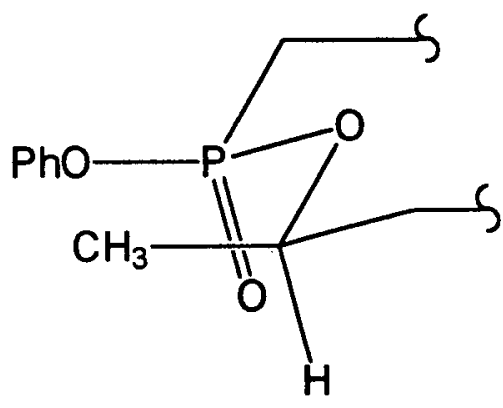

$\mathbf{R}^{*} \mathbf{R}^{*}$

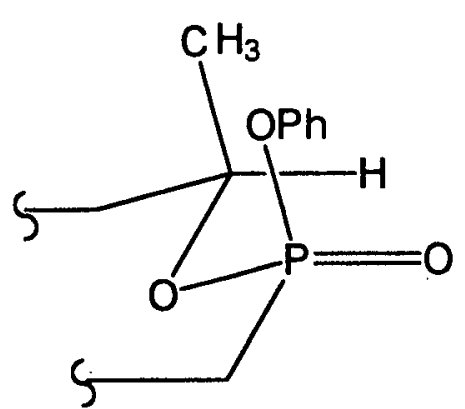

$\mathbf{R}^{\star} \mathbf{R}^{*}$

In the ${ }^{1} H$ NMR spectrum of the macrocyclic phosphonates, we observed a downfield shift of the C-13 methine signal relative to that of the open-chain 
precursor 44. In the synthesis of simple macrocyclic lactones, we also used the downfield shift of this methine proton in the cyclized product relative to the methine signal of the open chain hydroxy acid precursor to establish whether cyclization has taken place. Similarly, for the cyclic phosphonates, the electron withdrawing nature of the phosphonate moiety deshields the methine proton in the cyclic compound relative to the open chain precursor (Table 4), giving rise to the observed downfield shift. In addition, the C-1 methyl signal of the cyclic phosphonates $38 \mathrm{a}$ and $38 \mathrm{~b}$ shifts downfield in the ${ }^{1} \mathrm{H}$ NMR spectrum as is observed for the 13-tetradecanolide lactones.

Table 4. Comparison of the ${ }^{1} H$ NMR chemical shift data for the methine and methyl signals of the open chain hydroxy acid $\mathbf{4 4}$ with those of the macrocyclic phosphonates $\mathbf{3 8 a}$ and $\mathbf{3 8 b}$.

\begin{tabular}{ccc} 
Compound & Methine multiplet (ppm) & Methyl doublet (ppm) \\
\hline 44 & 3.78 & 1.17 \\
$38 \mathrm{a}$ & 4.75 & 1.22 \\
$38 \mathrm{~b}$ & 4.65 & 1.43 \\
\hline
\end{tabular}

\subsection{ANTIBODY PRODUCTION}

\subsubsection{Preparation of Antigen KLH-50}

As stated earlier in Section 2.3, small hapten molecules must be coupled to a carrier protein prior to immunization, in order to elicit an immune response. This 
coupling is achieved by means of a spacer molecule. A 5-carbon unit as linker has been shown to be the optimal length for a spacer, or linker, in a number of studies. ${ }^{73-76}$ For this purpose, the linker molecule $\mathbf{4 8}$ was synthesized in a $35 \%$ yield by reaction of 5-amino-5-pentanol with benzyloxy chloride (Cbz-Cl).

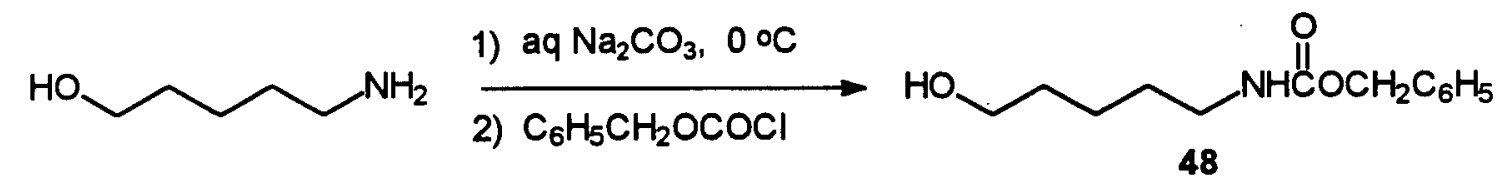

Of the two cyclic phenyl phosphonate diastereomers, $38 \mathrm{a}$ and $38 \mathrm{~b}$, only the minor diastereomer $\mathbf{3 8 b}$ was coupled to a carrier protein $(\mathrm{KLH})$ for immunization in mice for antibody production. Displacement of the phenoxy moiety of $38 \mathrm{~b}$ by the linker molecule $\mathbf{4 8}$ produced $\mathbf{4 9 a}$ in a $59 \%$ yield. Finally, hydrogenolysis of 49a in ethanol with hydrogen and $10 \% \mathrm{Pd} / \mathrm{C}$ afforded 50 in $85 \%$ yield.<smiles>CC1CCCCCCCCCCCP(=O)(Oc2ccccc2)O1</smiles>

38b
1) $\mathrm{nBuLi}^{\mathrm{T}} \mathrm{THF},-78^{\circ} \mathrm{C}$ $\mathrm{HO}\left(\mathrm{CH}_{2}\right)_{5} \mathrm{NHCbz}$

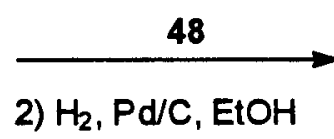

2) $\mathrm{H}_{2}, \mathrm{Pd} / \mathrm{C}, \mathrm{EtOH}$

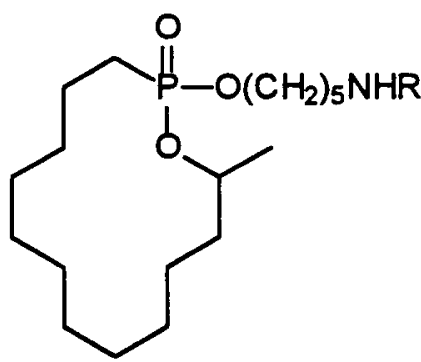

49a; $\mathrm{R}=\mathrm{Cbz}(59 \%)$ $50 ; R=H(85 \%)$ 
Amine $\mathbf{5 0}$ was coupled to carboxy residues of the carrier protein keyhole limpet hemocyanine $(\mathrm{KLH})$ using the water soluble coupling reagent 1-(3-dimethylaminopropyl)-3-ethylcarbodiimide hydrochloride (EDC). The coupling takes place between the amino group of $\mathbf{5 0}$ and carboxyl residues on the carrier protein.

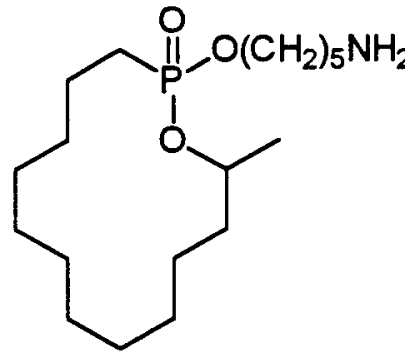

50

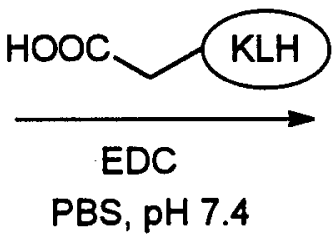

PBS, pH 7.4

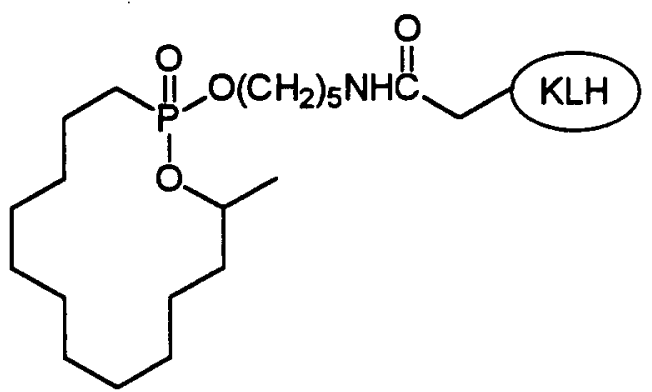

$\mathrm{KLH}-50$

An attempt to generate the diastereomeric hapten of $49 a$, namely $49 b$, from phosphonate 38a using the same reaction scale and conditions that produced 49a from 38b was attempted. However, isolation of the expected product by flash chromatography was not successful due to a poor yield. A subsequent attempt to isolate and characterize $49 \mathrm{~b}$ from the reaction of $38 \mathrm{a}$ with 48 after doubling the scale of the reaction resulted in a $14 \%$ yield of $49 \mathrm{~b}$.

Nucleophilic displacement reactions at phosphorus have been investigated. ${ }^{145-147}$ Green and Hudson carried out a series of nucleophilic displacement reactions on phosphorus. ${ }^{148}$ The stereochemical outcomes of these displacement 
reactions have been interpreted as proceeding with predominant inversion of the configuration at the phosphorus atom. Wadsworth reports mixed stereochemical results upon displacement at a phosphorus center, and the effect of added salt on the stereochemistry of nucleophilic displacements at phosphorus in phosphate esters and their analogues. ${ }^{149}$

The nucleophilic reactions involving displacement of the phenoxy moieties of cyclic phosphonates $\mathbf{3 8 a}$ and $\mathbf{3 8 b}$ with the linker molecule 48 are believed to have undergone inversion at the phosphorus centers. In both of the experiments, displacement of the phenoxy groups of compounds $38 \mathrm{a}$ and $\mathbf{3 8 b}$ with linker 48 produced clean diastereomeric products. In addition, the faster moving ' $a$ ' isomer of $\mathbf{3 8}$ (by TLC) on reaction with $\mathbf{4 8}$ generated the slower moving isomer, $\mathbf{4 9 b}$, while the reaction of $\mathbf{3 8 b}$ with $\mathbf{4 8}$ generated exclusively the faster moving isomer, 49a. These results are suggestive of inversion at the phosphorus centers of $\mathbf{3 8 a}$ and $\mathbf{3 8 b}$ on displacement with 48 . Further evidence to support inversion at the phosphorus centers of $\mathbf{3 8 a}$ and $\mathbf{3 8 b}$ on displacement with $\mathbf{4 8}$ is found in the analysis of the NMR data of these compounds as outlined below in Section 3.7. 


\subsubsection{Antibody Raised Against Antigen KLH-50}

Balb/c mice ( 6-8 week old females) were immunized with the KLH-50 conjugate. After the last injection, the mice were sacrificed and the spleens harvested. The mortal antibody-secreting spleen cells were fused with immortal myeloma cells to afford immortal antibody-producing hybrids (hybridomas), and these were plated into 96-well culture plates in HAT selection media (media containing hypoxanthine, aminopterine and thymidine). Spleen-myeloma hybrids are selected as follows: the fusion partners (myelomas; those used in this experimental are P3-X63-Ag8-653, or clone 653) are deficient in the enzyme hypoxanthine quanine phosphoribosyl transferase (HGPRT- or HPRT-) and cannot utilize exogeneous hypoxanthine in the synthesis of purine nucleotides. The presence of aminopterine, a dihydrofolate analogue and competitive inhibitor of dihydrofolate reductase $\left(\mathrm{K}_{\mathrm{i}}<10^{-9} \mathrm{M}\right){ }^{62}$ blocks the de novo synthesis of nucleotides. Thus in the presence of HAT selection media, unfused myelomas do not survive. Since spleen cells do not grow well in tissue culture, they die in about a week. Hybridomas are HGPRT+ (donated by the spleen cell) and can utilize exogeneous hypoxanthine and thymidine in their salvage pathway and survive. Cell lines obtained in this fashion can be maintained in continuous culture or frozen in liquid nitrogen indefinitely. 


\subsection{BINDING ASSAYS}

The particle concentration fluorescence immunoassay (PCFIA) technique ${ }^{150}$ was used in place of the traditional enzyme-linked immunosorbant assay (ELISA) for the initial screening of hybridomas. The PCFIA assays were carried out using hapten-protein conjugate-coated carboxyl polystyrene particles, 96 well filter assay plates, a goat antimouse fluorescein isothiocyanate (FITC) secondary antibody for detection at $385 \mathrm{~nm}$ wavelength, and a PCFIA buffer ( $2 \%$ fedal calf serum (FCS), $0.2 \%$ sodium azide, and $1 \times$ PBS, filter-sterilized through a $0.22 \mu \mathrm{m}$ filter).

A typical PCFIA assay involved the screening of supernatants from the hybridoma cells for hapten affinity using BSA-50 conjugate-coated carboxyl polystyrene particles as a solid phase. The BSA-50 conjugate was produced under the same conditions as the KLH-50 conjugate, then the BSA-50 conjugate was coupled through amino residues on the BSA with the carboxylate of the carboxy polystyrene particles using EDC as in Scheme 7. Once the supernatants from the hybridoma cells have incubated with the BSA-50 conjugate-coated carboxyl polystyrene particles, a FITC secondary antibody was used for detection (at $385 \mathrm{~nm}$ wavelength) of hapten-specific antibody binding. Positives from these screenings were subcloned by further limiting dilution onto 96-well microtiter plates to ensure we had stable monoclonal cell lines. A 
second PCFIA binding assay was then carried out to verify that the hybridomas were still secreting anti-hapten antibodies.
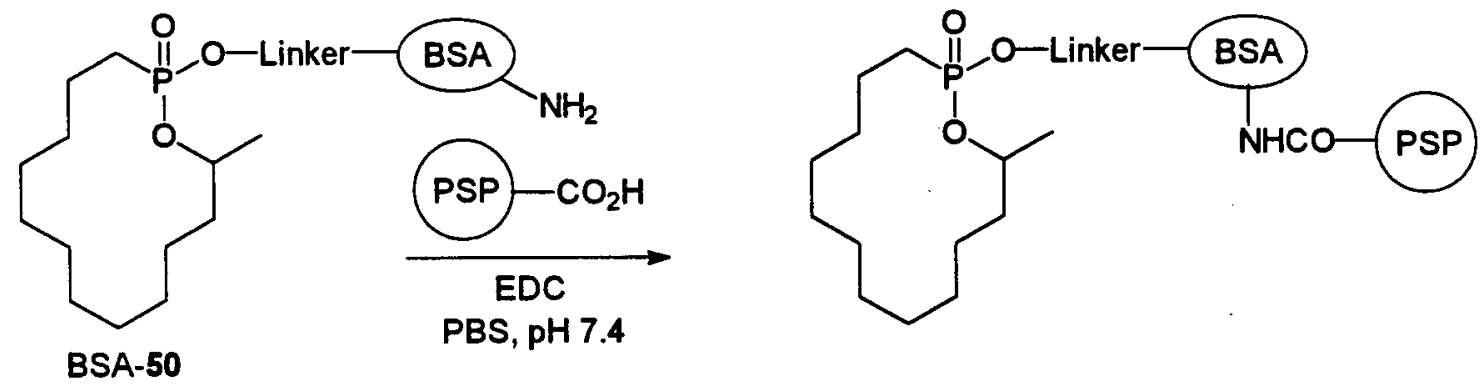

Scheme 7. Coupling of the BSA-50 conjugate with the carboxy polystyrene particles (PSP).

\subsection{ANTIBODY F123 ISOTYPING}

Using a standard isotyping assay, our monoclonal antibody F123 was found to be an IgM class antibody. IgM class antibodies, as described in Chapter 1, are expressed in the primary immune response.

Typical immunization protocols, such as the one we followed, include a large initial dose (challenge) of antigen, followed by booster injections containing a lower dose of antigen. Our protocol called for $100 \mu \mathrm{g}$ of the immunoconjugate KLH-50 per mouse on immunization, and $50 \mu \mathrm{g}$ per mouse for each booster injection. The time delay between the administration of the immunoconjugate into the mouse and the triggering of the primary response is not clear, nor is it clear at which stage of B cell differentiation, from stem cell to mature B cell, 
commitment to an ultimate antibody specificity occurs. Further refinement to the antibody specificity, by such mechanisms as affinity maturation and class switching (evolution, for example, from an IgM to an IgG class antibody), occurs under conditions in which the immune system is continuously challenged with the immuno-conjugate. A sufficiently stable hapten-protein conjugate is required to remain intact in vivo between booster injections to provide a constant challenge to the immune system of the mouse. One might speculate that if a sufficiently large immunizing dose of the KLH-50 conjugate was administered causing an initial immune response, while the amount of antigen in subsequent booster injections was not sufficiently large to allow sufficient lifetime of the conjugate for further refinement mechanisms to occur, fusion of these naive spleenocytes with immortal cells would result in IgM secreting hybridomas. Success in obtaining a lactone-forming catalytic antibody depended on the lifetime of the phosphonate immuno-conjugate, $\mathrm{KLH}-50$, in the mouse. If KLH-50 was susceptible to hydrolysis in the mouse, exocyclic (path a) rather than endocyclic (path b) cleavage (Scheme 8) should prevail since the 14-membered ring does not suffer from the ring strain in the seven membered ring phosphonate. In addition, endocyclic cleavage would result in the intact conjugate KLH-51, a hapten now resembling the phosphonic acid transition state analogues employed to obtain antibodies which catalyze hydrolytic reactions. However, as will be described later, we obtained a lactone-forming IgM antibody, one which was not found to have hydrolytic activity. 

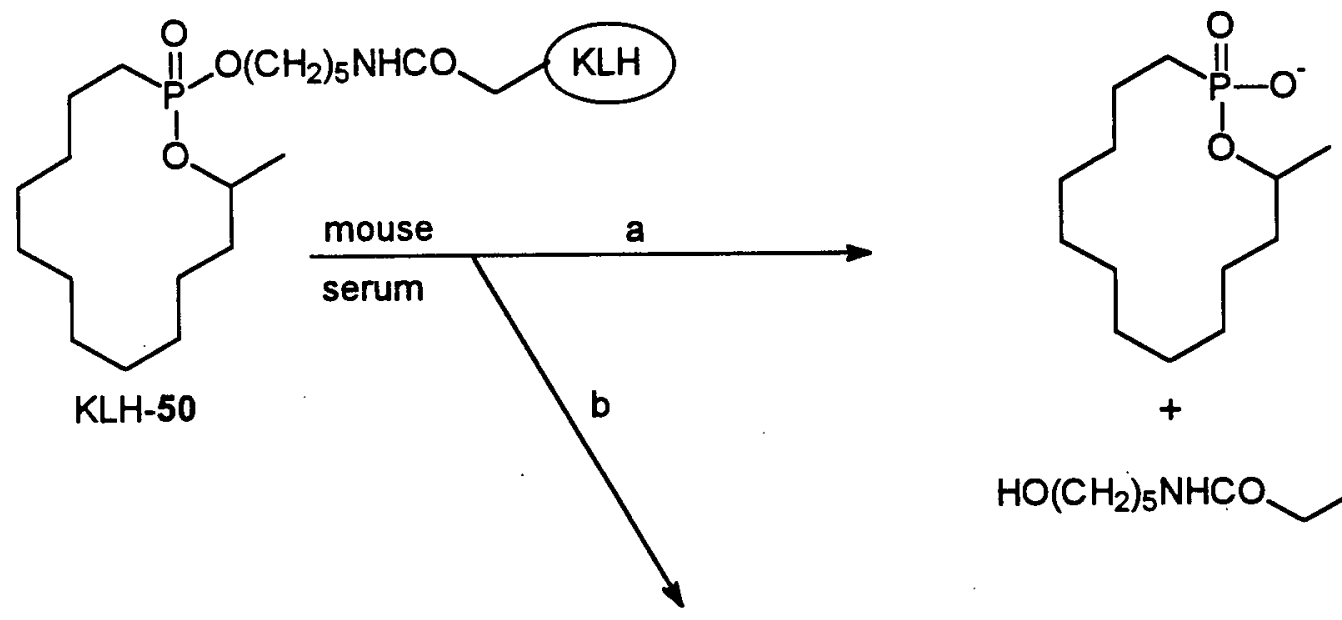

$\mathrm{HO}\left(\mathrm{CH}_{2}\right)_{5} \mathrm{NHCO}$
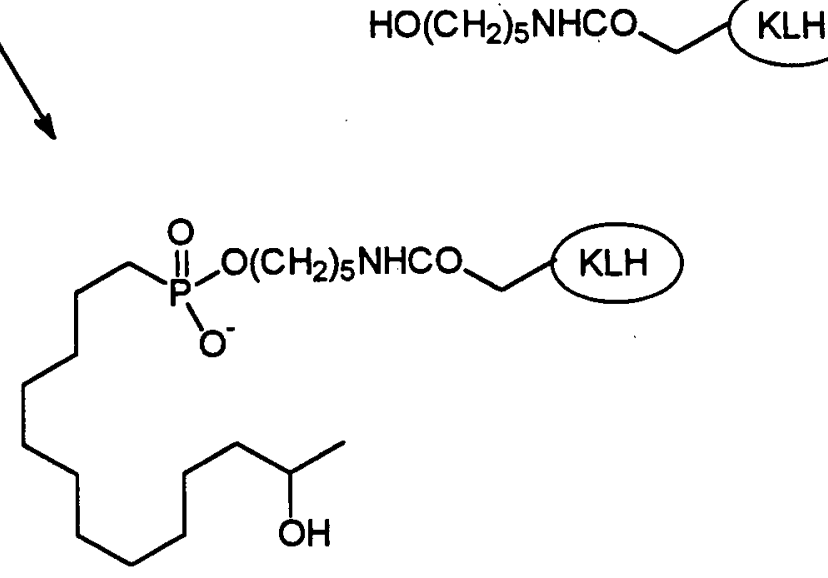

KLH-51

Scheme 8. Exocyclic (path a) versus endocyclic (path b) hydrolysis of immuno-conjugate $\mathrm{KLH}-50$ in mouse serum.

\subsection{ASCITES PRODUCTION}

Monoclonal antibodies selected for kinetic analysis, based on the binding assay results, were prepared by injecting a million hybridoma cells into pristane-primed Balb/c mice (6-8 week old females). The resulting ascites fluid was collected, and monoclonal antibodies were purified from ascites fluid by sheep-antimouse (SAM) affinity chromatography. The antibody samples were dialyzed into PBS buffer (8.2 mM NaHPO $, 137 \mathrm{mM} \mathrm{NaCl}, 2.7 \mathrm{mM} \mathrm{KCl}, 1.5 \mathrm{mM} \mathrm{H}_{2} \mathrm{PO}_{4}, \mathrm{pH}$ 7.4) for 
activity assays. Antibody concentration was determined by the absorbance at $280 \mathrm{~nm}$.

\subsection{SYNTHESIS OF SUBSTRATES AND HAPTEN DERIVATIVES}

\subsubsection{Synthesis of Substrate 55}

Gong, et $a l^{89}$ reported that a chromogenic substrate containing a 3-hydroxyindole moiety (see Scheme 9) might be useful in a direct catalytic assay. The indoyl strategy was suggested to be a facile chromogenic assay that might lend itself to the screening of large antibody libraries. The insoluble indigo product obtained upon carbonate cleavage affords high detection sensitivity since the indigo accumulates at the site of reaction, rather than diffusing through the reaction medium as is the case with soluble chromogenic species such as the p-nitrophenolate anion.

The synthesis of 55, shown in Scheme 10, began with the hydrolysis of 3-indoyl acetate in a deoxygenated solution of refluxing $2 \mathrm{~N} \mathrm{NaOH}$. The anhydride 52, in deoxygenated $\mathrm{EtOH}$ was then canulated into this reaction solution at $0^{\circ} \mathrm{C}$. Upon 
<smiles>O=C(CCCOC(=O)Oc1ccc([N+](=O)[O-])cc1)Oc1c[nH]c2ccccc12</smiles>

$\downarrow \lg G$<smiles>O=C(CCCO)Oc1c[nH]c2ccccc12</smiles><smiles>C[Te]</smiles>

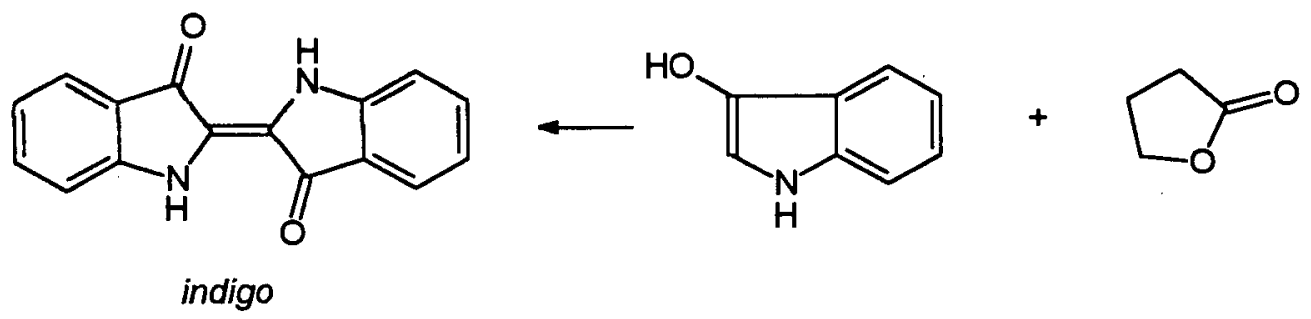

Scheme 9. Chromogenic assay reported by Gong, et al. (taken from ref 89).

isolation of crude indole 53 by ether extraction, followed by hydrogenolysis of the crude with $\mathrm{H}_{2}$ gas and $\mathrm{Pd} / \mathrm{C}$ in EtOAc, the resulting crude isolate was coupled to the hydroxy acid $54^{*}$ with 1,3-dicyclohexylcarbodiimide (DCC) and 4-dimethylaminopyridine (DMAP) in $\mathrm{CH}_{2} \mathrm{Cl}_{2}$ yielding the target hydroxy ester 55 .

* Prepared by D. Clyne. 
<smiles>CC(=O)Oc1c[nH]c2ccccc12</smiles>

1) $\mathrm{NaOH}-\mathrm{H}_{2} \mathrm{O}, \mathrm{N}_{2}$<smiles>O=C([O-])CCCOCc1ccccc1</smiles><smiles>O=C(CCCOCc1ccccc1)Oc1c[nH]c2ccccc12</smiles>

52<smiles>C1CCCCC1</smiles>

1) $\mathrm{H}_{2}, \mathrm{Pd} / \mathrm{C}, \mathrm{EtOAC}$

2)<smiles>CC(O)C[13C](=O)[13C](=O)O</smiles><smiles>CC(O)CCCCCCCCCCCC(=O)OCCCC(=O)Oc1c[nH]c2ccccc12</smiles>

Scheme 10. Synthesis of indoyl substrate 55.

Anhydride 52 was prepared by the DCC coupling of carboxylic acid $56^{\star *}$.<smiles>CCCC(COCCCC(=O)O)C(C)(C)C</smiles>

Substrate $\mathbf{5 5}$ was found to be insoluble in the PBS buffer. A variety of co-solvents, including $\mathrm{MeOH}, \mathrm{DMF}, \mathrm{CH}_{3} \mathrm{CN}$ and DMSO, were used in an attempt to solublize 55. Of the co-solvents used, a PBS solution containing $10 \%$ DMSO was found to be the most effective, however, complete solubility of $\mathbf{5 5}$ was only achieved by employing $0.5 \%$ Triton $X-100$ with the $10 \%$ DMSO. Solutions were

* Prepared by J. P. Ounsworth. 
determined to be homogeneous by examination under an inverted microscope (10x magnification).

Reaction of the indoyl substrate $\mathbf{5 5}$ with monoclonal antibody F123 did indeed lead to the expected insoluble byproduct, namely indigo, while none was observed in the blank experiment, however, the indigo could neither be easily nor conveniently quantified on the assay scale used.

Due to the low solubility of substrate $\mathbf{5 5}$ in the reaction buffer, along with the problem associated with quantifying the extent of the reaction (i.e. the amount of indigo formed), we elected to switch to the shorter, more soluble p-nitrophenyl ester substrate 57. In addition, the soluble p-nitrophenolate anion, resulting from reaction of $\mathbf{5 7}$ with the catalytic antibody, is a convenient chromophore for acquiring kinetic data spectrophotometrically.

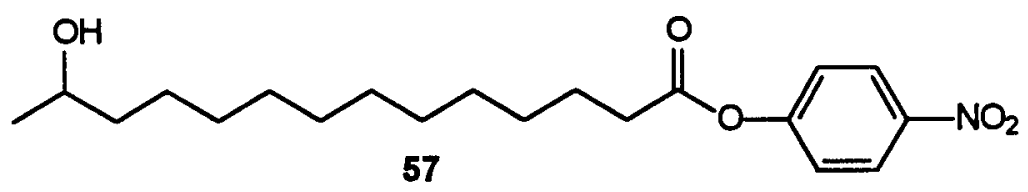

Substrate 57 , used in the catalytic assays for the monoclonal antibodies, differs from 55 in that 55 mimicks more closely the linker-arm portion of hapten molecule 50. However, it should not be surprising that the antibodies are tolerant to this substrate variability, since others ${ }^{89,151,152}$ suggest that antibody 
binding specificity is relatively insensitive to elements of the hapten and substrate close to the conjugation site. Also, antibodies specific for the steroid androstenedione were screened ${ }^{75}$ for specificity using derivatives of this steroid. This work showed that the antibodies were much less sensitive to changes in the ligand which were near the position of linker attachment on the steroid, and that the specificity was greatly affected by changes farthest from the position of attachment to the linker. This evidence supports the idea that the portion of the hapten which extends away from the carrier protein provides the most accessible epitopes for antibodies.

\subsubsection{Synthesis of Substrate 57}

The hydroxy p-nitrophenyl ester substrate $\mathbf{5 7}$ was obtained by reaction of 13-hydroxytetradecanoic acid (54) with p-nitrophenol in $\mathrm{CH}_{2} \mathrm{Cl}_{2}$ in the presence of DCC and DMAP under a $\mathrm{N}_{2}$ atmosphere to produce the desired substrate in $87 \%$ yield.

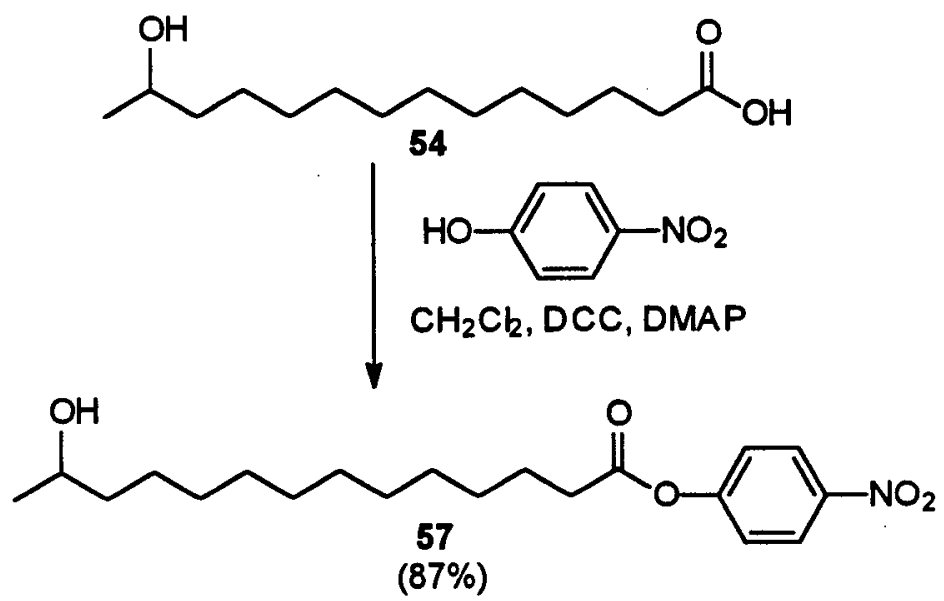




\subsubsection{Synthesis of Substrate 58}

Myristic acid, or tetradecanoic acid, was reacted with p-nitrophenol as below to produce p-nitrophenyl tetradecanoate (58) in $88 \%$ yield.

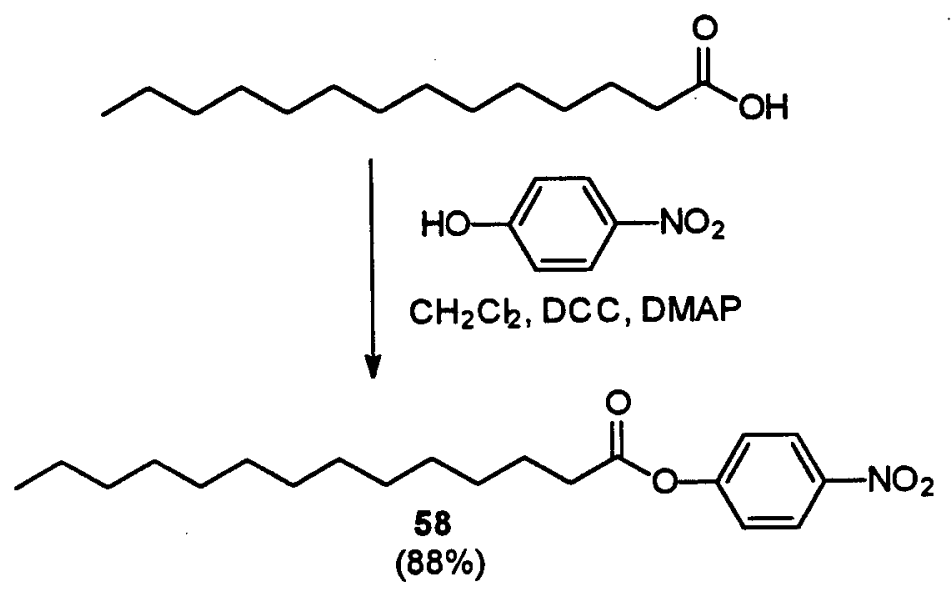

\subsubsection{Synthesis of Hapten Derivatives $60 \mathrm{a}$ and $60 \mathrm{~b}$}

The synthesis of the p-nitrophenylphosphonate hapten derivatives $60 \mathrm{a}$ and $60 \mathrm{~b}$ began with the hydrolysis of phenyl phosphonate $38 \mathrm{~b}$ using refluxing $3 \mathrm{~N}$ $\mathrm{NaOH}-\mathrm{THF}$ produced the phosphonic acid derivative 59 in a $73 \%$ yield. Conversion of $\mathbf{5 9}$ to the acid chloride with oxalyl chloride, followed by coupling of this phosphoryl chloride intermediate with p-nitrophenol (PNP) gave a 1.2:1 ratio of diastereomers $60 \mathrm{a}$ and $60 \mathrm{~b}$ in $69 \%$ yield. 


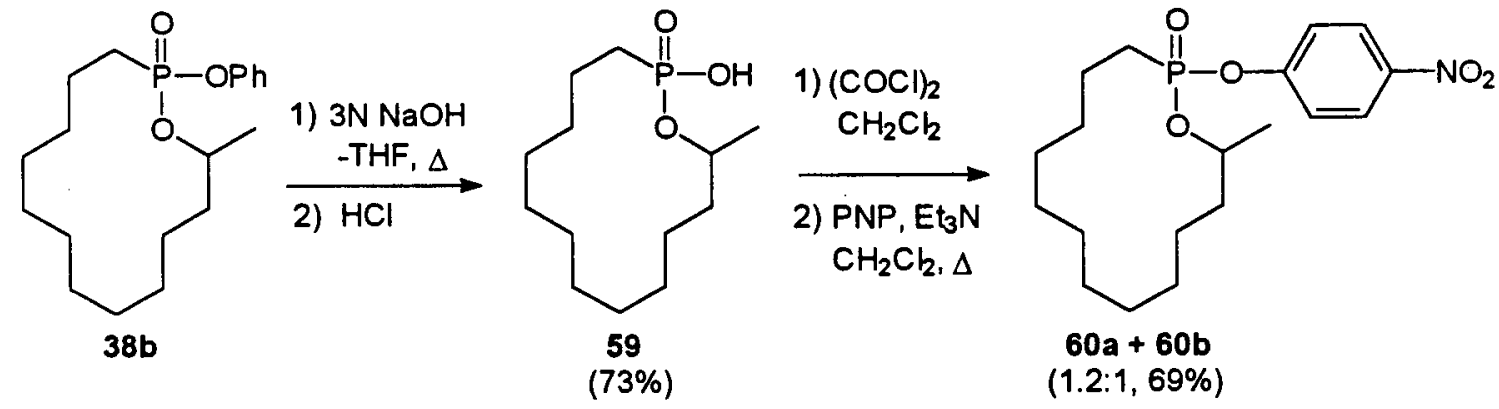

\subsubsection{Synthesis of Six-membered Ring Phenyl Phosphonates, 61a and $61 \mathrm{~b}$}

The six-membered ring phenyl phosphonates, $61 \mathrm{a}$ and $61 \mathrm{~b}$, were synthesized as an offshoot of the 14-membered ring project, and as such, the full characterization of the intermediates that led to compounds $61 \mathrm{a}$ and $61 \mathrm{~b}$ is not complete. However, the targets, $61 \mathrm{a}$ and $61 \mathrm{~b}$, have been fully characterized, and the stereochemistry of these two phenyl phosphonates has been firmly established, and this proved useful in elucidating the stereochemistry of the 14-membered ring analogues, $38 \mathrm{a}$ and $\mathbf{3 8 b}$, discussed in Section 3.7. The synthesis of $61 \mathrm{a}$ and $61 \mathrm{~b}$ (Scheme 11) began with the benzylation of the primary hydroxyl group of 1,3-butanediol to give 62 in $58 \%$ yield. The secondary hydroxyl of 62 was then protected as the THP ether 63 in $76 \%$ yield. This addition of the THP group created a second chiral center in $\mathbf{6 3}$, and therefore, two diastereomers of 63 were obtained. The two diastereomers were obtained in a $1: 1$ ratio as seen in the ${ }^{1} H$ NMR spectrum of 63 , which reveals two methyl doublets of equal intensity and two methine multiplets, corresponding to the 
methine proton of the THP group. Hydrogenolysis of the benzyl moiety of compound 63 gave alcohol 64 in an isolated yield of $85 \%$. The ${ }^{1} \mathrm{H}$ NMR spectrum of the flash chromatography-purified diastereomers of compound 64 reveals a diastereomeric ratio of approximately $1: 4$, rather than a $1: 1$ as would be expected, based on the relative intensities of the diagnostic methyl and methine signals. A portion of one of the diastereomers of 64 was accidently discarded during purification resulting in this $1: 4$ ratio. This was of no consequence, however, since the THP group was subsequently removed, destroying one of the two stereogenic centres in the molecule. The 1:4 ratio of isomers of alcohol 64 were then oxidized under the Swern conditions to give the aldehyde 65 in $96 \%$ yield. Aldehyde 65 was subsequently reacted with the stabilized Wittig reagent 32 to give the trans vinyl phosphonate 66 in a moderate yield of $55 \%$. Phosphonate 66 was then reacted with p-toluenesulphonic acid to liberate the secondary hydroxyl compound 67 in $70 \%$ yield. Removal of the THP group from 66 eliminated one of the two stereogenic centres in the molecule giving a single diastereomer, reflected in the ${ }^{1} \mathrm{H}$ NMR spectrum of 67 which contains only one methyl doublet. The alkene $\mathbf{6 7}$ was then reduced to give the saturated diphenyl phosphonate 68 in 93\% yield. Finally, the hydroxy diphenyl phosphonate 68 was reacted with n-butyllithium in THF at $-78^{\circ} \mathrm{C}$ to produce the cyclic phosphonates $61 \mathrm{a}$ and $61 \mathrm{~b}$ in a $96 \%$ yield and a $6: 1$ ratio of diastereomers based on the ${ }^{1} \mathrm{H}$ NMR spectrum of the crude product. 


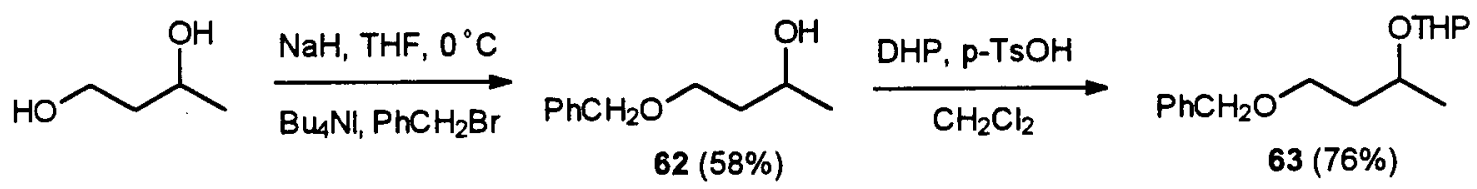

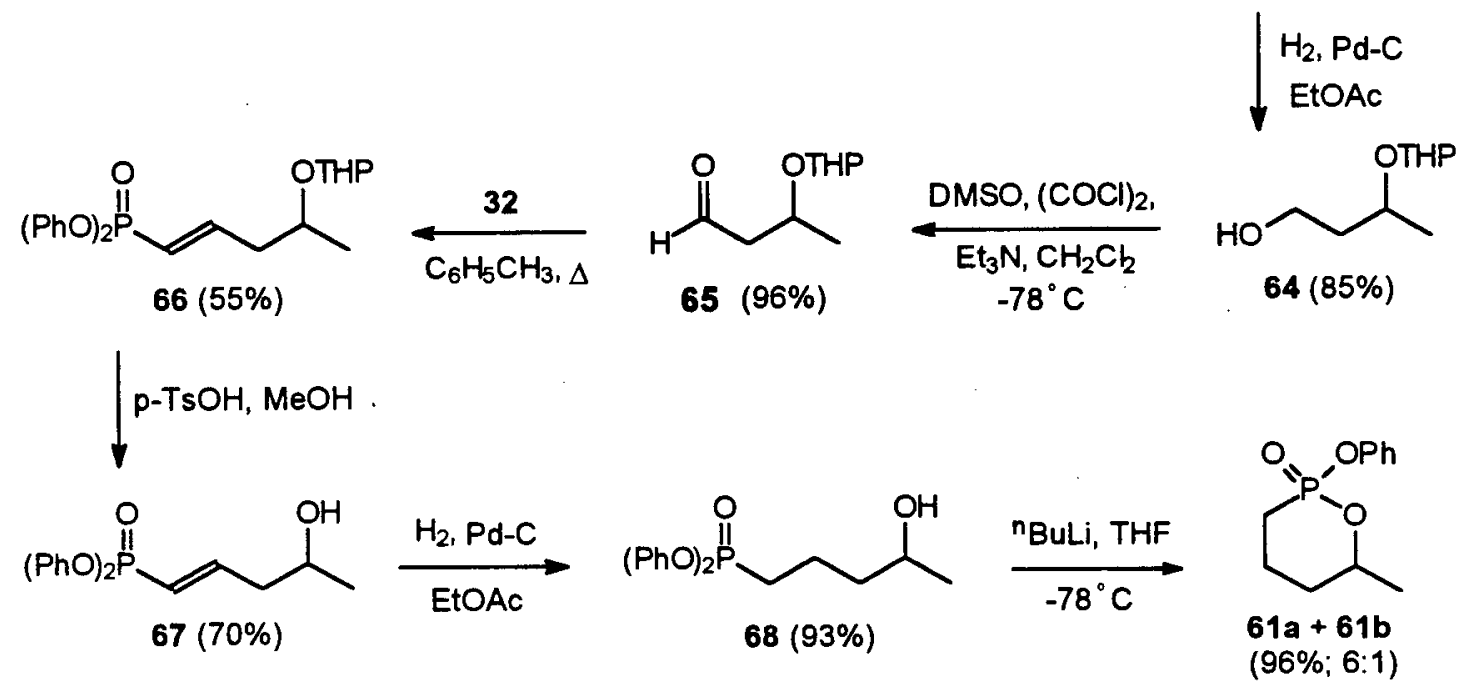

Scheme 11. Synthesis of cyclic phosphonates $61 \mathrm{a}$ and $61 \mathrm{~b}$.

\subsection{INVESTIGATION INTO THE RELATIVE STEREOCHEMISTRY OF CYCLIC PHOSPHONATES 38a AND 38b}

Table 5 below lists the ${ }^{1} \mathrm{H}$ NMR chemical shifts of the methine proton and the methyl protons for the 14 -membered ring phosphonates $38 \mathrm{a}, 38 \mathrm{~b}, 60 \mathrm{a}, 60 \mathrm{~b}$, 49a, $49 \mathrm{~b}$ and 50 , as well as those for the 28 -membered ring dimer 39 and the six-membered ring phosphonates $61 \mathrm{a}$ and $61 \mathrm{~b}$. In addition, Table 5 lists the ${ }^{31} \mathrm{P}$ NMR signals and TLC $R_{f}$ values for each compound. We first looked for a correlation between the ${ }^{1} \mathrm{H}$ and ${ }^{31} \mathrm{P}$ NMR spectra of the 28-membered macrocyclic phosphonate dimer 39 and those of the cyclic monomeric diastereomers, 38a and 38b. Since we only had a crystal structure for the dimer 
39, we hoped that the ${ }^{1} \mathrm{H}$ and ${ }^{31} \mathrm{P}$ NMR spectra of the 28-membered macrocyclic phosphonate dimer 39 , together with the structural information from the X-ray structure of $\mathbf{3 9}$ would allow us to infer structural information about monomers 38a and 38b, and ultimately the hapten molecule 50 , to which antibody F123 was raised.

The chemical shifts of the C-1 methyl doublets for both isomer $38 \mathrm{a}$ and the dimer 39 are at higher field than the methylene envelope, while that of isomer $38 \mathrm{~b}$ is at lower field than this envelope (see Spectral Appendix). In the case of compound 50, the methyl doublet lies just within the highfield region of the methylene envelope, that is, to the "isomer a side". This result is consistent with inversion at phosphorus, since $\mathbf{5 0}$ was produced on substitution of the phenol moiety of diastereomer $38 \mathrm{~b}$ with the linker 48 , giving rise to $49 \mathrm{a}$ which upon hydrogenolysis of the $\mathrm{Cbz}$ moiety of $49 \mathrm{a}$ yielded compound 50 . Compound $49 \mathrm{~b}$ was synthesized by displacement of the phenol moiety of 38a with linker $\mathbf{4 8}$ giving rise to compound $49 \mathrm{~b}$ exclusively.

Diastereomers $60 \mathrm{a}$ and $60 \mathrm{~b}$ were produced by conversion of the cyclic phosphonic acid $\mathbf{5 9}$ into two phosphoryl chloride intermediates (as observed by 
<smiles>[R]OP(=O)(CCCCCCCCCCCC)OC(C)C</smiles><smiles>CC(CCCCCCCCCCCP(=O)(O)OC(C)CCCCCCCCCCCP(=O)(Oc1ccccc1)Oc1ccccc1)OP(=O)(O)O</smiles><smiles>CC1CCCP(=O)(Oc2ccccc2)O1</smiles>

38a,38b R = Ph

$60 \mathrm{a}, 60 \mathrm{~b} R=\mathrm{PNP}$

49a,49b R $=\left(\mathrm{CH}_{2}\right)_{5} \mathrm{NHCbz}$

$50 \mathrm{R}=\left(\mathrm{CH}_{2}\right)_{5} \mathrm{NH}_{2}$

Table 5. Key ${ }^{1} H$ and ${ }^{31} P$ NMR chemical shifts ( $\delta$ values) and TLC $R_{r}$-values for the cyclic phosphonates.

\begin{tabular}{|c|c|c|c|c|}
\hline Compound & $\begin{array}{c}\delta^{1} \mathrm{H} \text { for } \mathrm{CH}_{3} \\
\text { protons (ppm) }\end{array}$ & $\begin{array}{c}\delta{ }^{1} \mathrm{H} \text { for methine } \\
\text { proton (ppm) }\end{array}$ & $\delta^{31} \mathrm{P}$ (ppm) & $\begin{array}{l}\text { TLC } R_{f} \\
\text { values }^{\dagger}\end{array}$ \\
\hline $38 a$ & 1.22 & 4.75 & 29.6 & 0.71 \\
\hline $38 b$ & 1.43 & 4.65 & 27.8 & 0.57 \\
\hline $60 a$ & 1.23 & 4.77 & 30.4 & 0.66 \\
\hline $60 \mathrm{~b}$ & 1.43 & 4.65 & 28.5 & 0.56 \\
\hline $49 a$ & 1.30 & 4.59 & 32.5 & 0.18 \\
\hline $49 b$ & 1.35 & 4.43 & 31.3 & 0.12 \\
\hline 50 & 1.32 & 4.95 & 33.1 & 0 \\
\hline 39 & 1.15 & 4.66 & 29.0 & 0.62 \\
\hline $61 a$ & 1.35 & 4.51 & 20.5 & 0.21 \\
\hline $61 b$ & 1.36 & 4.68 & 23.4 & 0.10 \\
\hline
\end{tabular}

${ }^{7}$ Obtained using a 1:1 mixture of petroleum ether and ethyl acetate. 
TLC) followed by substitution with p-nitrophenol. The ${ }^{1} \mathrm{H}$ and ${ }^{31} \mathrm{P}$ NMR chemical shifts ( $\delta$ values) for compounds $49 a$ and $49 b$ as well as for diastereomers $60 a$ and $60 \mathrm{~b}$ are consistent with the pattern observed with $38 \mathrm{a}$ and $\mathbf{3 8 b}$. That is, within each pair of 14-membered ring phosphonate diastereomers listed in Table 5, the ${ }^{1} \mathrm{H}$ NMR chemical shift of the C-1 methyl doublet is at higher field, while the shift of the methine proton is at lower field for all the a isomers compared with those for the corresponding $b$ isomers. The ${ }^{1} H$ NMR chemical shift of the $C-1$ methyl doublet for dimer 39 is consistent with those of the a isomers of the 14-membered ring phosphonates. The stereoview of the ORTEP representation of the macrocyclic dimer 39 (Figure 13) reveals that the doubly-bonded oxygen on the phosphorus atom is 'syn' to the $\mathrm{C}-13$ methine proton, and the $\mathrm{C}-1$ methyl group is 'syn' to the oxygen of the phenol moiety as illustrated in Figure 14. We are suggesting, therefore, that the a isomers of the 14-membered ring phosphonates listed in Table 5 have the $R^{*}, R^{*}$ relative stereochemistry between the C-1 methyl and the phosphorus atom consistent with that of compound 39 . In addition, we believe that the $\mathrm{C}-1$ methyl group and the OR group on phosphorus are mainly in a conformation in which both are equatorial in the a isomer as found in the X-ray structure of 39 (Figure 14). Support for the equatorial assignment of the OR groups on the phosphorus atoms of the 14-membered ring phosphonates listed in Table 5 comes from the ${ }^{31} P$ NMR chemical shift data. It has been observed that the ${ }^{31} \mathrm{P}$ NMR signal for the equitorial P-OR isomer is approximately $2 \mathrm{ppm}$ lower field than the 


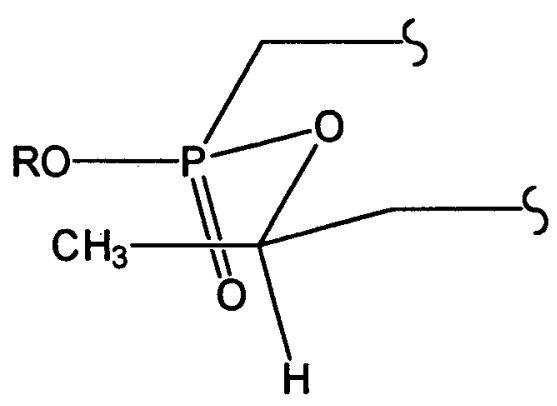

Figure 14. Relative stereochemistry about the phosphorus atom and the $\mathrm{C}-1$ carbon atom of dimer 39.

corresponding axial isomer in the cyclic phosphonates of hexopyranoses ${ }^{153-155}$ and in other six-membered ring phosphonates. ${ }^{156.157}$ This trend supports our correlation between compounds 39 and $38 \mathrm{a}$, since the ${ }^{31} \mathrm{P}$ NMR shift for isomer $38 \mathrm{a}$ is $2 \mathrm{ppm}$ downfield from that of isomer $\mathbf{3 8 b}$.

A final piece of evidence to support the equatorial assignment for the OPh group in compound $38 \mathrm{a}$ comes from a comparison of $38 \mathbf{a}$ and $38 \mathbf{b}$ with the six-membered ring anaolgues, 61a and $61 \mathrm{~b}$. The stereochemical assignments (as shown below) for compounds 61a and 61b were determined on the basis of ${ }^{1} \mathrm{H}$ NMR NOE (nuclear overhausser effects) difference experiments. Irradiation of the methine signal at $4.51 \mathrm{ppm}$ of phosphonate $61 \mathrm{a}$ resulted in enhancement of the phenyl signal between 7.4-7.2 ppm, whereas, irradiation of the corresponding methine signal for $61 \mathrm{~b}$ failed to produce an enhanced signal in the phenyl region. This NOE data is consistent with the stereochemical assignments for compounds $61 \mathrm{a}$ and $61 \mathrm{~b}$. 


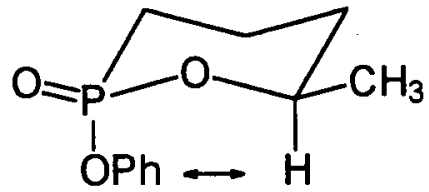

$61 \mathrm{a}$

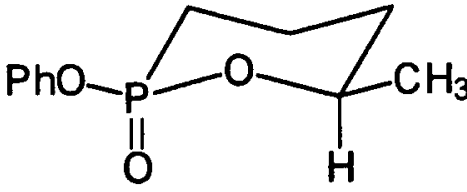

61b

In addition, the ${ }^{31} \mathrm{P}$ NMR shifts for compounds $61 \mathrm{a}$ and $61 \mathrm{~b}$, listed in Table 5, are in agreement with the trends described above for similar six-membered ring phosphonates. That is, the ${ }^{31} \mathrm{P}$ signal for phosphonate $61 \mathrm{~b}$, with the $\mathrm{OPh}$ group in the equitorial position, is at lower field than the corresponding axial isomer, 61a. With the stereochemistry of compounds $61 \mathrm{a}$ and $61 \mathrm{~b}$ firmly established, a correlation was made between these compounds and the 14-membered ring analogues, $38 \mathrm{a}$ and $\mathbf{3 8 b}$. Considering the structures for compounds $61 \mathrm{a}$ and 61b along with ${ }^{1} \mathrm{H}$ NMR data listed in Table 5, a 1,3-diaxial (or syn) relationship between the methine proton and the doubly-bonded oxygen attached to the phosphorus atom (as in 61b) results in a shift in the methine signal to lower field compared to the higher field methine signal when these two groups are anti to one another (as in 61a). The methine signal for compound 38a (at $4.75 \mathrm{ppm}$ ) is at lower field than that of compound $38 \mathrm{~b}$ (at $4.65 \mathrm{ppm}$ ), which supports our assignment of the OPh group being equatorial (and hence the doubly-bonded oxygen attached to the phosphorus atom in a 1,3-diaxial relationship with the methine proton) in phosphonate 38 a. 


\subsection{INITIAL INVESTIGATION FOR REACTIVITY OF MAB'S WITH SUBSTRATE 57.}

The concentrations of antibody stock solutions used in this study, obtained from immunoaffinity purification of ascites preparations, were determined using $\varepsilon=1.4$ and a molecular weight of $175 \mathrm{kDa}$ for $\mathrm{lgM}$ monomer.

Clones that showed the strongest binding to our hapten molecule were chosen for catalytic screening. Analyses were performed using 96-well microtiter plates and a microtiter plate reader (Bio-Tek Instruments) equipped with the Delta Soft II computer program (referred to later as the 'multiwell method'). A report by Masamune and co-workers ${ }^{90}$ also uses a microtiter plate reader for kinetic analysis of their catalytic monoclonal antibodies. Furthermore, Copeland states that many workers now perform absorption measurements with 96-well microtiter plate readers. ${ }^{158}$ All assays reported in this thesis by the microtiter method were performed at least in duplicate.

Three monoclonal antibodies, F123, F125 and F150 were selected, based on binding assays, for a reactivity test against substrate 57 (Figure 15). These clones were assayed spectrophotometrically $(405 \mathrm{~nm})$ at $37^{\circ} \mathrm{C}$ for 4-nitrophenolate anion release from substrate 57 on reaction with the antibody. Only monoclonal F123 showed significant reactivity with $\mathbf{5 7}$, and was selected for further study. An initial test of the catalytic potential of monoclonal F123 was 
carried out, involving three independent experiments on one microtiter plate. The first experiment was a reaction of substrate $57(88 \mu \mathrm{M})$ with antibody F123

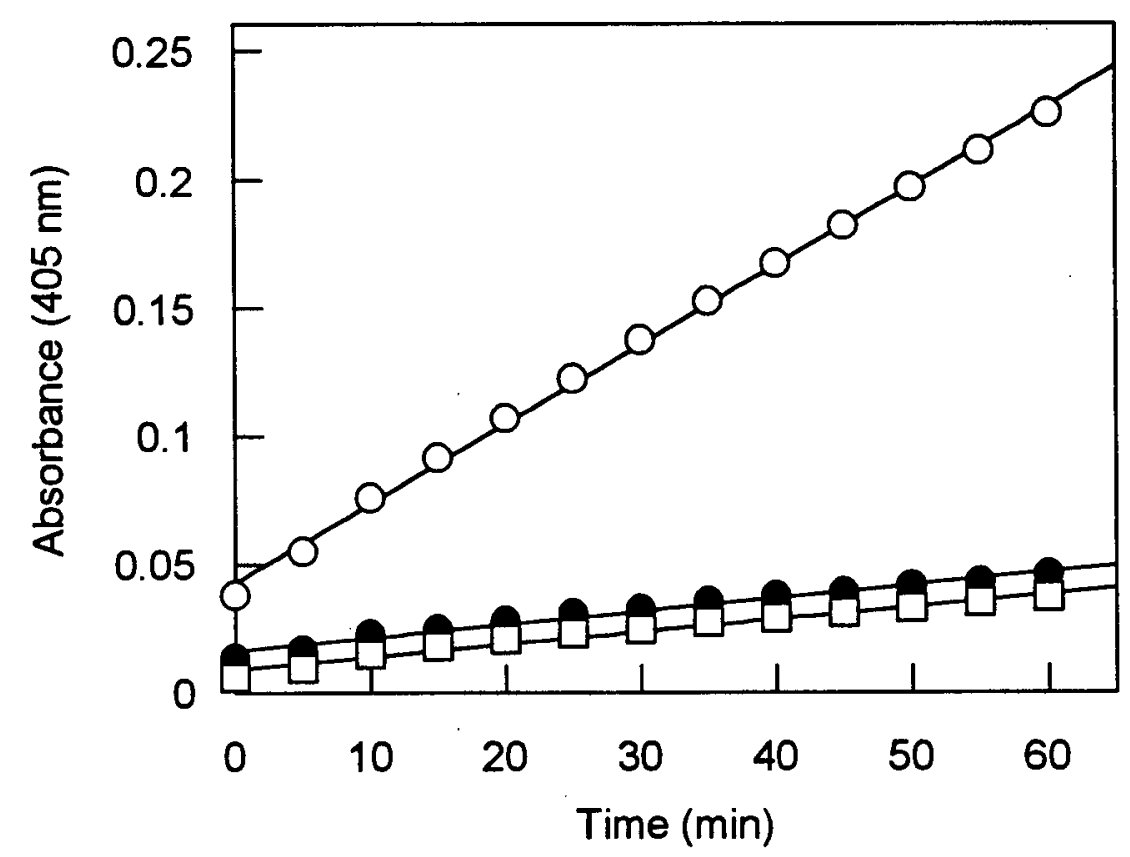

Figure 15. Monoclonal antibodies F123 $(0), F 125(\square)$ and F150 $(\bullet)$, each at a concentration of $2 \mu \mathrm{M}$, were assayed for activity with substrate $\mathbf{5 7}$ $(200 \mu \mathrm{M})$ in PBS buffer (pH 7.4) containing 10\% DMSO and $0.5 \%$ Triton $\mathrm{X}-100$ at $37^{\circ} \mathrm{C}$.

$(0.88 \mu \mathrm{M})$. The second experiment involved reaction of $57(88 \mu \mathrm{M})$ with antibody F123 $(0.44 \mu \mathrm{M})$. From the slopes (rates) of these two experiments (see Figure 16), we see that halving the antibody concentration resulted in a halving of the reaction rate (see Table 6). Finally, the third experiment involved reaction of $\mathbf{5 7}$ $(88 \mu \mathrm{M})$ in the presence of 0.25 equivalents $(0.22 \mu \mathrm{M})$ of hapten analogue 60 (a one-to-one mixture of both diastereomers) with antibody F123 $(0.88 \mu \mathrm{M})$. Here we expected to see inhibition of the p-nitrophenol release in the presence of the hapten derivative 60. From the slopes in Table 6, it is clear that compound $\mathbf{6 0}$ 
inhibits the antibody activity, demonstrating that antibody activity is associated with binding in the antibody-combining site.

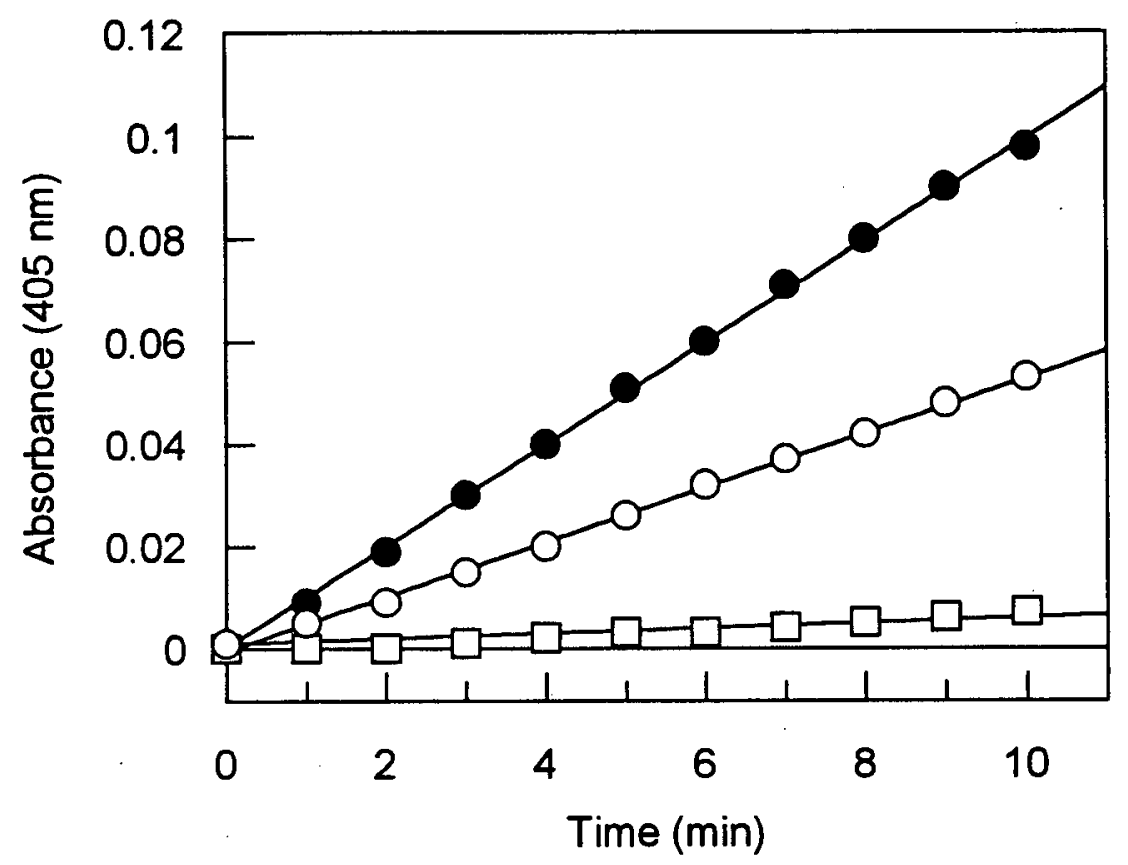

Figure 16. Initial experiments with antibody $\mathrm{F} 123$, substrate 57 , and hapten derivative 60 using PBS buffer (pH 7.4) containing 10\% DMSO and $0.5 \%$ Triton $\mathrm{X}-100$ at $37^{\circ} \mathrm{C}$. Reactions were run; (i) (•) $88 \mu \mathrm{M}$ in 57 and $0.88 \mu \mathrm{M}$ in $\mathrm{F} 123$, (ii) (O) $88 \mu \mathrm{M}$ in 57 and $0.44 \mu \mathrm{M}$ in $\mathrm{F} 123$, (iii) ( $\square$ ) $88 \mu \mathrm{M}$ in $57,0.88 \mu \mathrm{M}$ in $\mathrm{F} 123$ and $0.22 \mu \mathrm{M}$ of 60 (1:1 ratio of diastereomers).

The findings of these three experiments were encouraging, and suggested that monclonal F123 was behaving as a catalyst, and that the catalytic activity of F123 is associated with binding in the antibody-combining site. The next step was to prove that antibody $\mathrm{F} 123$ is indeed catalysing the cyclization of 57 to lactone 19 , and to then carry out a kinetic analysis of the reaction between 
antibody F123 and substrate $\mathbf{5 7}$ to determine the Michaelis-Menten parameters $\mathrm{K}_{\mathrm{m}}, \mathrm{V}_{\max }$ and $\mathrm{K}_{\text {cat. }}$

Table 6. Results of initial F123 antibody experiments.

\begin{tabular}{ccc}
\hline Experiment & Slope $(\Delta O D / \min )$ & Correlation Coefficient \\
\hline (i) & 0.0101 & 0.9995 \\
(ii) & 0.0056 & 0.9983 \\
(iii) & 0.0008 & 0.9935 \\
\hline
\end{tabular}

\subsection{ISOLATION OF F123-CYCLIZED MACROLACTONE 19}

Confirmation that F123 catalyzed the cyclization of substrate 57 to lactone 19 was achieved by isolation of 19 through ether extractions from pooled catalytic experiments. Several small-scale catalytic reactions of antibody F123 with substrate 57 in PBS buffer, $\mathrm{pH} 7.4$, containing 10\% DMSO and $0.5 \%$ Triton $\mathrm{X}-100$ at $37^{\circ} \mathrm{C}$ (ranging from $100-400 \mu \mathrm{M}$ in 57 , and each having a final volume of $250 \mu \mathrm{L}$ ) were pooled for ether extractions.

Initial identification of the antibody generated lactone was achieved by GC analyses. GC analysis of an independently synthesized sample of lactone 19 revealed a broad peak with a retention time of approximately 17 minutes, as seen in trace (a) of Figure 17 below. The GC trace of the ether extracts from the 
pooled antibody experiments also contained a broad peak at approximately 17 minutes, Figure 17 trace (b). The GC run for the ether extracts from the antibody experiment spiked with lactone 19, GC trace (c), showed an increase in the peak

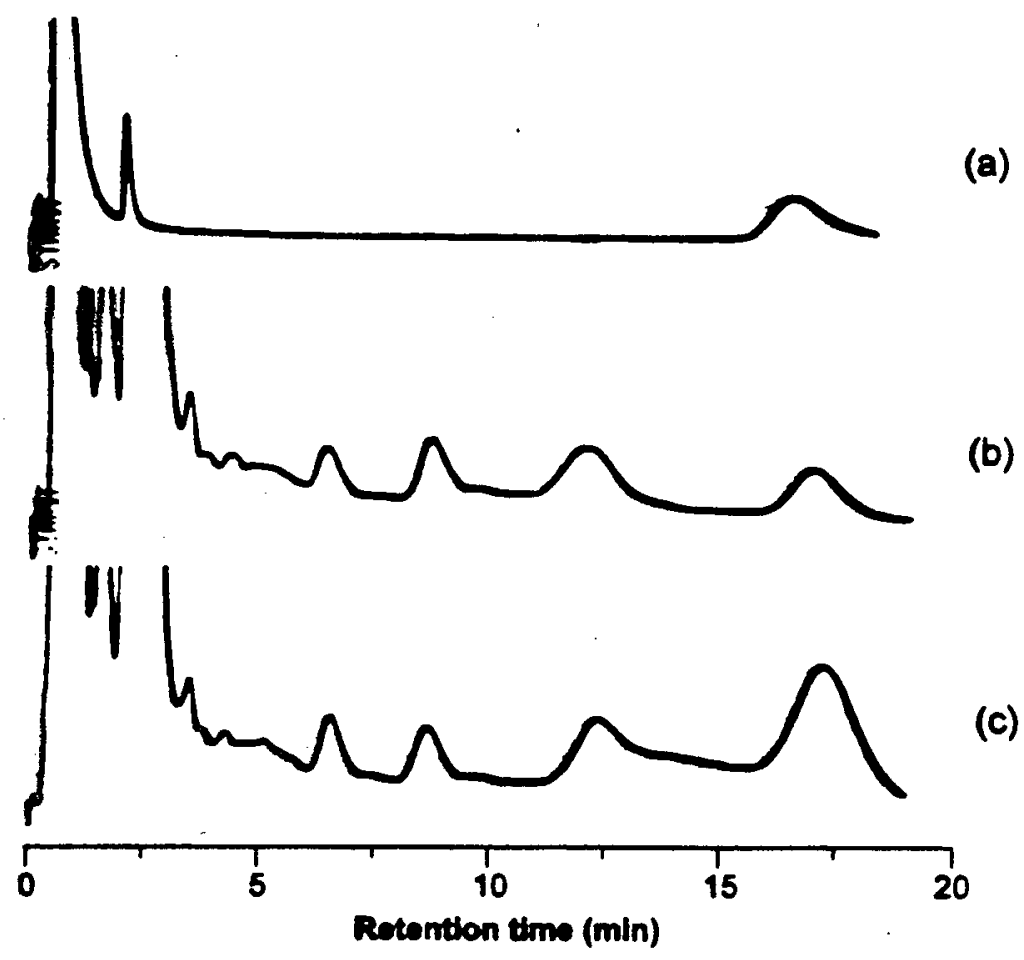

Figure 17. GC chromatograms of: (a) an independently synthesized sample of lactone 19; (b) ether extracts from the pooled F123 catalyzed cyclization reactions of substrate 57 ; (c) a spiked GC run of the ether extracts from the antibody experiment with an authentic sample of 19.

corresponding to lactone 19 having a retention time of approximately 17 minutes, confirming the presence of lactone 19 in the pooled antibody experiments.

Furthermore, the unambiguous identification of the antibody generated lactone was obtained by GCMS analysis. The high resolution mass spectrum of the 
GCMS lactone peak from the ether extracts was consistent with that of the independently synthesized lactone sample. As expected, the molecular ion peak for lactone 19 at $\mathrm{m} / \mathrm{z} 226$ was observed in both mass spectra. In addition, the anticipated fragment at $\mathrm{m} / \mathrm{z} 208$ was present in both mass spectra.

Finally, a large scale background experiment with $57(250 \mu \mathrm{M})$ in the reaction buffer (containing no antibody) was conducted at $37^{\circ} \mathrm{C}$ for five days. GCMS analysis of ether extracts from this background reaction revealed no detectable lactone.

\subsection{SPECIFICITY OF MONOCLONAL F123}

To illustrate that the activity of antibody F123 with $\mathbf{5 7}$ is not due to an esterolytic contaminant of the serum, an affinity purified control MAb raised against an unrelated hapten was run in parallel with F123. The control MAb showed no activity with substrate 57 (see Figure 18).

\subsection{REACTION OF P-NITROPHENYL TETRADECANOATE WITH F123}

Substrate 58, which lacks the secondary hydroxyl necessary for lactonization, was tested with catalytic antibody F123 and showed no activity. This also provided strong evidence that MAb F123 was not simply behaving as an 
esterase by hydrolyzing the p-nitrophenol ester moiety of substrate 57, but rather, acted by carrying out the desired macrolactonization (Figure 19).

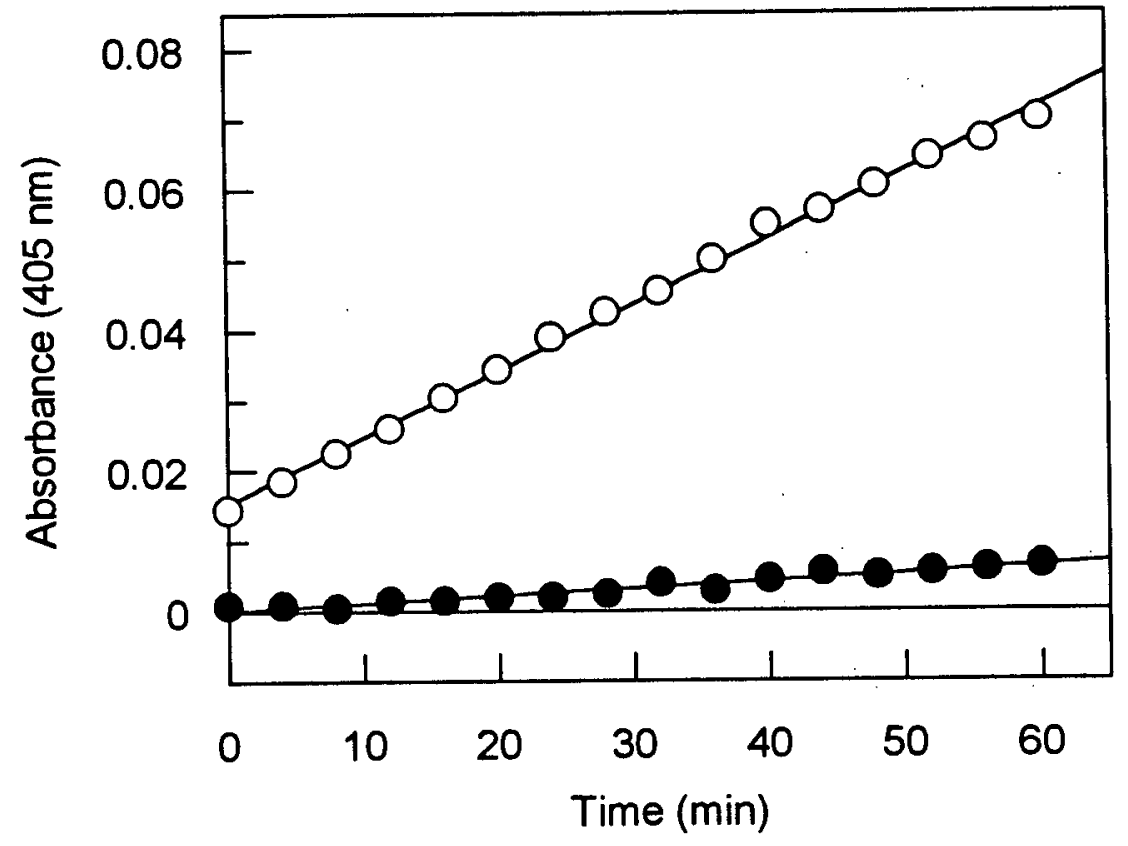

Figure 18. The activity of monoclonal $\mathrm{F} 123(\mathrm{O})$ is compared to that of a control monoclonal antibody, HIL-20 (•), using substrate 57 in both of the experiments. Each experiment was run $200 \mu \mathrm{M}$ in 57 and 2 $\mu \mathrm{M}$ in antibody, carried out in PBS buffer ( $\mathrm{pH} 7.4)$ containing $10 \%$ DMSO and $0.5 \%$ Triton $X-100$.<smiles>CCCCCCCCCCCC(=O)Oc1ccc([N+](=O)[O-])cc1</smiles><smiles>CCCCC[13CH2]CCCCCCCC(=O)Oc1ccc([N+](=O)[O-])cc1</smiles> 


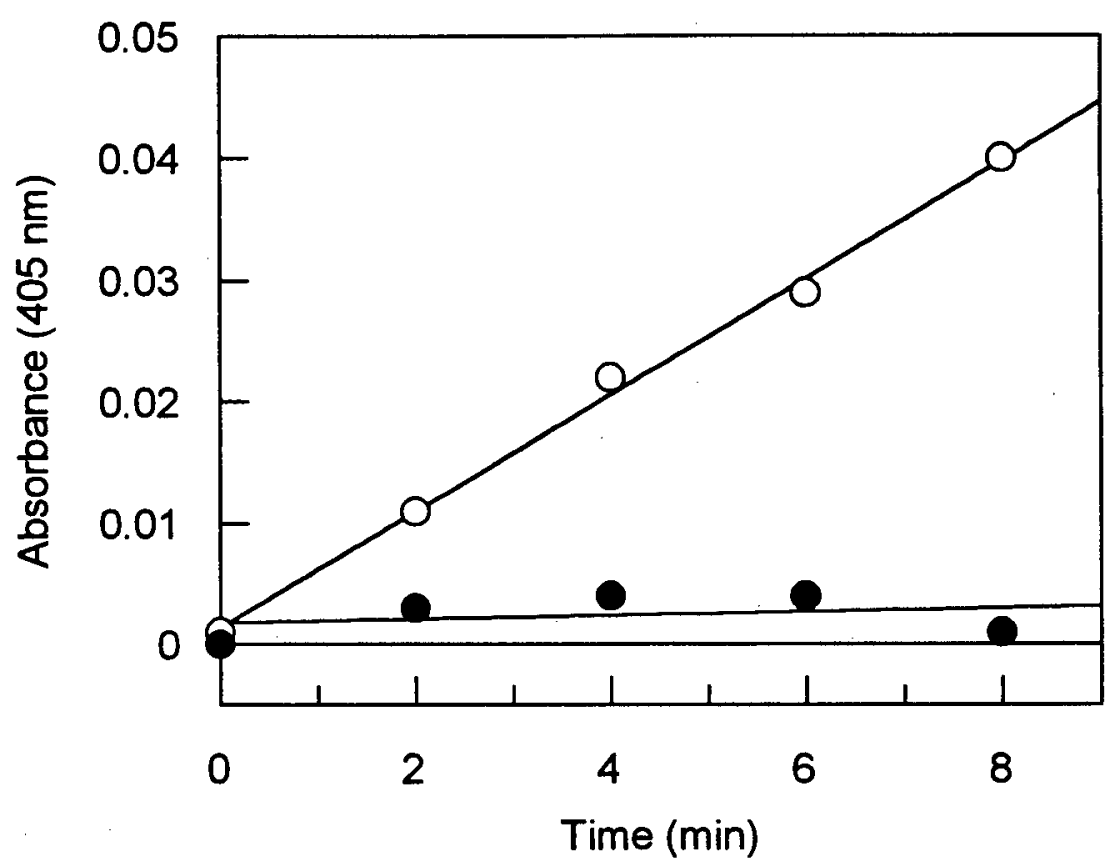

Figure 19. Comparison of antibody F123 activity with hydroxy ester substrate $57(0)$; with ester $58(\bullet)$. In each case, antibody was $0.46 \mu \mathrm{M}$; substrates were $100 \mu \mathrm{M}$; carried out in PBS buffer $(\mathrm{pH} 7.4)$ containing $10 \%$ DMSO and $0.5 \%$ Triton $\mathrm{X}-100$; total reaction volume was $225 \mu \mathrm{L}$.

\subsection{INHIBITION ASSAYS}

The F123 antibody catalyzed reaction of substrate 57 to lactone 19 was analyzed for inhibition by an independently synthesized sample of lactone 19. Lactonization of 57 by $\mathrm{F} 123$ was not inhibited in the presence of one molar equivalent of 19 (relative to substrate 57 ) as shown in Figure 20 below. 


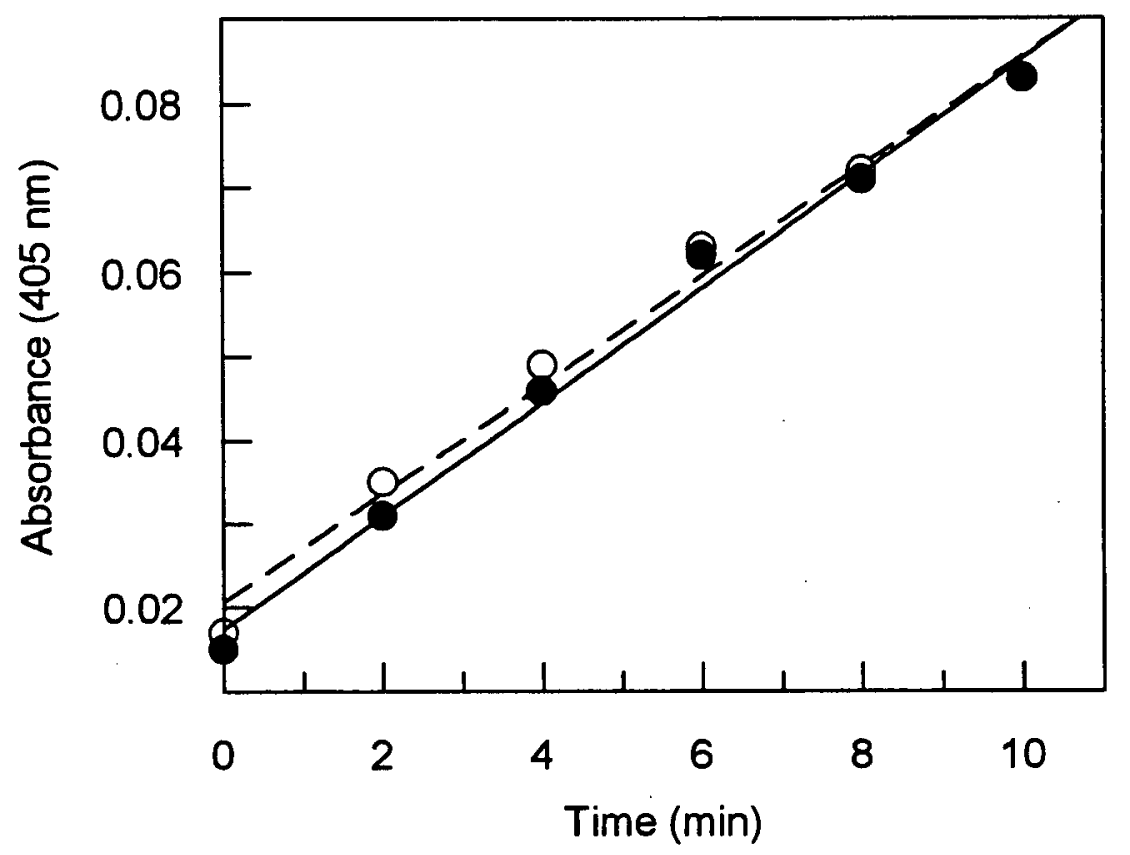

Figure 20. Antibody F123 activity with hydroxy ester substrate $57(0)$; with hydroxy ester substrate $\mathbf{5 7}$ in the presence of an equimolar amount of lactone 19 (•). Experiments were carried out in PBS buffer (pH 7.4) with $10 \%$ DMSO; $0.46 \mu \mathrm{M}$ in antibody $\mathrm{F} 123 ; 200 \mu \mathrm{M}$ in substrate; total reaction volume was $250 \mu \mathrm{L}$.

Continuing from the initial reactivity studies of antibody F123 described in Section 3.8, inhibition assays with a one-to-one mixture of the 4-nitrophenyl phosphonate diastereomers, $60 \mathrm{a}$ and $60 \mathrm{~b}$, were performed in the presence of substrate 57 and MAb F123. As Figure 21 shows, the mixture of $60 a$ and $60 \mathrm{~b}$ competitively inhibited the F123 antibody-catalyzed reaction of 57. Each data point in Figure 21 represents an average of two reaction runs, which agree within $10 \%$. 


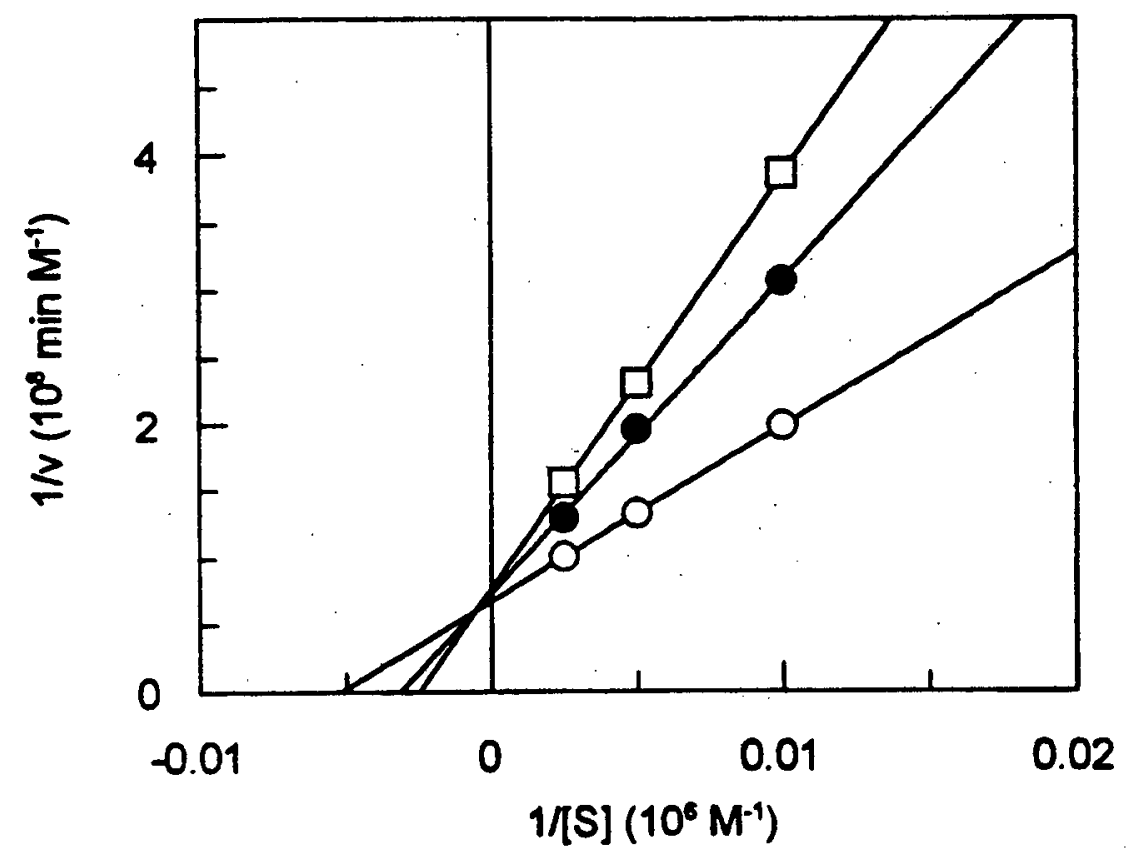

Figure 21. Competitive inhibition of the F123-catalyzed macrolactonization of substrate 57 by a one-to-one mixture of 4-nitrophenyl phosphonate diastereomers, $60 \mathrm{a}$ and $60 \mathrm{~b}$. The reactions were performed in PBS buffer (pH 7.4) containing 10\% DMSO and 0.5\% Triton X-100. The concentrations of the mixture of $60 \mathrm{a}$ and $60 \mathrm{~b}(1: 1)$ were: $(0) 0$ $\mu \mathrm{M} ;(\bullet) 2 \mu \mathrm{M}$; and $(\square) 5 \mu \mathrm{M}$.

By fitting the data from Figure 21 with the inhibitor concentrations to the computer program GraFit' ${ }^{T M}$, a value of $K_{i}=2.9 \pm 0.4 \mu \mathrm{M}$ was determined. Because of the chiral nature of enzymes and antibodies, we believe that this inhibition constant of $2.9 \pm 0.4 \mu \mathrm{M}$ represents an upper limit (where a smaller $\mathrm{K}_{\mathrm{i}}$ value is indicative of a more potent inhibitor), and the true $K_{i}$ is expected to be one-quarter this value since only one of the four stereoisomers in the mixture of $60 \mathrm{a}$ and $60 \mathrm{~b}$ diastereomers is believed to be responsible for the inhibition observed. Further inhibition studies using the four stereoisomers of 60 
separately are necessary to refine this inhibition constant. Nonetheless, the competitive inhibition of F123 with this mixture of 4-nitrophenyl phosphonate diastereomers, $60 \mathrm{a}$ and $60 \mathrm{~b}$, demonstrates that the catalytic activity is associated with binding in the antibody-combining site, as expected.

\subsection{DETERMINATION OF $k_{m}, v_{\max }$ AND $k_{\text {cat }}$ FOR ANTIBODY $F 123$ WITH SUBSTRATE 57}

Approximate values of $K_{m}$ and $V_{\max }$ may be determined for substrates by measuring initial reaction rates using three different (and wide-ranging) concentrations of the substrate. Once approximate values are obtained, accurate values of $K_{m}$ and $V_{\max }$ are then determined by measuring initial reaction rates using 5-8 different concentrations of the substrate, concentrations that typically range between $0.3-5$ times the approximated $K_{m}$ value.

For substrate 57, the experiment to determine approximate $K_{m}$ and $V_{\max }$ values was carried out with concentrations of $40,100,200$, and $400 \mu \mathrm{M}$ of 57 in the reaction buffer consisting of $10 \%$ DMSO and $0.5 \%$ Triton X-100 in PBS buffer, $\mathrm{pH}$ 7.4. The approximate $K_{m}$ was found to be $250 \mu \mathrm{M}$ for substrate 57 . With a solubility limit of $400 \mu \mathrm{M}$ for 57 , and an approximate $K_{m}$ of $250 \mu \mathrm{M}$, this meant that in order to achieve a more accurate value of $K_{m}$, we would need to increase the solubility of $\mathbf{5 7}$ in the reaction buffer in order to bracket the approximate $\mathrm{K}_{\mathrm{m}}$ by 0.3-5 times. This lead to a solubility study of substrate 57 . 


\subsubsection{Determination of the Solubility Limit of Substrate $\mathbf{5 7}$ and the $\mathrm{pH}$ of the Reaction Solution}

In an effort to attain a higher substrate solubility limit, the effect of varying the Triton $\mathrm{X}-100$ concentration in the reaction buffer mixture was investigated. Solubility limits for substrate $\mathbf{5 7}$ in the reaction buffer containing $0 \%, 0.25 \%$, $0.5 \%$ and $1.0 \%$ Triton $X-100$ were determined by examination of solutions under a microscope (10x magnification). As shown in Table 7, the solubility limit of $\mathbf{5 7}$ increases with increasing concentration of Triton $X-100$ in the reaction buffer used in this study. Conversely, it was found that the $\mathrm{pH}$ of the reaction solution decreased on increasing the concentration of Triton X-100.

Table 7. Solubility Study of Substrate $\mathbf{5 7}$ with Triton X-100.

\begin{tabular}{ccc}
\hline Triton X-100 Content (\%) & Solubility Limit of $57(\mu \mathrm{M})$ & $\mathbf{p H}$ \\
\hline 0 & 100 & 7.55 \\
0.25 & 200 & 7.58 \\
0.50 & 400 & 7.35 \\
1.00 & 800 & 6.95 \\
\hline
\end{tabular}

However, it was found that a Triton X-100 content of $1 \%$ or more in the reaction solution not only increased the solubility limit of $\mathbf{5 7}$ and decreased the $\mathrm{pH}$ of the solution, it appeared also to inhibit the antibody activity. To probe this apparent solubility/reactivity problem, catalytic experiments were carried out in the presence of $0 \%, 0.25 \%, 0.5 \%$ and $1 \%$ Triton $X-100$ (with $10 \%$ DMSO, $200 \mu \mathrm{M}$ in 
substrate 57, in PBS buffer, pH 7.4). It was observed that antibody activity appeared to decrease with increasing Triton X-100 content (see Figure 22 below). The $\mathrm{pH}$ of the four test buffers (containing $0 \%, 0.25 \%, 0.5 \%$ and $1.0 \%$

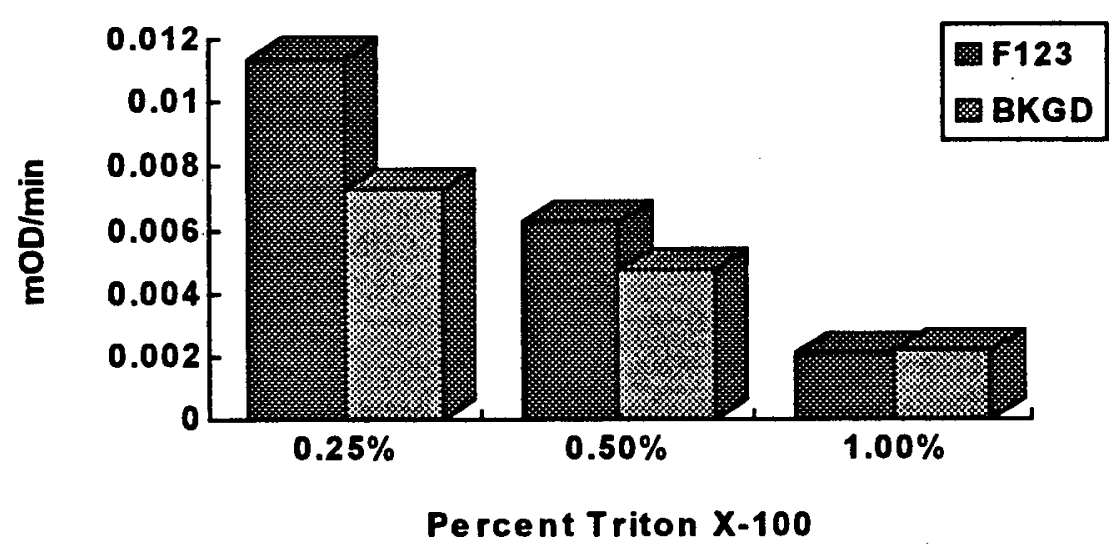

Figure 22. Antibody F123 reaction with substrate 57 compared to the background hydrolysis of $\mathbf{5 7}$ in the reaction buffer alone.

Triton $\mathrm{X}-100$ ) was determined, and found to be $7.55 ; 7.58 ; 7.35$ and 6.95 , respectively (Table 7). At this point, we believed that the apparent loss in antibody activity may be attributed to one of the following two factors, namely the increase in the surfactant concentration, Triton $\mathrm{X}-100$, or the drop in $\mathrm{pH}$ of the reaction buffer as a result of increasing the surfactant concentration. A decrease in $\mathrm{pH}$ of the reaction buffer (on increasing the Triton $\mathrm{X}-100$ concentration) would result in a shift in the equilibrium shown below toward the protonated form, p-nitrophenol, which would explain a decrease in the 
absorbance reading. Alternatively, the antibody may simple lose activity as the $\mathrm{pH}$ is reduced.

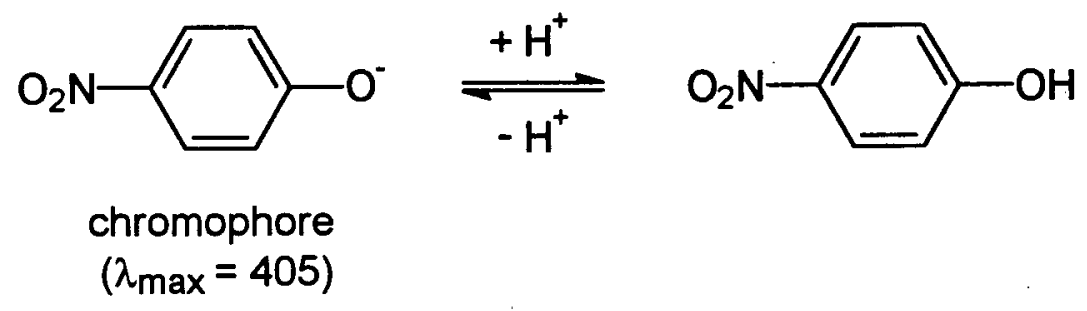

To determine if this $\mathrm{pH}$ depression was the cause of the apparent loss in antibody activity, the buffer strength of the PBS buffer used in the reaction solution was increased from $8 \mathrm{mM}$ sodium phosphate to $500 \mathrm{mM}$ sodium phosphate. The higher buffer capacity was sufficient to suppress the drop in $\mathrm{pH}$, ( $\mathrm{pH}$ was measured and found to be 7.45 for the $500 \mathrm{mM}$ sodium phosphate solution, compared to $\mathrm{pH} 6.95$ for the $8 \mathrm{mM}$ sodium phosphate solution), however, catalysis (as measured by the rate of release of $p$-nitrophenolate anion above background) was not observed (see Figure 23). This finding suggests that the increased concentration of Triton $X-100$ does not affect the position of equilibrium between the p-nitrophenolate anion and the protonated form, but rather, in some way inhibits antibody activity when the concentration of Triton $\mathrm{X}-100$ is $1 \%$ or higher. Further experiments are required to investigate the nature of this effect. Perhaps we have reached or exceeded the critical micelle concentration $(\mathrm{cmc})$ of the surfactant for our buffer system, or perhaps substrate molecules are being partitioned within the micelle wall, and in effect, the Triton 
$\mathrm{X}-100$ is competing with the antibody for substrate binding. If this is the case, the loss of substrate molecules to micelles would make it impossible to know the actual substrate concentration in our reaction mixture. Furthermore, at $1 \%$ Triton $X-100$, perhaps the surfactant binds sufficient substrate such that none is available to the antibody, and we simply observe background hydrolysis, as in the background samples.

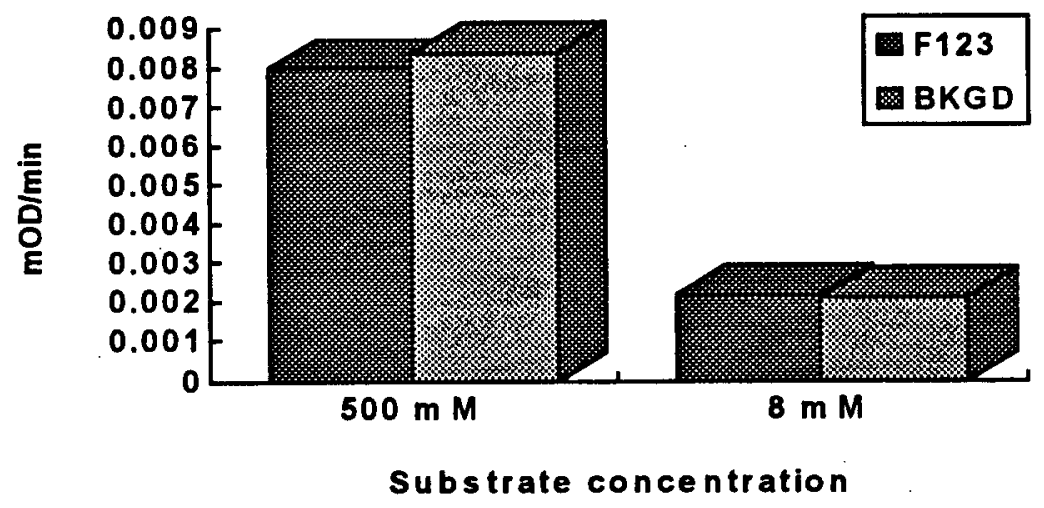

Figure 23. Comparison of the $\mathrm{F} 123$ reaction with substrate 57 and background hydrolysis of $\mathbf{5 7}$ using 10\% DMSO and $1.0 \%$ Triton X-100 in $8 \mathrm{mM}$ PBS buffer (pH 6.95); and F123 and $\mathbf{5 7}$ in a 10\% DMSO with $1.0 \%$ Triton X-100 in $500 \mathrm{mM}$ PBS buffer (pH 7.45).

\subsubsection{Determination of $K_{m}, V_{\max }$ and $k_{c a t}$ for Monoclonal $F 123$ with Substrate 57}

$K_{m}, V_{\max }$ and $K_{\text {cat }}$ determinations were performed on antibody F123 using two independent methods. The first method will be referred to as the 96-well multiwell method, employing a microtiter plate reader (Bio-Tek Instruments) 
equipped with the Delta Soft II computer program. The second method will be referred to as the spectrophotometer cuvette method.

The molar absorptivity $(\varepsilon)$ for the p-nitrophenolate anion in the reaction buffer was determined as follows. Measuring the absorbance $\left(\lambda_{\max }=405 \mathrm{~nm}\right)$ of a 0.1 $\mathrm{mM}$ solution of $\mathrm{p}$-nitrophenolate anion in the reaction buffer and applying Beer's Law, $A=\varepsilon c l$ (where $A$ is the absorbance, $c$ is the solute concentration expressed in moles per liter, and $\mathrm{I}$ is the pathlength in centimeters of the solution being measured), $\varepsilon$ for the p-nitrophenolate anion was found to be $10,830 \mathrm{~L} / \mathrm{mol} \cdot \mathrm{cm}$.

While the pathlength of the $1 \mathrm{~mL}$ quartz cuvettes used with the Unicam UVNIS spectrophotometer, employed in the spectrophotometer cuvette method, is known to be $1 \mathrm{~cm}$, the pathlength of the $250 \mu \mathrm{L}$ volumes of reation buffer in the 96-well microtiter plates employed in the multiwell method had to be determined.

The absorbance of a $0.1 \mathrm{M}$ solution of p-nitrophenolate in the reaction buffer was measured using the Unicam spectrometer $\left(\lambda_{\max }=405 \mathrm{~nm}\right)$ having a pathlength of $1 \mathrm{~cm}$. This result was used to determine the pathlength of the 250 $\mu \mathrm{L}$ reaction volume in the multiwell experiments by measuring the absorbance of a $250 \mu \mathrm{L}$ alliquot of this solution in a microtiter plate, and applying Beer's Law. The pathlength of the $250 \mu \mathrm{L}$ volume of reaction buffer in the microtiter plate was found to be $0.64 \mathrm{~cm}$. 
3.13.2.1 Determination of $K_{m}, V_{\text {max }}$ and $k_{c a t}$ for Monoclonal $F 123$ with 57 via the Multiwell Method

Assays were performed in 96-well microtiter plates, and the reaction buffer consisted of PBS containing 10\% DMSO and $0.5 \%$ Triton X-100 (for substrate solubility), at $\mathrm{pH} 7.4$. Without Triton $\mathrm{X}-100$, the solubility limit of substrate $\mathbf{5 7}$ is $200 \mu \mathrm{M}$, and with $0.5 \%$ Triton $\mathrm{X}-100$, this limit is increased to $400 \mu \mathrm{M}$. Final reaction volumes used were $250 \mu \mathrm{L}$, and the pathlength of the ELISA reader was determined above to be $0.64 \mathrm{~cm}$. Rates were determined by measuring 4-nitrophenolate release at $405 \mathrm{~nm}(\varepsilon=10,830 \mathrm{~L} / \mathrm{mol} \cdot \mathrm{cm})$ and defined as $\mathrm{mOD} / \mathrm{min}$. The antibody concentration used was $0.23 \mu \mathrm{M}$ (based on IgM monomer molecular weight of $175 \mathrm{kDa}$ ). Kinetic parameters were obtained using the method of initial rates and fitted to a Lineweaver-Burk analysis to obtain the Michaelis-Menten parameters $K_{m}, V_{\max }$ and $k_{\text {cat }}$ for substrate 57 (Figure 24). It should be noted that prior to reading the microtiter plates by the ELISA reader, mixing of the reaction buffer with a micro-pipette, until homogenous, caused the formation of bubbles at the liquid surface of the reaction solutions. Since the ELISA reader measures absorbance down through the top of each well, plate reading was delayed (approximately 10 minutes) until the bubbles had collapsed, after which time, the initial rates were measured. Since the antibody rate is expected to decrease with time, one might expect the actual initial rates would be greater if the reactions were monitored immediately after mixing, without a 10 minute delay time. 


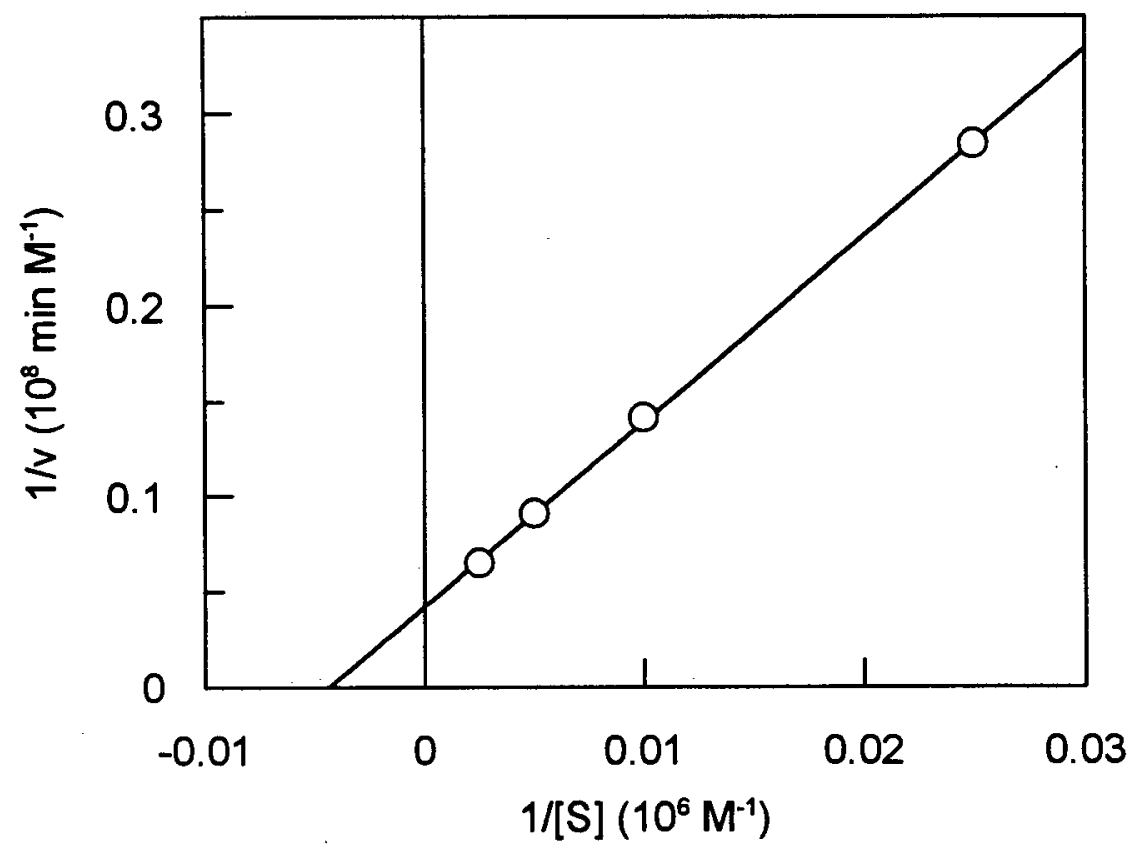

Figure 24. A Lineweaver-Burk analysis of the F123-catalyzed macrolactonization of hydroxy ester substrate 57 using the multiwell method.

At an antibody concentration of $0.23 \mu \mathrm{M}$, the multiwell method yielded a $\mathrm{V}_{\max }$ of $0.62 \pm 0.01 \mu \mathrm{mol} / \mathrm{min} \mathrm{mg}$ and $\mathrm{a} \mathrm{K}_{\mathrm{m}}$ of $250 \pm 10 \mu \mathrm{M}$. The $\mathrm{K}_{\text {cat }}$ for this experiment was calculated to be $1.1 \mathrm{~min}^{-1}$.

\subsubsection{Determination of $K_{m}, V_{\max }$ and $k_{c a t}$ for Monoclonal F123 with 57 via the Spectrophotometer Cuvette Method}

Analyses for $K_{m}, V_{\max }$ and $k_{\text {cat }}$ determinations were also performed using a Unicam UVNIS spectrophotometer in $1 \mathrm{~mL}$ quartz cuvettes with $1 \mathrm{~cm}$ pathlength (600 $\mu \mathrm{L}$ reaction volume) to compare techniques. Rates were determined by measuring 4-nitrophenolate release at $400 \mathrm{~nm}(\varepsilon=10,730 \mathrm{~L} / \mathrm{mol} \cdot \mathrm{cm})$, and the 
same reaction buffer as in the multiwell method was used in these measurements. Kinetic parameters were obtained using the method of initial rates and fitted to a Lineweaver-Burk analysis to obtain the Michaelis-Menten parameters $K_{m}, V_{\max }$ and $k_{c a t}$ for substrate 57 (Figure 25). The antibody concentration used was $0.25 \mu \mathrm{M}$ (based on IgM monomer molecular weight of $175 \mathrm{kDa}$ ). With this approach, unlike the multiwell method, the absorption can be read immediately after mixing, to obtain more accurate initial rates. Once all reagents and buffers were added to the cuvettes, they were covered with Parafilm, and inverted several times to ensure thorough mixing, then inserted into the spectrophotometer. A delay time of 1.5 minutes was programed into the spectrophotometer prior to reading the cuvettes to obtain the initial rates. This delay time of 1.5 minutes was to ensure equilibration of the reaction solution temperature to that of the spectrophotometer, $37{ }^{\circ} \mathrm{C}$, prior to reading the absorbances. The time required for mixing, together with the 1.5 minute delay, meant that the total delay time prior to recording the initial rates with this approach was approximately 2 minutes, compared to the 10 minute delay time for the multiwell method.

The Unicam UVNIS spectrometer experiments gave a $V_{\max }$ of $1.4 \pm 0.1$ $\mu \mathrm{mol} / \mathrm{min} \mathrm{mg}$ and $\mathrm{a} \mathrm{K}_{\mathrm{m}}$ of $330 \pm 50 \mu \mathrm{M}$ from Figure 25 . Since the antibody concentration was $0.25 \mu \mathrm{M}$ for this experiment, the $k_{\text {cat }}$ was calculated to be 2.2 $\mathrm{min}^{-1}$ by this approach. The $\mathrm{K}_{\mathrm{m}}$ value obtained by this approach is in agreement 
with that of the multiwell method, within experimental error. Of the two methods used,

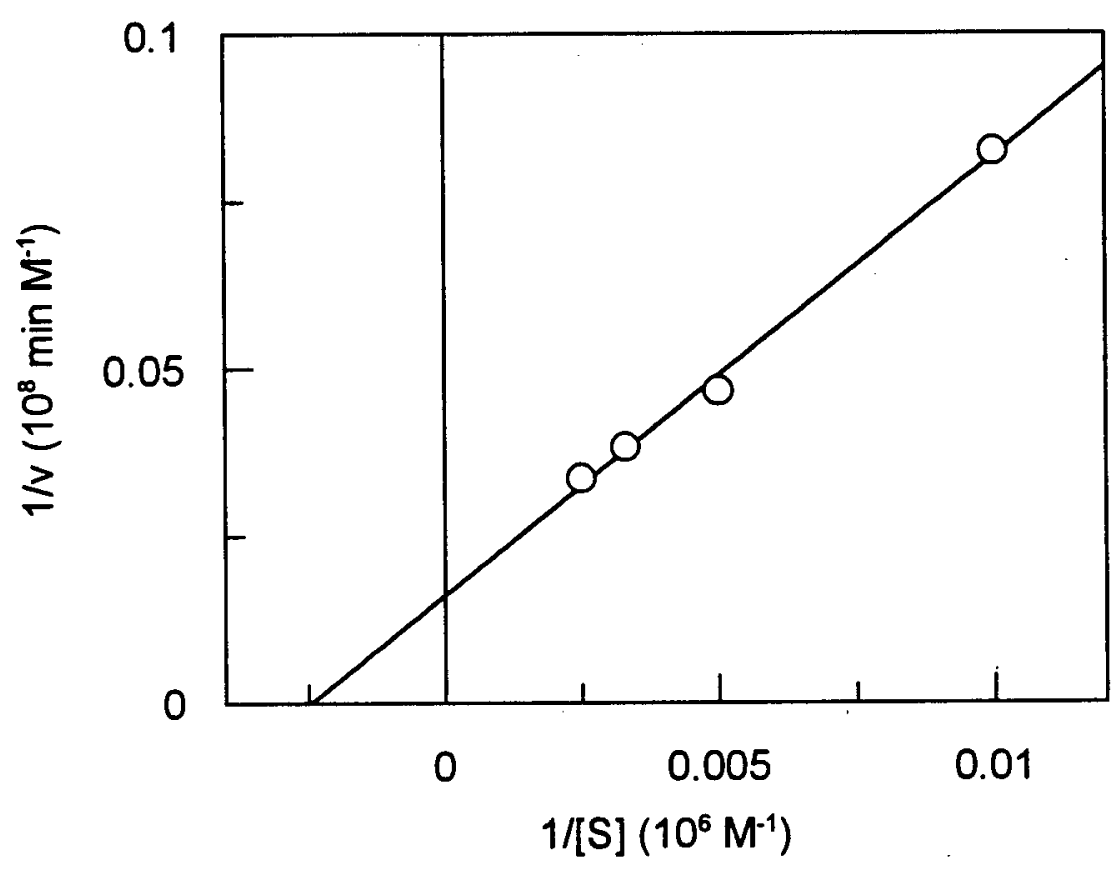

Figure 25. A Lineweaver-Burk analysis of the F123-catalyzed macrolactonization of hydroxy ester substrate 57 using the spectrophotometer cuvette method.

however, the correlation proved better with the multiwell method. The $k_{\text {cat }}$ values differ, however, by a factor of two. As we anticipated, the difference in delay times for the two approaches resulted in a difference in $k_{\text {cat }}$ values. This can be accounted for by taking into consideration the delay time required, in the multiwell method, prior to beginning reading the multiwell experiments. At 10 minutes, it is expected that the rates would have diminished somewhat from the true initial rates. It is reasonable to assume, therefore, that this delay in the measurement of initial rates for the multiwell experiments would result in a lower 
$V_{\max }$ and ultimately a lower $k_{\text {cat }}$ for the multiwell method. The $K_{m}$ values are, however, in good experimental agreement, as one would expect, since $K_{m}$ determination is relatively insensitive to this time delay problem.

Finally, the catalytic efficiency, or $K_{c a t} / K_{m}$, of antibody $F 123$ is compared below in Table 8 with that of the antibody reported by Napper, et al. ${ }^{59}$ which catalyzes the cyclization of a six-membered ring lactone (as described in Section 2.12.2).

Table 8. A comparison of the catalytic efficiency $\left(\mathrm{K}_{\text {cat }} / \mathrm{K}_{\mathrm{m}}\right)$ of antibody $\mathrm{F} 123$ with that of the antibody reported by Napper, et al. ${ }^{59}$

\begin{tabular}{cccc}
\hline Ring Size & $\mathbf{K}_{\text {cat }}\left(\mathbf{s}^{-1}\right)$ & $\mathbf{K}_{\mathrm{m}}(\mathbf{M})$ & $\mathbf{k}_{\text {cat }} / \mathbf{K}_{\mathbf{m}}\left(\mathbf{M}^{-1} \mathbf{s}^{-1}\right)$ \\
\hline $14^{\mathrm{a}}$ & 0.018 & $2.50 \times 10^{-4}$ & 72 \\
$14^{\mathrm{b}}$ & 0.037 & $3.30 \times 10^{-4}$ & 112 \\
$6^{\mathrm{c}}$ & 0.008 & $7.6 \times 10^{-5}$ & 105
\end{tabular}

${ }^{3}$ Data obtained by the multiwell method. ${ }^{b}$ Data obtained by the spectrophotometer cuvette method. "Data obtained from ref 59.

As shown in Table 8 , the antibody-catalyzed reaction for the formation of the six-membered ring lactone, 9 , has a lower $k_{\text {cat }}$ value compared to the two values of $k_{\text {cat }}$ for the antibody-catalyzed reaction leading to formation of the 14-membered ring lactone, 19. However, the lower $K_{m}$ value in the six-membered ring data set of $7.6 \times 10^{-5} \mathrm{M}$ compared with those of the 14-membered ring data sets results in comparable values for the catalytic efficiencies for these two antibodies. $k_{c a t} / K_{m}$ values for other catalytic antibodies reported in the literature ${ }^{159}$ range from $3.6 \times 10^{-4} \mathrm{M}^{-1} \mathrm{~s}^{-1}$ for a decarboxylating 
catalytic antibody to as high as $5.5 \times 10^{3} \mathrm{M}^{-1} \mathrm{~s}^{-1}$ for an antibody that catalyzes a proton transfer.

\subsection{SUMMARY AND CONCLUSIONS}

The macrocyclic phosphonate, 38, was synthesized in nine steps with a modest overall yield of $17 \%$. However, since only $20 \mathrm{mg}$ of 38 was required for this project, obtaining the target was of greater importance than the optimization of its yield, which can be accomplished at a later date. The key step in the synthesis of $\mathbf{3 8}$ was the use of the Mitsunobu reaction in the challenging ring-closing step, which proceeded in an $82 \%$ yield giving a $5: 1$ ratio of the two possible diastereomers.

The successful coupling of the macrocyclic transition state analogue 38 to the carrier protein $\mathrm{KLH}$, and subsequent production of monoclonal antibodies against the transition state analogue was evident by the positive results obtained in binding assays. Eight monoclonal antibodies showed binding above background to the BSA-transition state analogue conjugate in the PCFIA binding assay.

Ascites fluid was produced in Balb/c mice from the hybridomas of the three strongest binders, then affinity purified using a SAM column in preparation for 
catalytic testing. Of these three monoclonals, only F123 showed significant catalytic activity with substrate $\mathbf{5 7}$ as measured by release of the p-nitrophenolate anion.

Isotyping of the hybridoma supernatant revealed monoclonal F123 to be an IgM antibody. It is not clear why F123 is of the IgM class, however, this may suggest that the immuno-conjugate $\mathrm{KLH}-50$ was stable in the mouse long enough to elicit a primary immune response, but not long enough to allow for class switching to occur.

Pooled catalytic experiments revealed that F123 was catalyzing the production of the macrocyclic lactone 19. Ether extracts of the pooled reaction solutions were compared with that of an independently synthesized sample of authentic lactone by GC/MS analysis. Conversely, a large scale background experiment with 57 carried out at $37{ }^{\circ} \mathrm{C}$ for five days, followed by extraction with ether and GCMS analysis of the ether extracts revealed no detectable lactone.

Comparison of the reaction of F123 with substrate $\mathbf{5 7}$ run in parallel with an affinity purified monoclonal antibody raised against an unrelated antigen with $\mathbf{5 7}$ confirmed, that the release of p-nitrophenolate anion was not the result of an esterase contaminant; that the release of p-nitrophenolate anion occurred only with F123; and that F123 functions as a specific catalyst. Further evidence of 
the specific activity of F123 was established by the lack of activity of F123 with p-nitrophenyl tetradecanoate (59).

The reactivity of F123 with substrate 57 in the presence of one equivalent of lactone product 19 showed no product inhibition.

Hapten derivative 60 (in a one-to-one ratio of both diastereomers) proved to be a potent competitive inhibitor of the F123 catalysis with 57 (where the inhibition constant, $K_{i}$, for 60 was found to be $2.9 \pm 0.4 \mu \mathrm{M}$ ), demonstrating that the catalytic activity is associated with binding in the antibody-combining site.

The results of the solubility study of substrate $\mathbf{5 7}$ in the reaction buffer revealed that the maximum concentration of 57 in this buffer system to be $400 \mu \mathrm{M}$. An attempt was made to increase the concentration of 57 by increasing the concentration of the Triton $X-100$. However, it appeared that an increase in Triton X-100 concentration resulted in inhibition of the antibody activity. Hence, $400 \mu \mathrm{M} 57$ was accepted as the upper solubility limit for this study.

Antibody F123 displayed saturation kinetics, and the Michaelis-Menten kinetic parameters of $K_{m}, V_{\max }$ and $k_{c a t}$ for $F 123$ with substrate 57 were obtained using the method of initial rates and fitted to Lineweaver-Burk analyses using two independent methods. The multiwell method yielded a $K_{m}$ of $250 \pm 10 \mu \mathrm{M}, V_{\max }$ 
of $0.62 \pm 0.01 \mu \mathrm{mol} / \mathrm{min} \mathrm{mg}$ and $k_{\text {cat }}=1.1 \mathrm{~min}^{-1}$, while the spectrophotometer cuvette method yielded a $K_{m}$ of $330 \pm 50 \mu \mathrm{M}, V_{\max }$ of $1.4 \pm 0.1 \mu \mathrm{mol} / \mathrm{min} \mathrm{mg}$ and $k_{\text {cat }}=2.2 \mathrm{~min}^{-1}$. These two methods were found to be in good agreement with each other once we accounted for the time delay inherent in the multiwell method when determining initial rates.

In conclusion, while this work opens the door to the antibody-catalyzed formation of macrocyclic lactones, F123 is not yet viewed as a practical catalyst for preparative scale prodution of macrocyclic lactone 19. Much work remains in the full characterization of the activity of antibody F123 as a catalyst for this application.

In general, the chemical approaches towards the syntheses of macrocyclic lactones remain superior in terms of yields, however, biocatalytic methods offer promise as a result of the asymmetric control they often provide, an important factor to synthetic chemists.

\subsection{SUGGESTIONS FOR FUTURE WORK}

The work described in this thesis is the first step towards the characterization of a monoclonal antibody raised against a macrocyclic phosphonate, capable of catalyzing the formation of a 14-membered ring lactone. 
Future directions for this project potentially include:

1) Investigations into the use of organic solvents to raise the solubility limit of substrate 57.

2) Testing antibody F123 for stereospecific cyclization, as demonstrated in the work by Napper, et al. involving the stereospecific cyclization of a six-membered ring lactone by a catalytic antibody, by reacting F123 with enantiomerically pure isomers of substrate 57 , namely 69 and 70 .

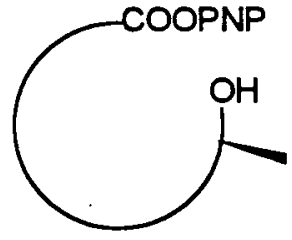

69

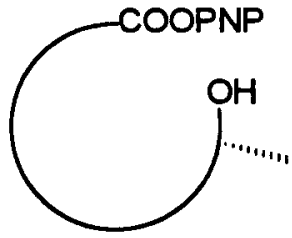

70

3) Varying the structure of the substrate molecule to further the study of the specificity of F123. Some suggestions for substrate modifications include compounds 71,72 and 73 . Compounds 71,57 and 72 would allow a comparison between the rates of lactonization involving a primary, secondary and a tertiary hydroxyl group. Compound $\mathbf{7 3}$ would probe the effect of a double bond, placed at various positions along the open chain molecule, on the rate of lactonization. 
Finally, the rates of lactonization for different ring sizes can be probed by varying the chain lengths of the substrate molecules.

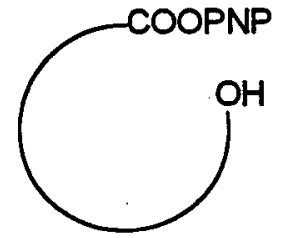

71

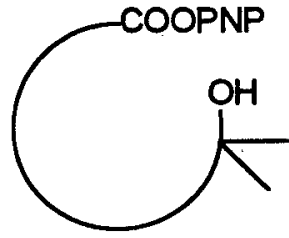

72

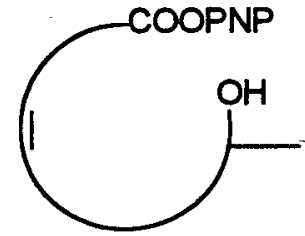

73

4) Production of a more efficient catalyst might be possible by modifying the existing hapten molecule. Two new hapten designs are suggested below, each of which offers qualities not possessed by the hapten used in this study, namely 50. Perhaps a hapten molecule such as $\mathbf{7 4}$ with a 14-membered ring PNP phosphonate and a linker arm extending from a remote junction, rather than

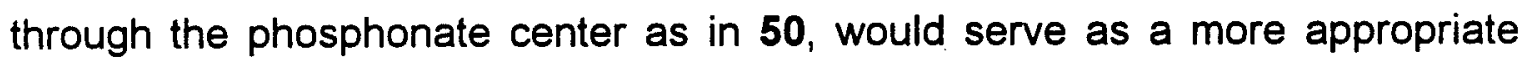
transition state analogue for eliciting catalytic antibodies to carry out macrolactonization reactions for two reasons. First, the PNP phosphonate moiety incorporates a nitroaryl ring, believed to be desirable for induction of a strong immune response. ${ }^{160}$ Secondly, linking the carrier protein through a more remote position from the phosphonate center should allow greater exposure of the phosphonate center as the key antibody epitope. The second proposed hapten design, 75, may not resemble the presumed transition state for the reaction as well as 50 or $\mathbf{7 4}$, however, it may provide more stability than the 
other potential haptens. This increased stability may lead to the production of a higher affinity $\lg G$ class antibody, rather than the IgM class obtained.
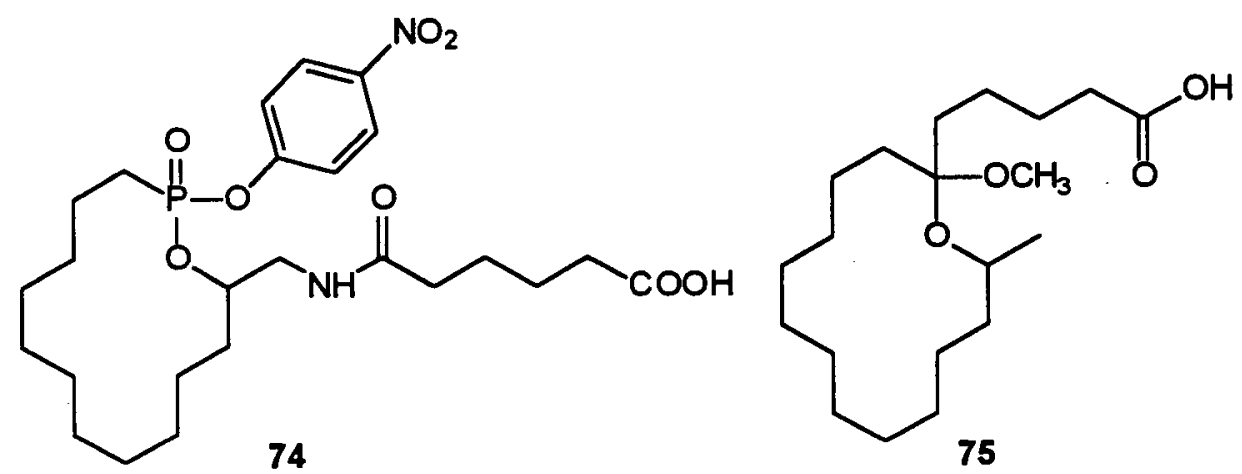

5) Enzymatic cleavage of the antibody molecule with pepsin, and isolation of the resulting Fab fragments by affinity chromatography followed by a kinetic analysis of the Fab portion, which contains the antibody combining site, for the lactonization reaction to obtain the Michaelis-Menten constants, and compare them to those of the native antibody.

6) The Fab fragment might allow NMR and MS studies of the antibody-substrate, and antibody-hapten complexes.

7) Crystallization of the Fab-hapten complex may be possible, and would allow sequencing of the antibody combining site. Knowing the amino acid sequence of the combining site would open the door to mutagenesis experiments for the purpose of probing the catalytic mechanism of the reaction. 


\section{CHAPTER IV EXPERIMENTAL}

\subsection{BIOLOGICAL METHODS}

Deionized water was used in the preparation of all buffers.

Phosphate buffered saline (PBS), available as a 10x solution, was diluted to give the $1 \times$ PBS $\left(8.2 \mathrm{mM} \mathrm{NaHPO}_{4}, 137 \mathrm{mM} \mathrm{NaCl}, 2.7 \mathrm{mM} \mathrm{KCl}, 1.5 \mathrm{mM} \mathrm{H}_{2} \mathrm{PO}_{4}, \mathrm{pH}\right.$ 7.4).

\subsubsection{Monoclonal Antibody Purification}

Monoclonal antibodies were purified from ascites fluid first by, filter-sterilization through a $0.22 \mu \mathrm{m}$ filter, followed by immunoaffinity purification using a sheep-antimouse (SAM) affinity column.

The ascites fluid was diluted in half using $1 \times$ PBS before $0.80 \mu \mathrm{m}$ filtration, followed by $0.45 \mu \mathrm{m}$, and finally $0.22 \mu \mathrm{m}$ filtration. The ascites were then loaded onto a SAM affinity column and washed with four bed volumes of $1 \times$ PBS. Antibodies were eluted from the SAM column with five bed-volumes of $0.1 \mathrm{M}$ glycine $(\mathrm{pH} \mathrm{2.5)}$ and collected in $1.5 \mathrm{~mL}$ centrifuge tubes. Eluates were neutralized by the addition of $50 \mu \mathrm{L}$ of saturated Tris buffer to each tube containing purified antibody. The antibody samples were dialyzed against $1 \mathrm{X}$ 
PBS buffer, $\mathrm{pH} 7.4$, and the concentration was determined by measuring the absorbance at $280 \mathrm{~nm}$ (where the OD reading/1.4 gives the concentration in $\mathrm{mg} / \mathrm{mL}$ ) prior to kinetic assays.

\subsubsection{Preparation of Immuno- and Binding-conjugates of $\mathbf{5 0}$}

Keyhole limpet hemocyanin (KLH) and bovine serum albumin (BSA) were supplied by the Sigma Chemical Co.

\subsubsection{KLH-50 Hapten Conjugate}

To a solution of $\mathrm{KLH}(15 \mathrm{mg})$ and $50(10.0 \mathrm{mg}, 28.8 \mu \mathrm{mol})$ in $0.5 \mathrm{~mL}$ of $0.1 \mathrm{M}$ MES buffer, $\mathrm{pH} 4.5$, and $4.5 \mathrm{~mL}$ of water was added 1-(3-(dimethylamino)propyl)-3-ethylcarbodiimide hydrochloride (EDC) $(25.0 \mathrm{mg}$, $0.131 \mathrm{mmol})$. The mixture was stirred at room temperature overnight. The coupled KLH-50 conjugate was then dialyzed against PBS buffer, $\mathrm{pH} 7.4$.

\subsubsection{BSA-49 Hapten Conjugate-Coated Carboxyl Polystyrene Particles}

Into a $30 \mathrm{~mL}$ siliconized Corex glass centifuge tube hapten $50(1.0 \mathrm{mg}, 2.9 \mu \mathrm{mol})$

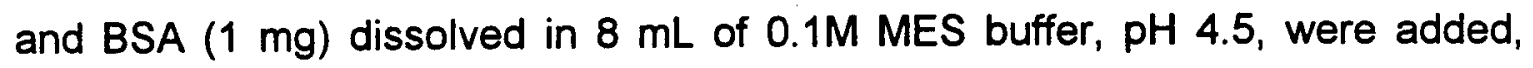
followed by $1 \mathrm{~mL}$ of a $5 \%(w / v)$ Fluoricon carboxyl polystyrene assay particle suspension and EDC $(5.0 \mathrm{mg}, 26 \mu \mathrm{mol})$. The mixture was incubated at room 
temperature for 24 hours. The BSA-50 crosslinked particles were then centrifuged (6000 rpm, $22^{\circ} \mathrm{C}, 20 \mathrm{~min}$, Sorval HB4 rotor) and the resulting pellet washed $2 x$ in $20 \mathrm{~mL}$ of PCFIA buffer, pH 7.4 (1x PBS pH 7.4, 2\% FCS and $0.2 \%$ $\mathrm{NaN}_{3}$ ). Finally, the particles were resuspended in a $40 \mathrm{~mL}$ volume of PCFIA buffer, $\mathrm{pH} 7.4$, to produce a final concentration of $0.125 \%(\mathrm{w} / \mathrm{v})$ particles and 25 $\mu \mathrm{g} / \mathrm{mL}$ protein.

\subsubsection{Kinetic Assays}

\subsubsection{Multiwell Method}

The catalytic reactions were performed in 96 well microtiter plates, and monitored in a microtiter plate reader (Bio-Tek Instruments) equipped with the Delta Soft II computer program. All reactions were performed in duplicates.

Typical reactions were $250 \mu \mathrm{L}$ in total volume, and all contained final concentrations (v/v) of $10 \%$ DMSO, $0.5 \%$ Triton X-100 and $89.5 \% 1 \times$ PBS buffer, $\mathrm{pH}$ 7.4. Catalyzed reactions were performed at $37^{\circ} \mathrm{C}$ in the presence of $0.23 \mu \mathrm{M}$ monoclonal antibody (based on IgM monomer molecular weight of $175 \mathrm{kDa}$ ) and were initiated by the addition of various amounts $(50-400 \mu \mathrm{M})$ of substrate from a DMSO stock solution. After addition of reagents, substrate, and antibody to the wells of the microtiter plate, a multichannel micropipette was used to mix contents until homogeneous. This mixing created bubbles at the surface of the reaction wells due to the Triton $X-100$, and a 10 minute delay was required for all 
bubbles to collapse prior to reading the plates to obtain initial rate data. The rates were determined by measuring the initial change in absorbance, due to 4-nitrophenolate release, at $405 \mathrm{~nm}(\varepsilon=10,830 \mathrm{~L} / \mathrm{mol} \cdot \mathrm{cm})$. The background hydrolysis rate of the substrate (in the absence of antibody) was also measured each time.

For antibody $\mathrm{F} 123$, the antibody-catalyzed reaction rates with four different substrate concentrations from 50 to $400 \mu \mathrm{M}$ were measured in the presence of $0.23 \mu \mathrm{M}$ of the antibody concentration. The Michaelis-Menten parameters were determined by standard methods.

\subsubsection{Spectrophotometer Cuvette Method}

Analysis for $V_{\max }$ and $K_{m}$ determinations were also performed using a Unicam UVNIS spectrophotometer in $1 \mathrm{~mL}$ quartz cuvettes with $1 \mathrm{~cm}$ pathlength to compare this technique with the multiwell method.

Typical reactions were $600 \mu \mathrm{L}$ in total volume, and all contained final concentrations $(v / v)$ of $10 \%$ DMSO, $0.5 \%$ Triton X-100 and $89.5 \% 1 \times$ PBS buffer, $\mathrm{pH}$ 7.4. Catalyzed reactions were performed at $37^{\circ} \mathrm{C}$ in the presence of $0.25 \mu \mathrm{M}$ monoclonal antibody (based on IgM monomer molecular weight of $175 \mathrm{kDa}$ ) and were initiated by the addition of various amounts $(50-400 \mu \mathrm{M})$ of substrate from a DMSO stock solution. The top of the cuvette was covered with Parafilm and the cell shaken several times prior to placement in the cell holder, and observation 
at the desired wavelength was obtained after a one-minute delay time. The rates were determined by measuring the initial change in absorbance, due to 4-nitrophenolate release, at $400 \mathrm{~nm}(\varepsilon=10,730 \mathrm{~L} / \mathrm{mol} \cdot \mathrm{cm})$. The background hydrolysis rate of the substrate (in the absence of antibody) was also measured each time. The Michaelis-Menten parameters were determined by standard methods.

\subsubsection{General Immunological Techniques.}

\subsubsection{Immunizations.}

Balb/c mice ( 6-8 week old females) were immunized with the KLH conjugate of hapten $50(\mathrm{KLH}-50)$ according to the following schedule: day $1,100 \mu \mathrm{g}$ of KLH-50 emulsified in complete Freund's adjuvant, subcutaneous injection; days 19, 50 and 117, administered booster immunizations of $50 \mu \mathrm{g}$ of KLH-50 emulsified in incomplete Freund's adjuvant, subcutaneous injection; day 127 the mice received an intraperotoneal booster immunization of $15 \mu \mathrm{g}$ of KLH-50 in saline $(100 \mu \mathrm{L})$. Four days after this last booster injection, the mice were sacrificed and the spleens harvested.

\subsubsection{Test Bleeds.}

The mouse was first warmed to dilate its blood vessels by shining a heat lamp directly into the open cage (from a distance of approximately 18 inches) until the 
tail veins became visible (usually between $5-10$ minutes). The mouse was removed and placed in a mouse restraint. The tail was wiped with $70 \%$ ethanol to enhance vasodilation of the tail veins. One of the tail veins was then pierced with a 26-gauge needle. Blood from the puncture hole was collected with a sterile heparinized capillary tube, and transferred to a microcentrifuge tube. The microcentrifuge tube was placed in a $37^{\circ} \mathrm{C}$ water bath until the blood clotted (approximately 20 minutes). The blood was then centrifuged at $600 \mathrm{~g}$ to pellet the clotted cells and separate the serum. The serum was then drawn off and transferred to a new tube and stored at $-20^{\circ} \mathrm{C}$ until needed.

\subsubsection{Polyethylene Glycol (PEG) Fusion}

The procedures described here are derived from a protocol prepared by Ms. Helen Merkens in Prof. Hermann Ziltener's lab at The Biomedical Research Centre entitled Fusion Protocol for Mouse Spleen Cell Hybrids for Monoclonal Antibody Production.

Table 9. Media and components used in hybridoma production.

Media

DMEM

HT Medium
Components

$1 \mathrm{M}$ Hepes buffer

$0.37 \% \mathrm{HCO}_{3}{ }^{-}$

$2 \mathrm{mM}$ L-Glutamine

1x10-4 M hypoxanthine

$1.6 \times 10^{-5} \mathrm{M}$ thymidine 


$\begin{array}{ll}\text { HAT Medium } & \begin{array}{l}1 \times 10^{-4} \mathrm{M} \text { hypoxanthine } \\ 4 \times 10^{-7} \mathrm{M} \text { aminopterine } \\ 1.6 \times 10^{-5} \mathrm{M} \text { thymidine } \\ 1 \mathrm{M} \mathrm{NaOH}\end{array} \\ & 0.17 \mathrm{M} \mathrm{NH}_{4} \mathrm{Cl} \\ & 0.017 \mathrm{M} \mathrm{Tris}-\mathrm{HCl}, \mathrm{pH} 7.2-7.4 \\ \text { Lysing Solution } & \\ & \\ \text { Fusion Medium } & 20 \% \mathrm{FBS} \\ & 5 \times 10^{-4} \mathrm{M} 2 \beta \text {-mercaptoethanol } \\ & 2 \% 10 \times 3 \mathrm{~T} 3 \text { conditioned medium } \\ & 2 \mathrm{mM} 1-\text { glutamine } \\ & 90 \% \mathrm{FCS} \\ \text { Freeze Medium } & 10 \% \mathrm{DMSO} \\ & 2 \% \mathrm{FCS} \\ \text { PCFIA Buffer } & 0.2 \% \text { sodium azide } \\ & 1 \times \mathrm{PBS}\end{array}$

\subsubsection{Cell Counting}

To a $10 \mu \mathrm{L}$ aliquot of a thoroughly suspended cell sample in a microfusion tube is added $10 \mu \mathrm{L}$ of a $0.2 \%(w / v)$ solution of trypan blue, a cell staining dye, in aqueous $580 \mathrm{mM} \mathrm{NaCl}$ solution and the resulting suspension thoroughly mixed. A $10 \mu \mathrm{L}$ volume of the cell suspension is slowly pipetted into the sample groove of a clean hemacytometer. The hemacytometer is placed on a inverted phase microscope and the cells in the four counting grids are counted, divided by four, and multiplied by $1 \times 10^{4}$. This number is then multiplied by two to account for the trypan blue dilution to afford the number of cells $/ \mathrm{mL}$. 


\subsubsection{Myelomas}

As the myeloma fusion partner, we used P3-X63-Ag8-653 (clone 653). The cells must be in the log phase $\left(2 \times 10^{5}\right.$ viable cells $\left./ \mathrm{mL}\right)$ at the time of fusion.

Day 1. The clone 653 is expanded into $4 \times 30 \mathrm{~mL}$ of DMEM-20\% heat inactivated FCS at approximately $10^{3}$ cells $/ \mathrm{mL}$.

Day 4. The cells are counted and each dish is split into four new dishes and brought up to a volume of $30 \mathrm{~mL}$ each with DMEM-20\% heat inactivated FCS at approximately $10^{5}$ cells $/ \mathrm{mL}$.

Day 5. The cell count is approximately $2 \times 10^{5}$ live cells per $\mathrm{mL}$, and $2 \times 10^{7}$ live cells with a $99 \%$ viability are required per fusion.

\subsubsection{PEG Solution for Cell Fusion}

A $50 \%$ (w/w) solution of polyethylene glycol (Merck PEG 4000) was prepared by autoclaving $10 \mathrm{gram}$ of polyethylene glycol at $121^{\circ} \mathrm{C}$ for 10 minutes. The liquid was cooled to about $56^{\circ} \mathrm{C}$ and $10 \mathrm{~mL}$ of warm DMEM was added. Finally, the mixture was neutralized with $7.5 \% \mathrm{HCO}_{3}{ }^{-}$and stored at room temperature. 


\subsubsection{Harvesting Spleenocytes}

All dissecting instruments are sterilized in $70 \%$ ethanol prior to use.

The mouse was anesthetized with carbon dioxide and killed by cervical dislocation, then wetted with $70 \%$ ethanol. A small incision was made through the skin of the abdomen. The skin was then stretched and torn to expose the peritoneal cavity along the left side of the mouse. An incision was made through the muscle of the peritoneal wall and the spleen carefully removed. Tweezers were used to extract the spleen and gently remove any connective tissue. The spleen was quickly transferred into a $10 \mathrm{~mL}$ sterile tube containing medium.

A spleen cell suspension was prepared by gently mashing the spleen through a fine mesh screen using the rubber end of a $10 \mathrm{cc}$ syringe plunger into a Petri dish containing $2 \%$ FCS-Hanks ${ }^{\star}$ solution, $\mathrm{pH} 7.4$. The cell suspension was then transferred into a $10 \mathrm{~mL}$ centrifuge tube, and the cells centrifuged at $300 \mathrm{~g}$ for 5 minutes. The supernatant was aspirated off and the cell pellet is resuspended in $5 \mathrm{~mL}$ of red blood cell lysing solution at $37^{\circ} \mathrm{C}$ for 7 minutes. The lysing buffer was neutralized by adding $5 \mathrm{~mL}$ of $2 \%$ FCS-Hanks solution and the cell suspension then centrifuged at $300 \mathrm{~g}$ for 5 minutes. The cell pellet was resuspended in $10 \mathrm{~mL}$ of $2 \%$ FCS-Hanks solution and a 1 in 20 dilution was made from which the number of viable cells was counted. This procedure results

* See ref 161 for a list of components contained in Hanks buffer. 
in $>1 \times 10^{8}$ cells of approximately $95 \%$ viability. $10^{8}$ live spleen cells are used per fusion.

\subsubsection{Harvesting Myelomas}

Healthy myelomas (in log phase, phase bright with smooth cell membrane, less than $2 \%$ dead by trypan blue staining) were pelleted by centrifugation at $300 \mathrm{~g}$ for 5 minutes, decanted, resuspended in $30 \mathrm{~mL}$ of complete DMEM and then transferred to a $50 \mathrm{~mL}$ conical tube. The cells were again pelleted by centrifugation, washed twice with $50 \mathrm{~mL}$ of serum-free DMEM, and resuspended in $10 \mathrm{~mL}$ of DMEM. An aliquot was diluted 1:10 (v/v) and then the cells were counted by the method described above.

\subsubsection{Fusion}

Myeloma and spleen cells are combined in a ratio of 1:5 in a $50 \mathrm{~mL}$ Falcon tube, centrifuged at $300 \mathrm{~g}$ for 5 minutes, and the supernatant was removed. The cell pellet was then resuspended in serum-free medium. This wash step was repeated three times. It is essential to remove all serum from the cell surface since this inhibits the fusion process. After the last wash the medium was removed until there was only a meniscus of liquid over the cell pellet. The tube bottom was knocked on a hard surface to liquify the pellet. Prior to the fusion, the PEG and serum-free RPMI* solutions were warmed to $37^{\circ} \mathrm{C}$. Next, $0.8 \mathrm{~mL}$

* See ref 161 for a list of components contained in RPMI buffer. 
of the PEG solution was added dropwise to the pellet over 60 seconds while gently tapping the tube. The mixture was allowed to stand for one minute before $1 \mathrm{~mL}$ of serum-free RPMI solution, $\mathrm{pH} 7.4$, was added dropwise over 60 seconds, followed by an additional $20 \mathrm{~mL}$ over a 5 minute period. The cells were then centrifuged for 5 minutes at $300 \mathrm{~g}$, and the supernatant was aspirated off. Finally, the pellet was resuspended in $40 \mathrm{~mL}$ of fusion medium.

\subsubsection{Transferring Fused Cells to the Growth Plates}

The cell suspension was plated into four 96-well flat bottomed plates, each well received $100 \mu \mathrm{L}$ or $5 \times 10^{4}$ cells, and the final volume of each well made up to $200 \mu \mathrm{L}$ with fusion medium. On days $1,2,3,7,10$ and 14 , approximately half of the medium in each well was removed using a sterile pasteur pipette and suction, and replaced with $100 \mu \mathrm{L}$ of fresh fusion medium. After approximately 7-8 days, colonies of hybridomas were visible.

\subsubsection{Selection and Expansion of Hybridomas}

The particle concentration fluorescence immunoassay (PCFIA) technique was used in place of the traditional enzyme-linked immunosorbant assay (ELISA) for the initial screening of hybridomas. The PCFIA assays were carried out using hapten-protein conjugate-coated carboxyl polystyrene particles, 96 well filter assay plates, a goat antimouse fluorescein isothiocyanate (FITC) secondary 
antibody for detection at $535 \mathrm{~nm}$ wavelength (excitation at $485 \mathrm{~nm}$ ), and a PCFIA buffer (filtered through a $0.22 \mu \mathrm{m}$ filter), $\mathrm{pH} 7.4$.

Supernatants from the hybridoma cells were screened for hapten affinity using the PCFIA immunoassay with BSA-50 conjugate-coated carboxyl polystyrene particles as the solid phase.

Cells from cultures displaying anti-hapten antibodies were subcloned by limited dilution in 96-well plates as described below.

\subsubsection{Cloning Cell Lines}

Any hybridoma cells from cultures displaying anti-hapten activity were cloned by limited dilution. The cells from a positive well (100 $\mu \mathrm{L}$ of cell suspension) were transferred and titrated 1:2 dilution step down the first column of a fresh 96-well growth plate that contained $100 \mu \mathrm{L}$ of media per well. The column was then also titrated across the plate and each well made up to a final volume of $100 \mu \mathrm{L}$ with additional media. The cells were allowed to grow for approximately 10 days, supernatants from wells with hybridomas were assayed, and then hapten-specific colonies were expanded as described above. Copies of these clones were expanded in $2 \mathrm{~mL}$ tissue culture dishes and frozen in liquid nitrogen. To prepare the clones for freezing, they were expanded in growth media. Once a cell density of $1-2 \times 10^{5}$ cells $/ \mathrm{mL}$ was reached the cells were 
centrifuged at $300 \mathrm{~g}$ for 5 minutes and supernatant was removed. The cell pellet was resuspended in freeze medium at a concentration of $2 \times 10^{6}$ cells $/ \mathrm{mL}$ and transferred to a $1 \mathrm{~mL}$ freezing vial. The cells were then cooled at a rate of $1^{\circ} \mathrm{C} /$ minute until they were frozen at a temperature $-195^{\circ} \mathrm{C}$. The frozen cells were then transferred into the liquid nitrogen storage tank. Once the hybridomas have been cloned and copies frozen in liquid nitrogen, they can be assayed for catalytic activity. Large quantities of monoclonal antibodies were produced in pristane-primed Balb/c mice as described below.

\subsubsection{Ascites Production}

Prior to ascites production, the Balb/c mice (6-8 week old females) were primed by injection of $200 \mu \mathrm{L}$ of pristane (2,6,10,14-tetramethylpentadecane) into the interperitoneal cavity. Pristane acts as an irritant causing macrophages to secrete cytokines thus creating a good environment for growing hybridomas. Approximately 10-14 days after pristane priming, each mouse was injected with $1 \times 10^{6}$ hybridoma cells in $0.5 \mathrm{~mL}$ of PBS into the peritoneal cavity using a 22 gauge needle. After 10-14 days the liquid tumors (ascites fluid) were ready to harvest. The mice were anesthetized with carbon dioxide and killed by cervical dislocation. A small incision was made in the skin above the abdomen and the skin pulled back to expose the abdomen muscles. Using tweezers, the muscles were pinched and held upwards like a tent, and a small incision was made through the muscles just large enough to drain the ascites fluid using a 
disposable Liquipette. The fluid was centrifuged to pellet any cells and the oily pristane layer on top was removed. The ascites fluid was decanted into a new tube and stored at $-20^{\circ} \mathrm{C}$.

\subsection{GENERAL CHEMICAL METHODS}

Unless otherwise stated, all reactions were performed under a $\mathrm{N}_{2}$ atmosphere using flame-dried glassware. Cold temperature baths were prepared as follows: $-78^{\circ} \mathrm{C}$ (dry ice-acetone), $-20^{\circ} \mathrm{C}$ (dry ice- $\mathrm{CCl}_{4}$ ), and $0^{\circ} \mathrm{C}$ (ice-water).

Anhydrous reagents and solvents were purified and prepared according to literature procedures. ${ }^{162}$ Chromatographic solvents and reagents were used as received unless noted otherwise. The low boiling fraction $\left(35-60^{\circ} \mathrm{C}\right)$ of petroleum ether was used. All reagents were supplied by the Aldrich Chemical Co. and unless otherwise stated were used without further purification. $n$-Butyllithium ( $n$-BuLi) was standardized by titration against 2,2-diphenylacetic acid in THF at room temperature to the appearance of a faint yellow colour.

All reactions were monitored by thin layer chromatography (TLC) and were judged to be completed when the starting material was consumed as determined by TLC. In the description of reaction work-ups, washing with brine refers to a saturated solution of $\mathrm{NaCl}$, drying of the organic phase was accomplished with 
$\mathrm{MgSO}_{4}$ and removal of solvent in vacuo or concentration of solvent refers to the use of a rotary evaporator using a water aspirator and heating using a water bath.

Preparative flash chromatography ${ }^{163}$ was performed using 230-400 mesh ASTM silica gel supplied by E. Merck Co. As an indicator of purity, all compounds were purified such that they showed a single spot by TLC.

Melting points (mp) were determined using a Mel-Temp III (Laboratory Devices) melting point apparatus and are uncorrected.

Infrared (IR) spectra were recorded on a Bomem Michelson 100 FT-IR spectrometer using internal calibration. IR spectra were recorded on the neat liquid or as a chloroform solution using $\mathrm{NaCl}$ solution cells.

Except where noted, proton nuclear magnetic resonance spectra ( ${ }^{1} H$ NMR) were recorded in deuteriochloroform solutions on a Bruker AC-200 (200 MHz) or Bruker $\mathrm{WH}-400(400 \mathrm{MHz})$ spectrometer. Chemical shifts are reported in parts per million (ppm) on the $\delta$ scale versus chloroform ( $\delta 7.24 \mathrm{ppm})$ as an internal standard. Signal multiplicity, spin-spin coupling constants (where possible) and integration ratios are indicated in parentheses. Phosphorus nuclear magnetic resonance spectra $\left({ }^{31} \mathrm{P} N \mathrm{NMR}\right)$ with proton decoupling were recorded in 
deuteriochloroform solutions on a Bruker AC-200 (81.75 MHz) spectrometer. Chemical shifts are given in parts per million (ppm) on the $\delta$ scale versus $85 \%$ phosphoric acid as an external standard.

Low- and high-resolution electron-impact (EI) mass spectral analyses were performed on a Kratos-AEI model MS 50 mass spectrometer. An ionization energy of $70 \mathrm{eV}$ was used in all measurements. Low-resolution desorption chemical ionization (DCl) mass spectral analyses, using $\mathrm{CH}_{4}$ or $\mathrm{NH}_{3}$ reagent gas as indicated, were recorded on a Delsi Nermag R10-10C mass spectrometer. High-resolution $\mathrm{DCl}$ mass spectral analyses, using $\mathrm{CH}_{4}$ or $\mathrm{NH}_{3}$ reagent gas as indicated, were recorded on a Kratos MS 80 RFA mass spectrometer.

Kinetic analyses using ultraviolet-visible (UV-Vis) spectroscopy were performed on a UV-4 Unicam spectrophotometer.

Thin-layer chromatography was performed on Merck silica gel $60 \mathrm{~F}_{254}$ pre-coated aluminium sheets. Visualization was achieved by irradiation with ultraviolet light at $254 \mathrm{~nm}$ and/or by spraying with anisaldehyde reagent (a solution of $1 \mathrm{~mL}$ anisaldehyde, $5 \mathrm{~mL}$ conc. $\mathrm{H}_{2} \mathrm{SO}_{4}$ and $10 \mathrm{~mL}$ glacial acetic acid in $90 \mathrm{~mL} \mathrm{MeOH}$ ) followed by heating. 
Microanalyses were carried out at the microanalytical laboratory of the University of British Columbia Chemistry Department using a Carlo Erba Elemental Analyzer 1106. Samples for microanalysis were purified by column chromatography using the solvent system indicated for each compound. 


\subsection{CHEMICAL METHODS}

11-(Tetrahydropyranyloxy)-dodecanal (33).<smiles>CC([OH2+])CCCCCCCCCC=O</smiles>

33

To a stirred solution of oxalyl chloride $(1.01 \mathrm{~mL}, 11.5 \mathrm{mmol})$ in $75 \mathrm{~mL}$ of dry $\mathrm{CH}_{2} \mathrm{Cl}_{2}$ under $\mathrm{N}_{2}$ at $-78^{\circ} \mathrm{C}$ was added DMSO $(1.80 \mathrm{~mL}, 25.2 \mathrm{mmol})$ dissolved

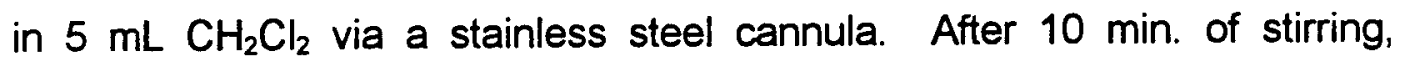
compound $42(3.00 \mathrm{~g}, 3.50 \mathrm{mmol})$ in $25 \mathrm{~mL}$ of $\mathrm{CH}_{2} \mathrm{Cl}_{2}$ was added to the activated DMSO via a stainless steel cannula. Finally, after stirring an additional $10 \mathrm{~min} ., \mathrm{Et}_{3} \mathrm{~N}(7.31 \mathrm{~mL}, 52.5 \mathrm{mmol})$ was syringed in, and the reaction mixture was allowed to warm to room temperature while maintaining stirring. After $3 \mathrm{~h}$, the solution was diluted with $100 \mathrm{~mL}$ of $\mathrm{Et}_{2} \mathrm{O}$ followed by $100 \mathrm{~mL}$ of water. The aqueous layer was further extracted with $3 \times 50 \mathrm{~mL}$ of $\mathrm{Et}_{2} \mathrm{O}$ and the combined $\mathrm{Et}_{2} \mathrm{O}$ extracts were dried over anhydrous $\mathrm{MgSO}_{4}$, filtered and concentrated under reduced pressure to a yellow oil. The crude product was then purified by flash chromatography using $4: 1$ petroleum ether and ethyl acetate to afford $2.59 \mathrm{~g}(87 \%)$ of 33 as a colourless oil.

IR (neat): 2927, 2854, 2728, 1725, 1458, 1362, 1322, 1124, 1075, 901 , $867 \mathrm{~cm}^{-1}$

${ }^{1} \mathrm{H}$ NMR $\left(200 \mathrm{MHz}, \mathrm{CDCl}_{3}\right) \delta: 9.74(\mathrm{t}, \mathrm{J}=1.7 \mathrm{~Hz}, 1 \mathrm{H}), 4.68(\mathrm{~m}, 0.5 \mathrm{H}), 4.62$ 
$(m, 0.5 \mathrm{H}), 3.88(\mathrm{~m}, 1 \mathrm{H}), 3.75(\mathrm{~m}, 0.5 \mathrm{H}), 3.68(\mathrm{~m}, 0.5 \mathrm{H}), 3.46(\mathrm{~m}, 1 \mathrm{H})$,

$2.38(\mathrm{~m}, 2 \mathrm{H}), 1.22-1.90(\mathrm{~m}, 22 \mathrm{H}), 1.18(\mathrm{~d}, \mathrm{~J}=6.2 \mathrm{~Hz}, 1.5 \mathrm{H}), 1.07$

(d, $J=6.2 \mathrm{~Hz}, 1.5 \mathrm{H}$ );

LRMS (DCl, $\left.\mathrm{NH}_{3}\right) m / z$ (relative intensity): $302\left(\mathrm{M}^{+}+18,12\right), 285\left(\mathrm{M}^{+}+1,3\right)$, $218(30), 201(15)$

HRMS ( $\mathrm{DCl}, \mathrm{CH}_{4}$ ) calcd. for $\mathrm{C}_{17} \mathrm{H}_{32} \mathrm{O}_{3}: 284.2351$, found 284.2409 .

1-Diphenylphosphinyl-12-(tetrahydropyranyloxy)-1-tridecene (36a and 36b).

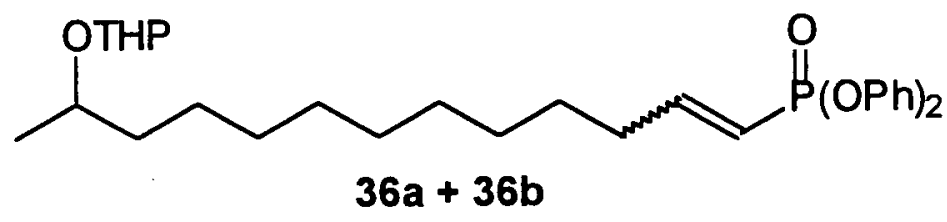

The Wittig reagent $32(2.15 \mathrm{~g}, 4.23 \mathrm{mmol})$ and aldehyde $33(1.2 \mathrm{~g}, 4.2 \mathrm{mmol})$ were dissolved in $17 \mathrm{~mL}$ of toluene and refluxed under $\mathrm{N}_{2}$ for 3 days. The solvent was removed under reduced pressure and the crude product was purified by flash chromatography using 5:1 petroleum ether and ethyl acetate to afford $1.12 \mathrm{~g} \mathrm{(52 \% )}$ of a colourless oil which was a mixture of cis and trans isomers $36 \mathrm{a}$ and $\mathbf{3 6 b}$. A small quantity of the crude product was repurified by flash chromatography using 5:1 petroleum ether and ethyl acetate and pure $36 \mathrm{a}$, the cis isomer, and pure $36 \mathrm{~b}$, the trans isomer, were isolated separately for analysis. 
Cis isomer 36a:

IR (neat): $2929,2855,1623,1593,1490,1459,1377,1270,1192$,

$1163,1129,1074,1025,998,931,763 \mathrm{~cm}^{-1}$;

${ }^{1} \mathrm{H}$ NMR $\left(400 \mathrm{MHz}, \mathrm{CDCl}_{3}\right) \delta: 7.15-7.38(\mathrm{~m}, 10 \mathrm{H}), 6.59$ (ddt, $\mathrm{J}=7.8,13.0$, $57.4 \mathrm{~Hz}, 1 \mathrm{H}), 5.76(\mathrm{dd}, \mathrm{J}=13.0,21.8 \mathrm{~Hz}, 1 \mathrm{H}), 4.74(\mathrm{~m}, 0.5 \mathrm{H}), 4.67$ $(m, 0.5 H), 3.94(m, 1 H), 3.81(m, 0.5 H), 3.74(m, 0.5 H), 3.52(m, 1 H)$, $2.27(d t, J=7.8,7.8 \mathrm{~Hz}, 2 \mathrm{H}), 1.85(\mathrm{~m}, 1 \mathrm{H}), 1.72(\mathrm{~m}, 1 \mathrm{H}), 1.24-1.68$ $(\mathrm{m}, 2 \mathrm{H}), 1.23(\mathrm{~d}, \mathrm{~J}=6.2 \mathrm{~Hz}, 1.5 \mathrm{H}), 1.13(\mathrm{~d}, \mathrm{~J}=6.2 \mathrm{~Hz}, 1.5 \mathrm{H})$;

${ }^{31} \mathrm{P}$ NMR $\left(81 \mathrm{MHz}, \mathrm{CDCl}_{3}\right)$ 8: 9.7;

LRMS (EI) m/z (relative intensity): 514 (0.2), 429 (6), 415 (20), 414 (54), 413 (100), 94 (28), 85 (31);

HRMS calcd. for $\mathrm{C}_{30} \mathrm{H}_{43} \mathrm{O}_{5} \mathrm{P}: 514.2848$, found 514.2835 ;

Anal. Calcd. for $\mathrm{C}_{30} \mathrm{H}_{43} \mathrm{O}_{5} \mathrm{P}: \mathrm{C}, 70.02 ; \mathrm{H}, 8.42$. Found: $\mathrm{C}, 69.93 ; \mathrm{H}, 8.34$.

Trans isomer $\mathbf{3 6 b}$ :

IR (neat): 2929, 2854, 1628, 1593, 1490, 1455, 1374, 1273, 1198, $1164,1128,1075,1025,996,932,869,826,767 \mathrm{~cm}^{-1}$

${ }^{1} \mathrm{H}$ NMR $\left(400 \mathrm{MHz}, \mathrm{CDCl}_{3}\right)$ 8: 7.10-7.38 (m, 10H), 7.20 (ddt, J = 6.6, 17.0, $25.4 \mathrm{~Hz}, 1 \mathrm{H}), 5.88(\mathrm{dd}, \mathrm{J}=17.0,23.4 \mathrm{~Hz}, 1 \mathrm{H}), 4.74(\mathrm{~m}, 0.5 \mathrm{H}), 4.67$ $(\mathrm{m}, 0.5 \mathrm{H}), 3.94(\mathrm{~m}, 1 \mathrm{H}), 3.81(\mathrm{~m}, 0.5 \mathrm{H}), 3.74(\mathrm{~m}, 0.5 \mathrm{H}), 3.52(\mathrm{~m}, 1 \mathrm{H})$, $2.27(\mathrm{dt}, \mathrm{J}=6.6,7.0 \mathrm{~Hz}, 2 \mathrm{H}), 1.85(\mathrm{~m}, 1 \mathrm{H}), 1.72(\mathrm{~m}, 1 \mathrm{H}), 1.24-1.68$ $(\mathrm{m}, 20 \mathrm{H}), 1.23(\mathrm{~d}, \mathrm{~J}=6.2 \mathrm{~Hz}, 1.5 \mathrm{H}), 1.13(\mathrm{~d}, \mathrm{~J}=6.2 \mathrm{~Hz}, 1.5 \mathrm{H})$; 
${ }^{31} \mathrm{P}$ NMR $\left(81 \mathrm{MHz}, \mathrm{CDCl}_{3}\right)$ 8: 11.9;

LRMS (EI) m/z (relative intensity): 514 (0.2), 429 (6), 415 (20), 414 (54), 413 (100), 94 (28), $85(31)$;

HRMS calcd. for $\mathrm{C}_{30} \mathrm{H}_{43} \mathrm{O}_{5} \mathrm{P}: 514.2848$, found 514.2852;

Anal. Calcd. for $\mathrm{C}_{30} \mathrm{H}_{43} \mathrm{O}$ P: $\mathrm{C}, 70.02 ; \mathrm{H}, 8.42$. Found: $\mathrm{C}, 69.91 ; \mathrm{H}, 8.30$.

12-Hydroxy-1-diphenylphosphinyl-tridecane (37).<smiles>CC(O)CCCCCCCCCCC[Pb](=O)O</smiles>

$\mathrm{p}-\mathrm{TsOH}(0.65 \mathrm{~g}, 3.4 \mathrm{mmol})$ was added to a stirred solution of compound 43 $(8.75 \mathrm{~g}, 17.0 \mathrm{mmol})$ in $200 \mathrm{~mL}$ of $\mathrm{MeOH}$ at room temperature. After $18 \mathrm{~h}$, the $\mathrm{MeOH}$ was removed under reduced pressure and the resulting oil was dissolved in $\mathrm{Et}_{2} \mathrm{O}$, washed with $2 \times 50 \mathrm{~mL}$ of water followed by $2 \times 50 \mathrm{~mL}$ of brine, dried over anhydrous $\mathrm{MgSO}_{4}$, filtered and concentrated under reduced pressure. The crude oil was purified by flash chromatography using 1:1 petroleum ether and ethyl acetate to afford $6.31 \mathrm{~g}(86 \%)$ of alcohol 37 as a colourless oil.

IR (neat): 3424, 3066, 2925, 2854, 1592, 1490, 1460, 1265, 1214, 1192 , $1163,1071,1025,1007,934,802,764 \mathrm{~cm}^{-1}$;

${ }^{1} \mathrm{H}$ NMR (400 MHz, $\left.\mathrm{CDCl}_{3}\right)$ 8: 7.11-7.32 (m, 10H), $3.76(\mathrm{~m}, 1 \mathrm{H}), 2.04(\mathrm{~m}, 2 \mathrm{H})$, 
$1.77(m, 2 H), 1.20-1.50(m, 18 H), 1.15(d, J=6.2 \mathrm{~Hz}, 3 \mathrm{H})$;

${ }^{31} \mathrm{P}$ NMR $\left(81 \mathrm{MHz}, \mathrm{CDCl}_{3}\right)$ 8: 25.9;

LRMS (EI) m/z (relative intensity): 432 (1), 431 (4), 415 (7), 414 (19);

HRMS calcd. for $\mathrm{C}_{25} \mathrm{H}_{37} \mathrm{O}_{4} \mathrm{P}: 432.2429$, found 432.2398 ;

Anal. Calcd. for $\mathrm{C}_{25} \mathrm{H}_{37} \mathrm{O}_{4} \mathrm{P}: \mathrm{C}, 69.41 ; \mathrm{H}, 8.63$. Found: $\mathrm{C}, 69.62 ; \mathrm{H}, 8.72$.

1-Phenyl-1-oxo-1-phospho-13-tetradecanolide (38a and 38b) and Dimer

39.

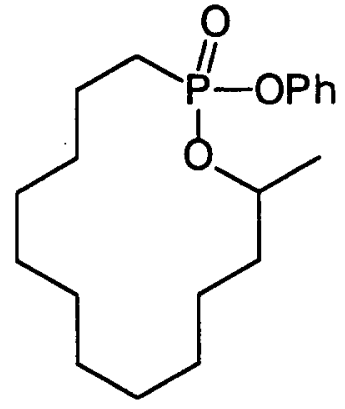

$38 a+38 b$

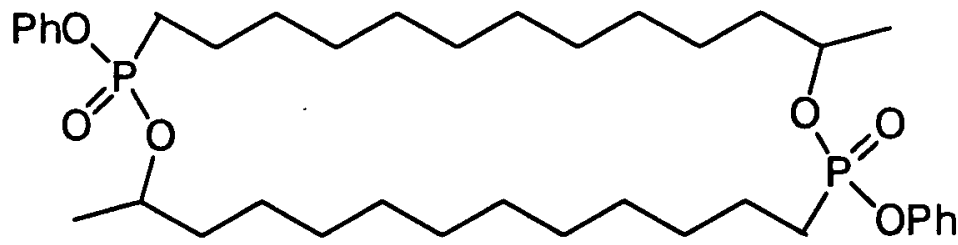

39

To a stirred solution of compound $44(125 \mathrm{mg}, 0.351 \mathrm{mmol})$ in $150 \mathrm{~mL}$ of dry $\mathrm{PhH}$ at room temperature under $\mathrm{N}_{2}$ was added $\mathrm{Ph}_{3} \mathrm{P}(368 \mathrm{mg}, 1.40 \mathrm{mmol}$ ) followed by DEAD $(221 \mu \mathrm{l}, 1.40 \mathrm{mmol})$. After $2 \mathrm{~h}$, the solvent was removed under reduced pressure and the resulting crude mixture was purified by flash chromatography using 2:1 hexane and ethyl acetate to afford the separated diastereomers; $\mathbf{3 8 a}$ and $\mathbf{3 8 b}$, in a 5:1 ratio based on the recovered yields, and a combined yield of $97.1 \mathrm{mg} \mathrm{(82 \% ).} \mathrm{In} \mathrm{addition,} 6 \mathrm{mg}$ of the dimeric side product, 39, was isolated as a colourless, crystalline solid. The $R_{q}$ values of 
the three cyclic products, $38 \mathrm{a}, 38 \mathrm{~b}$ and 39 , were found to be $0.71,0.57$ and 0.62 respectively by thin-layer chromatography using a $1: 1$ mixture of petroleum ether and ethyl acetate.

Diastereomer 38a (faster moving by TLC):

IR (neat): $2927,2859,1593,1490,1458,1380,1253,1210,1163,1071,991$, $920,766 \mathrm{~cm}^{-1}$;

${ }^{1} \mathrm{H}$ NMR $\left(400 \mathrm{MHz}, \mathrm{CDCl}_{3}\right)$ 8: 7.05-7.38 (m, 5H), $4.75(\mathrm{~m}, 1 \mathrm{H}), 1.24-1.88(\mathrm{~m}$, $22 \mathrm{H}), 1.22(\mathrm{~d}, \mathrm{~J}=6.3 \mathrm{~Hz}, 3 \mathrm{H})$;

${ }^{31} \mathrm{P}$ NMR $\left(81 \mathrm{MHz}, \mathrm{CDCl}_{3}\right)$ 8: 29.6;

LRMS (EI) m/z (relative intensity): 338 (52), 323 (5), 227 (16), 199 (9), 185 (38), 172 (69), 94 (100), 93 (31), 77 (17), 43 (39);

HRMS calcd. for $\mathrm{C}_{19} \mathrm{H}_{31} \mathrm{O}_{3} \mathrm{P}: 338.2011$, found 338.2002;

Anal. Calcd. for $\mathrm{C}_{19} \mathrm{H}_{31} \mathrm{O}_{3} \mathrm{P}: \mathrm{C}, 67.42 ; \mathrm{H}, 9.24$. Found: $\mathrm{C}, 67.20 ; \mathrm{H}, 9.20$.

Diastereomer 38b (slower moving by TLC): mp: $97-99^{\circ} \mathrm{C}$

IR $\left(\mathrm{CDCl}_{3}\right): 2932,2860,1593,1492,1456,1223,1011 \mathrm{~cm}^{-1}$;

${ }^{1} \mathrm{H}$ NMR $\left(400 \mathrm{MHz}, \mathrm{CDCl}_{3}\right) \delta: 7.05-7.38(\mathrm{~m}, 5 \mathrm{H}), 4.65(\mathrm{~m}, 1 \mathrm{H}), 1.93(\mathrm{~m}, 2 \mathrm{H})$, $1.20-1.73(\mathrm{~m}, 2 \mathrm{H}), 1.43(\mathrm{~d}, \mathrm{~J}=6.2 \mathrm{~Hz}, 3 \mathrm{H})$;

${ }^{31} \mathrm{P}$ NMR (81 MHz, $\left.\mathrm{CDCl}_{3}\right)$ 8: 27.8;

LRMS (EI) m/z (relative intensity): 338 (26), 323 (2), 227 (11), 199 (7), 185 
(30), 172 (59), 94 (100), 93 (3), 77 (20), 43 (75);

HRMS calcd. for $\mathrm{C}_{19} \mathrm{H}_{31} \mathrm{O}_{3} \mathrm{P}: 338.2011$, found 338.2009;

Anal. Calcd. for $\mathrm{C}_{19} \mathrm{H}_{31} \mathrm{O}_{3} \mathrm{P}: \mathrm{C}, 67.42 ; \mathrm{H}, 9.24$. Found: $\mathrm{C}, 67.15 ; \mathrm{H}, 9.39$.

Dimer 39:

mp: $103-105^{\circ} \mathrm{C}$

IR $\left(\mathrm{CDCl}_{3}\right): 2930,2856,1593,1491,1229,1012 \mathrm{~cm}^{-1}$;

${ }^{1} \mathrm{H}$ NMR (400 MHz, $\left.\mathrm{CDCl}_{3}\right) \delta: 7.10-7.33(\mathrm{~m}, 10 \mathrm{H}), 4.66(\mathrm{~m}, 2 \mathrm{H}), 1.84(\mathrm{~m}, 4 \mathrm{H})$,

$1.68(m, 4 H), 1.56(m, 4 H), 1.20-1.45(m, 40 H), 1.15(d, J=6.2 \mathrm{~Hz}$,

$6 \mathrm{H}$;

${ }^{31} \mathrm{P}$ NMR (81 MHz, $\left.\mathrm{CDCl}_{3}\right)$ ): 29.0;

LRMS (EI) m/z (relative intensity): 676 (1), 661 (1), 583 (100), 339 (19),

338 (10), 245 (7), 227 (12), 199 (6), 185 (15), $172(21), 94$ (27), 77 (5);

HRMS calcd. for $\mathrm{C}_{38} \mathrm{H}_{62} \mathrm{O}_{6} \mathrm{P}_{2}: 676.4022$, found 676.4002 ;

Anal. Calcd. for $\mathrm{C}_{38} \mathrm{H}_{62} \mathrm{O}_{6} \mathrm{P}_{2}: \mathrm{C}, 67.42 ; \mathrm{H}, 9.24$. Found: $\mathrm{C}, 67.51 ; \mathrm{H}, 9.28$.

11-Dodecen-2-ol (40).

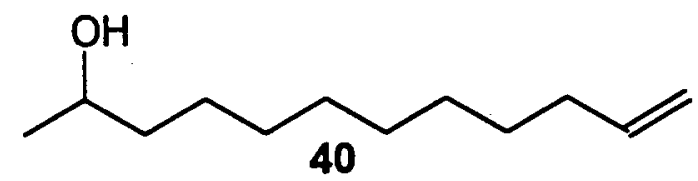

To a stirred solution of commercially available 10-undecenal ( $8.1 \mathrm{~g}, 48 \mathrm{mmol}$ ) in $250 \mathrm{~mL}$ of THF under $\mathrm{N}_{2}$ at $0^{\circ} \mathrm{C}$ was slowly added $3 \mathrm{M}$ methylmagnesium bromide $(18 \mathrm{~mL}, 53 \mathrm{mmol})$. After $0.5 \mathrm{~h}$ the reaction was quenched with 
saturated aqueous $\mathrm{NH}_{4} \mathrm{Cl}$, diluted with $\mathrm{Et}_{2} \mathrm{O}$, and the resulting precipitate was filtered and discarded. The filtrate was washed with $2 \times 100 \mathrm{~mL}$ of brine, dried over anhydrous $\mathrm{MgSO}_{4}$, filtered and the solvent removed under reduced pressure to give $13.6 \mathrm{~g}$ of crude oil. The residue was purified by flash chromatography using 4:1 petroleum ether and ethyl acetate to afford $7.96 \mathrm{~g}(90 \%)$ of $\mathbf{4 0}$ as a colourless oil.

IR (neat): $3351,3077,2922,2855,1641,1457,1373,1122,994,910,842$, $722 \mathrm{~cm}^{-1}$

${ }^{1} \mathrm{H}$ NMR $\left(400 \mathrm{MHz}, \mathrm{CDCl}_{3}\right) \delta: 5.78(\mathrm{ddt}, \mathrm{J}=6.7,10.4,17.3 \mathrm{~Hz}, 1 \mathrm{H}), 4.94$ (d, d, J = 10.4, $17.1 \mathrm{~Hz}, 2 \mathrm{H}), 3.75(\mathrm{~m}, 1 \mathrm{H}), 2.02(\mathrm{dt}, \mathrm{J}=6.3,6.7 \mathrm{~Hz}$, 2H), 1.63 (br. $s, 1 H), 1.20-1.50(m, 14 H), 1.16(d, J=6.2 \mathrm{~Hz}, 3 H)$; LRMS (EI) m/z (relative intensity): 184 (0.4), 166 (2), 151 (1), 141 (2), 138 (3), $124(10), 109(10), 96(29), 82(51), 69(40), 45(100), 41(62)$; HRMS calcd. for $\mathrm{C}_{12} \mathrm{H}_{24} \mathrm{O}: 184.1827$, found 184.1832;

Anal. Calcd. for $\mathrm{C}_{12} \mathrm{H}_{24} \mathrm{O}: \mathrm{C}, 78.20 ; \mathrm{H}, 13.12$. Found: $\mathrm{C}, 78.40 ; \mathrm{H}, 12.99$.

11-(Tetrahydropyranyloxy)-1-dodecene (41).<smiles>C=CCCCCCCCCC(C)[OH+]</smiles> 
To a stirred solution of 40 (10 g, $54 \mathrm{mmol})$ in $300 \mathrm{~mL}$ of $\mathrm{CH}_{2} \mathrm{Cl}_{2}$ was added DHP (5.5 $\mathrm{mL}, 65 \mathrm{mmol})$ and $\mathrm{p}-\mathrm{TsOH}(0.52 \mathrm{~g}, 2.7 \mathrm{mmol})$, and the mixture was stirred at room temperature under $\mathrm{N}_{2}$ for $2 \mathrm{~h}$. The solvent was then removed and the residue was diluted with $\mathrm{Et}_{2} \mathrm{O}$. The ether layer was washed with $2 \mathrm{x}$ $25 \mathrm{~mL}$ of saturated $\mathrm{NaHCO}_{3}, 1 \times 25 \mathrm{~mL}$ water and $1 \times 50 \mathrm{~mL}$ of brine, and dried over anhydrous $\mathrm{MgSO}_{4}$ and filtered. The solvent was removed under reduced pressure and the crude material ( $15.7 \mathrm{~g}$ of oil) was purified by flash chromatography using 10:1 petroleum ether and ethyl acetate to afford $12.2 \mathrm{~g}$ (84\%) of $\mathbf{4 1}$ as a colourless oil.

IR (neat): 3076, 2929, 2855, 1727, 1641, 1453, 1375, 1352, 1321, 1260 , $1200,1126,1076,1026,996,911,869,812,734 \mathrm{~cm}^{-1}$

${ }^{1} \mathrm{H}$ NMR $\left(400 \mathrm{MHz}, \mathrm{CDCl}_{3}\right) \delta: 5.78(\mathrm{ddt}, \mathrm{J}=6.7,10.4,17.1 \mathrm{~Hz}, 1 \mathrm{H}), 4.93$ (dd, $J=10.4,17.1 \mathrm{~Hz}, 2 \mathrm{H}), 4.70(\mathrm{~m}, 0.5 \mathrm{H}), 4.59(\mathrm{~m}, 0.5 \mathrm{H}), 3.89$ $(\mathrm{m}, 1 \mathrm{H}), 3.76(\mathrm{~m}, 0.5 \mathrm{H}), 3.68(\mathrm{~m}, 0.5 \mathrm{H}), 3.47(\mathrm{~m}, 1 \mathrm{H}), 2.02(\mathrm{dt}$, $J=6.3,6.7 \mathrm{~Hz}, 2 \mathrm{H}), 1.22-1.90(\mathrm{~m}, 2 \mathrm{H}), 1.07(\mathrm{~d}, J=6.2 \mathrm{~Hz}, 1.5 \mathrm{H})$, $1.19(\mathrm{~d}, \mathrm{~J}=6.2 \mathrm{~Hz}, 1.5 \mathrm{H})$;

LRMS (EI) m/z (relative intensity): 268 (0.3), 182 (1), 167 (2), 129 (25), 101 (43), 97 (28), 85 (100), 83 (36), 69 (40), 55 (73), 41 (67);

HRMS calcd. for $\mathrm{C}_{17} \mathrm{H}_{32} \mathrm{O}_{2}: 268.2402$, found 268.2404;

Anal. Calcd. for $\mathrm{C}_{17} \mathrm{H}_{32} \mathrm{O}_{2}: \mathrm{C}, 76.06 ; \mathrm{H}, 12.02$. Found: $\mathrm{C}, 76.23 ; \mathrm{H}, 11.95$. 
11-(Tetrahydropyranyloxy)-1-dodecanol (42).

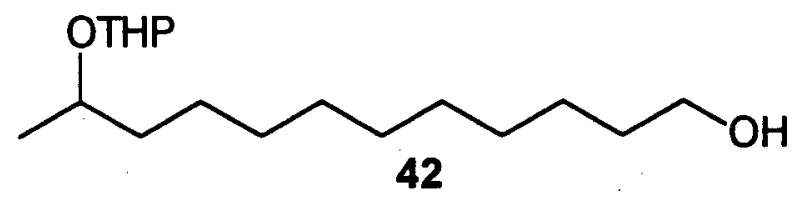

To compound $41(1.00 \mathrm{~g}, 3.73 \mathrm{mmol})$ in $5 \mathrm{~mL}$ of dry THF at $0{ }^{\circ} \mathrm{C}$ under $\mathrm{N}_{2}$ was added $1 \mathrm{M} \mathrm{BH}_{3}$. THF $(3.0 \mathrm{~mL}, 3.0 \mathrm{mmol})$ dropwise via syringe. After $1 \mathrm{~h}$, the reaction was quenched with $1.0 \mathrm{~mL}$ of water, and oxidized by the addition of $1.2 \mathrm{~mL}$ of $3 \mathrm{~N} \mathrm{NaOH}$ and $1.2 \mathrm{~mL}$ of $30 \% \mathrm{H}_{2} \mathrm{O}_{2}$. After 15 minutes of vigorous stirring, the mixture was extracted with $3 \times 50 \mathrm{~mL}$ of $\mathrm{Et}_{2} \mathrm{O}$. The combined ether extracts were dried over $\mathrm{MgSO}_{4}$, filtered and concentrated under reduced pressure. The crude material was purified by flash chromatography using $4: 1$ petroleum ether and ethyl acetate to afford $1.02 \mathrm{~g}(96 \%)$ of 42 as a colourless oil.

IR (neat): $3391,2928,2855,1455,1375,1339,1321,1260,1200,1184$, $1126,1076,1026,995,941,904,869,811,722 \mathrm{~cm}^{-1}$;

${ }^{1} \mathrm{H}$ NMR $\left(400 \mathrm{MHz}, \mathrm{CDCl}_{3}\right) \delta: 4.70(\mathrm{~m}, 0.5 \mathrm{H}), 4.59(\mathrm{~m}, 0.5 \mathrm{H}), 3.89(\mathrm{~m}, 1 \mathrm{H})$, $3.76(\mathrm{~m}, 0.5 \mathrm{H}), 3.68(\mathrm{~m}, 0.5 \mathrm{H}), 3.62(\mathrm{dt}, \mathrm{J}=5.1,6.4 \mathrm{~Hz}, 2 \mathrm{H}), 3.47$ $(m, 1 H), 1.81(m, 1 H), 1.68(m, 1 H), 1.53(m, 6 H), 1.18-1.43(m, 16 H)$, $1.19(\mathrm{~d}, \mathrm{~J}=6.2 \mathrm{~Hz}, 1.5 \mathrm{H}), 1.08(\mathrm{~d}, \mathrm{~J}=6.2 \mathrm{~Hz}, 1.5 \mathrm{H})$;

LRMS (DCl, $\left.\mathrm{NH}_{3}\right) m / z$ (relative intensity): $304\left(\mathrm{M}^{+}+18,100\right), 287\left(\mathrm{M}^{+}+1\right.$, $53), 286\left(M^{+}, 5\right), 262(6)$; 
HRMS (DCl, $\mathrm{CH}_{4}$ ) calcd. for $\mathrm{C}_{17} \mathrm{H}_{34} \mathrm{O}_{3}: 286.2508$, found 286.2499;

Anal. Calcd. for $\mathrm{C}_{17} \mathrm{H}_{34} \mathrm{O}_{3}: \mathrm{C}, 71.27 ; \mathrm{H}, 11.97$. Found: $\mathrm{C}, 71.04 ; \mathrm{H}, 11.91$.

1-Diphenylphosphinyl-12-(tetrahydropyranyloxy)-tridecane (43).<smiles>CC(CCCCCCCCCP(=O)(O)O)O[O-]</smiles>

A spatula tip of Pd-C (10\%) in $250 \mathrm{~mL}$ of EtOAc was saturated with $\mathrm{H}_{2}$ for 15 $\mathrm{h}$ before compound 36 ( $9.00 \mathrm{~g}, 17.5 \mathrm{mmol})$ in $5 \mathrm{~mL}$ of EtOAc was added via a steel cannula. This mixture was allowed to stir for an additional 3 days under $\mathrm{H}_{2}$ gas at a pressure slightly greater than one atmosphere. The reaction mixture was filtered through Celite and concentrated under reduced pressure to afford $8.95 \mathrm{~g}(99 \%)$ of $\mathbf{4 3}$ as a colourless oil.

IR (neat): 2929, 2854, 1739, 1593, 1491, 1461, 1373, 1272, 1200, 1163 , $1127,1074,1026,931,870,808,764 \mathrm{~cm}^{-1}$;

${ }^{1} \mathrm{H}$ NMR $\left(400 \mathrm{MHz}, \mathrm{CDCl}_{3}\right) \delta: 7.11-7.32(\mathrm{~m}, 10 \mathrm{H}), 4.68(\mathrm{~m}, 0.5 \mathrm{H}), 4.62(\mathrm{~m}$, $0.5 H), 3.88(m, 1 H), 3.72(m, 1 H), 3.47(m, 1 H), 2.04(m, 2 H)$, $1.22-1.90(m, 26 H), 1.08(d, J=6.2 \mathrm{~Hz}, 1.5 \mathrm{H}), 1.19(\mathrm{~d}, J=6.2 \mathrm{~Hz}$, $1.5 \mathrm{H}$;

${ }^{31} \mathrm{P}$ NMR $\left(81 \mathrm{MHz}, \mathrm{CDCl}_{3}\right)$ 8: 26.0;

LRMS (EI) m/z (relative intensity): 516 (0.4), 472 (0.2), 416 (42), 415 (68), 
388 (30), 359 (3), 345 (5), 303 (6), 289 (4), 261 (22), 248 (29), 172

(11), 141 (10), 94 (81), 85 (61), 78 (98), 77 (46), 55 (100);

HRMS calcd. for $\mathrm{C}_{30} \mathrm{H}_{45} \mathrm{O}_{5} \mathrm{P}: 516.3005$, found 516.3007;

Anal. Calcd. for $\mathrm{C}_{30} \mathrm{H}_{45} \mathrm{O}{ }_{5} \mathrm{P}: \mathrm{C}, 69.73 ; \mathrm{H}, 8.78$. Found: $\mathrm{C}, 69.94 ; \mathrm{H}, 8.90$.

Phenyl 12-Hydroxytrideane Phosphonic acid (44).<smiles>CC(O)CCCCCCCCCP(=O)(O)Oc1ccccc1</smiles>

Compound 37 (199 mg, $0.461 \mathrm{mmol}$ ) was dissolved in $5 \mathrm{~mL}$ of THF and 20 $\mathrm{mL}$ of $3 \mathrm{M} \mathrm{KOH}$, and refluxed for $1 \mathrm{~h}$. The THF was removed under reduced pressure and the remaining aqueous solution was acidified with $4 \mathrm{~N} \mathrm{HCl}$, then extracted with $\mathrm{Et}_{2} \mathrm{O}$. The combined $\mathrm{Et}_{2} \mathrm{O}$ extracts were dried over anhydrous $\mathrm{MgSO}_{4}$, filtered and evaporated under reduced pressure to afford $125 \mathrm{mg}$ (76\%) of $\mathbf{4 4}$ as a white solid.

$m p: 72-73^{\circ} \mathrm{C}$

IR $\left(\mathrm{CDCl}_{3}\right): 3614,2929,2856,1593,1492,1456,1213,1010,984 \mathrm{~cm}^{-1}$;

${ }^{1} \mathrm{H} \mathrm{NMR}\left(400 \mathrm{MHz}, \mathrm{CDCl}_{3}\right)$ ): 7.08-7.30 (m, 5H), $6.82(\mathrm{br} \mathrm{s}, 2 \mathrm{H}), 3.78(\mathrm{~m}$, $1 \mathrm{H}), 1.80(\mathrm{~m}, 2 \mathrm{H}), 1.62(\mathrm{~m}, 2 \mathrm{H}), 1.20-1.50(\mathrm{~m}, 18 \mathrm{H}), 1.17(\mathrm{~d}, \mathrm{~J}=6.2$ $\mathrm{Hz}, 3 \mathrm{H}$;

${ }^{31} \mathrm{P}$ NMR $\left(81 \mathrm{MHz}, \mathrm{CDCl}_{3}\right)$ 8: 32.7. 
LRMS (EI) m/z (relative intensity): 356 (0.8), 355 (3), 341 (8), 339 (2), 338 (5), 312(17), 227 (12), 199 (12), 185 (49), 172 (79), 157 (2), 110 (4), 94 (100), 77 (22);

HRMS calcd. for $\mathrm{C}_{19} \mathrm{H}_{33} \mathrm{O}_{4} \mathrm{P}: 356.2116$, found 356.2108;

Anal. Calcd. for $\mathrm{C}_{19} \mathrm{H}_{33} \mathrm{O}_{4} \mathrm{P}: \mathrm{C}, 64.01 ; \mathrm{H}, 9.34$. Found: $\mathrm{C}, 64.22 ; \mathrm{H}, 9.45$.

N-Cbz-5-amino-1-pentanol (48).

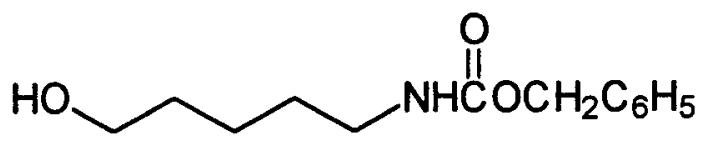

48

To a stirred solution of commercially available 5-amino-1-pentanol $(1.00 \mathrm{~g}$, $9.69 \mathrm{mmol}$ ) in $30 \mathrm{~mL}$ of aqueous $\mathrm{Na}_{2} \mathrm{CO}_{3}$ at $\mathrm{O}^{\circ} \mathrm{C}$ was added benzyl chloroformate $(\mathrm{Cbz}-\mathrm{Cl})(0.96 \mathrm{~mL}, 11 \mathrm{mmol})$ drop wise. The reaction mixture was stirred and allowed to warm to room temperature. After one hour the solution was diluted with EtOAc $(50 \mathrm{~mL})$ and the organic layer was extracted. The aqueous layer was extracted twice more with EtOAc $(75 \mathrm{~mL})$. The combined organic extracts were washed with $1 \mathrm{M} \mathrm{HCl}(50 \mathrm{~mL})$, saturated aqueous $\mathrm{NaHCO}_{3}(50 \mathrm{~mL})$, and finally with water $(2 \times 50 \mathrm{~mL})$. The mixture was dried over $\mathrm{MgSO}_{4}$, filtered and the solvent was removed under reduced pressure. The crude product was purified by flash chromatography using 2:1 petroleum ether and ethyl acetate to afforded $0.78 \mathrm{~g}(34 \%)$ of 48 as a white 
solid. In addition, $1.69 \mathrm{~g}$ of colourless oil, thought to be the di-protected product, was isolated and subsequently hydrolyzed in $1 \mathrm{M} \mathrm{NaOH}$ under reflux conditions. This reaction mixture was neutralized with $1 \mathrm{M} \mathrm{HCl}$, extracted with EtOAc, dried over anhydrous $\mathrm{MgSO}_{4}$, filtered and the solvent was removed under reduced pressure to yield an additional $1.08 \mathrm{~g}$ of compound 48 . The combined yield of $\mathbf{4 8}$ was $81 \%$.

mp: $43-45^{\circ} \mathrm{C}$;

IR $\left(\mathrm{CDCl}_{3}\right): 3692,3620,3453,2939,2862,1718,1516,1232 \mathrm{~cm}^{-1}$;

${ }^{1} \mathrm{H}$ NMR $\left(400 \mathrm{MHz}, \mathrm{CDCl}_{3}\right) \delta: 7.33(\mathrm{~m}, 5 \mathrm{H}), 5.08(\mathrm{~s}, 2 \mathrm{H}), 4.72(\mathrm{br} \mathrm{s}, 1 \mathrm{H})$, $3.62(t, J=6.4 \mathrm{~Hz}, 2 \mathrm{H}), 3.19(\mathrm{q}, \mathrm{J}=6.5 \mathrm{~Hz}, 2 \mathrm{H}), 1.65-1.30(\mathrm{~m}, 6 \mathrm{H})$;

LRMS (DCl, $\left.\mathrm{NH}_{3}\right) \mathrm{m} / \mathbf{z}$ (relative intensity): $255\left(\mathrm{M}^{+}+18,10\right), 238\left(\mathrm{M}^{+}+1,75\right)$, $237\left(\mathrm{M}^{+}, 3\right), 220(1), 194(99), 146(2), 108$ (62), 102 (15), 91 (100); HRMS calcd. for $\mathrm{C}_{13} \mathrm{H}_{19} \mathrm{NO}_{3}: 237.1365$, found 237.1373; Anal. Calcd. for $\mathrm{C}_{13} \mathrm{H}_{19} \mathrm{NO}_{3}: \mathrm{C}, 65.78 ; \mathrm{H}, 8.07 ; \mathrm{N}, 5.91$. Found: $\mathrm{C}, 65.86$; H, 8.23; N 5.93 . 
Cbz linked 1-oxo-1-phospho-13-tetradecanolide (49a).

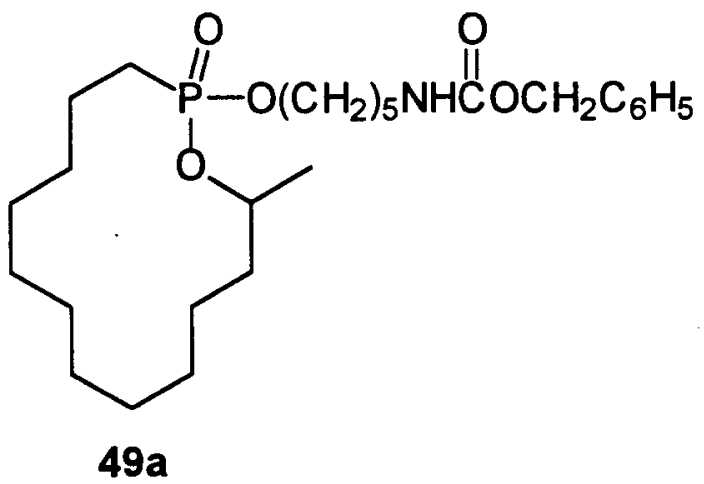

The alcohol $48\left(\mathrm{HO}\left(\mathrm{CH}_{2}\right)_{5} \mathrm{NHCbz}\right)(26.0 \mathrm{mg}, 108 \mu \mathrm{mol})$ was dissolved in 4.0 $\mathrm{mL}$ of THF at $-78^{\circ} \mathrm{C}$ under a $\mathrm{N}_{2}$ atmosphere and treated with $1.2 \mathrm{M} \mathrm{nBuLi}$ $(98.0 \mu \mathrm{L}, 118 \mu \mathrm{mol})$. The alkoxide was allowed to form for $10 \mathrm{~min}$ before this mixture was cannulated into a stirred solution of $38 \mathrm{~b}(16.6 \mathrm{mg}, 49.0 \mu \mathrm{mol})$ in $8.0 \mathrm{~mL}$ of THF at $-78^{\circ} \mathrm{C}$ under a $\mathrm{N}_{2}$ atmosphere. This mixture was allowed to warm slowly to room temperature, and was stirred overnight. The THF was then removed under reduced pressure, and the crude oil purified by column chromatography $\left(2 \% \mathrm{MeOH}\right.$ in $\mathrm{CH}_{2} \mathrm{Cl}_{2}$ ) to afford $13.8 \mathrm{mg}(59 \%)$ of $49 \mathrm{a}$, a colourless oil.

$\operatorname{IR}\left(\mathrm{CDCl}_{3}\right): 3453,2935,2861,1715,1516,1451,1233,1016 \mathrm{~cm}^{-1}$;

${ }^{1} \mathrm{H}$ NMR (400 MHz, $\left.\mathrm{CDCl}_{3}\right)$ 8: $7.34(\mathrm{~m}, 5 \mathrm{H}), 5.07(\mathrm{~s}, 2 \mathrm{H}), 4.86(\mathrm{br} \mathrm{s}, 1 \mathrm{H})$, 4.59 (ddq, J = 5.3, 6.2, $6.5 \mathrm{~Hz}, 1 \mathrm{H}), 3.95(\mathrm{~m}, 2 \mathrm{H}), 3.17(\mathrm{dt}, \mathrm{J}=6.4$, $6.5 \mathrm{~Hz}, 2 \mathrm{H}), 1.20-1.80(\mathrm{~m}, 28 \mathrm{H}), 1.30(\mathrm{~d}, \mathrm{~J}=6.2 \mathrm{~Hz}, 3 \mathrm{H})$;

${ }^{31} \mathrm{P}$ NMR $\left(81 \mathrm{MHz}, \mathrm{CDCl}_{3}\right)$ 8: 32.5; 
LRMS (DCl, $\left.\mathrm{NH}_{3}\right) m / z$ (relative intensity): $482\left(\mathrm{M}^{+}+1,100\right), 374$ (3), $284(4)$, 255 (14), 238 (30), 194 (31), 91 (10);

HRMS calcd. for $\mathrm{C}_{26} \mathrm{H}_{44} \mathrm{NO}_{5} \mathrm{P}: 481.2957$, found $482.3032\left(\mathrm{M}^{+}+1\right)$;

Anal. Calcd. for $\mathrm{C}_{26} \mathrm{H}_{44} \mathrm{NO}_{5} \mathrm{P}: \mathrm{C}_{1} 64.83 ; \mathrm{H}_{1} 9.21 ; \mathrm{N}, 2.91$. Found: $\mathrm{C}, 64.59 ; \mathrm{H}$, $9.10 ; \mathbf{N}, 3.00$.

Cbz linked 1-oxo-1-phospho-13-tetradecanolide (49b).

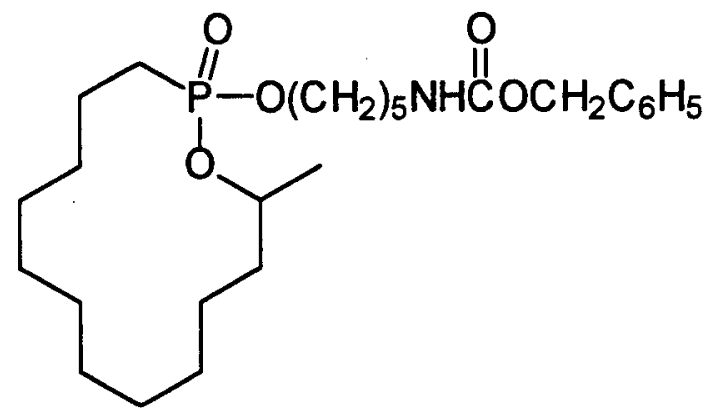

$49 b$

Alcohol $48\left(\mathrm{HO}\left(\mathrm{CH}_{2}\right)_{5} \mathrm{NHCbz}\right)(59.0 \mathrm{mg}, 230 \mu \mathrm{mol})$ was dissolved in $15.0 \mathrm{~mL}$ of THF at $-78{ }^{\circ} \mathrm{C}$ under a $\mathrm{N}_{2}$ atmosphere and treated with $1.4 \mathrm{M} \mathrm{nBuLi}$ (176 $\mu \mathrm{L}, 250 \mu \mathrm{mol})$. The alkoxide was allowed to form for $10 \mathrm{~min}$ before this mixture was cannulated into a stirred solution of $38 \mathrm{a}(69.0 \mathrm{mg}, 283 \mu \mathrm{mol})$ in $10.0 \mathrm{~mL}$ of THF at $-78^{\circ} \mathrm{C}$ under a $\mathrm{N}_{2}$ atmosphere. This mixture was allowed to warm slowly to room temperature, and was stirred overnight. The THF was then removed under reduced pressure, and the crude oil purified by column chromatography $\left(2 \% \mathrm{MeOH}\right.$ in $\mathrm{CH}_{2} \mathrm{Cl}_{2}$ ) to afford $18.5 \mathrm{mg}(14 \%)$ of $49 b$, a colourless oil. 
IR (neat): 3293, 3064, 3033, 2927, 2859, 1711, 1533, 1456, 1242, $1013 \mathrm{~cm}^{-1}$;

${ }^{1} \mathrm{H}$ NMR $\left(400 \mathrm{MHz}, \mathrm{CDCl}_{3}\right) \delta: 7.33(\mathrm{~m}, 5 \mathrm{H}), 5.07(\mathrm{~s}, 2 \mathrm{H}), 4.84(\mathrm{br} \mathrm{s}, 1 \mathrm{H})$,

$4.43(d d q, J=2.7,3.7,6.3,1 H), 4.01(m, 2 H), 3.18(d t, J=6.4$,

$6.6 \mathrm{~Hz}, 2 \mathrm{H}), 1.20-1.80(\mathrm{~m}, 28 \mathrm{H}), 1.35(\mathrm{~d}, \mathrm{~J}=6.3 \mathrm{~Hz}, 3 \mathrm{H})$;

${ }^{31}$ P NMR (81 MHz, $\left.\mathrm{CDCl}_{3}\right)$ 8: 31.3;

LRMS (EI) m/z. (relative intensity): 481 (15), 374 (55), 346 (20), 263 (100), $219(10), 193(7), 91(69)$;

HRMS calcd. for $\mathrm{C}_{26} \mathrm{H}_{44} \mathrm{NO}_{5} \mathrm{P}: 481.2957$, found 481.2951.

1-0-linker-1-oxo-1-phospho-13-tetradecanolide (50).

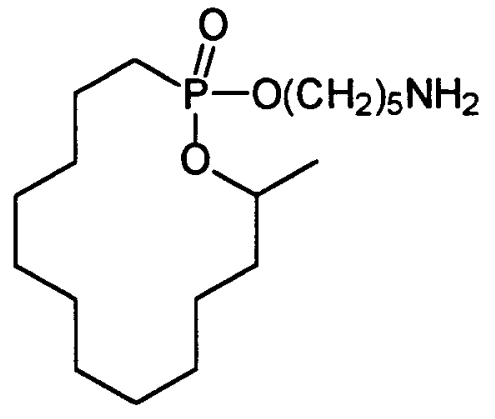

50

A spatula tip of $\mathrm{Pd}-\mathrm{C}(10 \%)$ stirring in $15 \mathrm{~mL}$ of $\mathrm{EtOH}$ was saturated with $\mathrm{H}_{2}$ for $12 \mathrm{~h}$ before a solution of compound $49 \mathrm{a}(13.8 \mathrm{mg}, 28.6 \mu \mathrm{mol})$ in $5 \mathrm{~mL}$ of EtOH was added via a steel cannula. This mixture was allowed to stir for an additional five hours under $\mathrm{H}_{2}$ pressure of one atmosphere. The reaction 
mixture was filtered through Celite and concentrated under reduced pressure to afford $8.5 \mathrm{mg}(85 \%)$ of $\mathbf{5 0}$ as a white solid.

IR ( $\left.\mathrm{CDCl}_{3}\right): 3692,3632,3181,2934,2861,1603,12651209,1008 \mathrm{~cm}^{-1}$

${ }^{1} \mathrm{H}$ NMR $\left(400 \mathrm{MHz}, \mathrm{CDCl}_{3}\right) \delta: 8.37(\mathrm{br} \mathrm{s}, 2 \mathrm{H}), 4.61(\mathrm{~m}, 1 \mathrm{H}), 4.05(\mathrm{~m}, 1 \mathrm{H})$, $3.95(\mathrm{~m}, 1 \mathrm{H}), 3.01(\mathrm{br} \mathrm{s}, 2 \mathrm{H}), 1.20-1.90(\mathrm{~m}, 28 \mathrm{H}), 1.32(\mathrm{~d}, \mathrm{~J}=6.2 \mathrm{~Hz}$, $3 \mathrm{H})$;

${ }^{31} \mathrm{P} \mathrm{NMR}\left(81 \mathrm{MHz}, \mathrm{CDCl}_{3}\right)$ 8: 33.1;

LRMS (DCl, $\left.\mathrm{NH}_{3}\right) \mathrm{m} / 2$ (relative intensity): $348\left(\mathrm{M}^{+}+1,93\right), 345$ (7), 344 (30), $86(21)$

HRMS $\left(\mathrm{DCl}, \mathrm{CH}_{4}+\mathrm{NH}_{3}\right.$ ) calcd. for $\mathrm{C}_{18} \mathrm{H}_{38} \mathrm{NO}_{3} \mathrm{P}: 347.2589$, found 347.2593.

\section{4-Benzoxybutanoic anhydride (52).}<smiles>O=C(O)CCCOCc1ccccc1</smiles>

4-Benzoxybutanoic acid (56) (2.0 g, 10 mmoles) was dissolved in $50 \mathrm{~mL}$ of anhydrous $\mathrm{Et}_{2} \mathrm{O}$ with $\mathrm{DCC}(1.1 \mathrm{~g}, 5.33$ mmoles $)$ at room temperature under $\mathrm{N}_{2}$. After 3.5 hours of stirring, the DCU (dicyclohexylurea) formed during the reaction was filtered off by aspiration, and the ether was removed under reduced pressure to give a quantitative yield of anhydride $\mathbf{5 2}$ as a colourless 
oil. The crude $\mathbf{5 2}$ obtained was carried on to the next step without further purification.

$\operatorname{IR}\left(\mathrm{CDCl}_{3}\right): 3031,2932,2857,1814,1719,1643,1496,1452,1274,1101$ $1067,741 \mathrm{~cm}^{-1}$

${ }^{1} \mathrm{H}$ NMR $\left(200 \mathrm{MHz}, \mathrm{CDCl}_{3}\right) \delta: 7.33(\mathrm{~m}, 5 \mathrm{H}), 4.49(\mathrm{~s}, 2 \mathrm{H}), 3.50(\mathrm{t}, \mathrm{J}=6.2 \mathrm{~Hz}$, $2 \mathrm{H}$ ), $2.57(\mathrm{t}, \mathrm{J}=6.2 \mathrm{~Hz}, 2 \mathrm{H}$ ), 1.95 (quint, $\mathrm{J}=6.2 \mathrm{~Hz}, 2 \mathrm{H}$ );

LRMS (DCl, $\left.\mathrm{NH}_{3}\right) \mathrm{m} / \mathrm{z}$ (relative intensity): $388\left(\mathrm{M}^{+}+18,70\right), 195$ (9), 193 (3), $178(11), 177(100), 108(26), 91(23)$;

HRMS (DCl, $\left.\mathrm{CH}_{4}\right)$ calcd. for $\mathrm{C}_{12} \mathrm{H}_{22} \mathrm{O}_{5}:\left(\mathrm{M}^{+}+1\right) 371.1856$, found

$$
\left(M^{+}+1\right) 371.1874 \text {. }
$$

Indoyl 4-benzoxybutanoate (53).

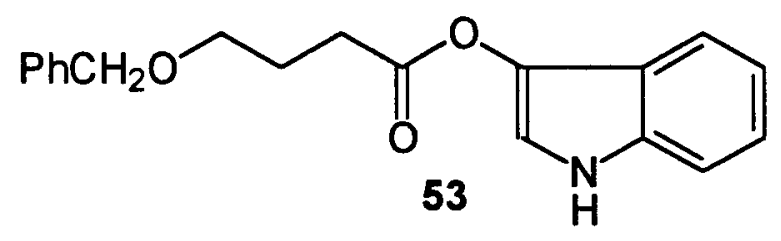

To a $\mathrm{N}_{2}$ purged solution of $2 \mathrm{~N} \mathrm{NaOH}$ ( $5 \mathrm{~mL}$ ) in a 3-neck round-bottom flask, fitted with a condenser, was added 3-indolyl acetate (135 $\mathrm{mg}, 0.77$ mmoles) via a stainless steel cannula. The mixture was heated to reflux until the 3-indolyl acetate had completely dissolved. The reaction mixture was then cooled to $0^{\circ} \mathrm{C}$, then anhydride $\mathbf{5 2}$ was added via cannula. After one hour of 
stirring at $0^{\circ} \mathrm{C}$ the mixture was transferred to a separatory funnel containing $\mathrm{Et}_{2} \mathrm{O}$ and water. The layers were separated, and the ether layer was dried over $\mathrm{MgSO}_{4}$, filtered, and the solvent removed under reduced pressure to yield $102 \mathrm{mg}$ (43\%) of 53 as a dark red-burgundy oil.

$\operatorname{IR}\left(\mathrm{CDCl}_{3}\right): 3478,3065,2959,2931,2868,1747,1223,1156,1128 \mathrm{~cm}^{-1}$

${ }^{1} \mathrm{H}$ NMR $\left(200 \mathrm{MHz}, \mathrm{CDCl}_{3}\right)$ 8: $7.84(\mathrm{br} \mathrm{s}, 1 \mathrm{H}), 7.60-7.08(\mathrm{~m}, 10 \mathrm{H}), 4.54(\mathrm{~s}$, $2 \mathrm{H}), 3.62(\mathrm{t}, J=6.2 \mathrm{~Hz}, 2 \mathrm{H}), 2.77(\mathrm{t}, \mathrm{J}=6.2 \mathrm{~Hz}, 2 \mathrm{H}), 2.10(\mathrm{~m}$, $J=6.2 \mathrm{~Hz}, 2 \mathrm{H})$;

LRMS (EI) m/z (relative intensity): 309 (0.4), 177 (4), 132 (40), 107 (36), $91(100), 77(7)$

HRMS calcd. for $\mathrm{C}_{19} \mathrm{H}_{19} \mathrm{NO}_{3}:\left(\mathrm{M}^{+}+1\right) 310.1443$, found $\left(\mathrm{M}^{+}+1\right) 310.1445$.

(Indoyl butanoate) 13-hydroxytetradecanoate (55).<smiles>CC(O)CCCCCCCCCCCC(=O)OCCCC(=O)Oc1c[nH]c2ccccc12</smiles>

Crude 53 (143 mg, 0.461 mmoles) was hydrogenolyzed overnight under an atmosphere of $\mathrm{N}_{2}$ (slightly greater than one atmosphere of pressure) with a spatula tip of $10 \% \mathrm{Pd} / \mathrm{C}$ in $30 \mathrm{~mL}$ of EtOH. The mixture was filtered through 
Celite, and the EtOH removed under reduced pressure, and the crude product was reacted with the hydroxy acid 54 (134 $\mathrm{mg}, 0.548$ mmoles) using DCC (113 mg, 0.548 mmoles) and a spatula tip of DMAP (11 mg, 0.091 mmoles) in $\mathrm{CH}_{2} \mathrm{Cl}_{2}$. After 2 hours of stirring, the reaction mixture was filtered by aspiration to remove the $\mathrm{DHU}$ formed, and the $\mathrm{CH}_{2} \mathrm{Cl}_{2}$ was evaporated under reduced pressure. The resulting crude red oil was purified on silica using a 2:1 mixture of petroleum ether and EtOAc to give $78 \mathrm{mg} \mathrm{(38 \% )} \mathrm{of} \mathrm{the}$ substrate 55 .

IR $\left(\mathrm{CDCl}_{3}\right): 3395,2924,2852,1730,1458,1164,740 \mathrm{~cm}^{-1}$;

${ }^{1} \mathrm{H}$ NMR $\left(200 \mathrm{MHz}, \mathrm{CDCl}_{3}\right) \delta: 8.02(\mathrm{br} \mathrm{s}, 1 \mathrm{H}), 7.58(\mathrm{~m}, 5 \mathrm{H}), 4.21(\mathrm{t}$, $J=6.2 \mathrm{~Hz}, 2 \mathrm{H}), 3.78(\mathrm{~m}, 1 \mathrm{H}), 2.73(\mathrm{t}, \mathrm{J}=6.2 \mathrm{~Hz}, 2 \mathrm{H}), 2.30(\mathrm{t}, \mathrm{J}=6.2$ $\mathrm{Hz}, 2 \mathrm{H}), 2.14(\mathrm{t}, \mathrm{J}=6.2 \mathrm{~Hz}, 2 \mathrm{H}), 1.60(\mathrm{t}, \mathrm{J}=6.2 \mathrm{~Hz}, 2 \mathrm{H}), 1.40(\mathrm{~m}, 2 \mathrm{H})$, $1.25(\mathrm{~m}, 16 \mathrm{H}), 1.17(\mathrm{~d}, \mathrm{~J}=6.0 \mathrm{~Hz}, 3 \mathrm{H})$;

LRMS (EI) m/z (relative intensity): 445 (0.7), 226 (4), 184 (0.5), 141 (24), $133(100), 86(1)$;

HRMS calcd. for $\mathrm{C}_{26} \mathrm{H}_{39} \mathrm{NO}_{5}:\left(\mathrm{M}^{+}\right)$445.2828, found $\left(\mathrm{M}^{+}\right)$445.2829;

p-Nitrophenyl 13-Hydroxytetradecanoate (57).<smiles>CC(O)CCCCCCCCCCCC(=O)Oc1ccc([N+](=O)[O-])cc1</smiles> 
To a stirred solution of 54 (100 mg, 0.41 mmoles) in $20 \mathrm{~mL}$ of $\mathrm{CH}_{2} \mathrm{Cl}_{2}$ was added p-nitrophenol (68 mg, 0.49 mmoles), DCC (102 mg, $0.38 \mathrm{mmoles}$ ) and DMAP (10 mg, 82 umoles). The mixture was allowed to stir at room temperature under $\mathrm{N}_{2}$ overnight. The solvent was then removed under reduced pressure, and the crude material was purified by flash chromatography using $4: 1$ petroleum ether and ethyl acetate to afford $130 \mathrm{mg}$ (87\%) of $\mathbf{5 7}$ as a white solid. A small quantity of p-nitrophenol was found to be present in the purified sample of $\mathbf{5 7}$ as seen by the multiplets at 8.15 and $6.88 \mathrm{ppm}$ in their ${ }^{1} \mathrm{H}$ NMR spectra which correspond to the aromatic protons of p-nitrophenol.

mp: $69-72^{\circ} \mathrm{C}$;

IR $\left(\mathrm{CDCl}_{3}\right): 3613,2930,2856,1762,1616,1594,1492,1348,1208 \mathrm{~cm}^{-1}$;

${ }^{1} \mathrm{H}$ NMR $\left(400 \mathrm{MHz}, \mathrm{CDCl}_{3}\right) \delta: 8.25(\mathrm{~m}, 2 \mathrm{H}), 7.25(\mathrm{~m}, 2 \mathrm{H}), 3.78(\mathrm{~m}, \mathrm{~J}=6.2 \mathrm{~Hz}$, $1 \mathrm{H}), 2.57(\mathrm{t}, \mathrm{J}=7.5 \mathrm{~Hz}, 2 \mathrm{H}$ ), 1.74 (quint, $\mathrm{J}=7.4 \mathrm{~Hz}, 2 \mathrm{H}$ ), $1.21-1.63$ $(m, 19 H), 1.18(d, J=6.2 \mathrm{~Hz}, 3 \mathrm{H})$;

LRMS $\left(\mathrm{DCl}, \mathrm{NH}_{3}\right) m / z$ (relative intensity): $383\left(\mathrm{M}^{+}+18,85\right), 366\left(\mathrm{M}^{+}+1,4\right)$, 365 (3), 348 (77), 227 (10), 226 (22), 225 (100), 143 (15), 125 (10), $123(35), 110(12), 109(16), 100(13), 99(25), 98(18)$;

HRMS (DCl, $\mathrm{NH}_{3}$ ) calcd. for $\mathrm{C}_{20} \mathrm{H}_{32} \mathrm{NO}_{5}:\left(\mathrm{M}^{+}+1\right) 366.2281$, found $\left(M^{+}+1\right) 366.2271$ 
Anal. Calcd. for $\mathrm{C}_{20} \mathrm{H}_{31} \mathrm{NO}_{5}: \mathrm{C}, 65.71 ; \mathrm{H}, 8.55 ; \mathrm{N}, 3.83$. Found: $\mathrm{C}, 66.00$; $H, 8.49 ; N, 3.84$.

p-Nitrophenyl Tetradecanoate (58).

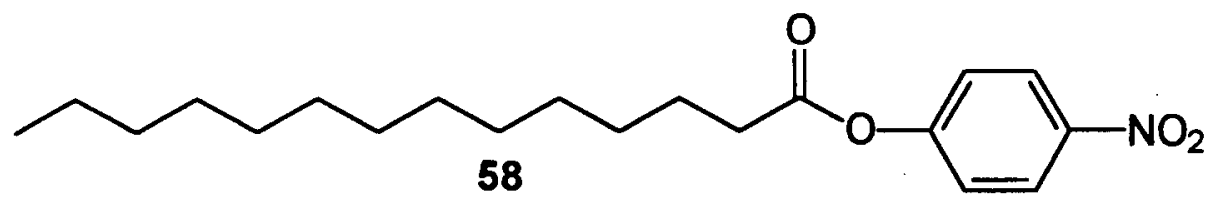

To a stirred solution of commercially available myristic acid $(0.50 \mathrm{~g}, 2.2$ mmoles) in $50 \mathrm{~mL}$ of $\mathrm{CH}_{2} \mathrm{Cl}_{2}$ was added p-nitrophenol (0.37 g, $2.6 \mathrm{mmoles}$ ), DCC (0.70 g, $2.6 \mathrm{mmoles})$ and DMAP ( $54 \mathrm{mg}, 0.44 \mathrm{mmoles})$. The mixture was allowed to stir at room temperature under $\mathrm{N}_{2}$ overnight. The solvent was then removed under reduced pressure, and the crude material was purified by flash chromatography using $20: 1$ petroleum ether and ethyl acetate to afford $0.67 \mathrm{~g}(88 \%)$ of 58 as a white solid.

$\mathrm{mp:} 52-54^{\circ} \mathrm{C}$;

IR $\left(\mathrm{CDCl}_{3}\right): 2931,2856,1762,1616,1593,1492,1457,1348,1207 \mathrm{~cm}^{-1}$;

${ }^{1} \mathrm{H}$ NMR $\left(400 \mathrm{MHz}, \mathrm{CDCl}_{3}\right) \delta: 8.25(\mathrm{~m}, 2 \mathrm{H}), 7.25(\mathrm{~m}, 2 \mathrm{H}), 2.57(\mathrm{t}, \mathrm{J}=7.5 \mathrm{~Hz}$, 2H), 1.73 (quint, $J=7.5 \mathrm{~Hz}, 2 \mathrm{H}), 1.45-1.15(\mathrm{~m}, 23 \mathrm{H})$;

LRMS (EI) $m / z$ (relative intensity): 349 (0.1), 319 (0.6), 239 (4), 211 (100), $151(0.8), 137(3), 123(4), 109(27), 85$ (16), 71 (28), 57 (45), 43 (38); 
HRMS calcd. for $\mathrm{C}_{20} \mathrm{H}_{31} \mathrm{NO}_{4}: 349.2253$, found 349.2251;

Anal. Calcd. for $\mathrm{C}_{20} \mathrm{H}_{31} \mathrm{NO}_{4}: \mathrm{C}, 68.72 ; \mathrm{H}, 8.95$. Found: $\mathrm{C}, 68.89 ; \mathrm{H}, 8.90$.

1-Oxo-1-phosphonic acid-13-tetradecanolide (59).

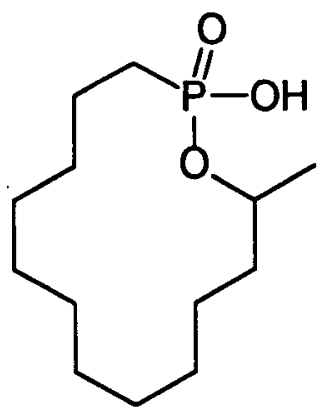

59

Compound $38 \mathrm{~b}$ ( $62 \mathrm{mg}, 0.18 \mathrm{mg}$ ) was dissolved in $20 \mathrm{~mL}$ of THF and $10 \mathrm{~mL}$ of $1.5 \mathrm{M} \mathrm{NaOH}$ and the resulting solution was refluxed for $18 \mathrm{~h}$. The THF was removed and the residual solution was acidified with $4 \mathrm{~N} \mathrm{HCl}$ then extracted with $\mathrm{Et}_{2} \mathrm{O}$. The combined ether extracts were dried over anhydrous $\mathrm{MgSO}_{4}$, filtered and concentrated under reduced pressure to afford $35 \mathrm{mg}(73 \%)$ of 59 as a white solid. This compound was used in subsequent steps without further purification.

mp: $65-68^{\circ} \mathrm{C}$;

IR $\left(\mathrm{CDCl}_{3}\right): 3160,2932,2861,1701,1452,1203,1007 \mathrm{~cm}^{-1}$;

${ }^{1} \mathrm{H}$ NMR (400 MHz, $\left.\mathrm{CDCl}_{3}\right)$ 8: $4.54(\mathrm{~m}, 1 \mathrm{H}), 3.75(\mathrm{br} \mathrm{s}, 1 \mathrm{H}), 1.77(\mathrm{~m}, 2 \mathrm{H}), 1.58$ $(m, 4 H), 1.20-1.48(m, 16 H), 1.36(d, J=6.2 \mathrm{~Hz}, 3 H)$; 
${ }^{31} \mathrm{P}$ NMR (81 MHz, $\mathrm{CDCl}_{3}$ ) 8: 35.2;

LRMS $\left(\mathrm{DCl}, \mathrm{NH}_{3}\right) \mathrm{m} / \mathrm{z}$ (relative intensity): $280\left(\mathrm{M}^{+}+18,4\right), 263\left(\mathrm{M}^{+}+1,100\right)$, 262 (9), 179 (25), 165 (35), 151 (48), 137 (25), 109 (14), 96 (16);

HRMS (DCl, $\mathrm{CH}_{4}$ ) calcd. for $\mathrm{C}_{13} \mathrm{H}_{27} \mathrm{O}_{3} \mathrm{P}: 262.1698$, found 262.1627;

Anal. Calcd. for $\mathrm{C}_{13} \mathrm{H}_{27} \mathrm{O}{ }_{3} \mathrm{P}: \mathrm{C}, 59.50 ; \mathrm{H}, 10.38$. Found: $\mathrm{C}, 59.58 ; \mathrm{H}, 10.47$.

1-p-Nitrophenyl-1-oxo-1-phospho-13-tetradecanolide (60a and 60b).

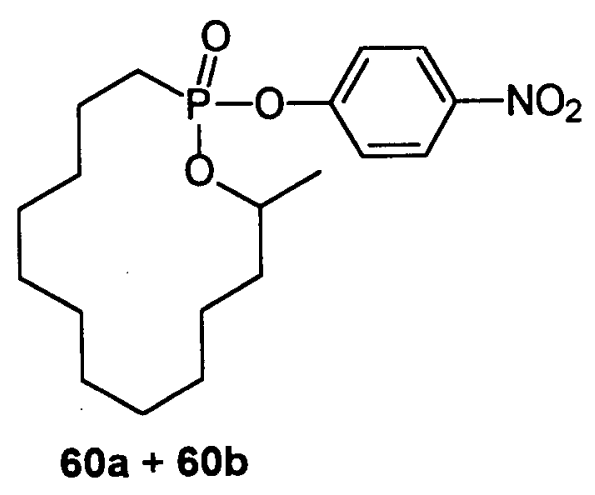

Acid $59(90.0 \mathrm{mg}, 344 \mu \mathrm{mol})$ was dissolved in $40 \mathrm{~mL}$ of $\mathrm{CH}_{2} \mathrm{Cl}_{2}$ at $0^{\circ} \mathrm{C}$ under a $\mathrm{N}_{2}$ atmosphere. Then $(\mathrm{COCl})_{2}(120 \mu \mathrm{L}, 1.37 \mathrm{mmol})$ was added, and the mixture was allowed to stir for $20 \mathrm{hr}$. The solvent, as well as excess $(\mathrm{COCl})_{2}$, were removed under reduced pressure. The resulting acid chloride was redissolved in $40 \mathrm{~mL}$ of $\mathrm{CH}_{2} \mathrm{Cl}_{2}$, then p-nitrophenol (150 $\mathrm{mg}, 1.08 \mathrm{mmol}$ ) and $\mathrm{Et}_{3} \mathrm{~N}(100 \mu \mathrm{L}, 717 \mu \mathrm{mol})$ were added, and the mixture was refluxed overnight. The reaction mixture was then washed with $3 \times 25 \mathrm{~mL}$ of $\mathrm{NaHCO}_{3}$, followed by $3 \times 25 \mathrm{~mL}$ of water. The $\mathrm{CH}_{2} \mathrm{Cl}_{2}$ layer was dried over $\mathrm{MgSO}_{4}$, filtered and the solvent removed under reduced pressure to afford $130 \mathrm{mg}$ of crude 
product. This crude material was purified by column chromatography using 3:1 petroleum ether and ethyl acetate to afford the separated diastereomers; $60 \mathrm{a}$ and $60 \mathrm{~b}$, in a 1.2:1 ratio based on the isolated yields and a combined yield of $91.0 \mathrm{mg} \mathrm{(69 \% ).} \mathrm{A} \mathrm{small} \mathrm{quantity} \mathrm{of} p$-nitrophenol was found to be present in both of the purified diastereomers as seen by the multiplets at 8.15 and $6.88 \mathrm{ppm}$ in their ${ }^{1} \mathrm{H}$ NMR spectra which correspond to the aromatic protons of p-nitrophenol.

Diastereomer 60a:

IR (neat): 3459, 3113, 3080, 2929, 2859, 1611, 1591, 1522, 1492, 1458, $1403,1380,1346,1292,1238,1162,1110,995,911,860,751 \mathrm{~cm}^{-1}$

${ }^{1} \mathrm{H}$ NMR $\left(400 \mathrm{MHz}, \mathrm{CDCl}_{3}\right) \delta: 8.22(\mathrm{~m}, 2 \mathrm{H}), 7.34(\mathrm{~m}, 2 \mathrm{H}), 4.77(\mathrm{~m}, 1 \mathrm{H}), 1.95$ $(\mathrm{m}, 2 \mathrm{H}), 1.20-1.84(\mathrm{~m}, 2 \mathrm{OH}), 1.23(\mathrm{~d}, \mathrm{~J}=6.2 \mathrm{~Hz}, 3 \mathrm{H})$;

${ }^{31} \mathrm{P}$ NMR $\left(81 \mathrm{MHz}, \mathrm{CDCl}_{3}\right)$ 8: 30.4;

LRMS (EI) m/z (relative intensity): 383 (43), 367 (20), 366 (77), 353 (21), 349 (35), 340 (17), 337 (4), 322 (17), 286 (18), 258 (25), 246 (8), 245 (56), 244 (16), 230 (44), 217 (100), 201 (10), 189 (16), 129 (28), 97 (11), 83 (21), $69(43), 55(97)$;

HRMS calcd. for $\mathrm{C}_{19} \mathrm{H}_{30} \mathrm{NO}_{5} \mathrm{P}: 383.1862$, found 383.1859 .

Diastereomer 60b:

IR (neat): 3450, 3113, 3080, 2929, 2859, 1611, 1591, 1522, 1491, 1459, 
$1345,1235,1163,1110,1004,910,859,753 \mathrm{~cm}^{-1}$

${ }^{1} \mathrm{H}$ NMR $\left(400 \mathrm{MHz}, \mathrm{CDCl}_{3}\right) \delta: 8.22(\mathrm{~m}, 2 \mathrm{H}), 7.36(\mathrm{~m}, 2 \mathrm{H}), 4.65(\mathrm{~m}, 1 \mathrm{H}), 2.20$

(m, 2H), 1.20-1.84 (m, 2OH), $1.43(\mathrm{~d}, \mathrm{~J}=6.3 \mathrm{~Hz}, 3 \mathrm{H})$;

${ }^{31} \mathrm{P}$ NMR (81 MHz, $\left.\mathrm{CDCl}_{3}\right)$ 8: 28.5;

LRMS (EI) m/z (relative intensity): 383 (9), 367 (2), 366 (9), 353 (2), 349 (3), 340 (2), 337 (0.2), 322 (2), $286(3), 258$ (5), 246 (2), 245 (11), 244 (4), 230 (11), 217 (22), 201 (2), 189 (3), 129 (2), 109 (29), 97 (5), 83 (12), $81(24), 69$ (37), 55 (100);

HRMS calcd. for $\mathrm{C}_{19} \mathrm{H}_{30} \mathrm{NO}_{5} \mathrm{P}: 383.1862$, found 383.1861 .

6-Methyl-2-oxo-2-phenoxy-1,2-oxaphosphorinane (61a and 61b).<smiles>CC1CCCP(=O)(Oc2ccccc2)O1</smiles>

$61 a+61 b$

Compound 68 (495 mg, $1.55 \mathrm{mmol}$ ) was dissolved in $30 \mathrm{~mL}$ of dry THF and stirred under $\mathrm{N}_{2}$, then cooled to $-78^{\circ} \mathrm{C}$ with a dry-ice acetone bath. 1.2 $\mathrm{M}$ n-BuLi (94 $\mu \mathrm{L}, 1.1 \mathrm{mmol}$ ) was then added via syringe, and after stirring at $-78{ }^{\circ} \mathrm{C}$ for $2.5 \mathrm{~h}$, the dry-ice acetone bath was removed. The solvent was removed under reduced pressure, and the crude product was purified by flash chromatography using $1: 1$ petroleum ether and ethyl 
acetate to afford $0.286 \mathrm{mg} \mathrm{(83 \% )}$ of $61 \mathrm{a}$ and $0.57 \mathrm{mg} \mathrm{(17 \% )} \mathrm{of} 61 \mathrm{~b}$ as colourless oils.

Isomer 61a:

IR (neat): 2946, 1592, 1491, 1455, 1384, 1302, 1255, 1209, 1161, 1079 , $1049,1032,980,921,839,789,765 \mathrm{~cm}^{-1}$;

${ }^{1} \mathrm{H}$ NMR $\left(400 \mathrm{MHz}, \mathrm{CDCl}_{3}\right)$ : $7.11-7.34(\mathrm{~m}, 5 \mathrm{H}), 4.51(\mathrm{~m}, 1 \mathrm{H}), 2.02-2.20$ $(\mathrm{m}, 2 \mathrm{H}), 1.94(\mathrm{~m}, 1 \mathrm{H}), 1.68-1.84(\mathrm{~m}, 2 \mathrm{H}), 1.51(\mathrm{~m}, 1 \mathrm{H}), 1.35(\mathrm{dd}$, $J=2.3,6.3 \mathrm{~Hz}, 3 \mathrm{H})$;

${ }^{31} \mathrm{P}$ NMR $\left(81 \mathrm{MHz}, \mathrm{CDCl}_{3}\right) \delta: 20.5$;

LRMS (EI) m/z (relative intensity): 226 (29), 211 (6), 185 (23), 172 (25), 144 (24), 115 (9), 94 (100), 77 (18);

HRMS calcd. for $\mathrm{C}_{11} \mathrm{H}_{15} \mathrm{O}_{3} \mathrm{P}: 226.0759$, found 226.0756;

Isomer 61b:

IR (neat): 2943, 1593, 1491, 1383, 1291, 1250, 1210, 1153, 1026, $951,783 \mathrm{~cm}^{-1}$;

${ }^{1} \mathrm{H}$ NMR (400 MHz, $\left.\mathrm{CDCl}_{3}\right) \delta: 7.11-7.34(\mathrm{~m}, 5 \mathrm{H}), 4.68(\mathrm{~m}, 1 \mathrm{H}), 1.96-2.22$ $(m, 3 H), 1.71-1.86(m, 2 H), 1.45-1.54(m, 1 H), 1.36(d d, J=2.3$ $6.3 \mathrm{~Hz}, 3 \mathrm{H})$;

${ }^{31} \mathrm{P}$ NMR $\left(81 \mathrm{MHz}, \mathrm{CDCl}_{3}\right)$ 8: 23.4;

LRMS (EI) m/z (relative intensity): 226 (41), 211 (7), 185 (27), 172 (30), 
144 (26), 115 (9), 94 (100), 77 (18);

HRMS calcd. for $\mathrm{C}_{11} \mathrm{H}_{15} \mathrm{O}_{3} \mathrm{P}: 226.0759$, found 226.0759 ;

Anal. Calcd. for $\mathrm{C}_{11} \mathrm{H}_{15} \mathrm{O}_{3} \mathrm{P}: \mathrm{C}, 58.39 ; \mathrm{H}, 6.69$. Found: $\mathrm{C}, 58.07 ; \mathrm{H}, 6.71$.

\section{1-Benzyloxy-3-butanol (62).}

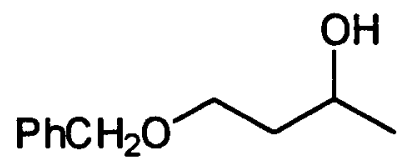

62

1,3-Butanediol ( $5.0 \mathrm{~g}, 56 \mathrm{mmol}$ ) was dissolved in $125 \mathrm{~mL}$ of dry THF, and cooled to $0{ }^{\circ} \mathrm{C}$ under $\mathrm{N}_{2}$ prior to the addition of a $60 \%$ dispersion of $\mathrm{NaH}$ in mineral oil $(2.7 \mathrm{~g}, 67 \mathrm{mmol})$ over a 10 minute period. Upon addition of the $\mathrm{NaH}$, the mixture was stirred for 10 minutes, then $\mathrm{Bu}_{4} \mathrm{NI}(1.0 \mathrm{~g}, 2.8 \mathrm{mmol})$ was added, followed by the dropwise addition of benzyl bromide $(8.0 \mathrm{~mL}, 67$ mmol). The ice-water bath was removed, and the reaction mixture was stirred at room temperature for $2.5 \mathrm{~h}$ before diluting the mixture with $\mathrm{Et}_{2} \mathrm{O}$, and quenching with water, followed by $1 \mathrm{M} \mathrm{HCl}$. The mixture was then extracted with $\mathrm{Et}_{2} \mathrm{O}$, and the combined $\mathrm{Et}_{2} \mathrm{O}$ extracts were dried over anhydrous $\mathrm{MgSO}_{4}$, filtered and solvent was evaporated under reduced pressure. The crude product was purified by flash chromatography using 1:1 petroleum ether and ethyl acetate to afford $5.8 \mathrm{~g} \mathrm{(58 \% )}$ of 62 as a colourless oil. 
${ }^{1} \mathrm{H}$ NMR $\left(200 \mathrm{MHz}, \mathrm{CDCl}_{3}\right) \delta: 7.32(\mathrm{~m}, 5 \mathrm{H}), 4.52(\mathrm{~s}, 2 \mathrm{H}), 4.00(\mathrm{~m}, 1 \mathrm{H}), 3.65$ $(\mathrm{m}, 2 \mathrm{H}), 2.63(\mathrm{~s}, 1 \mathrm{H}), 1.73(\mathrm{~m}, 2 \mathrm{H}), 1.18(\mathrm{~d}, \mathrm{~J}=6.2 \mathrm{~Hz}, 3 \mathrm{H})$;

LRMS (EI) m/z (relative intensity): 180 (2), 161 (11), 120 (15), 108 (11), 107 (46), $92(16), 91(100), 79(16), 65(12)$.

1-Benzyloxy-3-(Tetrahydropyranyloxy) butane (63).

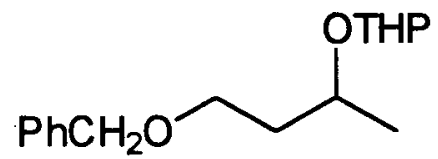

63

To a stirred solution of 62 (260 mg, $1.44 \mathrm{mmol})$ in $5 \mathrm{~mL}$ of $\mathrm{CH}_{2} \mathrm{Cl}_{2}$ was added DHP (158 $\mu \mathrm{L}, 1.73 \mathrm{mmol})$ and $\mathrm{p}-\mathrm{TsOH}(14 \mathrm{mg}, 0.072 \mathrm{mmol})$, and the mixture was stirred at room temperature under $N_{2}$ for $2 \mathrm{~h}$. The solvent was then removed and the residue was diluted with $\mathrm{Et}_{2} \mathrm{O}$. The ether layer was washed with $2 \times 25 \mathrm{~mL}$ of saturated $\mathrm{NaHCO}_{3}, 1 \times 25 \mathrm{~mL}$ water and $1 \times 50 \mathrm{~mL}$ of brine, dried over anhydrous $\mathrm{MgSO}_{4}$ and filtered. The solvent was removed under reduced pressure and the crude product was purified by flash chromatography using 5:1 petroleum ether and ethyl acetate to afford $288 \mathrm{mg}$ (76\%) of 63 as a colourless oil.

${ }^{1} \mathrm{H}$ NMR $\left(200 \mathrm{MHz}, \mathrm{CDCl}_{3}\right) \delta: 7.30(\mathrm{~m}, 5 \mathrm{H}), 4.70(\mathrm{~m}, 0.4 \mathrm{H}), 4.55(\mathrm{~m}, 0.6 \mathrm{H})$, $4.49(m, 2 H), 3.75-4.08(m, 2 H), 3.62(m, 1 H), 3.48(m, 2 H), 1.60-2.00$ $(m, 4 H), 1.40-1.60(m, 4 H), 1.24(d, J=6.2 H z, 1.5 H), 1.11(d$, 
$\mathrm{J}=6.2 \mathrm{~Hz}, 1.5 \mathrm{H}$;

LRMS (DCl, $\left.\mathrm{NH}_{3}\right) m / z$ (relative intensity): $282\left(\mathrm{M}^{+}+18,4\right), 265\left(\mathrm{M}^{+}+1,4\right)$,

181 (66), 179 (16), 91 (88), 85 (100);

HRMS (DCl, $\mathrm{CH}_{4}$ ) calcd. for $\mathrm{C}_{16} \mathrm{H}_{24} \mathrm{O}_{3}: 264.1725$, found 264.1648.

\section{3-(Tetrahydropyranyloxy) butan-1-ol (64).}

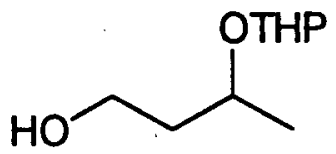

64

A spatula tip of $\mathrm{Pd}-\mathrm{C}(10 \%)$ stirring in $20 \mathrm{~mL}$ of EtOAc was saturated with $\mathrm{H}_{2}$ for $12 \mathrm{~h}$ before a solution of compound $63(230 \mathrm{mg}, 0.871 \mathrm{mmol})$ in $5 \mathrm{~mL}$ of $\mathrm{EtOH}$ was added via a steel cannula. This mixture was allowed to stir for an additional five hours under $\mathrm{H}_{2}$ pressure of one atmosphere. The reaction mixture was filtered through Celite and concentrated under reduced pressure to give $146 \mathrm{mg}$ of crude product, which was purified by flash chromatography using 1:1 petroleum ether and ethyl acetate to afford $129 \mathrm{mg}(85 \%)$ of 64 as a colourless oil.

IR (neat): $3408,2918,1447,1376,1322,1260,1201,1128,1027,1001$, $907,868,811 \mathrm{~cm}^{-1}$ 
${ }^{1} \mathrm{H}$ NMR $\left(200 \mathrm{MHz}, \mathrm{CDCl}_{3}\right) \delta: 4.68(\mathrm{~m}, 0.2 \mathrm{H}), 4.55(\mathrm{~m}, 0.8 \mathrm{H}), 3.40-4.13$

$(\mathrm{m}, 6 \mathrm{H}), 2.35(\mathrm{br} \mathrm{s}, 1 \mathrm{H}), 1.28(\mathrm{~d}, \mathrm{~J}=6.2 \mathrm{~Hz}, 0.6 \mathrm{H}), 1.15(\mathrm{~d}$, $J=6.2 \mathrm{~Hz}, 1.4 \mathrm{H}$ );

LRMS $\left(\mathrm{DCl}, \mathrm{NH}_{3}\right) \mathrm{m} / z$ (relative intensity): $192\left(\mathrm{M}^{+}+18,1\right), 175\left(\mathrm{M}^{+}+1\right.$, 4), $173(2), 108(6), 101(13), 86(10), 85$ (100), 55 (18).

3-(Tetrahydropyranyloxy) butanal (65).<smiles>CC([OH+])CC=O</smiles>

65

To a stirred solution of oxalyl chloride $(75 \mu \mathrm{L}, 0.86 \mathrm{mmol})$ in $10 \mathrm{~mL}$ of dry $\mathrm{CH}_{2} \mathrm{Cl}_{2}$ under $\mathrm{N}_{2}$ at $-78^{\circ} \mathrm{C}$ was added DMSO (102 $\left.\mu \mathrm{L}, 1.44 \mathrm{mmol}\right)$ dissolved in $2 \mathrm{~mL} \mathrm{CH} \mathrm{Cl}_{2}$ via a stainless steel cannula. After $10 \mathrm{~min}$. of stirring, compound 64 (102 mg, $0.575 \mathrm{mmol}$ ) in $5 \mathrm{~mL}$ of $\mathrm{CH}_{2} \mathrm{Cl}_{2}$ was added to the activated DMSO via a stainless steel cannula. Finally, after stirring an additional $10 \mathrm{~min}$., $\mathrm{Et}_{3} \mathrm{~N}(410 \mu \mathrm{L}, 2.95 \mathrm{mmol})$ was syringed in, and the reaction mixture was allowed to warm to room temperature while maintaining stirring. After $3 \mathrm{~h}$, the solution was diluted with $50 \mathrm{~mL}$ of $\mathrm{Et}_{2} \mathrm{O}$ followed by 50 $\mathrm{mL}$ of water. The aqueous layer was further extracted with $3 \times 50 \mathrm{~mL}$ of $\mathrm{Et}_{2} \mathrm{O}$ and the combined $\mathrm{Et}_{2} \mathrm{O}$ extracts were dried over anhydrous $\mathrm{MgSO}_{4}$, filtered and concentrated under reduced pressure to a yellow oil. The crude product 
was then purified by flash chromatography using $4: 1$ petroleum ether and ethyl acetate to afford $95 \mathrm{mg}(96 \%)$ of 65 as a colourless oil.

${ }^{1} \mathrm{H}$ NMR $\left(200 \mathrm{MHz}, \mathrm{CDCl}_{3}\right) \delta: 9.80(\mathrm{~m}, 1 \mathrm{H}), 4.68(\mathrm{~m}, 0.8 \mathrm{H}), 4.55(\mathrm{~m}, 0.2 \mathrm{H})$,

4.18-4.43 (m, 1H), 3.63-3.99 (m, 2H), $3.48(m, 1 H), 2.55(m, 2 H)$,

$1.40-1.85(\mathrm{~m}, 8 \mathrm{H}), 1.26(\mathrm{~d}, \mathrm{~J}=6.2 \mathrm{~Hz}, 0.6 \mathrm{H}), 1.20(\mathrm{~d}, \mathrm{~J}=6.2 \mathrm{~Hz}$, 2.4H).

1-Diphenylphosphinyl-4-(tetrahydropyranyloxy)-1-pentene (66).<smiles>CC([OH+])C/C=C/P(=O)(O[In])OC(F)(F)I</smiles>

66

The Wittig reagent $32(1.9 \mathrm{~g}, 3.8 \mathrm{mmol})$ and aldehyde $65(0.43 \mathrm{~g}, 2.5 \mathrm{mmol})$ were dissolved in $40 \mathrm{~mL}$ of toluene and refluxed under $\mathrm{N}_{2}$ for 3 days. The solvent was removed under reduced pressure and the crude product was purified by flash chromatography using 5:1 petroleum ether and ethyl acetate to afford $0.55 \mathrm{~g}(55 \%)$ of 66 as a colourless oil.

IR (neat): $2941,2870,1629,1592,1489,1455,1379,1341,1271,1214$, $1192,1163,1127,1074,1026,994,934,767 \mathrm{~cm}^{-1}$;

${ }^{1} \mathrm{H}$ NMR $\left(200 \mathrm{MHz}, \mathrm{CDCl}_{3}\right)$ 8: 7.10-7.38 (m, 10H), $7.00(\mathrm{~m}, 1 \mathrm{H}), 5.95$

$(m, 1 H), 4.68(m, 0.5 H), 4.55(m, 0.5 H), 3.73-4.00(m, 2 H), 3.35-3.60$ 
$(m, 1 H), 2.30-2.55(m, 2 H), 1.35-1.90(m, 6 H), 1.18(d, J=6.2 \mathrm{~Hz}$,

$1.5 \mathrm{H}), 1.08(\mathrm{~d}, \mathrm{~J}=6.2 \mathrm{~Hz}, 1.5 \mathrm{H})$;

${ }^{31} \mathrm{P} \mathrm{NMR}\left(81 \mathrm{MHz}, \mathrm{CDCl}_{3}\right) \delta: 10.8$;

LRMS (EI) m/z (relative intensity): 402 (1), 318 (28), 301 (22), 275 (26),

$274(100), 259(17), 181(13), 162(10), 141(13), 133(15), 118(18)$

117 (96), 116 (65), 115 (47), 94 (85), 77 (87);

HRMS calcd. for $\mathrm{C}_{22} \mathrm{H}_{27} \mathrm{O}_{5} \mathrm{P}: 402.1596$, found 402.1605 .

4-Hydroxy-1-diphenylphosphinyl-1-pentene (67).<smiles>CC(O)C/C=C/P(=O)(O)OC(C)C</smiles>

67

$\mathrm{p}-\mathrm{TsOH}$ ( $26 \mathrm{mg}, 0.14 \mathrm{mmol}$ ) was added to a stirred solution of compound 66

(0.55 g, $1.4 \mathrm{mmol}$ ) in $20 \mathrm{~mL}$ of $\mathrm{MeOH}$ at room temperature. After $5 \mathrm{~h}$, the $\mathrm{MeOH}$ was removed under reduced pressure and the resulting oil was dissolved in $\mathrm{Et}_{2} \mathrm{O}$, washed with $2 \times 20 \mathrm{~mL}$ of water followed by $2 \times 20 \mathrm{~mL}$ of brine, dried over anhydrous $\mathrm{MgSO}_{4}$, filtered and concentrated under reduced pressure. The crude oil was purified by flash chromatography using 1:1 petroleum ether and ethyl acetate to afford $0.31 \mathrm{~g}(70 \%)$ of alcohol 67 as a colourless oil.

IR (neat): $3403,2971,1629,1592,1489,1456,1198,1164,1120,1072$, 
$1025,937,814,767 \mathrm{~cm}^{-1}$

${ }^{1} \mathrm{H}$ NMR $\left(400 \mathrm{MHz}, \mathrm{CDCl}_{3}\right)$ 8: 7.12-7.35 (m, 10H), 6.94 (ddt, J = 7.2, 17.1, $23.1 \mathrm{~Hz}, 1 \mathrm{H}), 5.94(\mathrm{ddt}, \mathrm{J}=1.4,17.1,23.1 \mathrm{~Hz}, 1 \mathrm{H}), 3.88(\mathrm{~m}, 1 \mathrm{H}), 2.37$ (dt, J = 1.4, 7.7 Hz, 2H), $1.61(\mathrm{br} \mathrm{s}, 1 \mathrm{H}), 1.14(\mathrm{~d}, \mathrm{~J}=6.2 \mathrm{~Hz}, 3 \mathrm{H})$;

${ }^{31} \mathrm{P}$ NMR $\left(81 \mathrm{MHz}, \mathrm{CDCl}_{3}\right)$ 8: 10.8;

LRMS (EI) $m / 2$ (relative intensity): 318 (16), 274 (48), 259 (8), 181 (6), $133(7), 117$ (830), $94(82), 77(100)$;

HRMS calcd. for $\mathrm{C}_{17} \mathrm{H}_{19} \mathrm{O}_{4} \mathrm{P}: 318.1021$, found 318.1014;

Anal. Calcd. for $\mathrm{C}_{17} \mathrm{H}_{19} \mathrm{O} \mathrm{O}_{4} \mathrm{P}: \mathrm{C}, 64.13 ; \mathrm{H}, 6.02$. Found: $\mathrm{C}, 64.03 ; \mathrm{H}, 6.11$.

1-Diphenylphosphinyl pentan-4-ol (68).<smiles>CC(O)CCCP(=O)(O)O</smiles>

68

A spatula tip of $\mathrm{Pd}-\mathrm{C}(10 \%)$ in $20 \mathrm{~mL}$ of EtOAc was saturated with $\mathrm{H}_{2}$ for $16 \mathrm{~h}$ before compound $67(0.31 \mathrm{~g}, 0.97 \mathrm{mmol})$ in $3 \mathrm{~mL}$ of EtOAc was added via a steel cannula. This mixture was allowed to stir for an additional 2 days under $\mathrm{H}_{2}$ gas at a pressure slightly greater than one atmosphere. The reaction mixture was filtered through Celite and concentrated under reduced pressure to afford $0.29 \mathrm{~g}(93 \%)$ of 68 as a colourless oil.

IR (neat): 3411, 2940, 1592, 1490, 1456, 1374, 1202, 1164, 1126, 1069 , 
$1025,1007,935,763 \mathrm{~cm}^{-1}$;

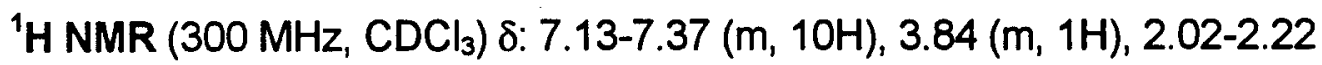

$(m, 2 H), 1.76-2.02(m, 3 H), 1.61(d t, J=6.4,7.5 \mathrm{~Hz}, 2 \mathrm{H}), 1.21$

(d, J = 6.2 Hz, 3H);

${ }^{31} \mathrm{P}$ NMR $\left(81 \mathrm{MHz}, \mathrm{CDCl}_{3}\right) \delta: 25.6$;

LRMS (EI) m/z (relative intensity): 320 (1), 305 (10), 227 (100), 185 (15),

$172(25), 140(25), 95(57), 94(96), 91$ (75), 77 (86). 


\section{REFERENCES}

1) Brockmann, H.; Henkel, W. Naturwissenschaften 1950, 37, 138.

2) Woodward, R. B. Angew. Chem. 1957, 69, 50.

3) Morin, R.; Gorman, M. Kirk-Othmer Encycl. Chem. Technol. 2nd ed. 1967, 12,632 .

4) Vanek, Z.; Majer, J. Antibiotics (N.Y.) 1967, 2, 154.

5) Omura, S.; Nakagawa, A. J. Antibiot. 1971, $28,401$.

6) Vazquez, D. Antibiotics (N.Y.) 1975, 3, 459.

7) Majer, J. J. Chromatogr. Lib. 1978, 15, 273.

8) Mallams, A. Kirk-Othmer Encycl. Chem. Technol. 3rd ed. 1978, 2, 937.

9) Korzybski, T.; Kowszyk-Gindifer, Z.; Kurylowicz, W. Antibiotics: Origin, Nature, and Properties; American Society for Microbiology: Washington, DC, 1978; Vol. 1.

10) Berdy, J. CRC Handbook of Antibiotic Compounds; CRC: Boca Raton, FL, 1980; Vol. 2.

11) Hata, T.; Omura, S. Drug Action and Drug Resistance in Bacteria; University of Tokyo: Tokyo, 1971; Vol. 1.

12) Oleinick, N. L. Antibiotics (N.Y.) 1975, 3, 396.

13) Edelstein, P. H.; Meyer, R. D. Antimicrob. Agents Chemother. 1980, 18, 403.

14) Edelstein, P. H.; Pasiecznik, K. A.; Yasui, V. K.; Meyer, R. D. Antimicrob. Agents Chemother. 1982, 22, 90.

15) Gribble, M. J.; Chow, A. W. Med. Clin. North Am. 1982, 66, 79.

16) Smith, H. Antibiotics in Clinical Practice; 3rd ed.; University Park Press: Baltimore, MD, 1977. 
17) Vannuffel, P.; Di Giambattista, M.; Morgan, E. A.; Cocito, C. J. Biol. Chem. 1992, 267, 8377.

18) Omura, S.; Nakagawa, A.; Shibata, K.; Sano, H. Tetrahedron Lett. 1982 , $23,4713$.

19) Omura, S.; Nakagawa, A.; Tanaka, Y. Trends in Antibiotic Research; Japan Antibiotics Research Foundation: Tokyo, 1982.

20) Komiyama, K.; Edanami, K.; Yamamoto, H.; Umezawa, I. J. Antibiot. 1982, $35,703$.

21) Umezawa, I.; Takeshima, H.; Komiyama, K.; Koh, Y.; Yamamoto, H.; Kawaguchi, M. J. Antibiot. 1981, 34, 259.

22) Glasby, J. S. Encyclopaedia of Antibiotics, 2nd ed; John Wiley \& Sons: New York, 1979.

23) Krohn, K.; Kirst, H.A.; Maag, H. Antibiotics and Antiviral Compounds: Chemical Synthesis and Modification; VHC Verlagsgesellschaft mbH, Weinheim (Federal Republic of Germany) and VHC Publishers Inc., New York, NY (USA), 1993.

24) Lukacs, G. Recent Progress in the Chemical Synthesis of Antibiotics and Related Microbial Products Vol. 2; Springer-Verlag: New York, NY, 1993.

25) Lukacs, G. Recent Progress in the Chemical Synthesis of Antibiotics; Springer-Verlag: New York, NY, 1990.

26) Omura, S. Macrolide Antiboitics: Chemistry, Biology and Practice; Academic: Orlando, FL, 1984.

27) Paterson, I.; Mansuri, M. M. Tetrahedron 1985, 41, 3569.

28) Spracklin, D. K.; Weiler, L. J. Chem. Soc., Chem. Commun. 1992, 1347.

29) Graham, R. J.; Weiler, L. Tetrahedron Lett. 1991, 32, 1027.

30) Keller, T. H.; Neeland, E. G.; Rettig, S.; Trotter, J.; Weiler, L. J. Am. Chem. Soc. 1988, 110, 7858.

31) Keller, T. H.; Weiler, L. Tetrahedron Lett. 1990, 31, 6307.

32) Keller, T. H.; Weiler, L. J. Am. Chem. Soc. 1990, 112, 450. 
33) Ferreira, J. T. B.; Neeland, E. G.; Ounsworth, J. P.; Weiler, L. Can. J. Chem. 1987, 65, 2314.

34) Neeland, E. G.; Ounsworth, J. P.; Sims, R. J.; Weiler, L. Tetrahedron Lett. $1987,28,35$.

35) Vedejs, E.; Dolphin, J. M.; Mastalerz, H. J. Am. Chem. Soc. 1983, 105, 127.

36) Still, W. C.; Novak, V. J. J. Am. Chem. Soc. 1984, 106, 1148.

37) Baker, W. R.; Clark, J. D.; Stephens, R. L.; Kim, K. H. J. Org. Chem. $1988,53,2340$.

38) Evans, D. A.; Carreira, E. M. Tetrahedron Lett. 1990, 31, 4703.

39) Galli, C.; Illuminati, G.; Mandolini, L. J. Am. Chem. Soc. 1973, 95, 8374.

40) Bartra, M.; Urpi, F.; Vilarrasa, J. Recent Progress in the Chemical Synthesis of Antibiotics and Related Microbial Products; Springer-Verlag: New York, NY, 1993; Vol. 2.

41) Castro, B. R. Org. React. 1982, 29, 1.

42) Mitsunobu, O. Synthesis 1981, 1.

43) Kurihara, T.; Nakajima, Y.; Mitsunobu, O. Tetrahedron Lett. 1976, 2455.

44) March, J. Advanced Organic Chemistry: Reactions, Mechanisms, and Structure; 3 ed.; John Wiley \& Sons: New York, NY, 1985, p 186.

45) Corey, E. J.; Nicolaou, K. C. J. Am. Chem. Soc. 1974, 96, 5614.

46) Mukaiyama, T.; Usui, M.; Saigo, K. Chem. Lett. 1976, 49.

47) Inanaga, J.; Hirata, K.; Saeki, H.; Katsuki, T.; Yamaguchi, M. Bull. Chem. Soc. Jpn. 1979, 52, 1989.

48) Smith, A. B., III; Leahy, J. W.; Noda, I.; Remiszewski, S. W.; Liverton, N. J.; Zibuck, R. J. Am. Chem. Soc. 1992, 114, 2995.

49) Gatfield, I. L. Ann. NY Acad. Sci. 1984, 434, 569.

50) Makita, A.; Nihira, T.; Yamada, Y. Tetrahedron Lett. 1987, 28, 805. 
51) Antczak, U.; Gora, J.; Antczak, T.; Galas, E. Enzyme Microb. Technol. $1991,13,589$.

52) O'Hagan, D.; Zaidi, N. A. J. Chem. Soc. PI 1993, 2389.

53) Guo, Z.-W.; Ngooi, T. K.; Scilimati, A.; Fulling, G.; Sih, C. J. Tetrahedron Lett. 1988, 29, 5583.

54) Mori, K.; Tomioka, H. Liebigs Ann. Chem. 1992, 1011.

55) Lobell, M.; Schneider, M. P. Tetrahedron Asym. 1993, 4, 1027.

56) Tramontano, A.; Janda, K. D.; Lerner, R. A. Science 1986, 234, 1566.

57) Jacobs, J. W.; Pollack, S. J.; Schultz, P. G. Science 1986, 234, 1570.

58) Kitazume, T.; Takeda, M. J. Chem. Soc., Chem. Commun. 1995, 39.

59) Napper, A. D.; Benkovic, S. J.; Tramontano, A.; Lerner, R. A. Science 1987, 237, 1041.

60) Pauling, L. Chem. Eng. News 1946, 24, 1375.

61) Jencks, W. P. Catalysis in Chemistry and Enzymology; McGraw-Hill: New York, NY, 1969.

62) Goding, J. W. Monoclonal Antibodies: Principles and Practices; 2 nd Ed. ed.; Academic: Orlando, FI, 1986.

63) Kohler, G.; Milstein, C. Nature (London) 1975, 256, 495.

64) Schultz, P.G. Angew. Chem. Int. Ed. Eng. 1989, 28, 1283.

65) Harlow, E.; Lane, D. Antibodies: A Laboratory Manual; Cold Spring Harbor Laboratory: Cold Spring Harbor, NY, 1988.

66) Davies, D. R.; Padlan, E. A.; Sheriff, S. Annu. Rev. Biochem. 1990, 59, 439.

67) Haynes, M. R.; Stura, E. A.; Hilvert, D.; Wilson, I. A. Science 1994, 263 , 646.

68) Getzoff, E. D.; Tainer, J. A.; Lerner, R. A.; Geysen, H. M. Adv. Immunol. $1988,43,1$. 
69) Winter, G.; Milstein, C. Nature 1991, 349, 293.

70) Davis, M. M.; Bjorkman, P. J. Nature (London) 1988, 334, 395.

71) Honjo, T.; Habu, S. Annu. Rev. Biochem. 1985, 54, 803.

72) Tonegawa, S. Nature (London) 1983, 302, 575.

73) Schechter, I. Nature (London) 1970, 228, 639.

74) Lowe, C. R.; Harvey, M. J.; Craven, D. B.; Dean, P. D. G. Biochem. J. 1973, 133, 499.

75) Milewich, L.; Gomez-Sanchez, C.; MacDonald, P. C.; Siiteri, P. K. J. Ster. Biochem. 1975, 6, 1381.

76) Humphries, G. M. K.; McConnel, H. M. Biophys. J. 1976, 16, 275.

77) Milstein, C. Sci. Am. 1980, 243, 66.

78) Brown, A. J. J. Chem. Soc. 1902, 81, 373.

79) Henri, V. Lois Générales de l' action des diastases, Hermann, Paris, 1903.

80) Michaelis, L., Menten, M. L. Biochem. Z. 1913, 49, 333.

81) Walsh, C. Enzymatic Reaction Mechanisms; W.H. Freeman: San Francisco, 1979, p 34.

82) (a) Otera, J. Chem. Rev. 1993, 93, 1449; (b) Chen, C. 'S.; Sih, C. J. Angew. Chem. Int. Ed. Engl. 1989, 28, 695.

83) Klibanov, A. M. CHEMTECH. 1986, 354.

84) Zaks, A.; Kilbanov, A. M. Science 1984, 224, 1249.

85) Cotterill, I. C.; Sutherland, A. G.; Roberts, S. M.; Grobbauer, R.; Spreitz, J.; Faber, K. J. Chem. Soc., Perkin Trans. I 1991, 1365.

86) Ashley, J. A.; Benkovic, S. J.; Janda, K. D.; Wirsching, P.; Lerner, R. A. Science 1991, 252, 680.

87) Tramontano, A.; Ammann, A. A.; Lerner, R. A. J. Am. Chem. Soc. 1988, 110, 2282. 
88) Janda, K. D.; Shevlin, C. G.; Lerner, R. A. Science 1993, 259, 490.

89) Gong, B.; Lesley, S. A.; Schultz, P. G. J. Am. Chem. Soc. 1992, 114, 1486.

90) Tsumuraya, T.; Suga, H.; Meguro, S.; Tsunakawa, A.; Masamune, S. J. Am. Chem. Soc. 1995, 117, 11390.

91) Jacobsen, J. R.; Prudent, J. R.; Kochersperger, L.; Yonkovich, S.; Schultz, P. G. Science 1992, 256, 365.

92) Lilly, M. D. J. Chem. Technol. Biotechnol. 1982, 32, 162.

93) Antonini, E.; Carrea, G.; Cremonesi, P. Enzyme Microb. Technol. 1981, 3, 291.

94) Shevlin, C.G.; Hilton, S.; Janda, K.D. Bioorg. Med. Chem. Let. 1994, 4, 297.

95) Zaks, A.; Kilbanov, A. M. J. Biol. Chem. 1988, 263, 8017.

96) Zaks, A.; Kilbanov, A. M Proc. Natl. Acad. Sci. U.S.A. 1985, 82, 3192.

97) Ashley, J. A.; Janda, K. D. J. Org. Chem. 1992, 57, 6691.

98) Cambou, B.; Kilbanov, A. M. J. Am. Chem. Soc. 1984, 106, 2687.

99) Guibe-Jampel, E.; Rousseau, G. Tetrahedron Lett. 1987, 28, 3563.

100) Hsu, S.- H.; Wu, S.- S.; Wang, Y.- F.; Wong, C.- H. Tetrahedron Lett. $1990,31,6403$.

101) Luisi, P. L. Angew. Chem. Int. Ed. Engl. 1985, 24, 439.

102) Meier, P.; Luisi, P. L. Solid Phase Biochem. 1980, 5, 269.

103) Barbaric, S.; Luisi, P. L. J. Am. Chem. Soc. 1981, 103, 4239.

104) Janda, K. D.; Ashley, J. A.; Jones, T. M.; McLeod, D. A.; Schloeder, D. M.; Weinhouse, M. I. J. Am. Chem. Soc. 1990, 112, 8886.

105) Spitznagel, T. M.; Jacobs, J. W.; Clark, D. S. Enzyme Microb. Technol. 1993, 15, 916. 
106) Durfor, C. N.; Bolin, R. J.; Sugasawara, R. J.; Massey, R. J.; Jacobs, J. W.; Schultz, P. G. J. Am. Chem. Soc. 1988, 110, 8713.

107) Okahata, Y.; Yamaguchi, M.; Tanaka, F.; Fujii, I. Tetrahedron 1995, 51, 7673.

108) Wolfenden, R. Annu. Rev. Biophys. Bioeng. 1976, 5, 271-306.

109) Fersht, A. Enzyme Structure and Mechanism; Freeman: New York, 1985.

110) Adams, J. A.; Benkovic, S. J.; Borders, J., C.L.; Janda, K. D.; Lerner, R. A. Science 1990, 250, 1135.

111) Martin, M. T.; Napper, A. D.; Schultz, P. G.; Rees, A. R. Biochemistry 1991, 30, 9757.

112) Janda, K. D.; Lerner, R. A.; Tramontano, A. J. Am. Chem. Soc. 1988, 110, 4835.

113) Benkovic, S. J.; Napper, A. D.; Lerner, R. A. Proc. Natl. Acad. Sci. U.S.A. $1988,85,5355$.

114) Janda, K. D.; Schloeder, D.; Benkovic, S. J.; Lerner, R. A. Science 1988, $241,1188$.

115) Janjic, N.; Tramontano, A. J. Am. Chem. Soc. 1989, 111, 9109.

116) Shokat, K. M.; Leumann, C. J.; Sugasawara, R.; Schultz, P. G. Angew. Chem. Int. Ed. Eng. 1988, 27, 1172.

117) Shokat, K. M.; Leumann, C. J.; Sugasawara, R.; Schultz, P. G. Nature (London) 1989, 338, 269.

118) Cochran, A.; Schultz, P. G. J. Am. Chem. Soc. 1990, 112, 9414.

119) Hilton, S.; Li, T.; Janda, K. D. J. Am. Chem. Soc. 1995, 117, 2123.

120) Iverson, B. L.; Cameron, K. E.; Jahangiri, G. K.; Pasternak, D. S. J. Am. Chem. Soc. 1990, 112, 5320.

121) Fujii, I.; Lerner, R. A.; Janda, K. D. J. Am. Chem. Soc. 1991, 113, 8528.

122) Jackson, D. Y.; Schultz, P. G. J. Am. Chem. Soc. 1991, 113, 2319.

123) Reymond, J.- L.; Janda, K. D.; Lerner, R. A. Angew. Chem. Int. Ed. Eng. $1991,30,1711$. 
124) Hilvert, D. Acc. Chem. Res. 1993, 26, 552.

125) Jackson, D. Y.; Liang, M. N.; Bartlett, P. A.; Schultz, P. G. Angew. Chem. Int. Ed. Eng. 1992, 31, 182.

126) Bence, L. M.; Irvine, J. I.; Stimson, W. H.; Tedford, M. C.; Suckling, C. J. J. Chem. Soc. Perkin Trans. 11993, 1925.

127) Hsieh, L. C.; Yonkovich, S.; Kochersperger, L.; Schultz, P. G. Science $1993,260,337$.

128) Cook, C. E.; Allen, D. A.; Miller, D. B.; Whisnant, C. C. J. Am. Chem. Soc. $1995,117,7269$.

129) Wagner, J.; Lerner, R. A.; Barbas, C. F. I. Science 1995, 270, 1797.

130) Koch, T.; Reymond, J.- L.; Lerner, R. A. J. Am. Chem. Soc. 1995, 117, 9383.

131) Reymond, J.- L.; Chen, Y. Tetrahedron Lett. 1995, 36, 2575.

132) Jacobs, J. W. Ph.D. Thesis, University of California, Berkeley, 1990.

133) Spracklin, D. K. Ph.D. Thesis, University of British Columbia, 1994.

134) From reference 69 in Masamune, S.; Bates, G.S.; Corcoran, J.W. Angew. Chem., Int. Ed. Engl. 1977, 16, 585.

135) Roush, W. R. J. Org. Chem. 1979, 44, 4010.

136) Stork, G.; Nakamura, E. J. Org. Chem. 1979, 44, 4011.

137) Jones, G. H.; Hamamura, E. K.; Moffatt, J. G. Tetrahedron Lett. 1968, 5731.

138) Campbell, D. A. J. Org. Chem. 1992, 57, 6331.

139) Hughes, D. L.; Reamer, R. A. J. Org. Chem. 1996, 61, 2967.

140) Jacobs, J.; Schultz, P. G. J. Am. Chem. Soc. 1987, 109, 2174.

141) Dale. J. J. Chem. Soc. 1963, 85, 93.

142) Groth, P. Acta Chem. Scand. A 1979, 33, 199. 
143) Mohamadi, F.; Richards, N. G. J.; Guida, W. C.; Liskamp, R.; Lipton, M.; Caufield, C.; Chang, G.; Hendrickson, T.; Still, W. C. J. Comp. Chem. $1990,11,440$.

144) Burkert, U.; Allinger, N. L. ACS Monograph 177 American Chemical Society: Washington, DC, 1982.

145) McEwen, W.E. Topics in Phosphorus Chemistry Vol. 2; John Wiley \& Sons: New York, NY, 1965.

146) Wadsworth, Jr., W. S.; Larsen, S.; Horten, H. L. J. Org. Chem. 1973, 38, 256.

147) Thatcher, G.R.J.; Kluger, R. Adv. Phys. Org. Chem. 1989, 25, 99.

148) Green, M.; Hudson, R. F. Proc. Chem. Soc. 1959, 227.

149) Wadsworth, Jr., W. S. J. Org. Chem. 1973, 38, 2921.

150) Babcock, J.; Watts, J.; Aebersold, R.; Ziltener, H. Anal. Biochem. 1991, 196, 245.

151) Nakayama, G. R.; Schultz, P. G. J. Am. Chem. Soc. 1992, 114, 780.

152) Lavey, B. J.; Janda, K. D. J. Org. Chem. 1996, 61, 7633.

153) (a) Darrow, J. W.; Drueckhammer, D. G. J. Org. Chem. 1994, 59, 2976; (b) Darrow, J. W.; Drueckhammer, D. G. Bioorg. Med. Chem. 1996, 4, 1341.

154) Hanessian, S.; Galéotti, N.; Rosen, P.; Oliva, G.; Babu, S. Bioorg. Med. Chem. Lett. 1994, 4, 2763.

155) Harvey, T. C.; Simiand, C.; Weiler, L.; Withers, S. G. J. Org. Chem., in press.

156) Gorenstein, D. G. Chem. Rev. 1987, 87, 1047.

157) Chang, J. W.; Gorenstein, D. G. Tetrahedron 1987, 43, 5187.

158) Copeland, R. A. Enzymes: A Practical Introduction To Structure, Mechanism, And Data Analysis; VCH Publishers Inc., New York, NY (USA), 1996, p 135.

159) Neil, T.R., Nat. Prod. Rep. 1996, 13, 479. 
160) Lavey, B. J.; Janda, K. D. J. Org. Chem. 1996, 61, 7633.

161) Morton, H. J. In Vitro 1970, 6, 89.

162) Perrin, D.D.; Armarego, W.L.F. Purification of Laboratory Chemicals; 3rd ed.; Permagon: New York, NY, 1988.

163) Still, W.C.; Kahn, M.; Mitra, A. J. Org. Chem. 1978, 43, 2923. 


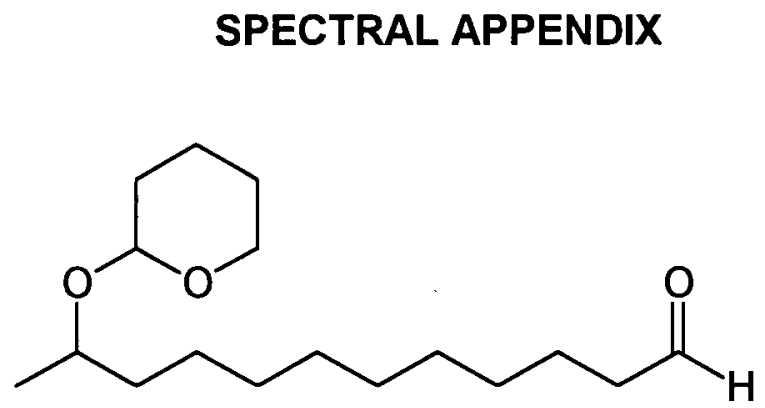

33
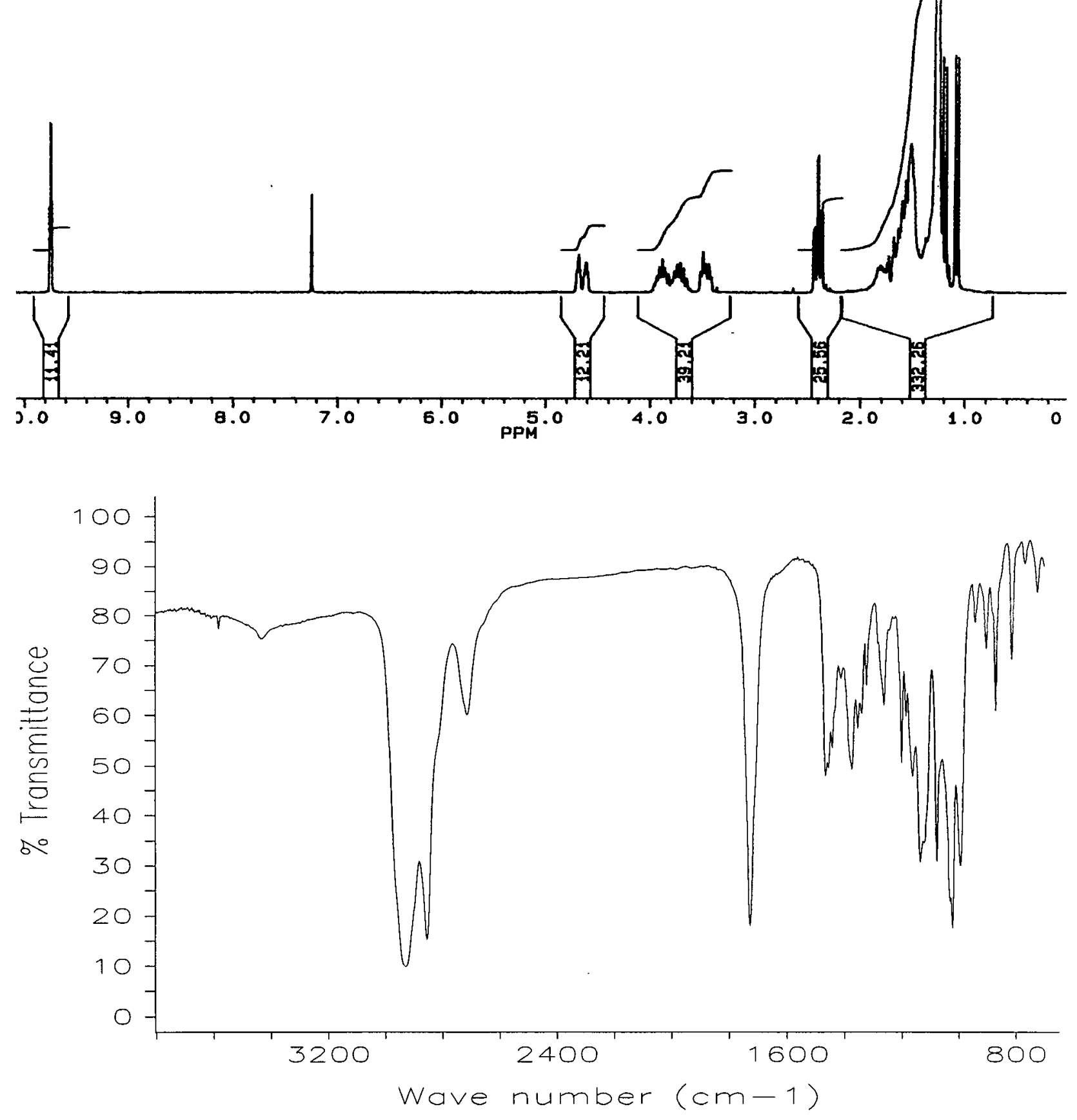

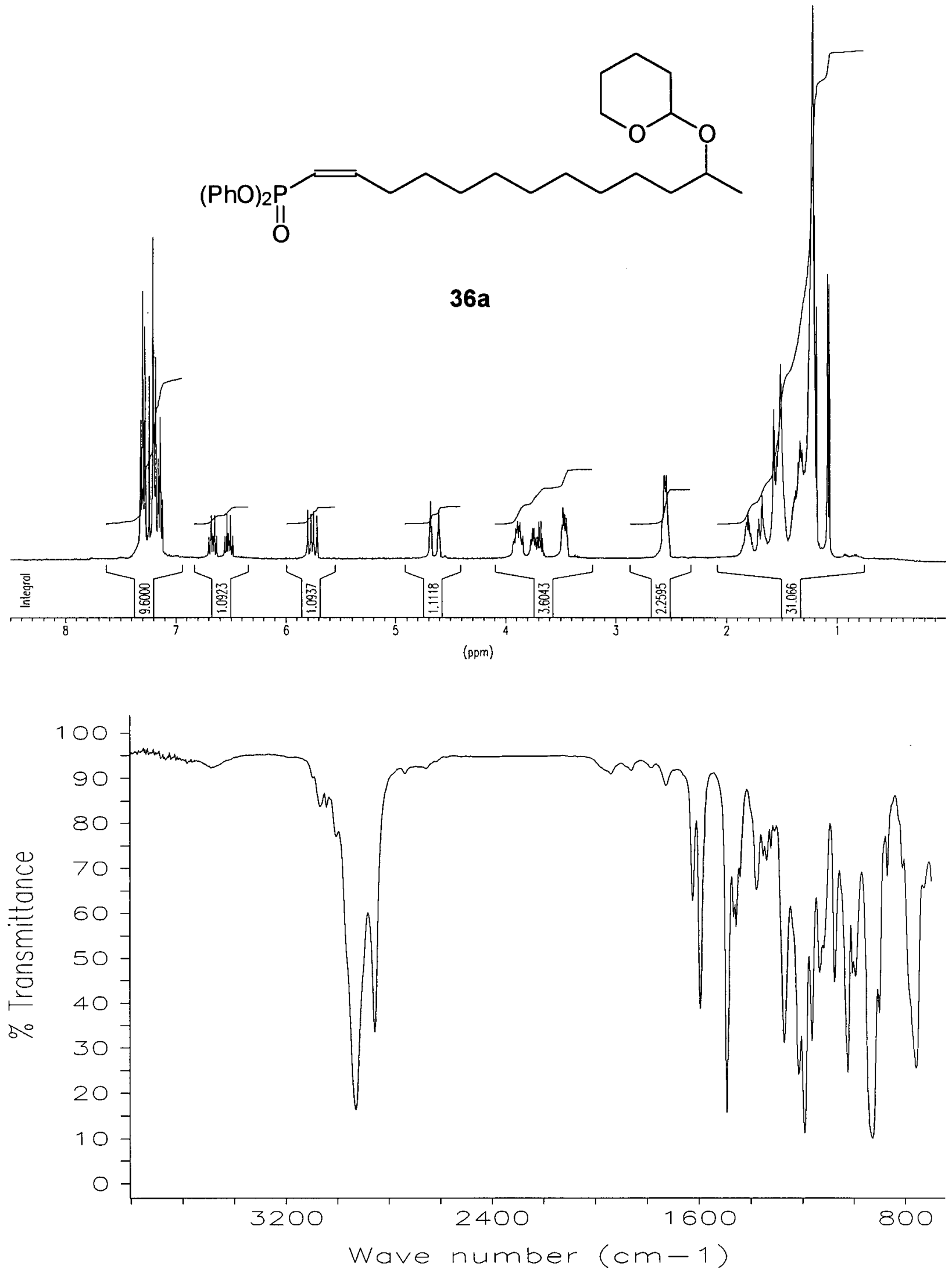

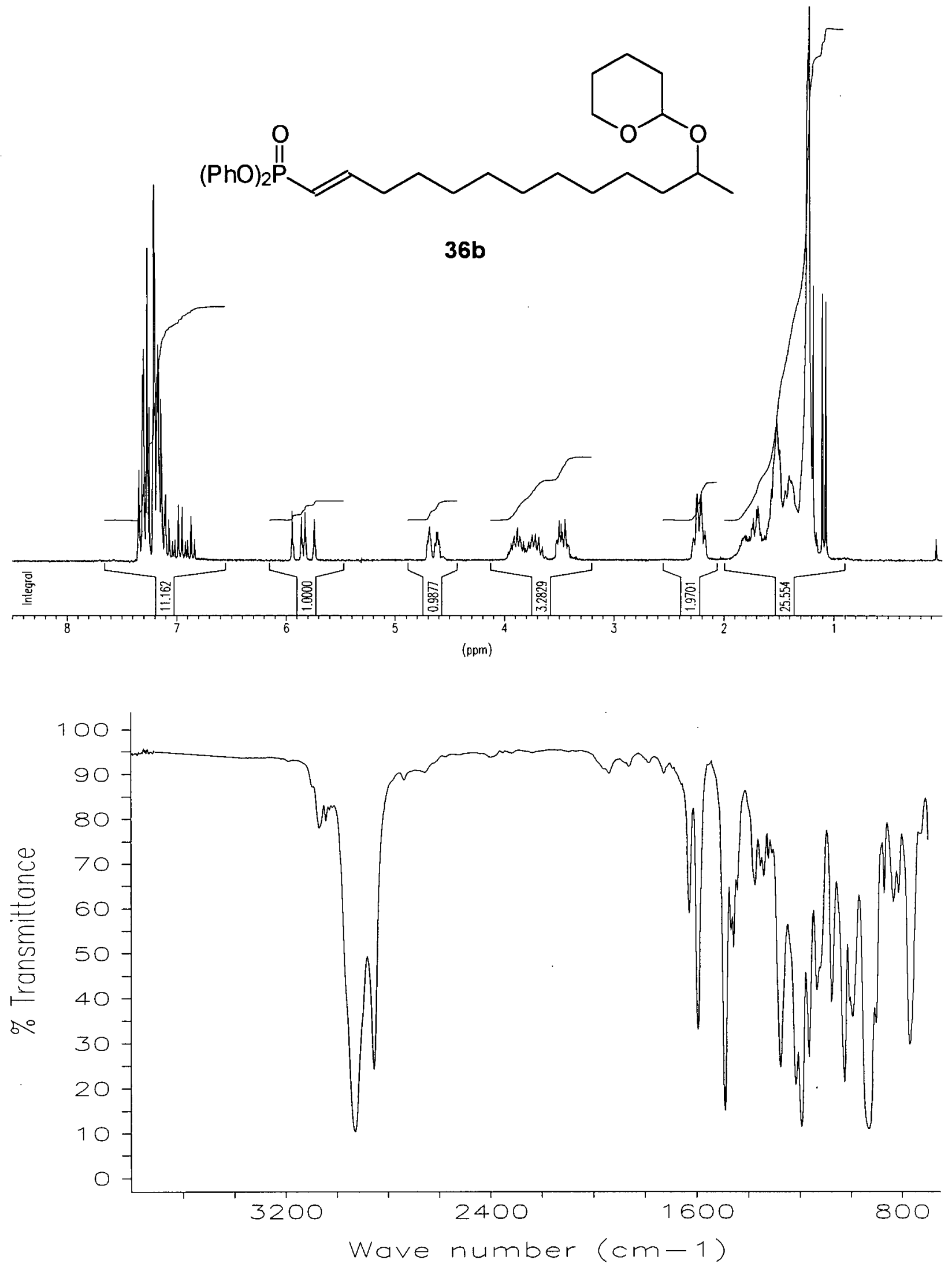

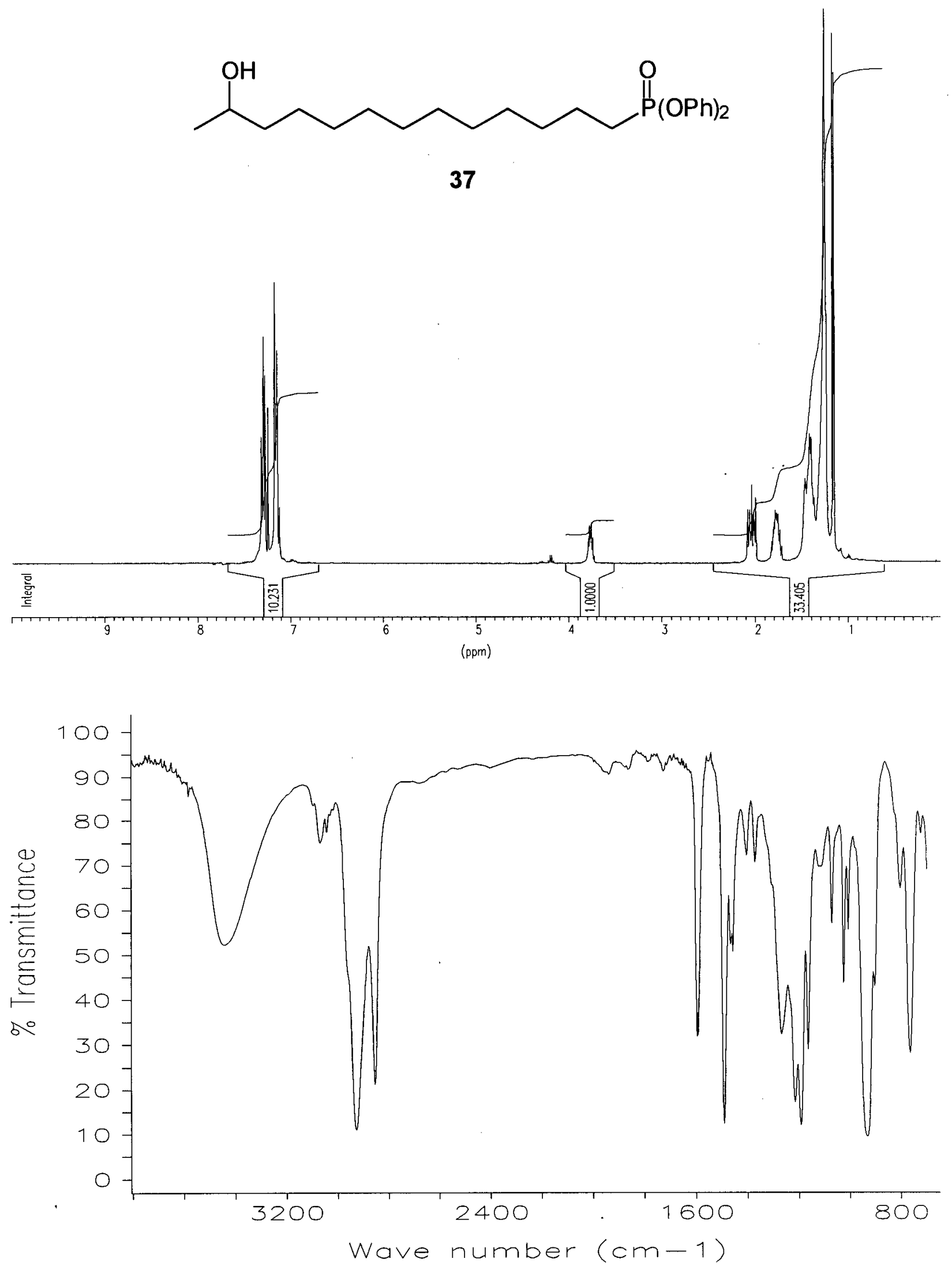
17) Vannuffel, P.; Di Giambattista, M.; Morgan, E. A.; Cocito, C. J. Biol. Chem. 1992, 267, 8377.

18) Omura, S.; Nakagawa, A.; Shibata, K.; Sano, H. Tetrahedron Lett. 1982, $23,4713$.

19) Omura, S.; Nakagawa, A.; Tanaka, Y. Trends in Antibiotic Research; Japan Antibiotics Research Foundation: Tokyo, 1982.

20) Komiyama, K.; Edanami, K.; Yamamoto, H.; Umezawa, I. J. Antibiot. 1982, $35,703$.

21) Umezawa, I.; Takeshima, H.; Komiyama, K.; Koh, Y.; Yamamoto, H.; Kawaguchi, M. J. Antibiot. 1981, 34, 259.

22) Glasby, J. S. Encyclopaedia of Antibiotics, 2 nd ed.; John Wiley \& Sons: New York, 1979.

23) Krohn, K.; Kirst, H.A.; Maag, H. Antibiotics and Antiviral Compounds: Chemical Synthesis and Modification; VHC Verlagsgesellschaft $\mathrm{mbH}$, Weinheim (Federal Republic of Germany) and VHC Publishers Inc., New York, NY (USA), 1993.

24) Lukacs, G. Recent Progress in the Chemical Synthesis of Antibiotics and Related Microbial Products Vol. 2; Springer-Verlag: New York, NY, 1993.

25) Lukacs, G. Recent Progress in the Chemical Synthesis of Antibiotics; Springer-Verlag: New York, NY, 1990.

26) Omura, S. Macrolide Antiboitics: Chemistry, Biology and Practice; Academic: Orlando, FL, 1984.

27) Paterson, I.; Mansuri, M. M. Tetrahedron 1985, 41, 3569.

28) Spracklin, D. K; Weiler, L. J. Chem. Soc., Chem. Commun. 1992, 1347.

29) Graham, R. J.; Weiler, L. Tetrahedron Lett. 1991, 32, 1027.

30) Keller, T. H.; Neeland, E. G.; Rettig, S.; Trotter, J.; Weiler, L. J. Am. Chem. Soc. 1988, 110, 7858.

31) Keller, T. H.; Weiler, L. Tetrahedron Lett. 1990, 31, 6307.

32) Keller, T. H.; Weiler, L. J. Am. Chem. Soc. 1990, 112, 450. 
33) Ferreira, J. T. B.; Neeland, E. G.; Ounsworth, J. P.; Weiler, L. Can. J. Chem. 1987, 65, 2314.

34) Neeland, E. G.; Ounsworth, J. P.; Sims, R. J.; Weiler, L. Tetrahedron Lett. $1987,28,35$.

35) Vedejs, E.; Dolphin, J. M.; Mastalerz, H. J. Am. Chem. Soc. 1983, 105, 127.

36) Still, W. C.; Novak, V. J. J. Am. Chem. Soc. 1984, 106, 1148.

37) Baker, W. R.; Clark, J. D.; Stephens, R. L.; Kim, K. H. J. Org. Chem. 1988, 53, 2340.

38) Evans, D. A.; Carreira, E. M. Tetrahedron Lett. 1990, 31, 4703.

39) Galli, C.; Illuminati, G.; Mandolini, L. J. Am. Chem. Soc. 1973, 95, 8374.

40) Bartra, M.; Urpi, F.; Vilarrasa, J. Recent Progress in the Chemical Synthesis of Antibiotics and Related Microbial Products; Springer-Verlag: New York, NY, 1993; Vol. 2.

41) Castro, B. R. Org. React. 1982, 29, 1.

42) Mitsunobu, O. Synthesis 1981, 1.

43) Kurihara, T.; Nakajima, Y.; Mitsunobu, O. Tetrahedron Lett. 1976, 2455.

44) March, J. Advanced Organic Chemistry: Reactions, Mechanisms, and Structure; 3 ed.; John Wiley \& Sons: New York, NY, 1985, p 186.

45) Corey, E. J.; Nicolaou, K. C. J. Am. Chem. Soc. 1974, 96, 5614.

46) Mukaiyama, T.; Usui, M.; Saigo, K. Chem. Lett. 1976, 49.

47) Inanaga, J.; Hirata, K.; Saeki, H.; Katsuki, T.; Yamaguchi, M. Bull. Chem. Soc. Jpn. 1979, 52, 1989.

48) Smith, A. B., III; Leahy, J. W.; Noda, I.; Remiszewski, S. W.; Liverton, N. J.; Zibuck, R. J. Am. Chem. Soc. 1992, 114, 2995.

49) Gatfield, I. L. Ann. NY Acad. Sci. 1984, 434, 569.

50) Makita, A.; Nihira, T.; Yamada, Y. Tetrahedron Lett. 1987, 28, 805. 
51) Antczak, U.; Gora, J.; Antczak, T.; Galas, E. Enzyme Microb. Technol. 1991, 13, 589.

52) O'Hagan, D.; Zaidi, N. A. J. Chem. Soc. Pl 1993, 2389.

53) Guo, Z.-W.; Ngooi, T. K.; Scilimati, A.; Fulling, G.; Sih, C. J. Tetrahedron Lett. 1988, 29, 5583.

54) Mori, K.; Tomioka, H. Liebigs Ann. Chem. 1992, 1011.

55) Lobell, M.; Schneider, M. P. Tetrahedron Asym. 1993, 4, 1027.

56) Tramontano, A.; Janda, K. D.; Lerner, R. A. Science 1986, 234, 1566.

57) Jacobs, J. W.; Pollack, S. J.; Schultz, P. G. Science 1986, 234, 1570.

58) Kitazume, T.; Takeda, M. J. Chem. Soc., Chem. Commun. 1995, 39.

59) Napper, A. D.; Benkovic, S. J.; Tramontano, A.; Lerner, R. A. Science 1987, 237, 1041.

60) Pauling, L. Chem. Eng. News 1946, 24, 1375.

61) Jencks, W. P. Catalysis in Chemistry and Enzymology, McGraw-Hill: New York, NY, 1969.

62) Goding, J. W. Monoclonal Antibodies: Principles and Practices; 2 nd Ed. ed.; Academic: Orlando, FI, 1986.

63) Kohler, G.; Milstein, C. Nature (London) 1975, 256, 495.

64) Schultz, P.G. Angew. Chem. Int. Ed. Eng. 1989, 28, 1283.

65) Harlow, E.; Lane, D. Antibodies: A Laboratory Manual; Cold Spring Harbor Laboratory: Cold Spring Harbor, NY, 1988.

66) Davies, D. R.; Padlan, E. A.; Sheriff, S. Annu. Rev. Biochem. 1990, 59, 439.

67) Haynes, M. R.; Stura, E. A.; Hilvert, D.; Wilson, I. A. Science 1994, 263, 646.

68) Getzoff, E. D.; Tainer, J. A.; Lerner, R. A.; Geysen, H. M. Adv. Immunol. $1988,43,1$. 
69) Winter, G.; Milstein, C. Nature 1991, 349, 293.

70) Davis, M. M.; Bjorkman, P. J. Nature (London) 1988, 334, 395.

71) Honjo, T.; Habu, S. Annu. Rev. Biochem. 1985, 54, 803.

72) Tonegawa, S. Nature (London) 1983, 302, 575.

73) Schechter, I. Nature (London) 1970, 228, 639.

74) Lowe, C. R.; Harvey, M. J.; Craven, D. B.; Dean, P. D. G. Biochem. J. 1973, 133, 499.

75) Milewich, L.; Gomez-Sanchez, C.; MacDonald, P. C.; Siiteri, P. K. J. Ster. Biochem. 1975, 6, 1381.

76) Humphries, G. M. K.; McConnel, H. M. Biophys. J. 1976, 16, 275.

77) Milstein, C. Sci. Am. 1980, 243, 66.

78) Brown, A. J. J. Chem. Soc. 1902, 81, 373.

79) Henri, V. Lois Générales de l' action des diastases, Hermann, Paris, 1903.

80) Michaelis, L., Menten, M. L. Biochem. Z. 1913, 49, 333.

81) Walsh, C. Enzymatic Reaction Mechanisms; W.H. Freeman: San Francisco, 1979, p 34.

82) (a) Otera, J. Chem. Rev. 1993, 93, 1449; (b) Chen, C. 'S.; Sih, C. J. Angew. Chem. Int. Ed. Engl. 1989, 28, 695.

83) Klibanov, A. M. CHEMTECH. 1986, 354.

84) Zaks, A.; Kilbanov, A. M. Science 1984, 224, 1249.

85) Cotterill, I. C.; Sutherland, A. G.; Roberts, S. M.; Grobbauer, R.; Spreitz, J.; Faber, K. J. Chem. Soc., Perkin Trans. / 1991, 1365.

86) Ashley, J. A.; Benkovic, S. J.; Janda, K. D.; Wirsching, P.; Lerner, R. A. Science 1991, 252, 680.

87) Tramontano, A.; Ammann, A. A.; Lerner, R. A. J. Am. Chem. Soc. 1988, 110, 2282. 
88) Janda, K. D.; Shevlin, C. G.; Lerner, R. A. Science 1993, 259, 490.

89) Gong, B.; Lesley, S. A.; Schultz, P. G. J. Am. Chem. Soc. 1992, 114, 1486.

90) Tsumuraya, T.; Suga, H.; Meguro, S.; Tsunakawa, A.; Masamune, S. J. Am. Chem. Soc. 1995, 117, 11390.

91) Jacobsen, J. R.; Prudent, J. R.; Kochersperger, L.; Yonkovich, S.; Schultz, P. G. Science 1992, 256, 365.

92) Lilly, M. D. J. Chem. Technol. Biotechnol. 1982, 32, 162.

93) Antonini, E.; Carrea, G.; Cremonesi, P. Enzyme Microb. Technol. 1981, 3, 291.

94) Shevlin, C.G.; Hilton, S.; Janda, K.D. Bioorg. Med. Chem. Let. 1994, 4, 297.

95) Zaks, A.; Kilbanov, A. M. J. Biol. Chem. 1988, 263, 8017.

96) Zaks, A.; Kilbanov, A. M Proc. Natl. Acad. Sci. U.S.A. 1985, 82, 3192.

97) Ashley, J. A.; Janda, K. D. J. Org. Chem. 1992, 57, 6691.

98) Cambou, B.; Kilbanov, A. M. J. Am. Chem. Soc. 1984, 106, 2687.

99) Guibe-Jampel, E.; Rousseau, G. Tetrahedron Lett. 1987, 28, 3563.

100) Hsu, S.- H.; Wu, S.- S.; Wang, Y.- F.; Wong, C.- H. Tetrahedron Lett. $1990,31,6403$.

101) Luisi, P. L. Angew. Chem. Int. Ed. Engl. 1985, 24, 439.

102) Meier, P.; Luisi, P. L. Solid Phase Biochem. 1980, 5, 269.

103) Barbaric, S.; Luisi, P. L. J. Am. Chem. Soc. 1981, 103, 4239.

104) Janda, K. D.; Ashley, J. A.; Jones, T. M.; McLeod, D. A.; Schloeder, D. M.; Weinhouse, M. I. J. Am. Chem. Soc. 1990, 112, 8886.

105) Spitznagel, T. M.; Jacobs, J. W.; Clark, D. S. Enzyme Microb. Technol. 1993, 15, 916. 
106) Durfor, C. N.; Bolin, R. J.; Sugasawara, R. J.; Massey, R. J.; Jacobs, J. W.; Schultz, P. G. J. Am. Chem. Soc. 1988, 110, 8713.

107) Okahata, Y.; Yamaguchi, M.; Tanaka, F.; Fujii, I. Tetrahedron 1995, 51 , 7673.

108) Wolfenden, R. Annu. Rev. Biophys. Bioeng. 1976, 5, 271-306.

109) Fersht, A. Enzyme Structure and Mechanism; Freeman: New York, 1985.

110) Adams, J. A.; Benkovic, S. J.; Borders, J., C.L.; Janda, K. D.; Lerner, R. A. Science 1990, 250, 1135.

111) Martin, M. T.; Napper, A. D.; Schultz, P. G.; Rees, A. R. Biochemistry $1991,30,9757$.

112) Janda, K. D.; Lerner, R. A.; Tramontano, A. J. Am. Chem. Soc. 1988, 110, 4835.

113) Benkovic, S. J.; Napper, A. D.; Lerner, R. A. Proc. Natl. Acad. Sci. U.S.A. $1988,85,5355$.

114) Janda, K. D.; Schloeder, D.; Benkovic, S. J.; Lerner, R. A. Science 1988, $241,1188$.

115) Janjic, N.; Tramontano, A. J. Am. Chem. Soc. 1989, 111, 9109.

116) Shokat, K. M.; Leumann, C. J.; Sugasawara, R.; Schultz, P. G. Angew. Chem. Int. Ed. Eng. 1988, 27, 1172.

117) Shokat, K. M.; Leumann, C. J.; Sugasawara, R.; Schultz, P. G. Nature (London) 1989, 338, 269.

118) Cochran, A.; Schultz, P. G. J. Am. Chem. Soc. 1990, 112, 9414.

119) Hilton, S.; Li, T.; Janda, K. D. J. Am. Chem. Soc. 1995, 117, 2123.

120) Iverson, B. L.; Cameron, K. E.; Jahangiri, G. K.; Pasternak, D. S. J. Am. Chem. Soc. 1990, 112, 5320.

121) Fujii, I.; Lerner, R. A.; Janda, K. D. J. Am. Chem. Soc. 1991, 113, 8528.

122) Jackson, D. Y.; Schultz, P. G. J. Am. Chem. Soc. 1991, 113, 2319.

123) Reymond, J.- L.; Janda, K. D.; Lerner, R. A. Angew. Chem. Int. Ed. Eng. $1991,30,1711$. 
124) Hilvert, D. Acc. Chem. Res. 1993, 26, 552.

125) Jackson, D. Y.; Liang, M. N.; Bartlett, P. A.; Schultz, P. G. Angew. Chem. Int. Ed. Eng. 1992, 31, 182.

126) Bence, L. M.; Irvine, J. I.; Stimson, W. H.; Tedford, M. C.; Suckling, C. J. J. Chem. Soc. Perkin Trans. 1 1993, 1925.

127) Hsieh, L. C.; Yonkovich, S.; Kochersperger, L.; Schultz, P. G. Science 1993, 260, 337.

128) Cook, C. E.; Allen, D. A.; Miller, D. B.; Whisnant, C. C. J. Am. Chem. Soc. 1995, 117, 7269 .

129) Wagner, J.; Lerner, R. A.; Barbas, C. F. I. Science 1995, 270, 1797.

130) Koch, T.; Reymond, J.- L.; Lerner, R. A. J. Am. Chem. Soc. 1995, 117, 9383.

131) Reymond, J.- L.; Chen, Y. Tetrahedron Lett. 1995, 36, 2575.

132) Jacobs, J. W. Ph.D. Thesis, University of California, Berkeley, 1990.

133) Spracklin, D. K. Ph.D. Thesis, University of British Columbia, 1994.

134) From reference 69 in Masamune, S.; Bates, G.S.; Corcoran, J.W. Angew. Chem., Int. Ed. Engl. 1977, 16, 585.

135) Roush, W. R. J. Org. Chem. 1979, 44, 4010.

136) Stork, G.; Nakamura, E. J. Org. Chem. 1979, 44, 4011.

137) Jones, G. H.; Hamamura, E. K.; Moffatt, J. G. Tetrahedron Lett. 1968, 5731.

138) Campbell, D. A. J. Org. Chem. 1992, 57, 6331.

139) Hughes, D. L.; Reamer, R. A. J. Org. Chem. 1996, 61, 2967.

140) Jacobs, J.; Schultz, P. G. J. Am. Chem. Soc. 1987, 109, 2174.

141) Dale. J. J. Chem. Soc. 1963, 85, 93.

142) Groth, P. Acta Chem. Scand. A 1979, 33, 199. 
143) Mohamadi, F.; Richards, N. G. J.; Guida, W. C.; Liskamp, R.; Lipton, M.; Caufield, C.; Chang, G.; Hendrickson, T.; Still, W. C. J. Comp. Chem. $1990,11,440$.

144) Burkert, U.; Allinger, N. L. ACS Monograph 177 American Chemical Society: Washington, DC, 1982.

145) McEwen, W.E. Topics in Phosphorus Chemistry Vol. 2; John Wiley \& Sons: New York, NY, 1965.

146) Wadsworth, Jr., W. S.; Larsen, S.; Horten, H. L. J. Org. Chem. 1973, 38, 256.

147) Thatcher, G.R.J.; Kluger, R. Adv. Phys. Org. Chem. 1989, 25, 99.

148) Green, M.; Hudson, R. F. Proc. Chem. Soc. 1959, 227.

149) Wadsworth, Jr., W. S. J. Org. Chem. 1973, 38, 2921.

150) Babcock, J.; Watts, J.; Aebersold, R.; Ziltener, H. Anal. Biochem. 1991, 196, 245.

151) Nakayama, G. R.; Schultz, P. G. J. Am. Chem. Soc. 1992, 114, 780.

152) Lavey, B. J.; Janda, K. D. J. Org. Chem. 1996, 61, 7633.

153) (a) Darrow, J. W.; Drueckhammer, D. G. J. Org. Chem. 1994, 59, 2976; (b) Darrow, J. W.; Drueckhammer, D. G. Bioorg. Med. Chem. 1996, 4, 1341.

154) Hanessian, S.; Galéotti, N.; Rosen, P.; Oliva, G.; Babu, S. Bioorg. Med. Chem. Lett. 1994, 4, 2763.

155) Harvey, T. C.; Simiand, C.; Weiler, L.; Withers, S. G. J. Org. Chem., in press.

156) Gorenstein, D. G. Chem. Rev. 1987, 87, 1047.

157) Chang, J. W.; Gorenstein, D. G. Tetrahedron 1987, 43, 5187.

158) Copeland, R. A. Enzymes: A Practical Introduction To Structure, Mechanism, And Data Analysis; VCH Publishers Inc., New York, NY (USA), 1996, p 135.

159) Neil, T.R., Nat. Prod. Rep. 1996, 13, 479. 
160) Lavey, B. J.; Janda, K. D. J. Org. Chem. 1996, 61, 7633.

161) Morton, H. J. In Vitro 1970, 6, 89.

162) Perrin, D.D.; Armarego, W.L.F. Purification of Laboratory Chemicals; 3rd ed.; Permagon: New York, NY, 1988.

163) Still, W.C.; Kahn, M.; Mitra, A. J. Org. Chem. 1978, 43, 2923. 


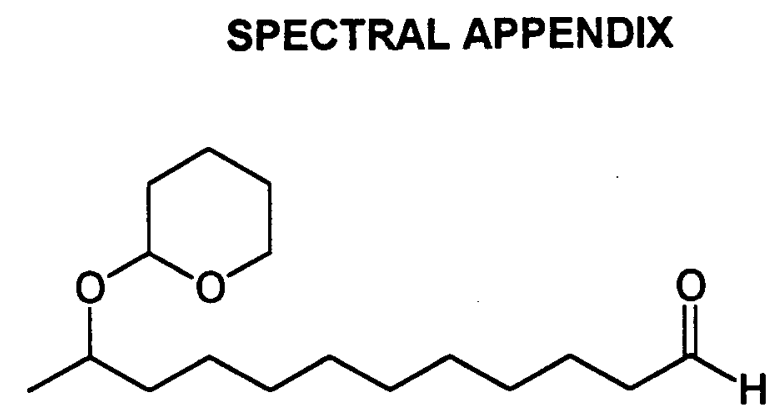

33
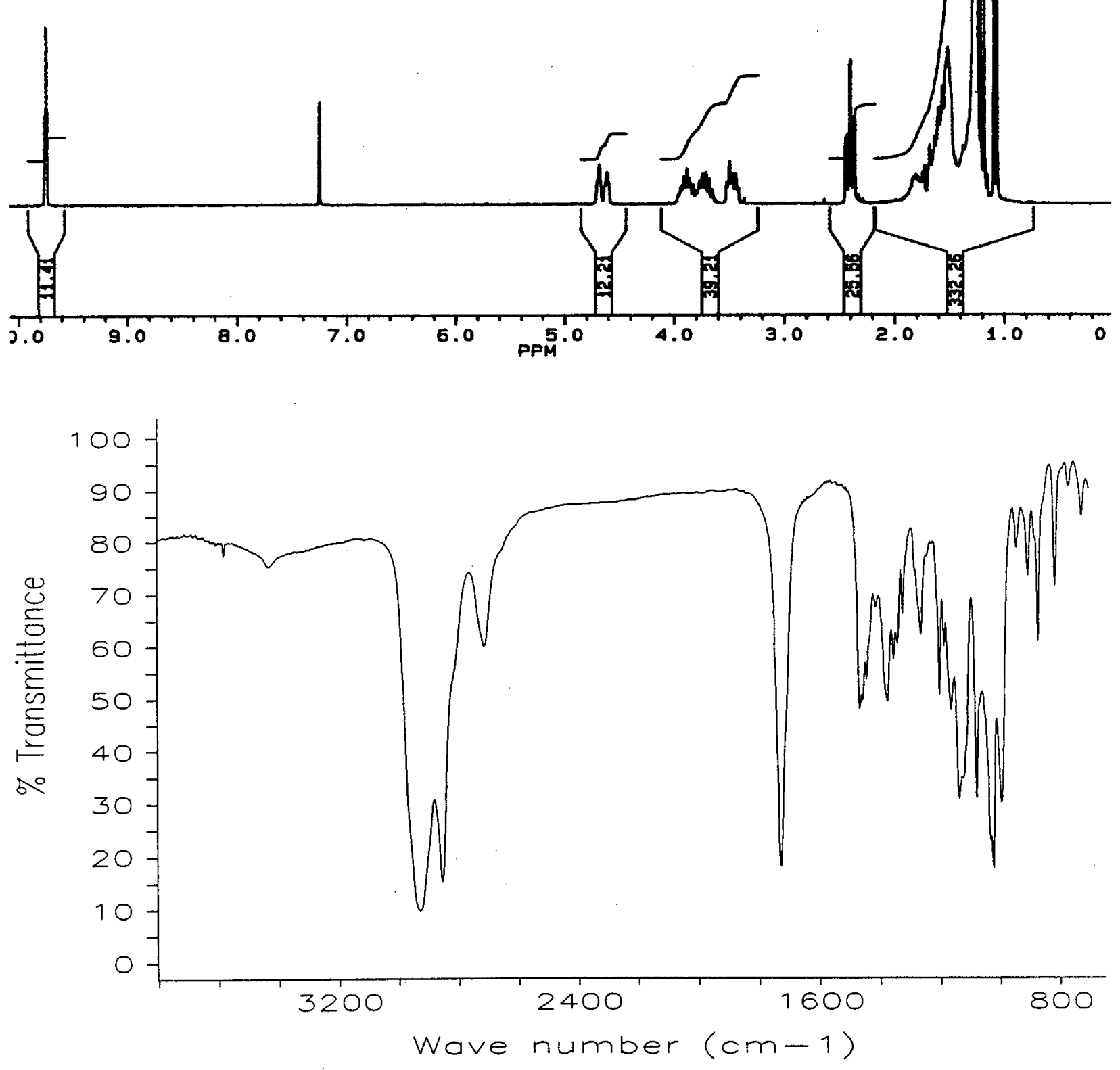

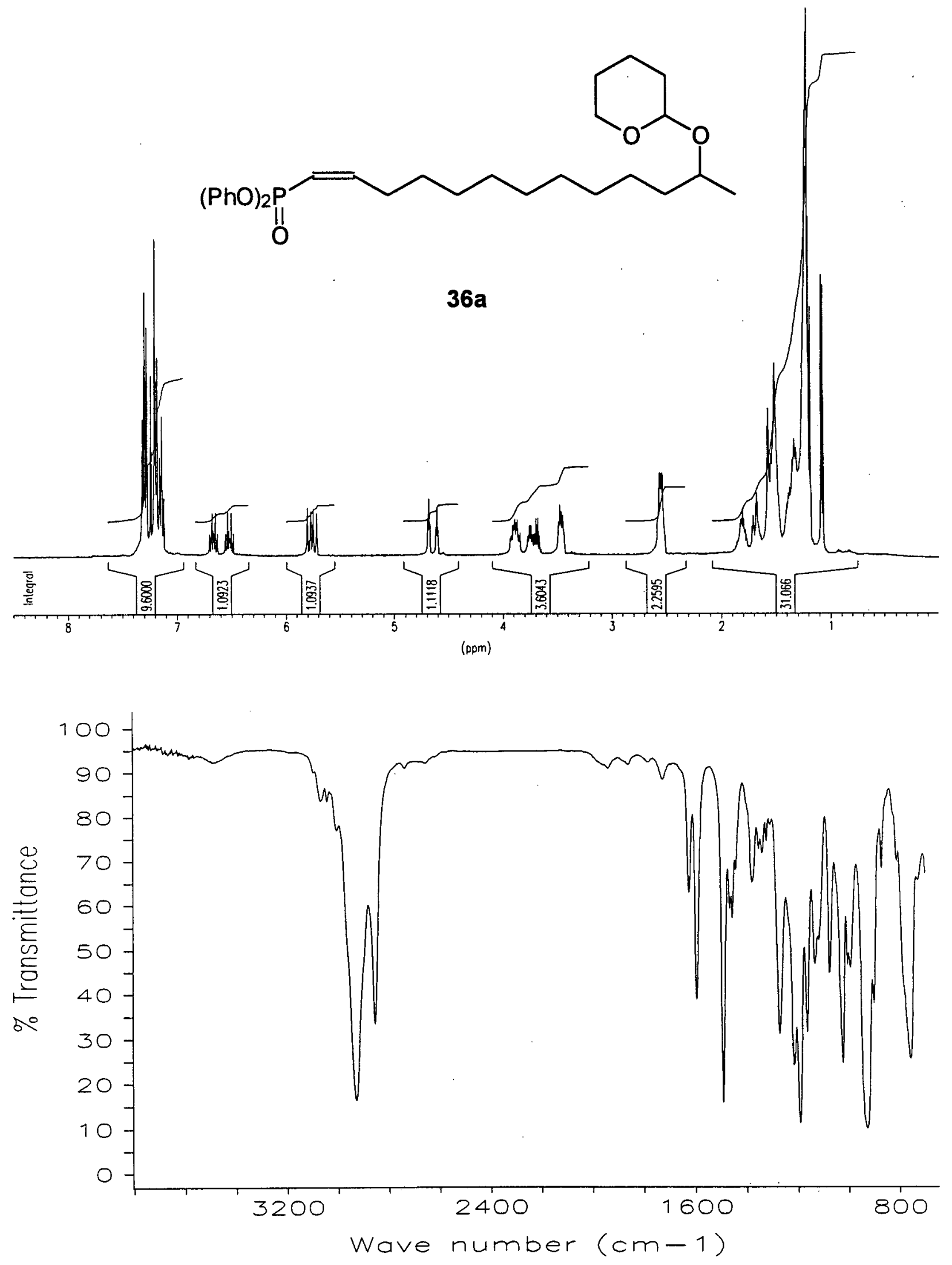

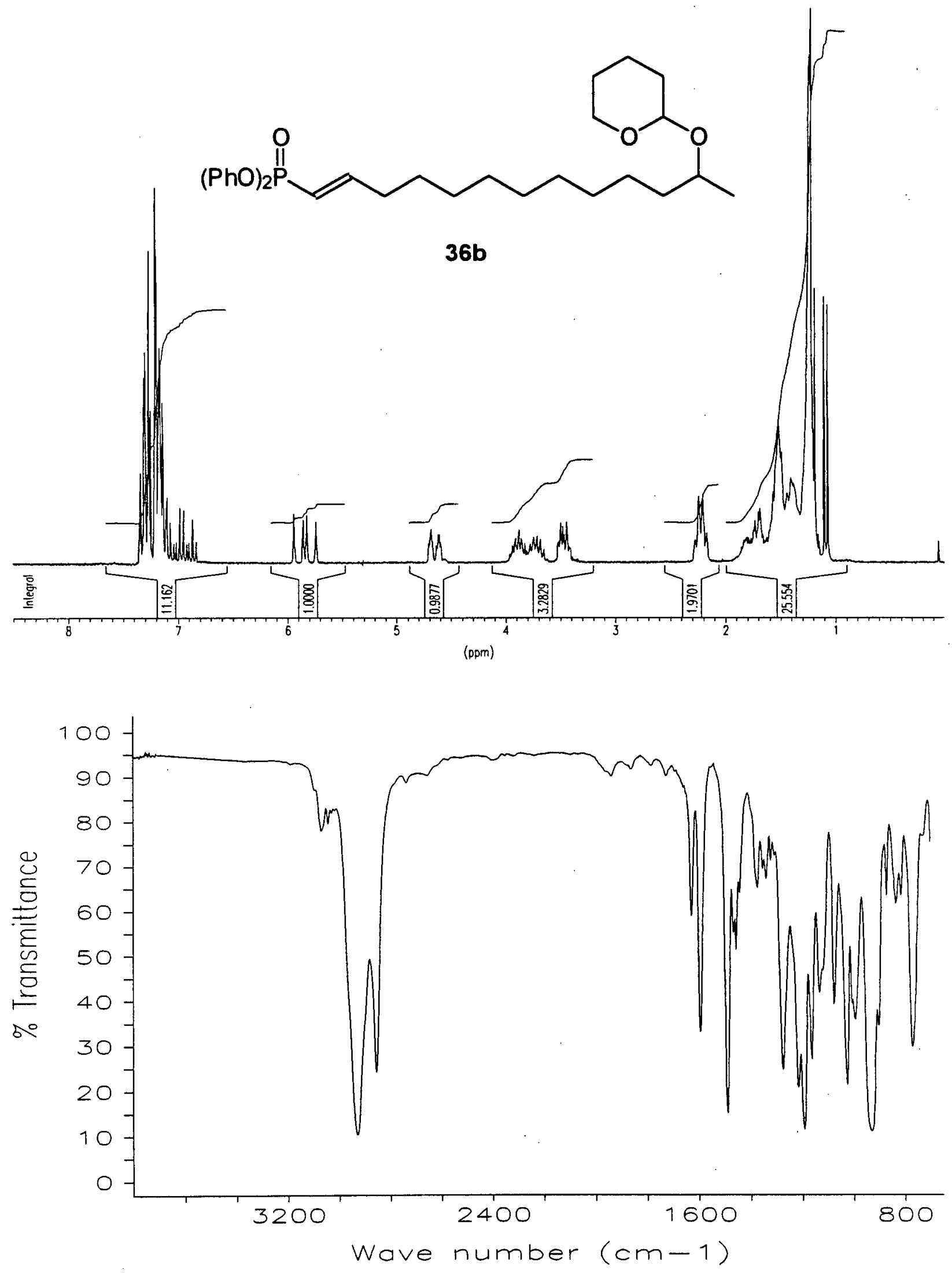

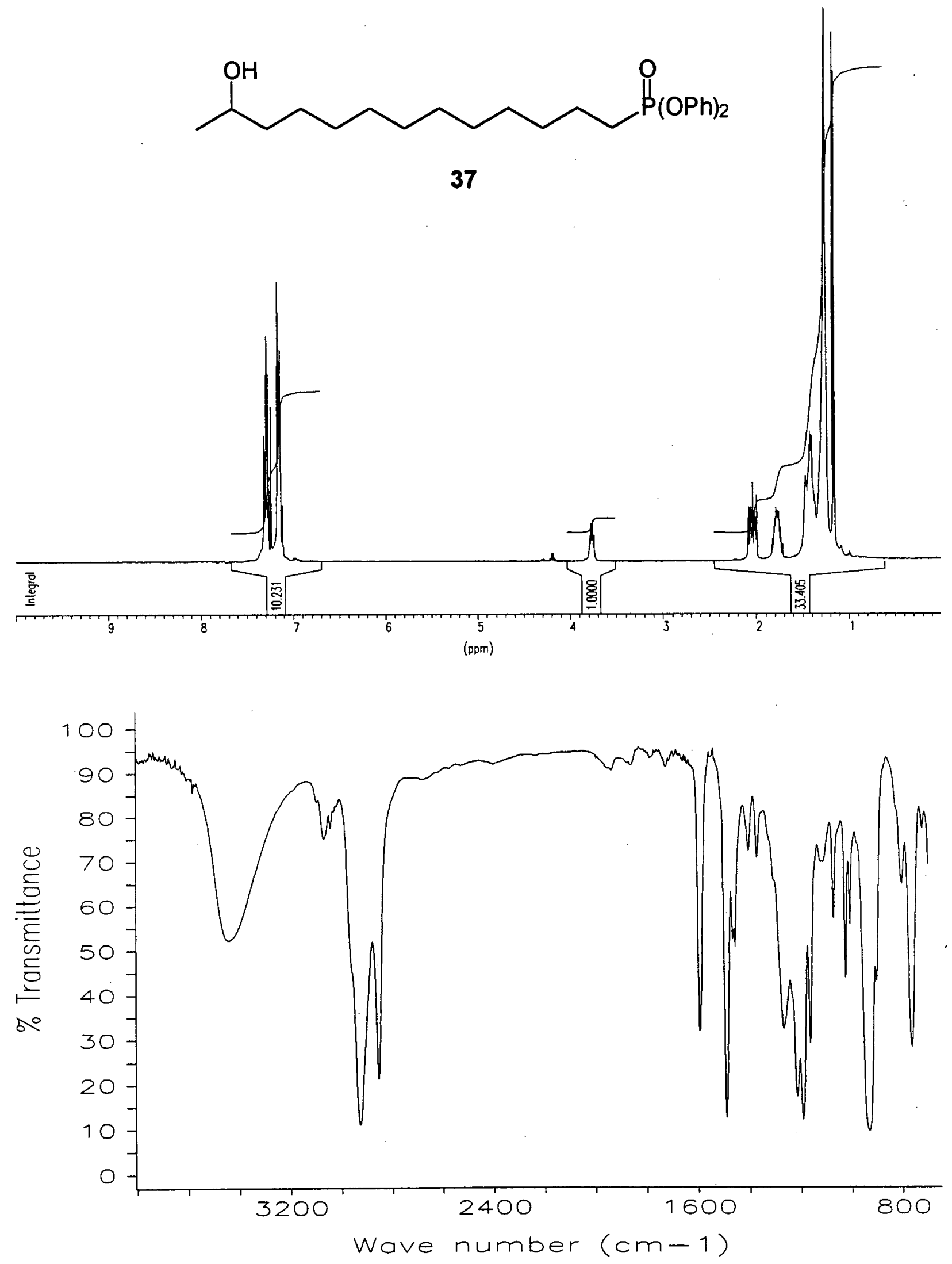

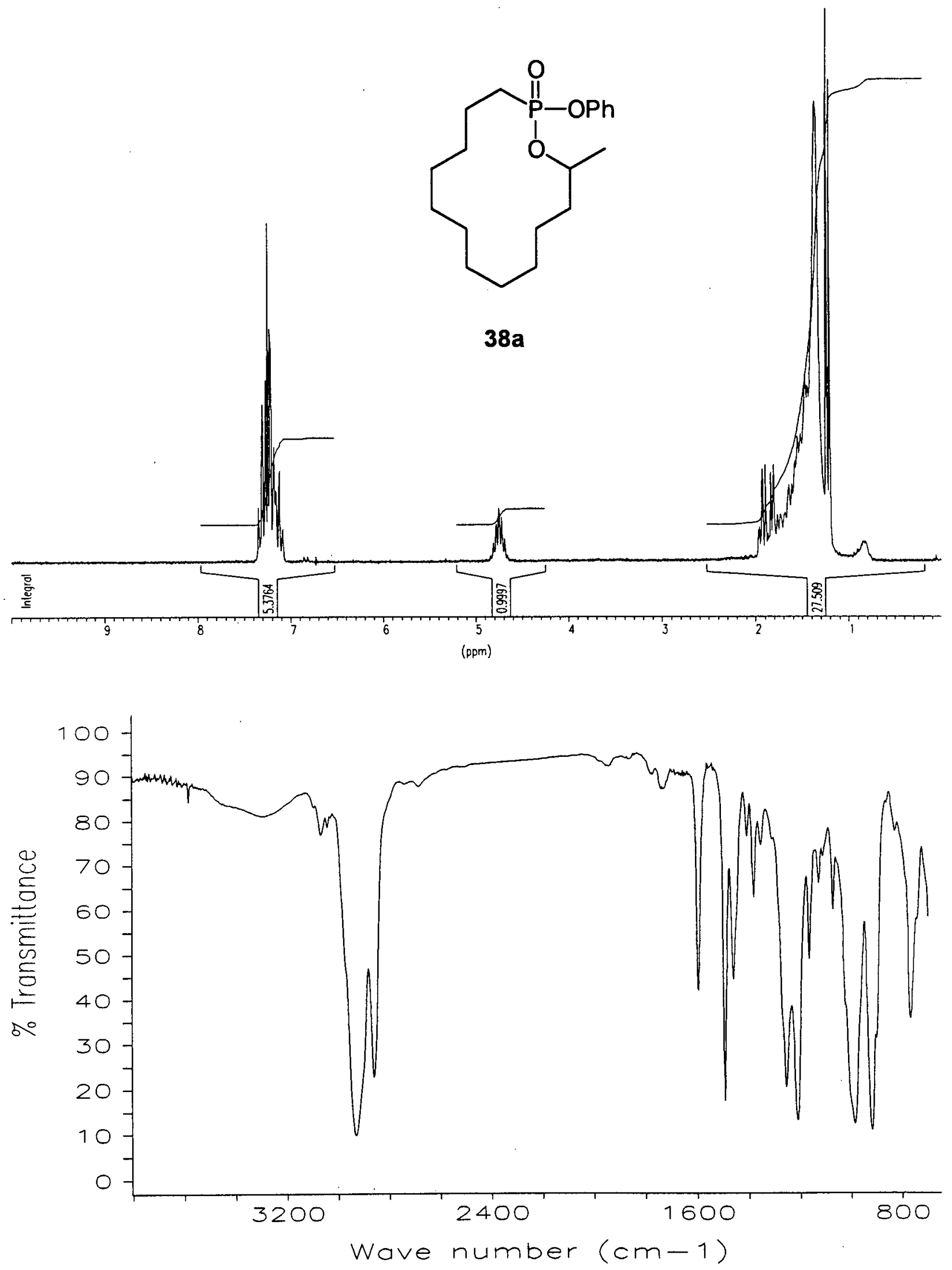

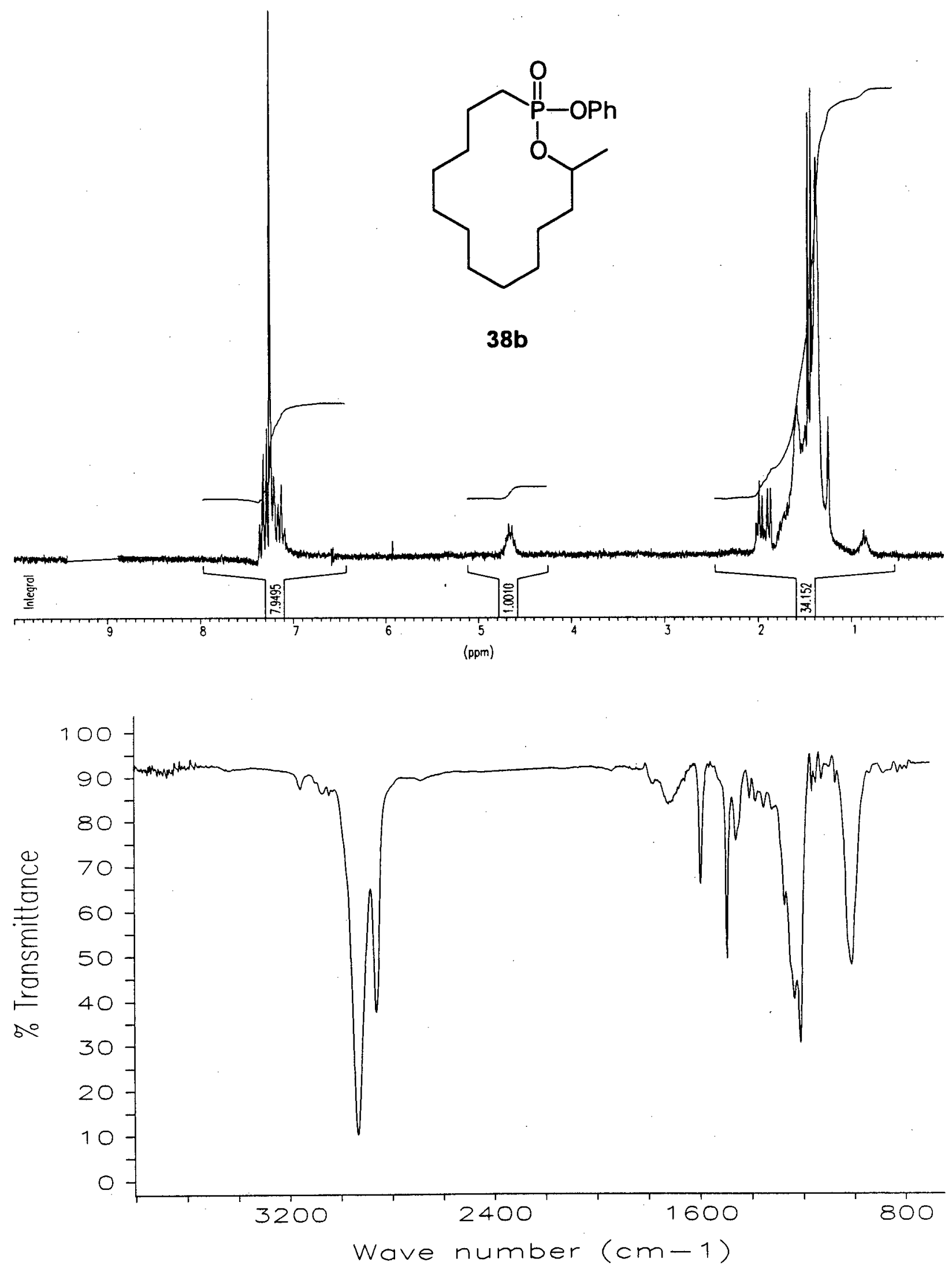


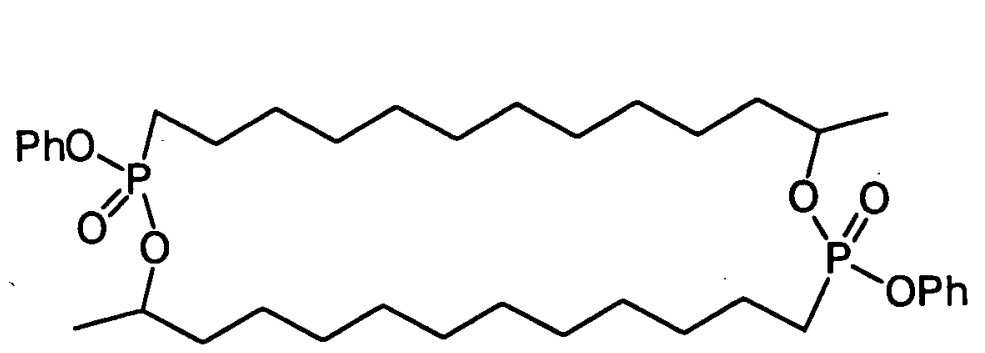

39
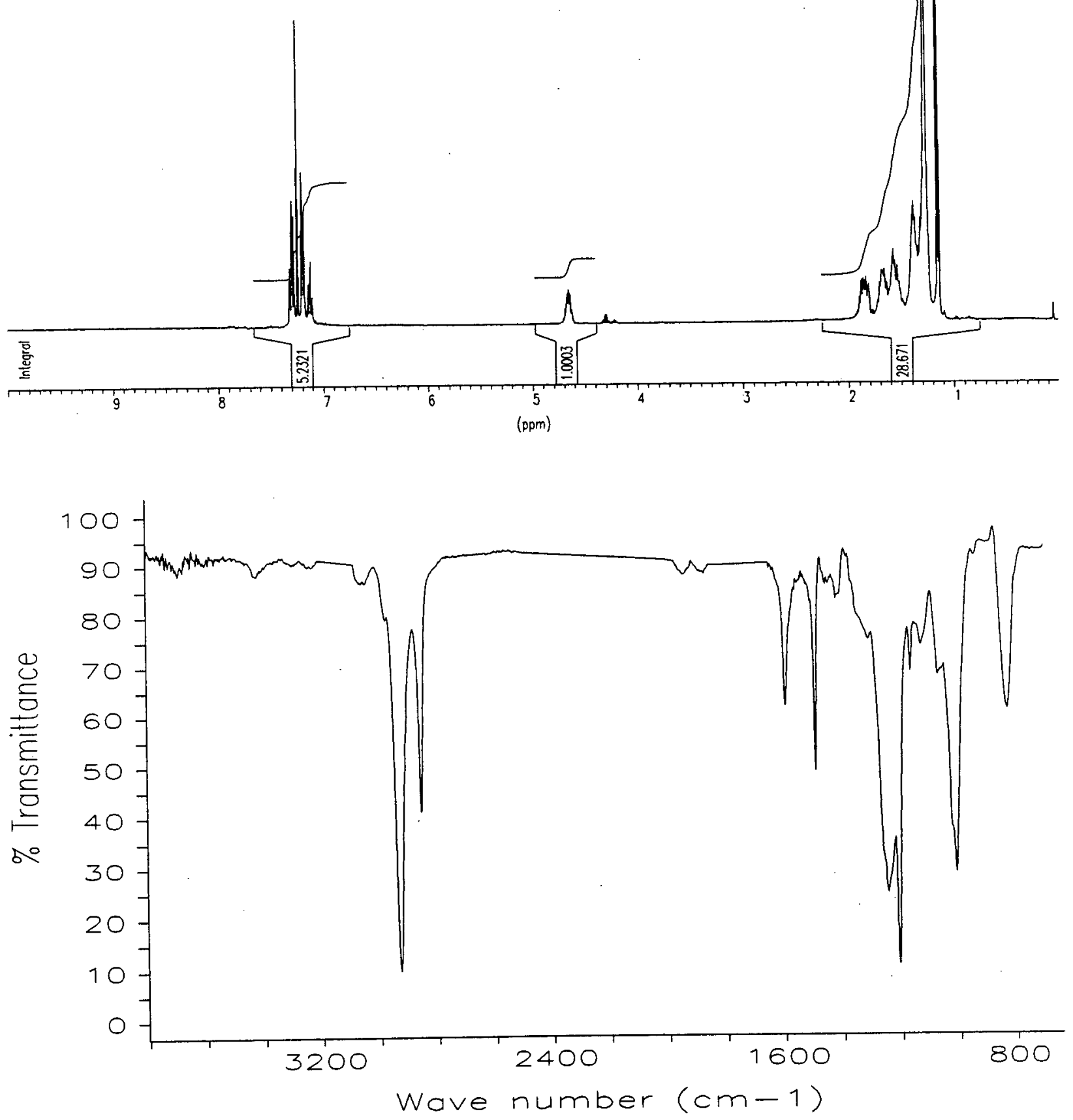

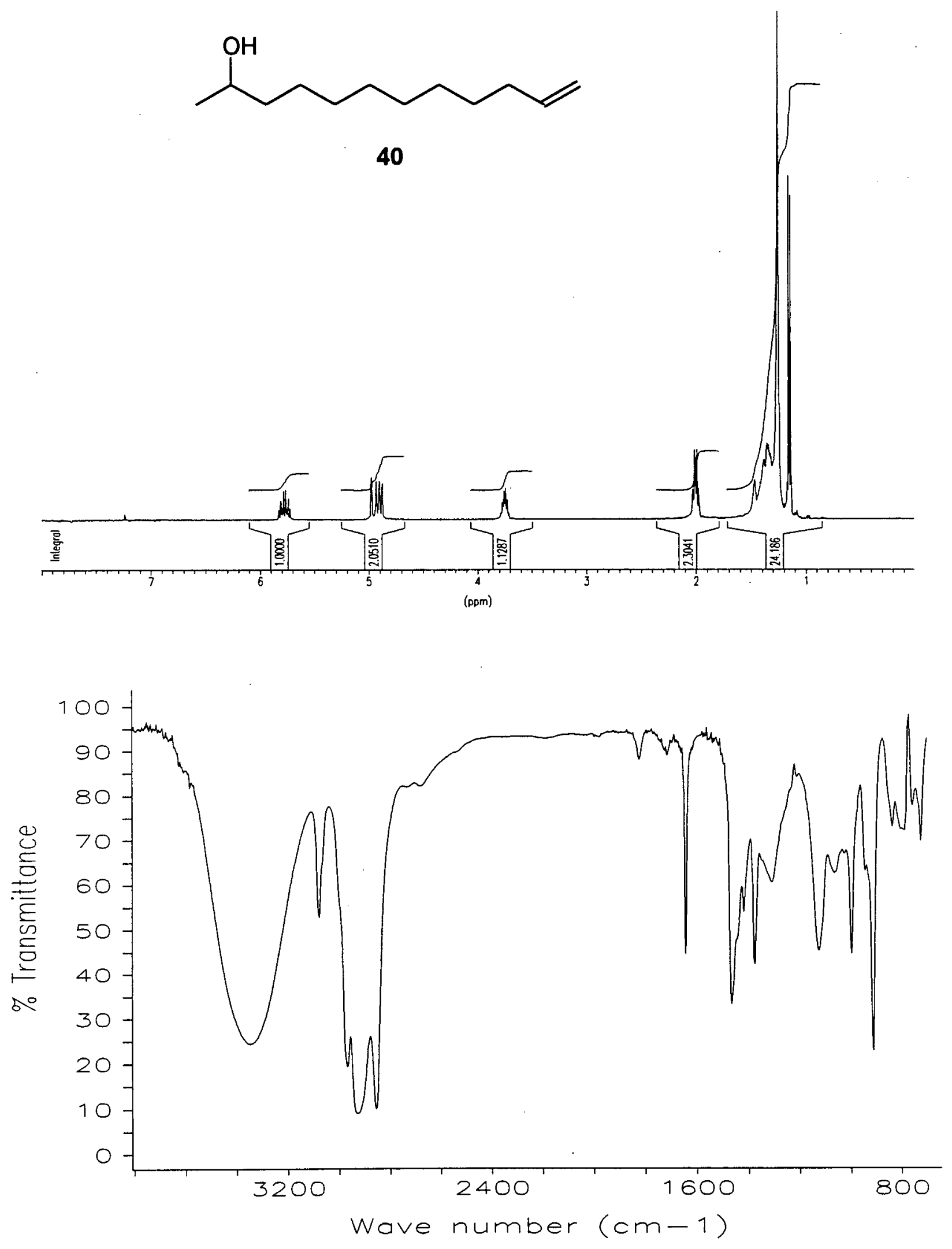

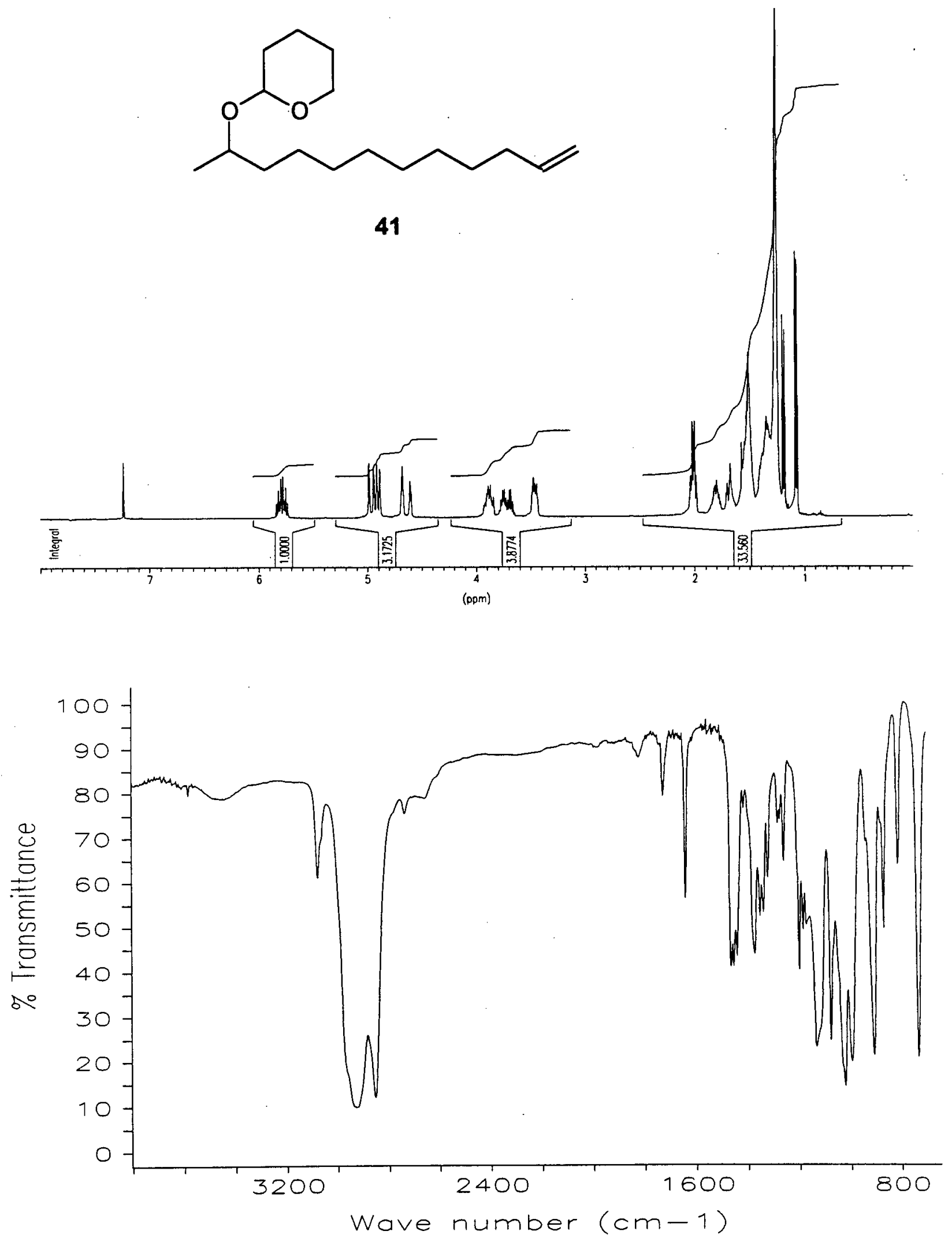

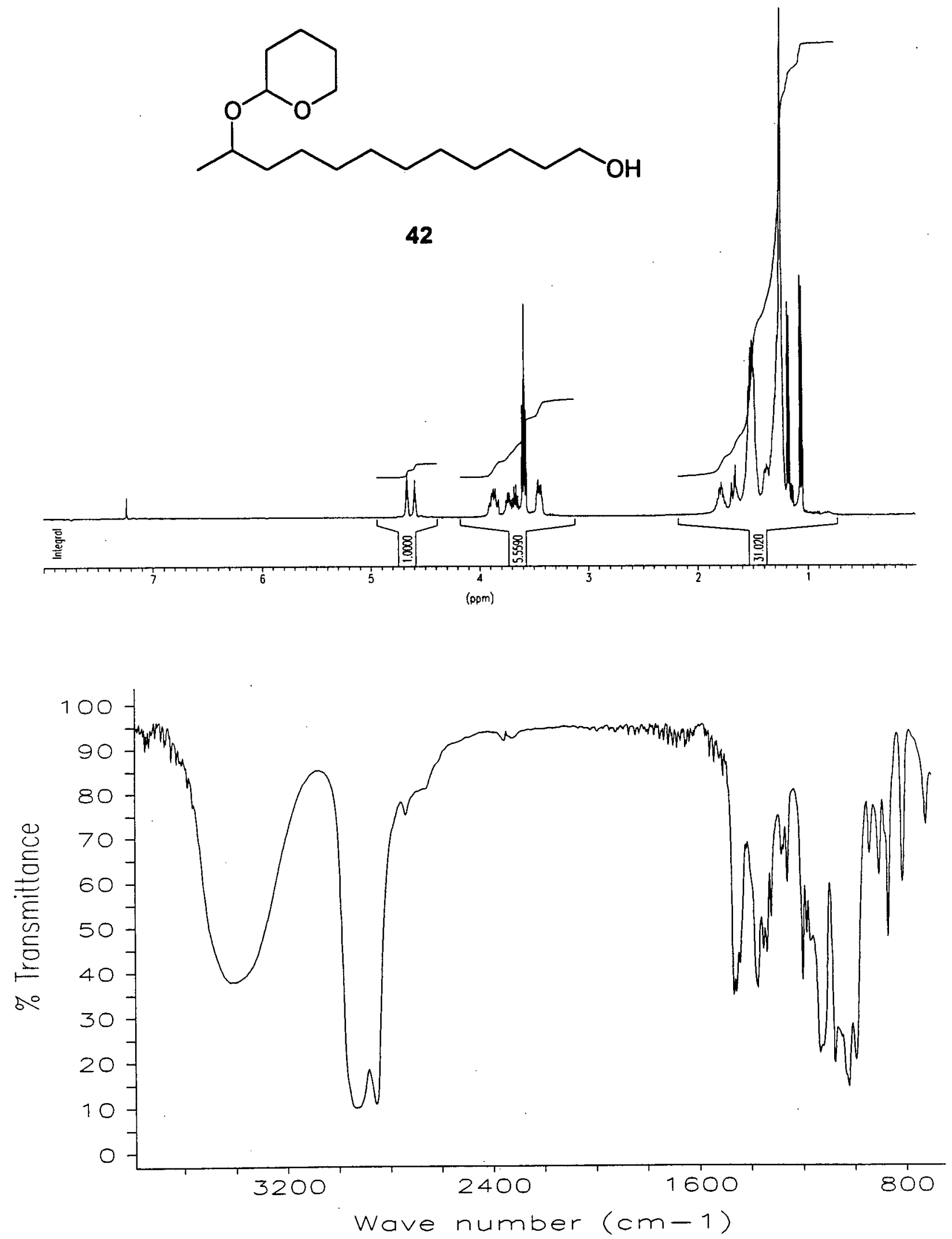

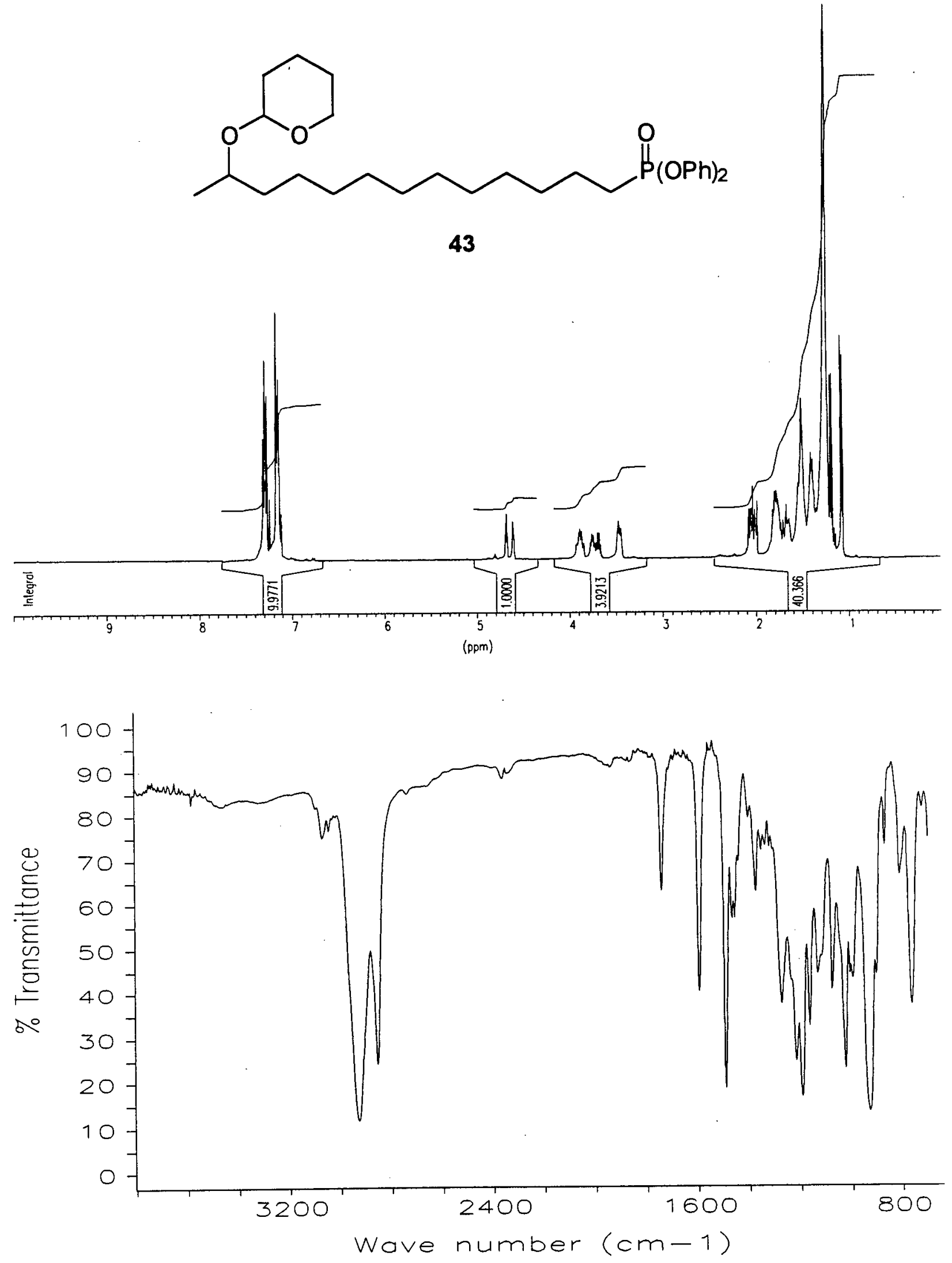

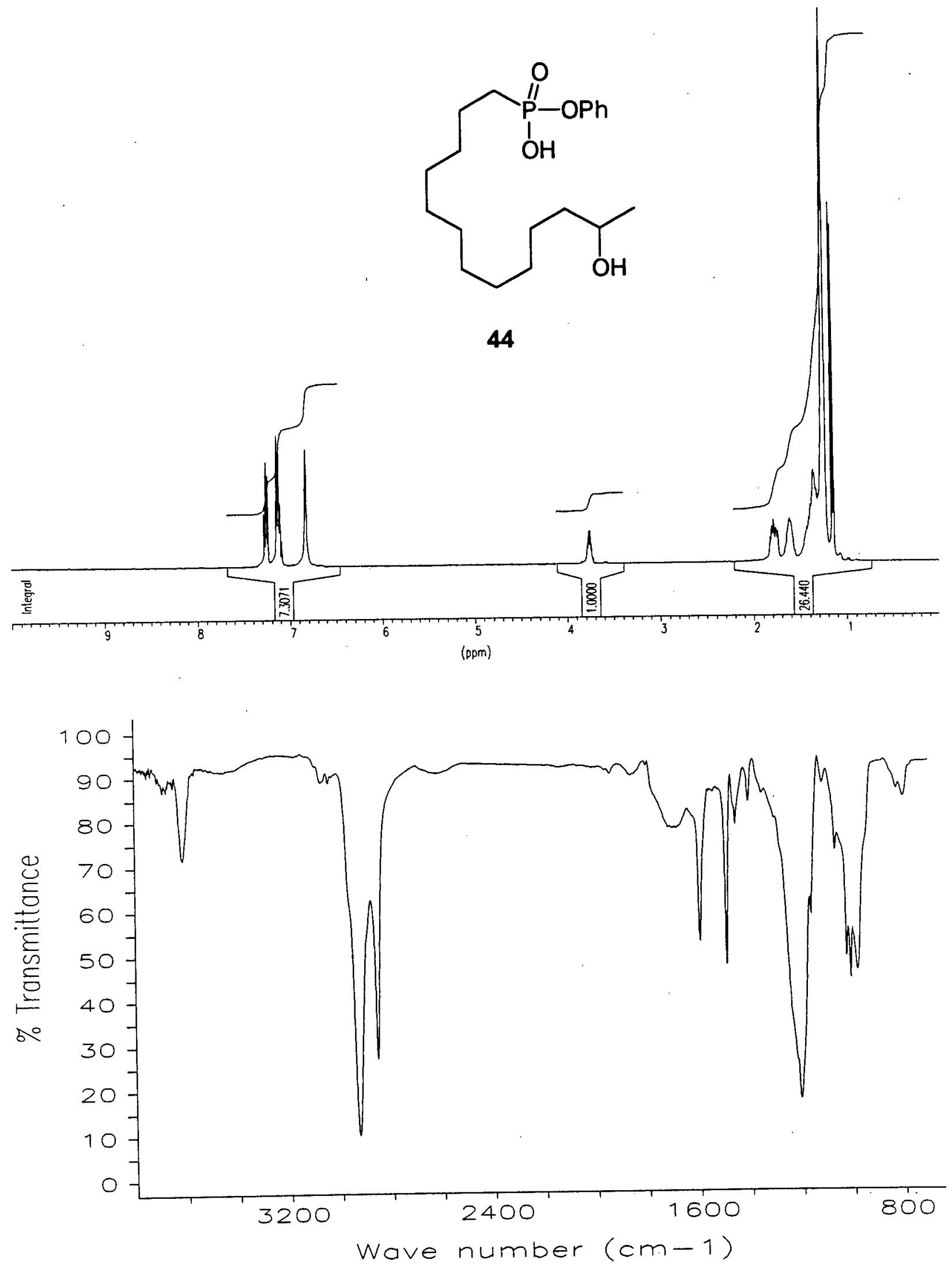

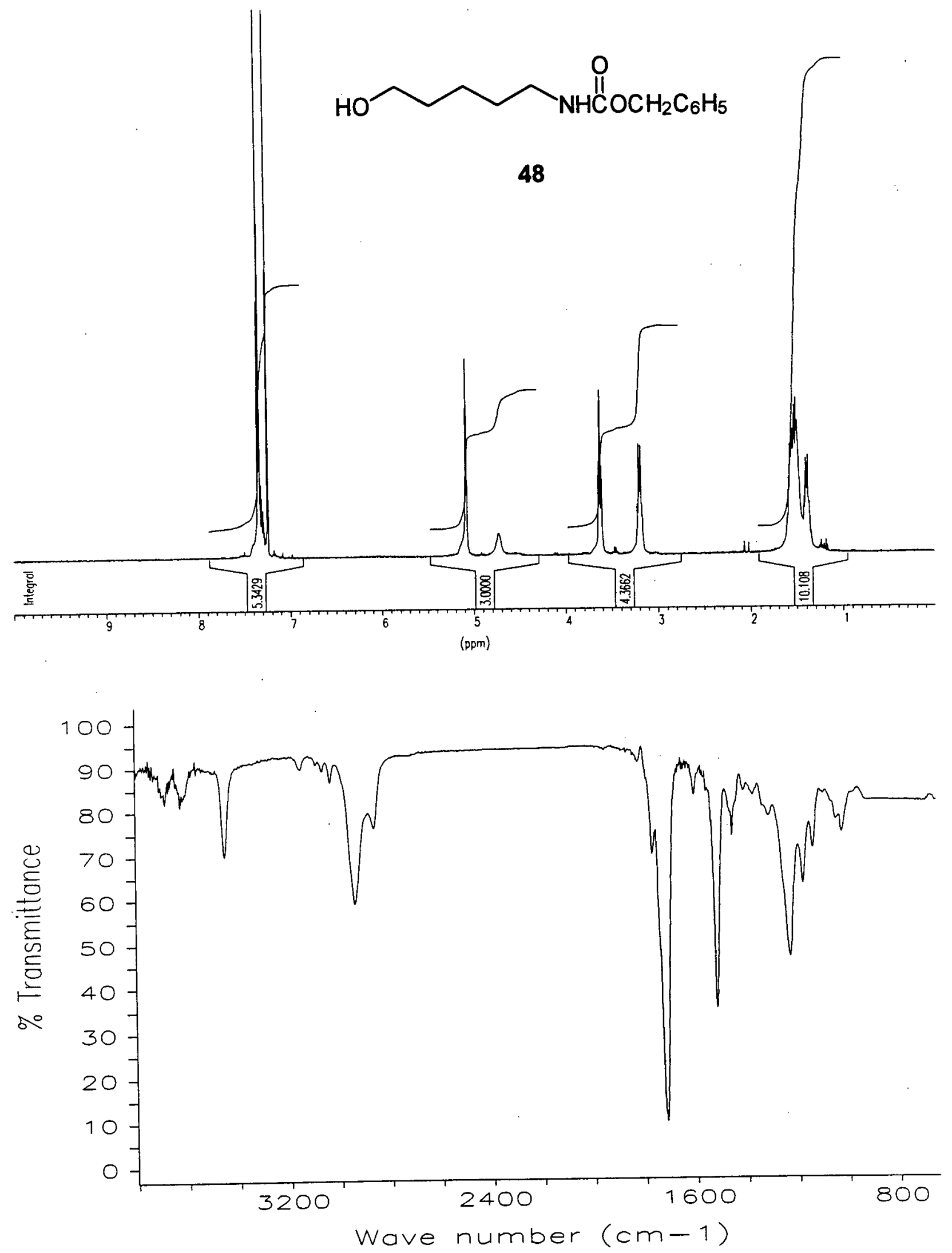

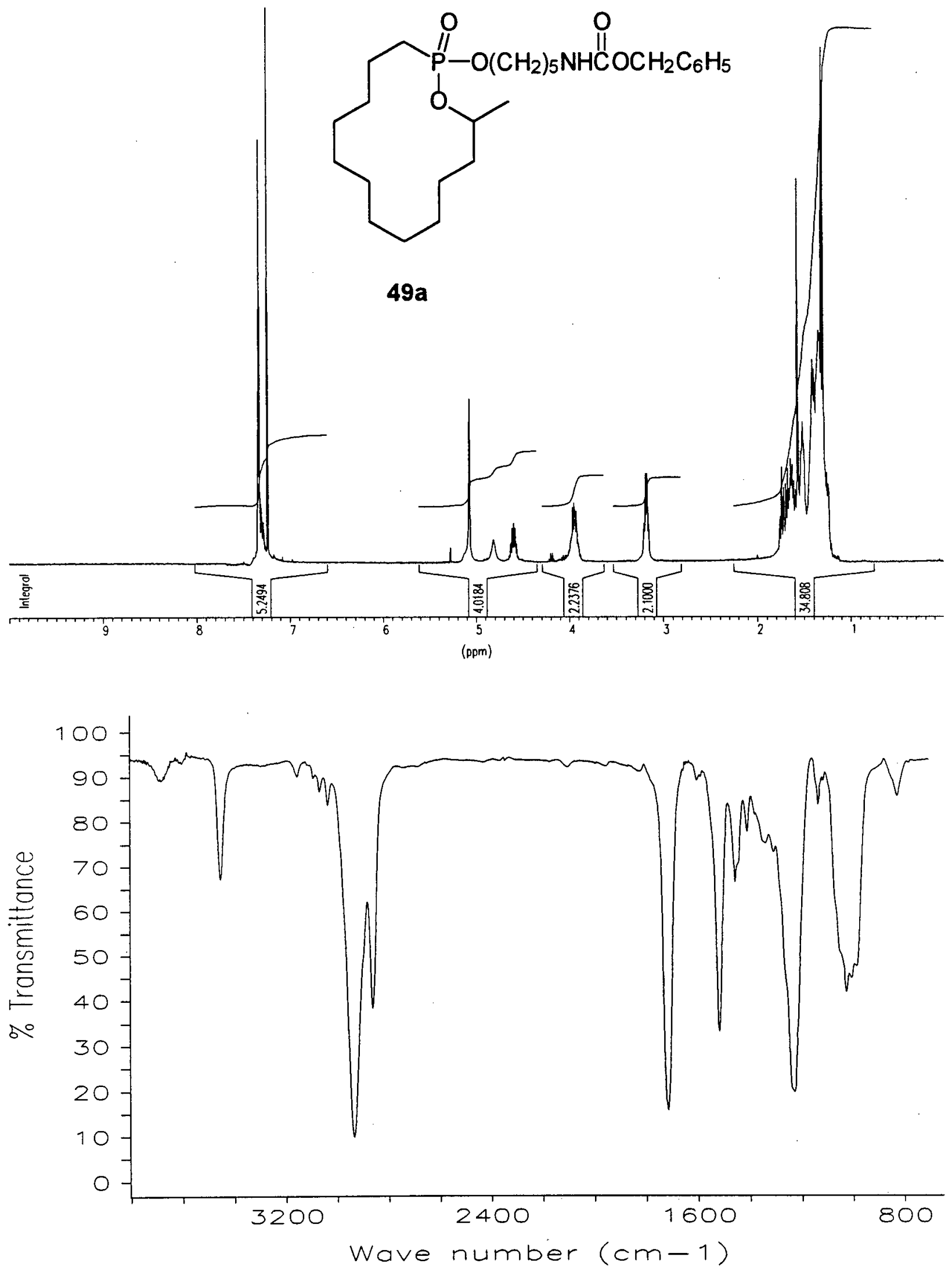

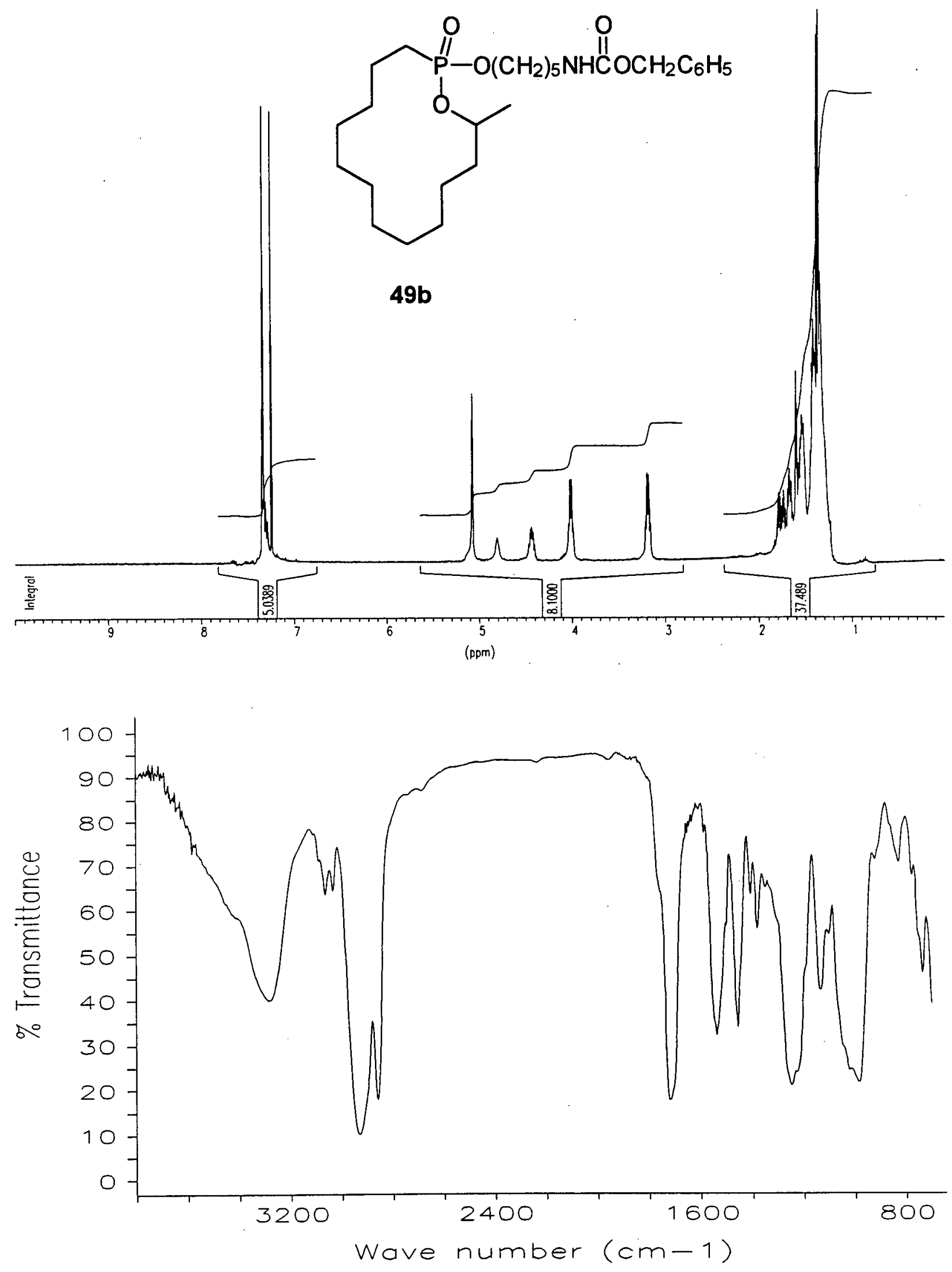

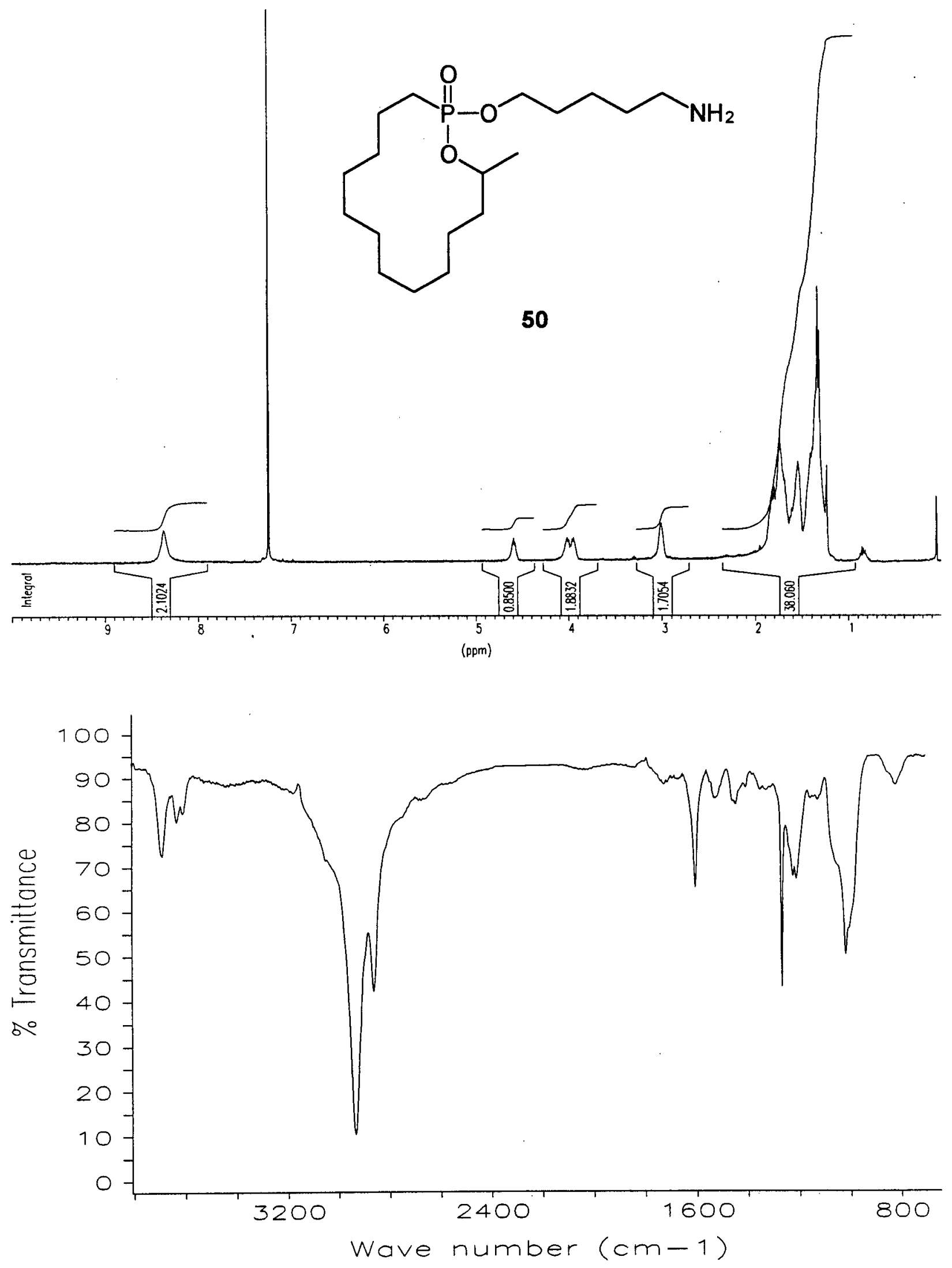

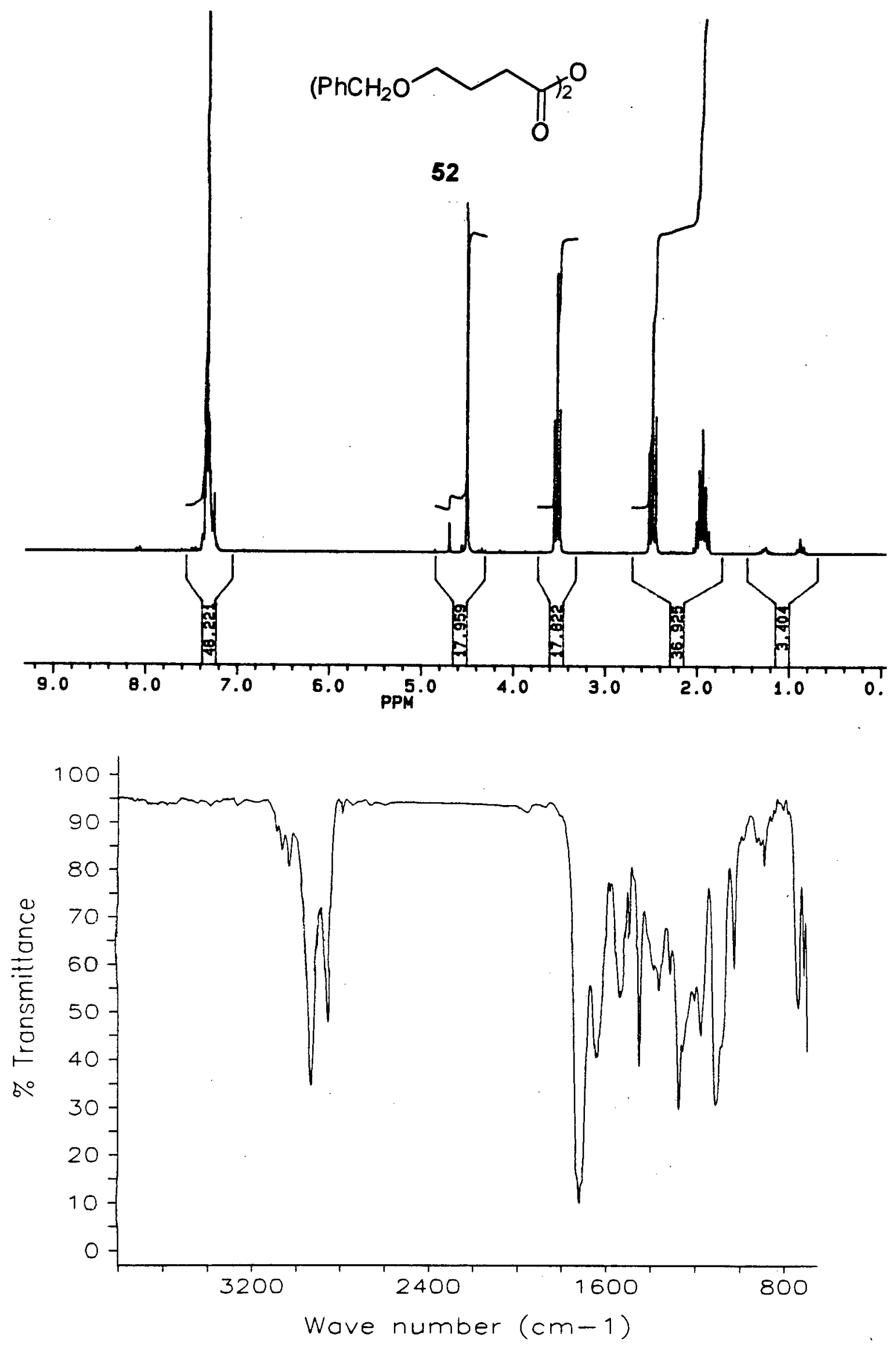

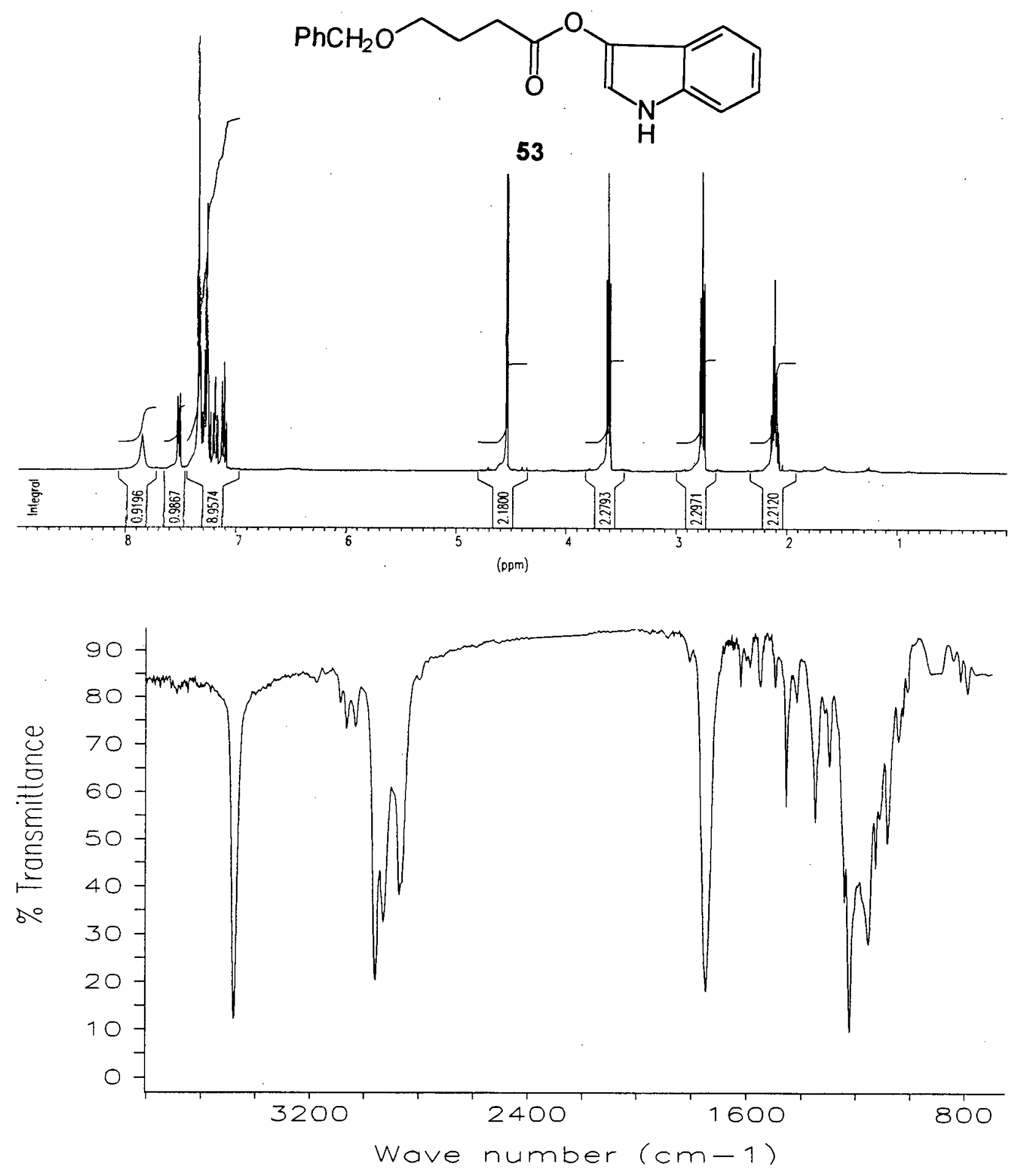

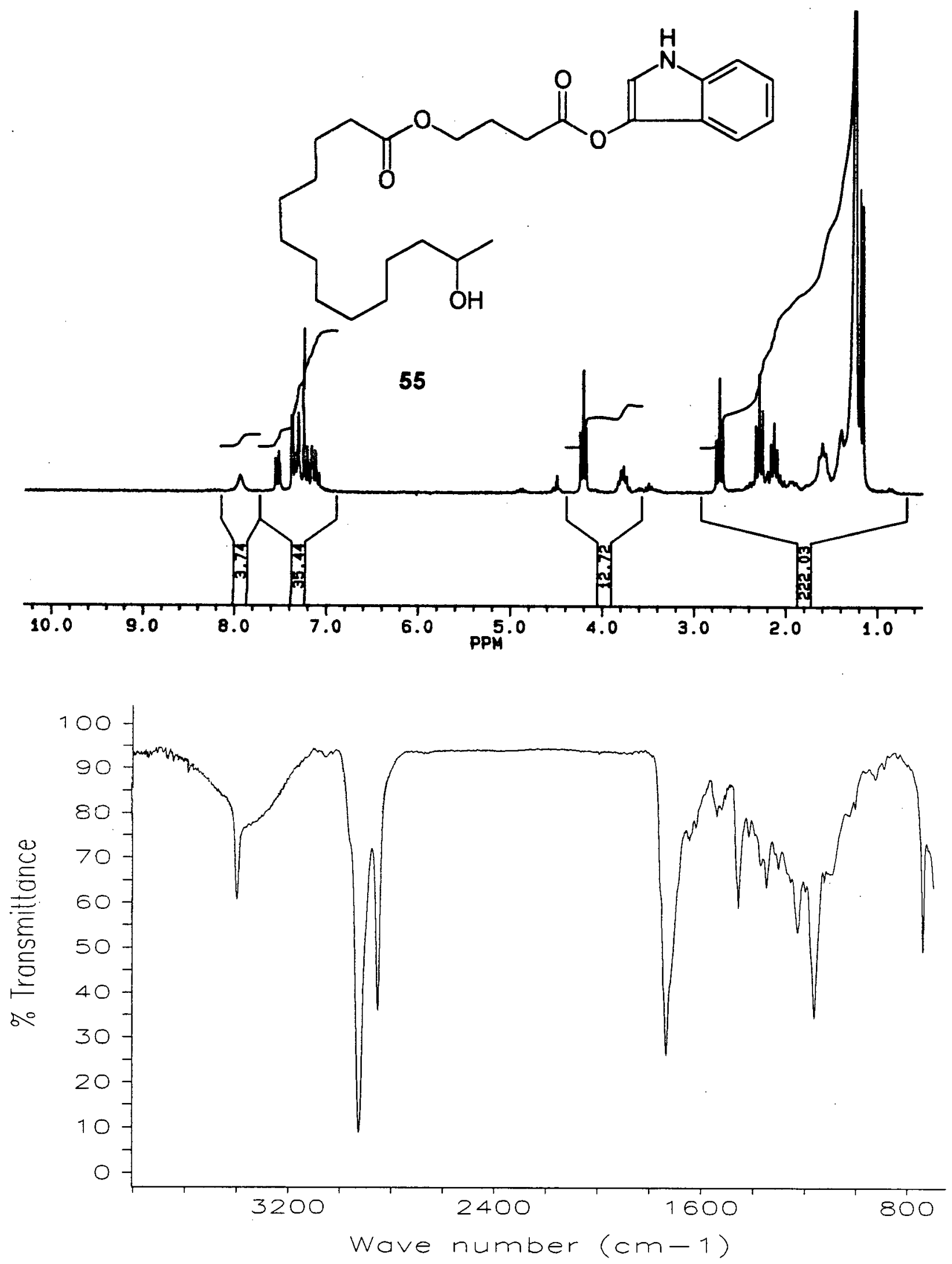

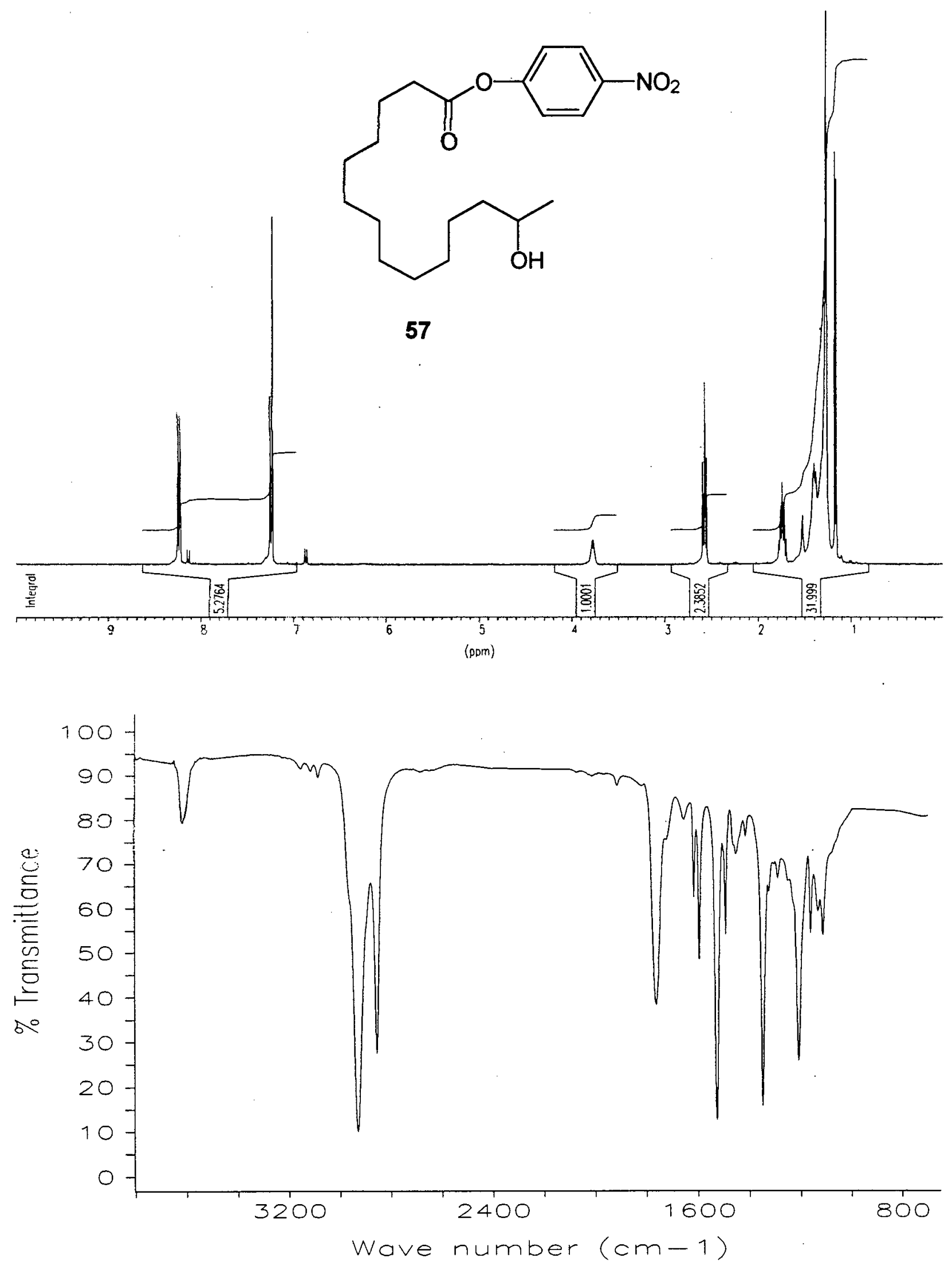

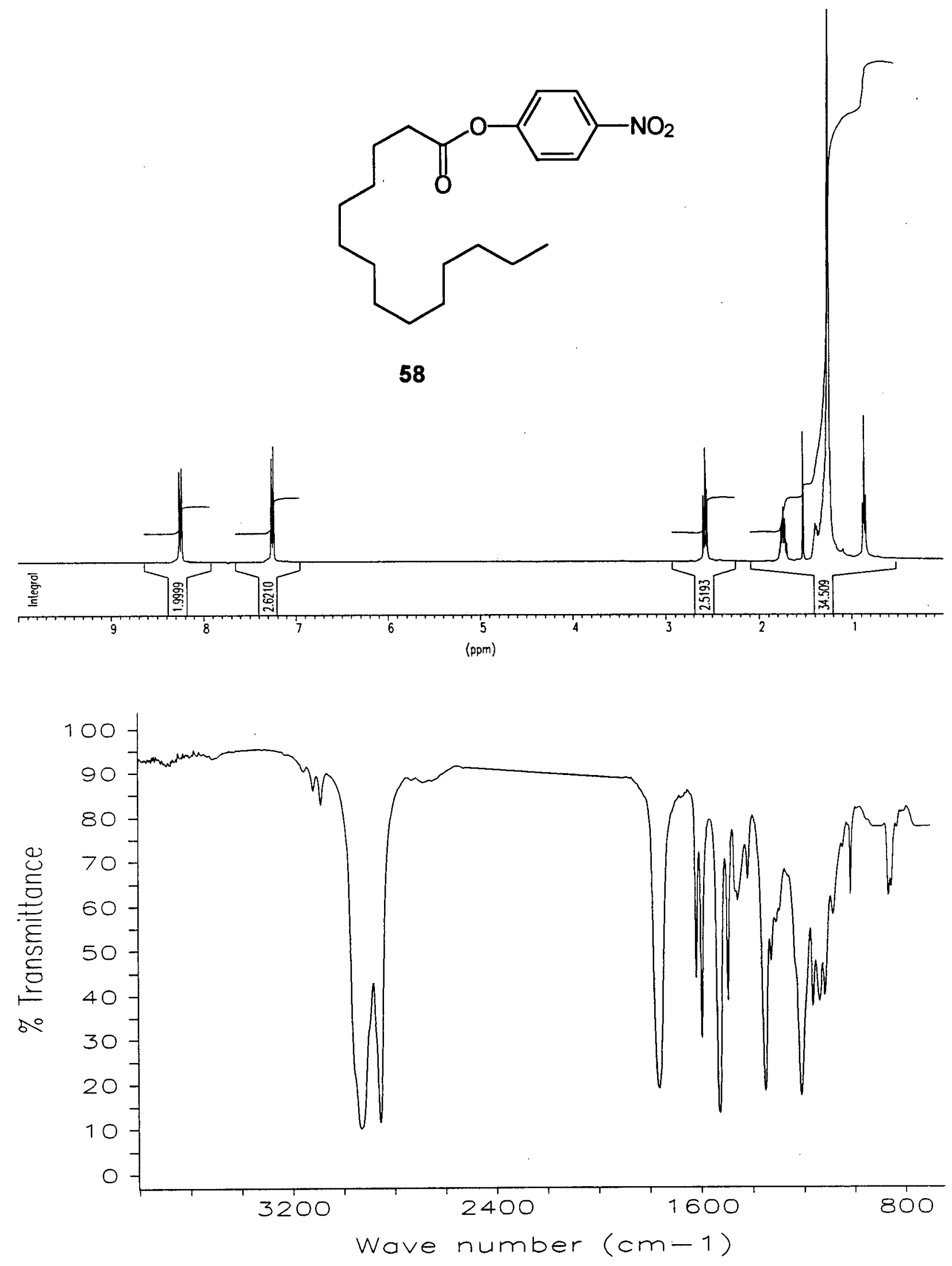


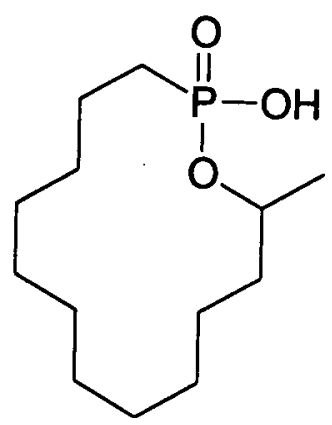

59
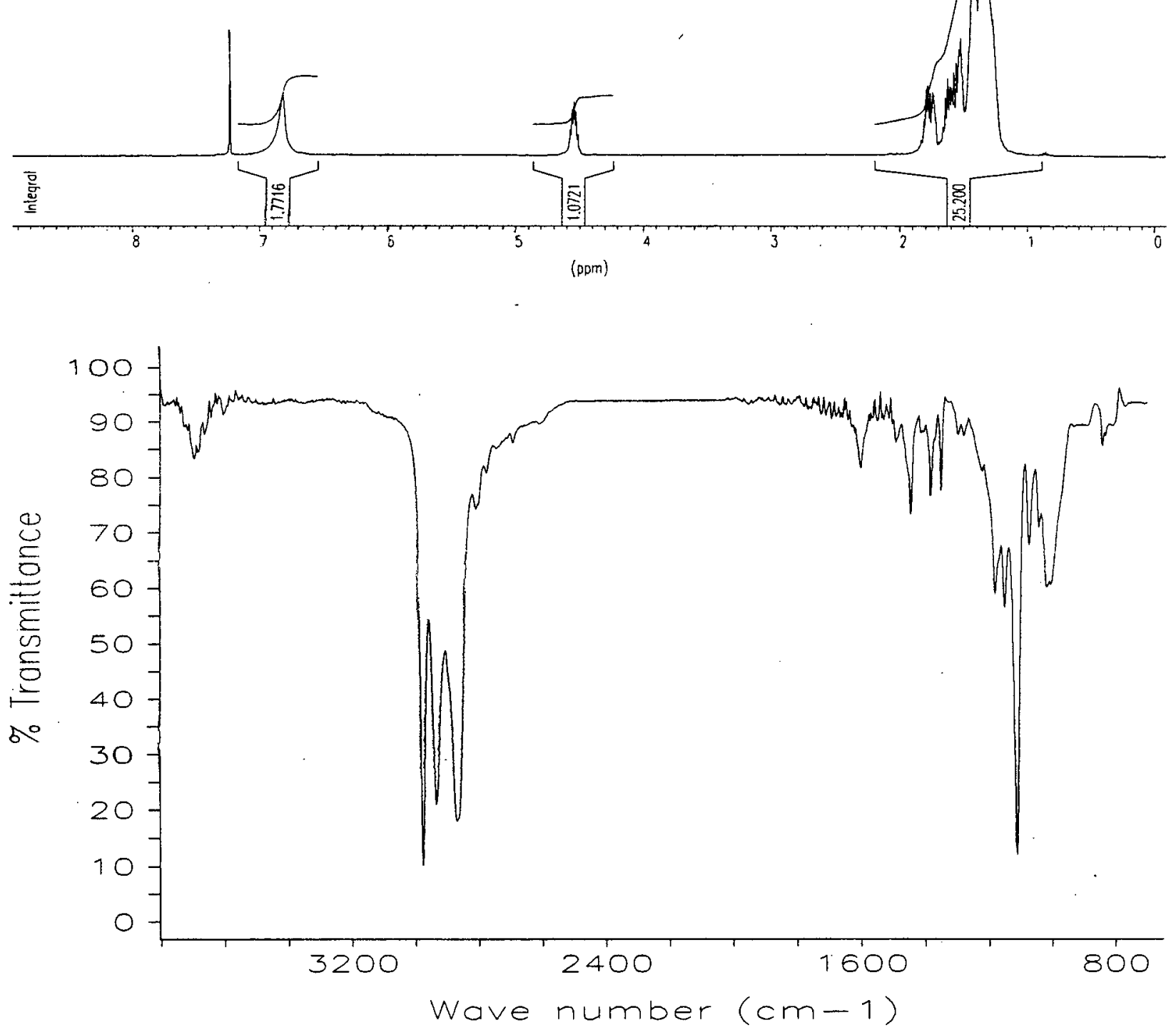

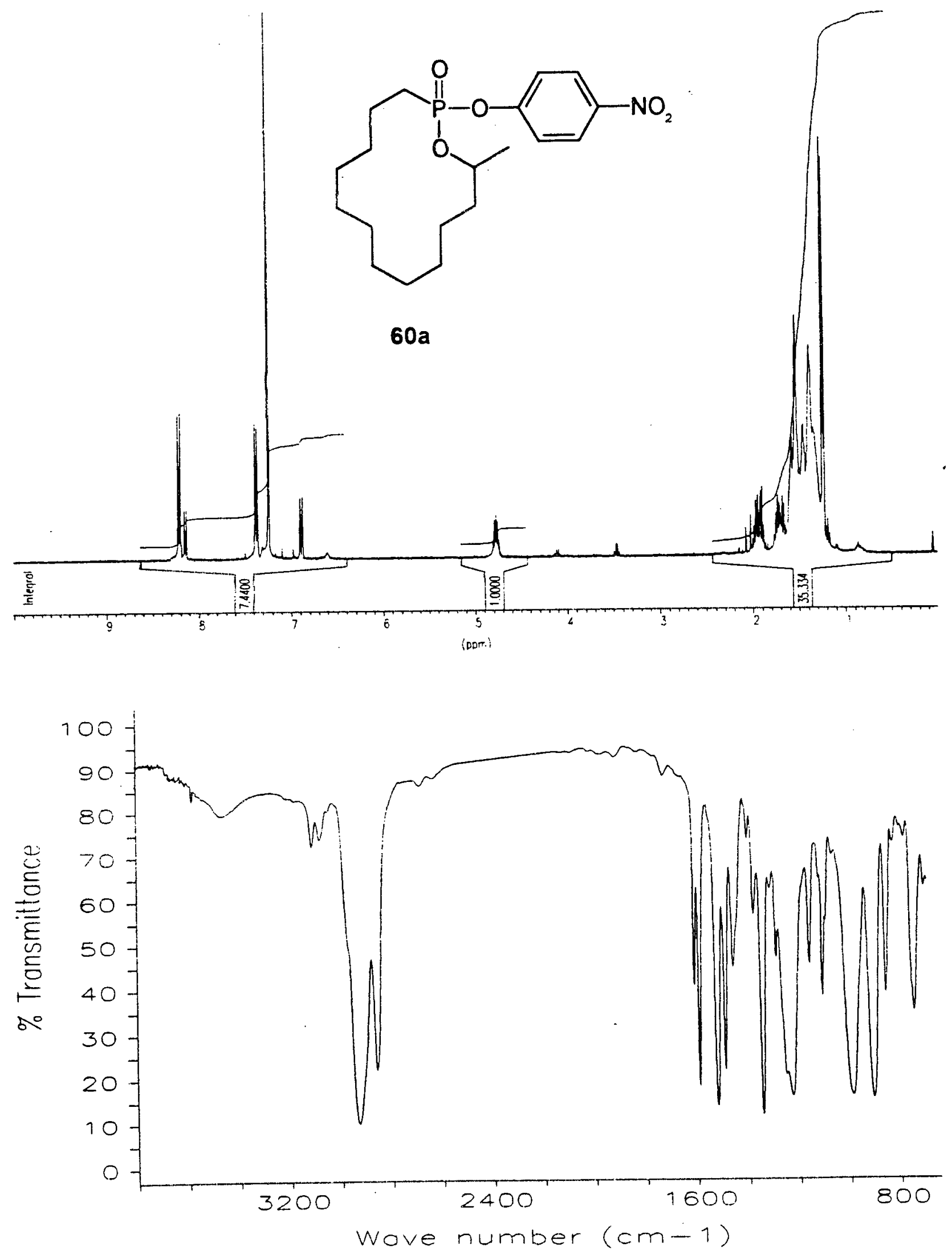

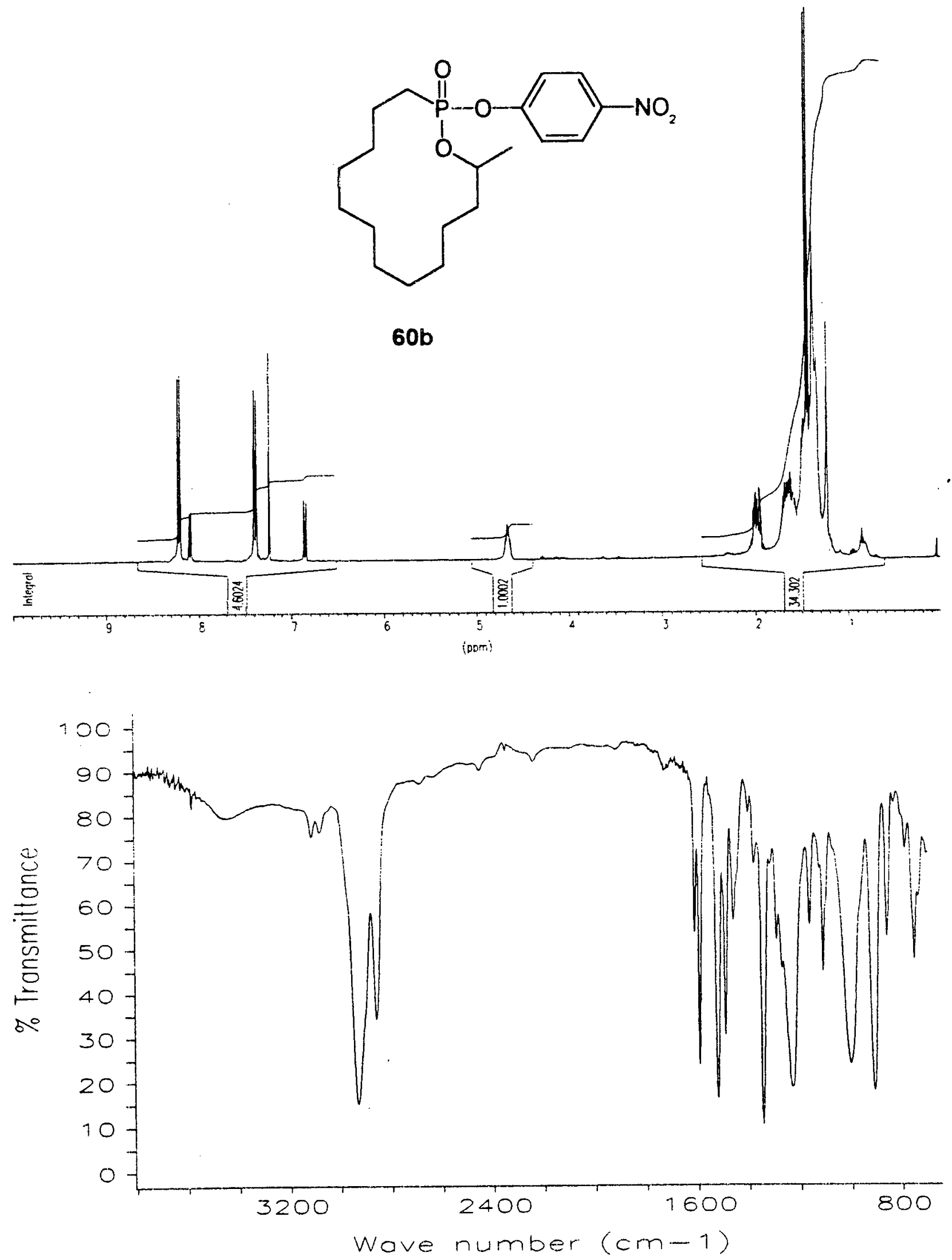

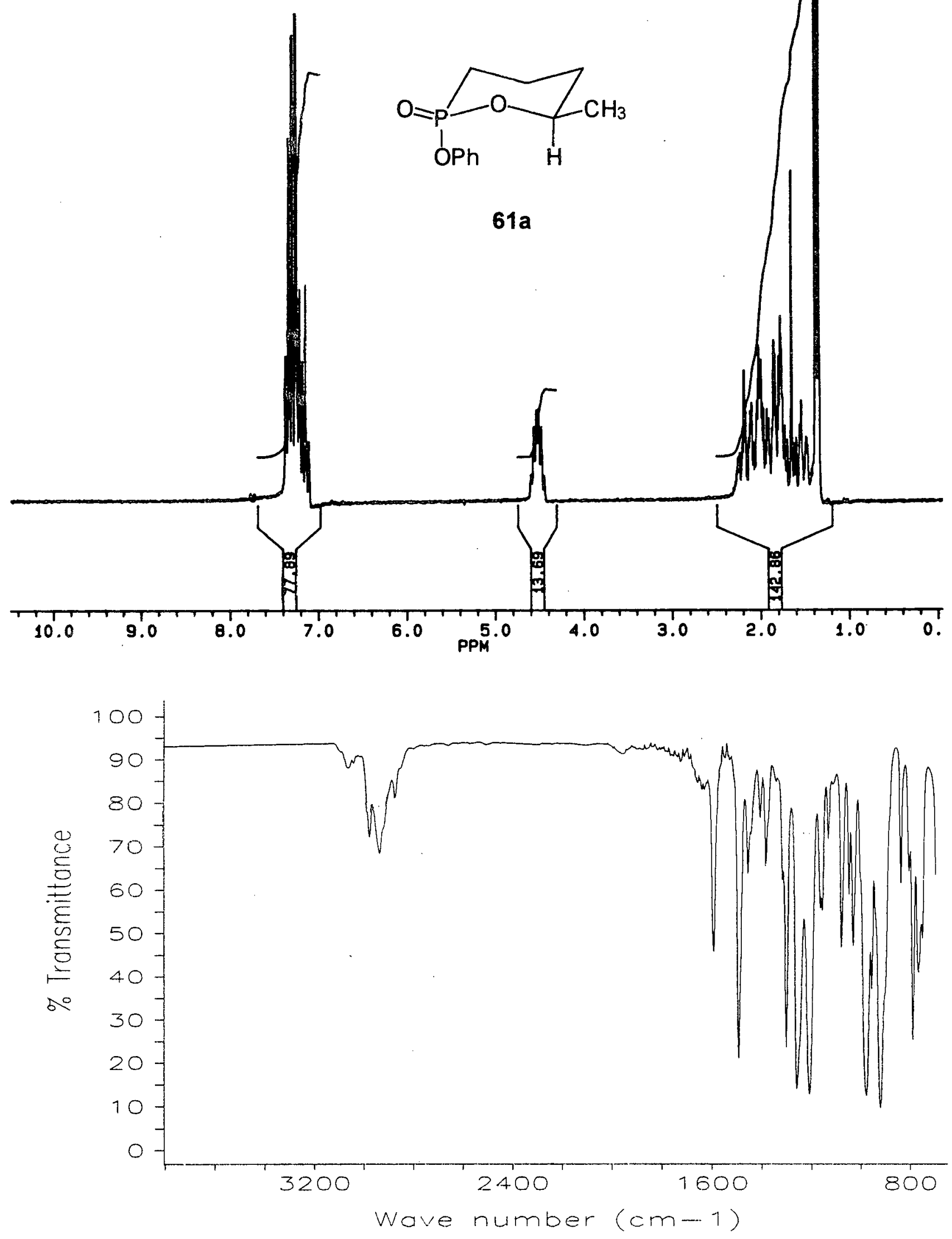

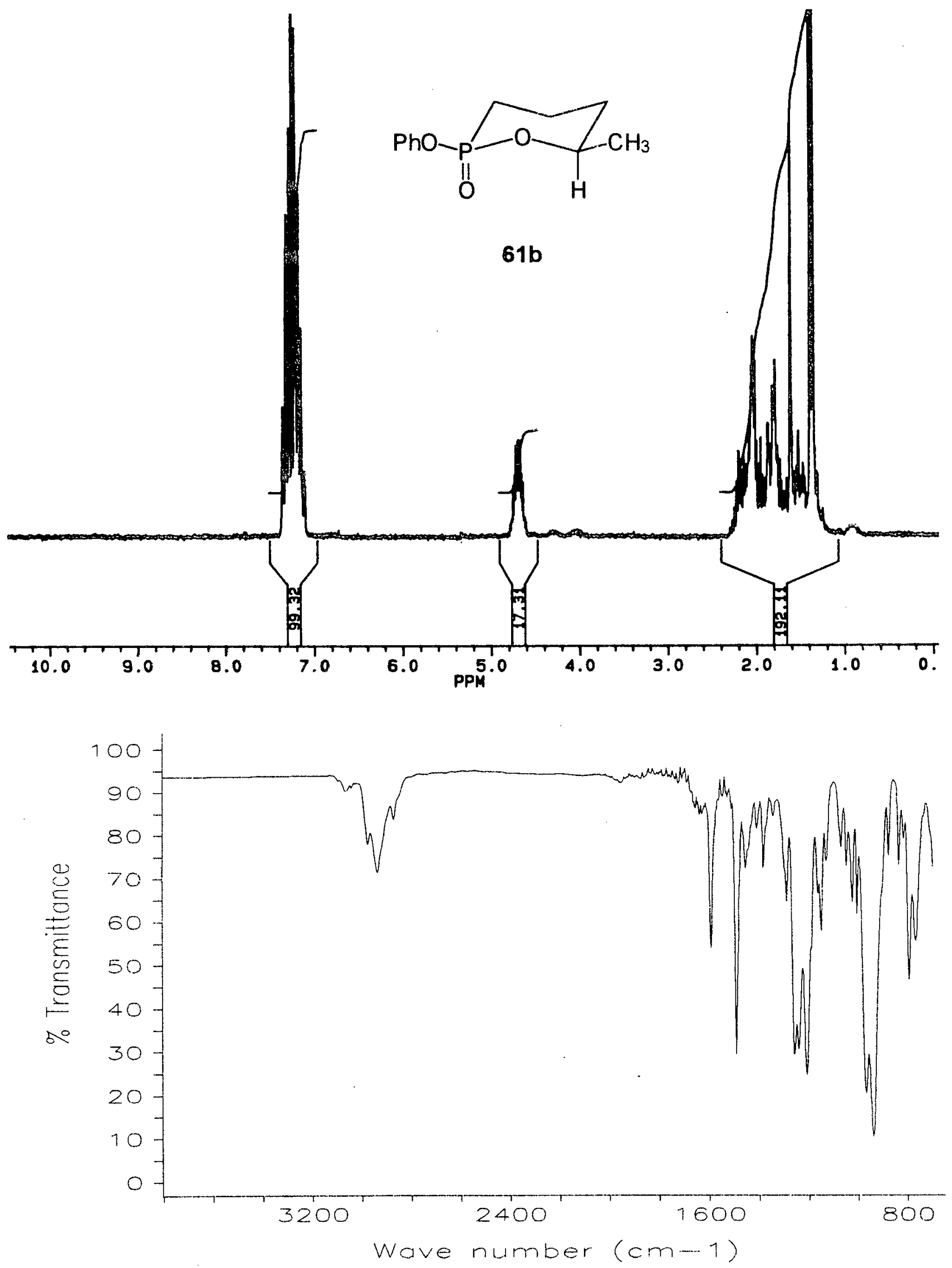


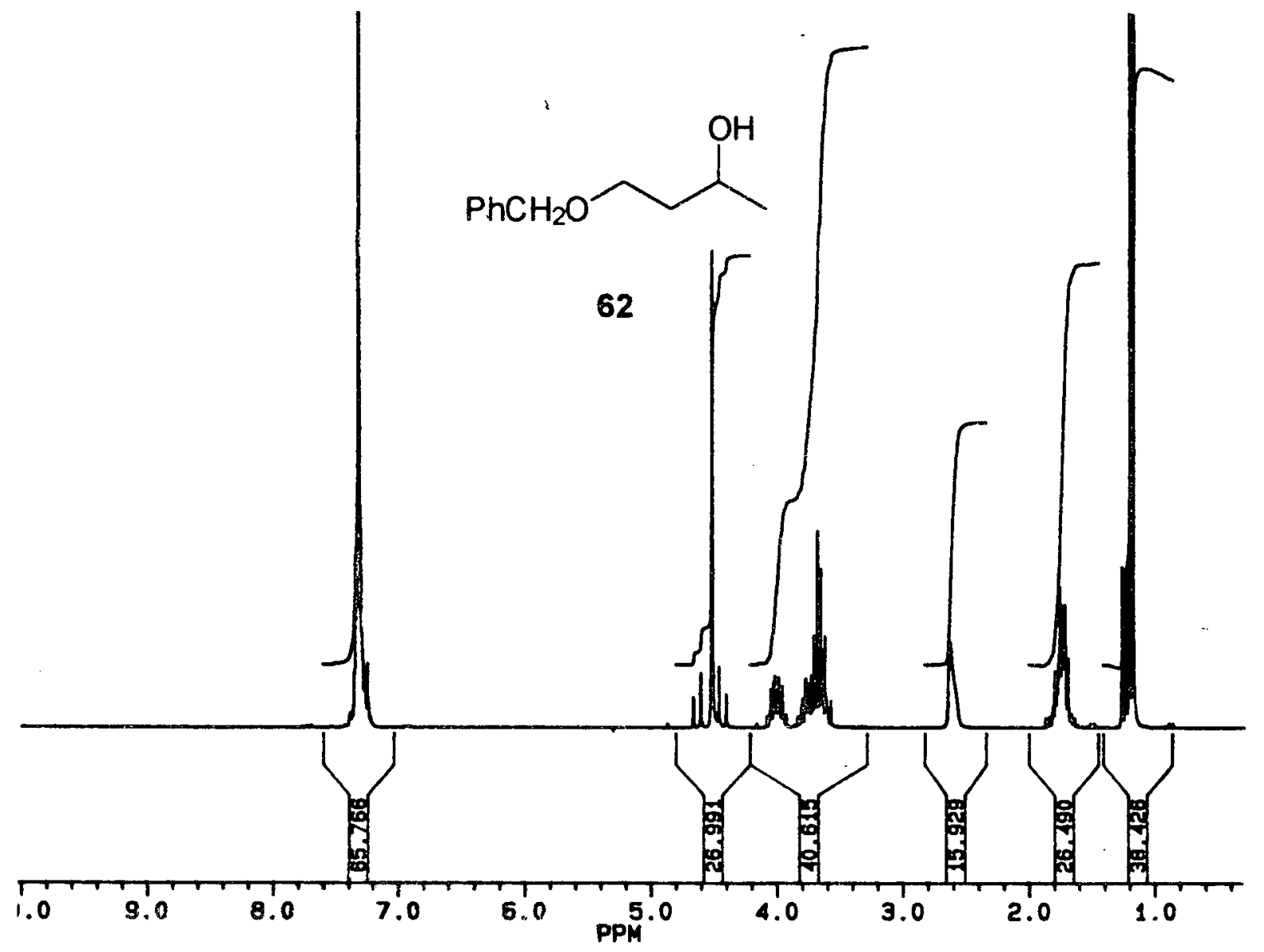




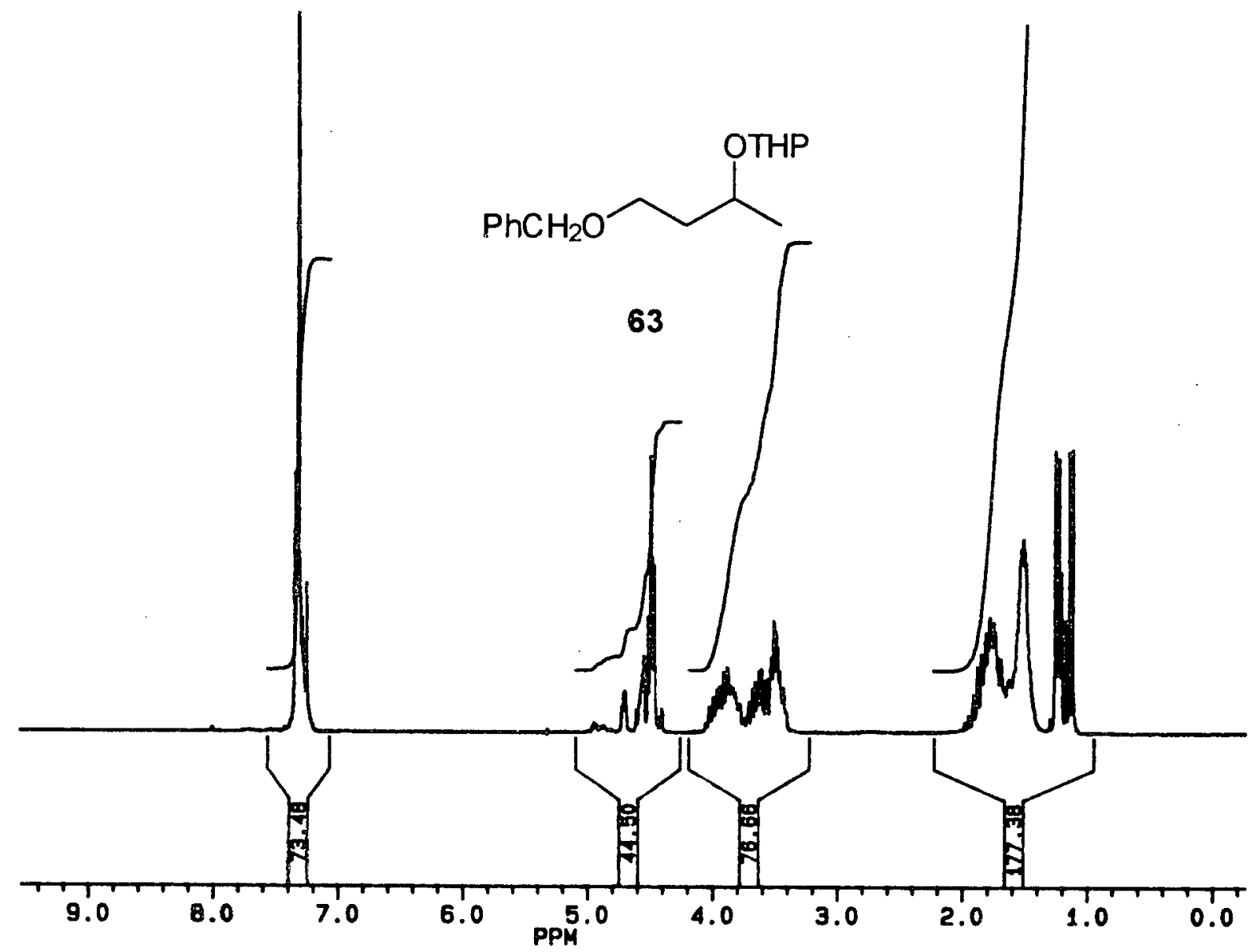



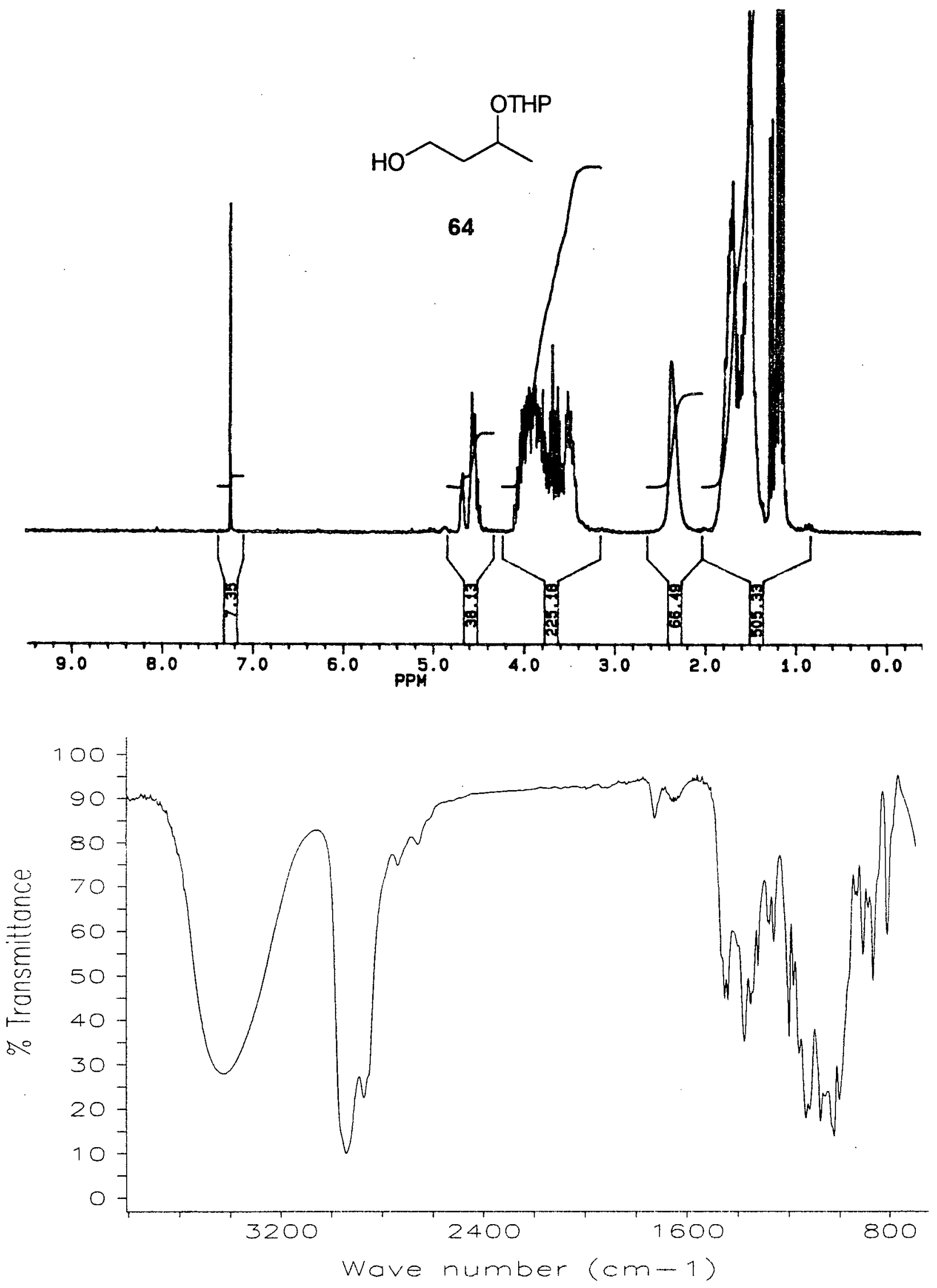


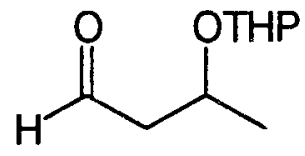

65

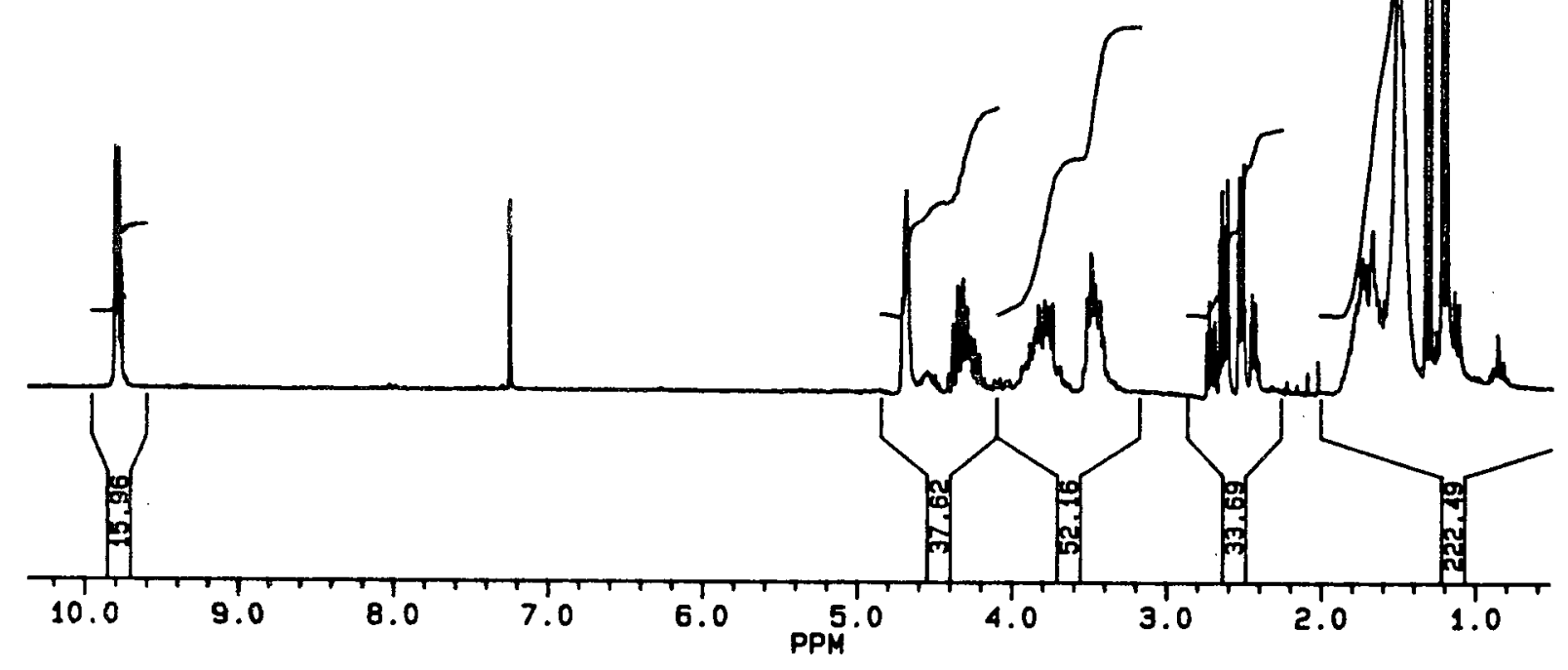



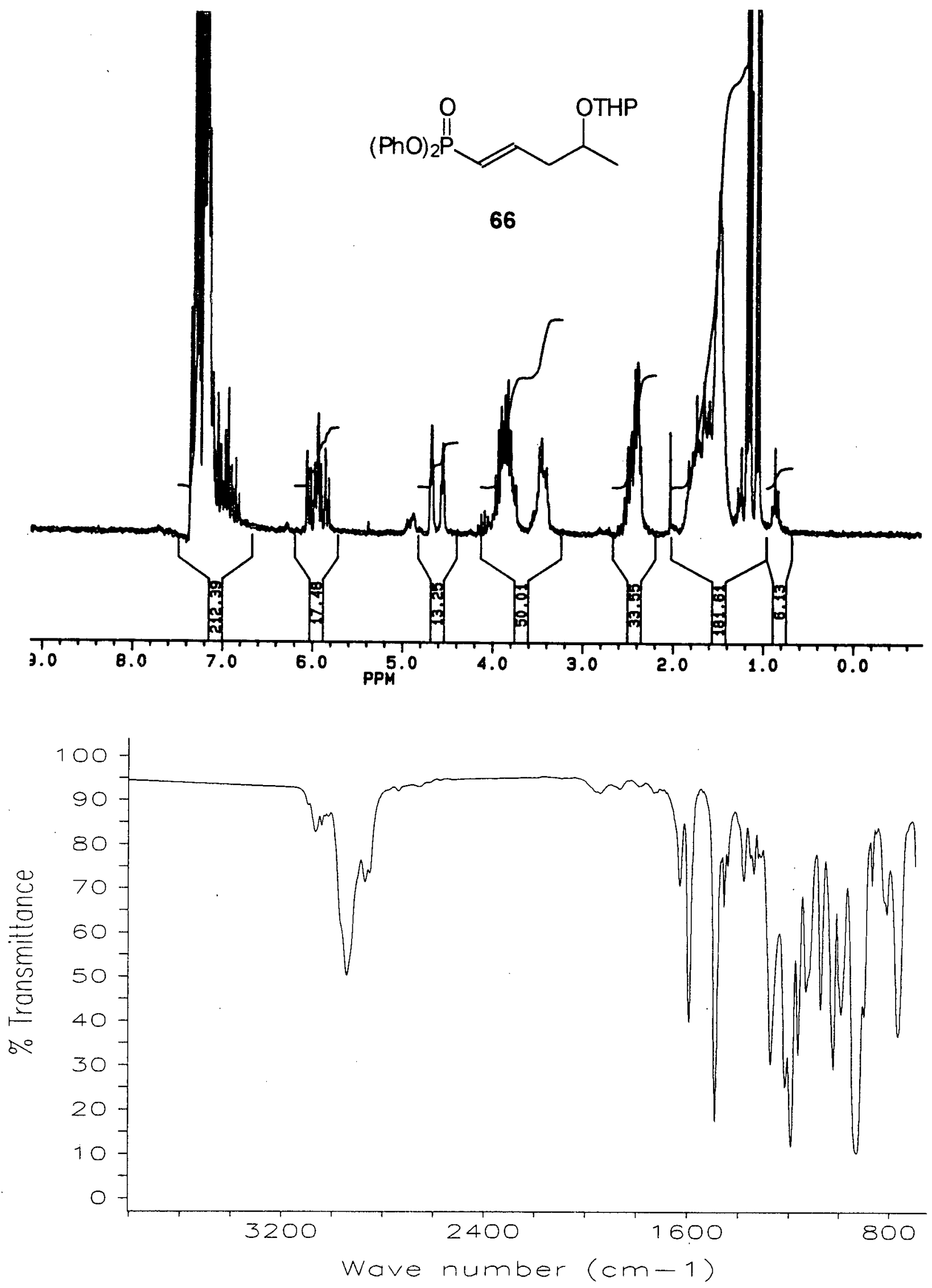

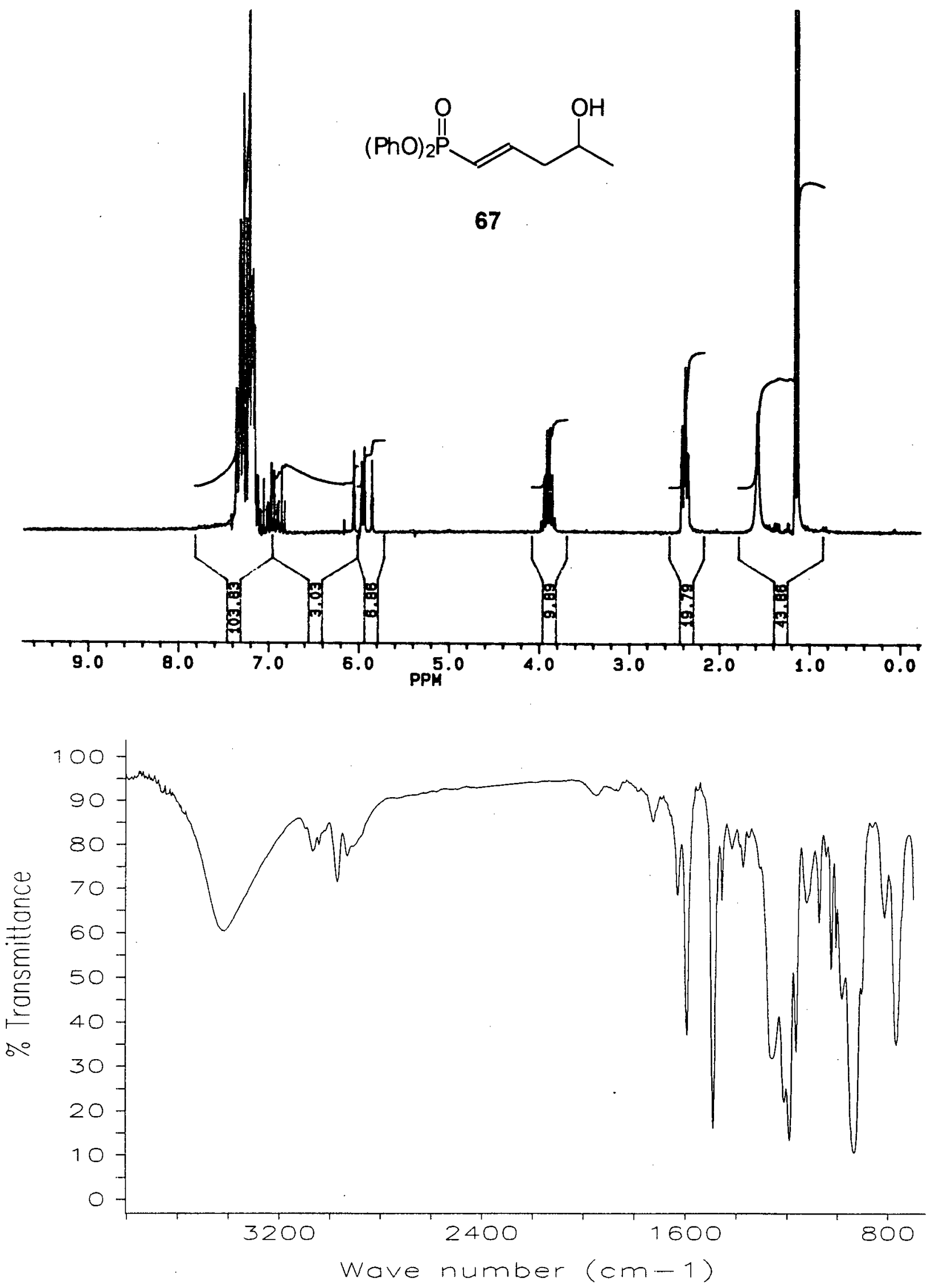

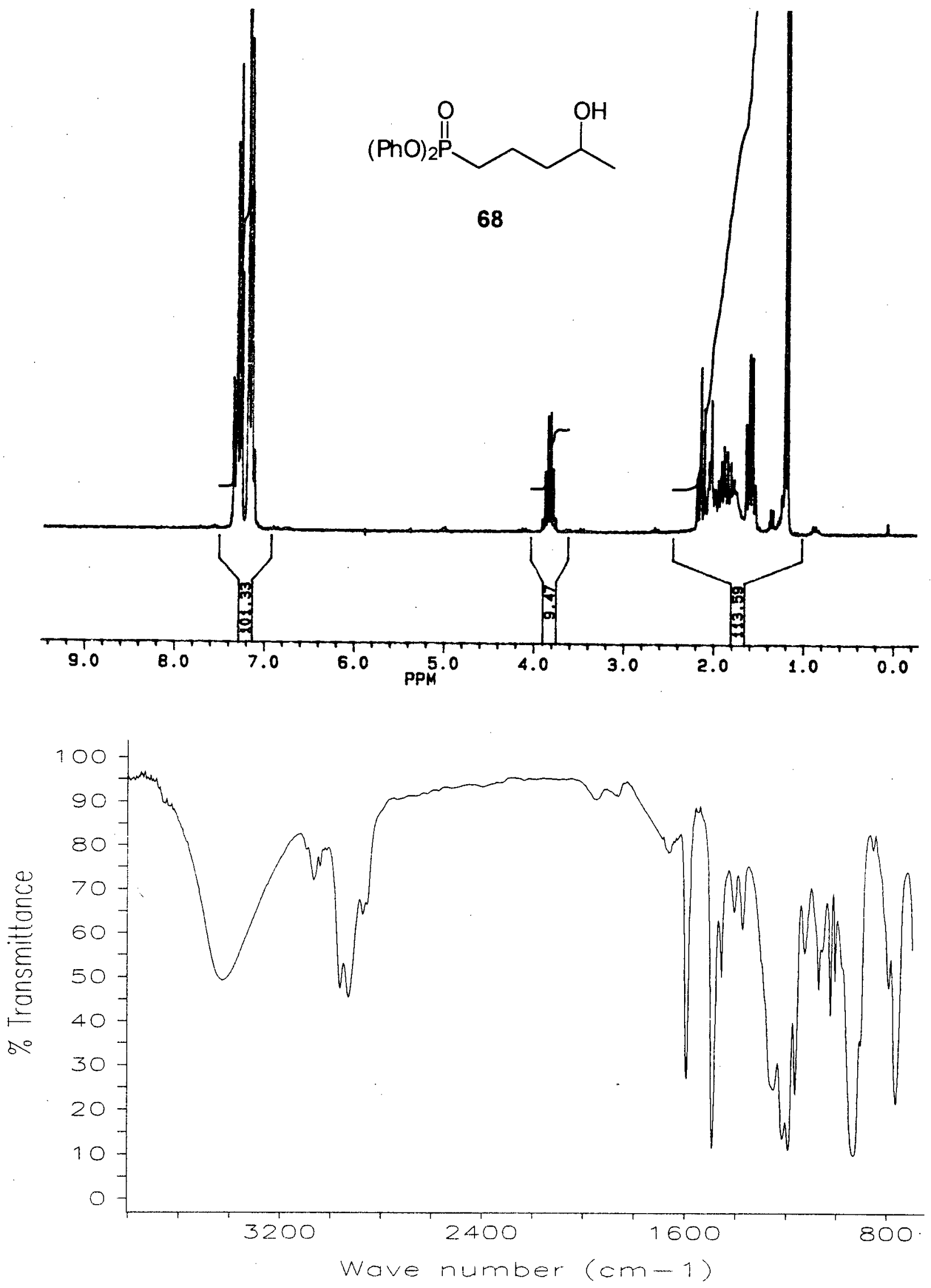